\title{
An operation under general anaesthesia and cognitive ageing
}

Citation for published version (APA):

Dijkstra, J. B. (1997). An operation under general anaesthesia and cognitive ageing. [Doctoral Thesis, Maastricht University]. NeuroPsych Publishers. https://doi.org/10.26481/dis.19970404jd

Document status and date:

Published: 01/01/1997

DOI:

10.26481/dis.19970404jd

Document Version:

Publisher's PDF, also known as Version of record

\section{Please check the document version of this publication:}

- A submitted manuscript is the version of the article upon submission and before peer-review. There can be important differences between the submitted version and the official published version of record.

People interested in the research are advised to contact the author for the final version of the publication, or visit the DOI to the publisher's website.

- The final author version and the galley proof are versions of the publication after peer review.

- The final published version features the final layout of the paper including the volume, issue and page numbers.

Link to publication

\footnotetext{
General rights rights.

- You may freely distribute the URL identifying the publication in the public portal. please follow below link for the End User Agreement:

www.umlib.nl/taverne-license

Take down policy

If you believe that this document breaches copyright please contact us at:

repository@maastrichtuniversity.nl

providing details and we will investigate your claim.
}

Copyright and moral rights for the publications made accessible in the public portal are retained by the authors and/or other copyright owners and it is a condition of accessing publications that users recognise and abide by the legal requirements associated with these

- Users may download and print one copy of any publication from the public portal for the purpose of private study or research.

- You may not further distribute the material or use it for any profit-making activity or commercial gain

If the publication is distributed under the terms of Article $25 \mathrm{fa}$ of the Dutch Copyright Act, indicated by the "Taverne" license above, 


\section{AN OPERATION \\ UNDER GENERAL ANAESTHESIA AND COGNITIVE AGEING}


Neuropsych Publishers Maastricht

J.B. Dijkstra, Maastricht 1997

An operation under general anaesthesia and cognitive aging / Jeanette Bermadette Dijkstra. - Maastricht: Universitaire Pers Maastricht. - III.

ISBN 90-75579 $03 \sim 9$

Neuropsych Publishers is a non profit organisation which aims at promoting the science of "Brain \& Behaviour" and improving the application of the products of this science in health care and education. Neuropsych Publishers accomplishes these aims by publishing books, dissertations and other products of scientific actiwity, by disseminating educational materialls and publication of tests, assessment scales and other psychometric instrumems in the fiold of Neuropsychology, Neuropsychiatry and other areas within the domain of Brain \& Behaviour.

Postal address:

Neuropsych Publishers

Department of Psychiatry \& Neuropsychology

Section Neuropsychology, Neuropsychialry, and Psychobiology

University Maastricht.

PO Box 616

NL-6200 MD Maastricht

The Netherlands 


\title{
AN OPERATION UNDER GENERAL ANAESTHESIA AND COGNITIVE AGEING
}

\author{
PROEFSCHRIFT
}

ter verkrijging van de graad van doctor aan de

Universiteit Maastricht,

op gezag van de Rector Magnificus, Prof. Mr. M. J. Cohen

volgens het besluit van het College van Decanen,

in het openbaar te verdedigen op

vrijdag 4 april 1997 om 14.00 wur

door

\section{Jeanette Bernadette Dijkstra}

geboren op 15 april. 1968 te Joune 
Promotor:

Beoordelingscommissie:
Prof. dir. J. Jolles

Prof. dr. A. Appels (Voorzitter)

Dr. B. Bonke (Erasmus Universiteit Rotterdam)

Prof. dr. M. van den Hout

Dr. J. Møller (Rigshospitalet Kopenhagen, Denemarken)

Prof. dr. R. Reneman

The studies described in this thesis were carried out at the Maastricht Brain \& Behaviour Institute, the Department of Psychiatry \& Neuropsychology of the University Maastricht and University Hospital Maastricht 
Aan mijn vader Voor mijn moeder 



\section{Table of contents}

Prologue

I The influence of surgery on cognitive functioning in elderly people: possible determinants and methodological issues

Introduction

Ageing, cognition and anaesthesia

Cognitive function and age

An operation under general anaesthesia as predictor for

cognitive decline in the elderly

$\begin{array}{ll}\text { General anaesthesia as a risk factor for dementia } & 16\end{array}$

Influence of surgery on cognition

History

Short and long-term cognitive effects

Determinants of cognitive dysfunctions

Discussion

Methodological issues

Measurements used in the assessment of cognitive change

Use of parallel test versions and control groups in the measurement of change

How to analyse cognitive change? $\quad 38$

$\begin{array}{lr}\text { Discussion } & 39\end{array}$

Concluding remarks $\quad 40$

II Cardiopulmonary bypass (CPB) and cognitive function 45

Introduction $\quad 46$

CPB and the brain $\quad 47$

$\begin{array}{ll}\text { The heart-lung machine } & 47\end{array}$

Pathophysiology of CPB $\quad 48$

The influence of CPB on cerebral physiology 49

The influence of changes in cerebral physiology on cerebral linjury 50

Cognitive changes following CPB 5 .

Methodological issues 51

Incidence of cognitive changes after short and long follow-up periods $\quad 52$

Controlled studies $\quad 56$

Cognitive domains studied $\quad 57$

Variables associated with cognitive change 61

Interventions to reduce the incidence of cognitive deficits 66

$\begin{array}{ll}\text { Concluding remarks } & 67\end{array}$

III The influence of age on postoperative cognitive recovery after $\begin{array}{ll}\text { coronary artery bypass graft surgery } & 77\end{array}$

$\begin{array}{ll}\text { Introduction } & 78\end{array}$

Materials and methods $\quad 78$

Results $\quad 81$

Discussion $\quad 85$ 
IV How to assess individual cognitive change after an intervention 89 Introdiction $\quad 90$

Matterials and methods 91

Results 94

$\begin{array}{ll}\text { Discussion } & 98\end{array}$

$V$ The influence of an operation under general anaesthesia on $\begin{array}{ll}\text { cognitive functioning in the elderly } & 101\end{array}$

$\begin{array}{ll}\text { Introduction } & 102\end{array}$

Materials and methods $\quad 103$

$\begin{array}{ll}\text { Results } & 106\end{array}$

Discussion $\quad 111$

VI An operation under general anaesthesia as risk factor for age-related cognitive decline: results from a large

cross-sectional population study

$\begin{array}{ll}\text { Introduction } & 116\end{array}$

$\begin{array}{ll}\text { Materials and methods } & 117\end{array}$

$\begin{array}{ll}\text { Results } & 120\end{array}$

$\begin{array}{ll}\text { Discussion } & 123\end{array}$

$\begin{array}{lr}\text { VII Concluding remarks } & 127\end{array}$

\section{Appendix}

The influence of microembolic events on cognitive ontcome after

Coronary artery bypass graft (CABG) surgery

$\begin{array}{ll}\text { Summary } & 137\end{array}$

$\begin{array}{lr}\text { Samenvatting } & 1.43\end{array}$

Dankwoord 1.49

$\begin{array}{ll}\text { Curriculum Vitae } & 151\end{array}$ 


\section{PROLOGUE}

The influence of an operation under general ancesthesia on cognitive function in the ageing population

Cognitive dysfunctions after an operation under general anaesthesia can occur, especially in elderly patients. These dysfunctions can lead to a diminished quality of life and have an impact on society when patients prematurely lose their independence. It is difficult to estimate the extent of this sociall burden. It incommodes families and friends who need to care for these elderly relatives with cognitive deficits. It is possible that elderly people lose the potential to earn an income, or require special services due to these cognitive deficits, which can constitute a financial burden on society as well. Every year about 30 million patients in the countries of the European Union require an operation under general anaesthesia and about $35 \%$ of these patients are older than 60 years. Every effort should be made to identify mechanisms and preventable causes of cognitive deficits after an operation under general anaesthesia.

Many clinicians and family members can provide anecdotal evidence of elderly patients whose cognitive function deteriorated and did not recover after surgery. An often-heard comment of family members is "he/she has never been the same after the operation". Also patients complain of recent memory loss (forgetting a close friend's name or their own telephone number), difficulty with simple arithmetic, or a poor concentration span, that makes it difficult to follow the story line of a novel or television programme. Other common symptoms include poor handwriting, visual disturbances not corrected by their regular glasses, and poor judgement of distance in walking or driving. These examples suggest that an operation under general anaesthesia can cause a permanent change in cognitive abilities. For some patients who suffer only transient (weeks to months) cognitive impairments, the complaints may only be annoying, but for others they may constitute a serious crisis, especially if the impairments are permanent and result in the loss of job or, in the elderly, independence.

Impaired cognitive functions after an operation can range from momentary postoperative confusion and delirium to permanent brain damage. Many papers describe early and short lasting delirium in postoperative patients. These are well summarised by Dyer et al. [2] and Parikh and Chung [11]. However, the literature is contradictory about changes in cognitive function that persist for weeks to months. Only a few studies reported a decline in cognitive performance 3 to 6 weeks after an operation $33-5,10 \#$. Most studies failed to find evidence of protracted cognitive dysfunction. However, the cognitive complaints patients report deal especially with long-term effects. The failure to find long-term cognitive deficits may be because the psychological tests used were not reliable, i.e. test-retest correlations had not been ascertained. In other words, the variation in test scores before and after an operation is very large due to reasons unconnected with the operative procedures used. Practice effects have been largely ignored, possibly because their size has been underestimated [12]. Thus, when patients are assessed postoperatively, cumulative benefits of practice can easily outweigh changes caused by the operation. The impact of practice is intensified when precisely the same test material is re-administered. Moreover, in the great majority of studies tests were used that had been developed either as a diagnostic for use in neurological patients or for the measurement of intelligence-related constructs in normal subjects and in patients. These tests were not devised for use in the evaluation of medical or other interventions.

An ample literature describes the rising incidence of cognitive dysfunctions with adwancing 
age. However, some doubt has been cast on the inevitability of a chronologically preordained decline in cognitive function. For example, Rabbitt [12] and Houx and colleagues [7] emphasize that factors other than biological ageing may have a greater role than ageing in the cognitive dysfunction observed in elderly subjects. Houx and coworkers studied 250 subjects aged 20 to 80 years and observed that healthy subjects who were characterised by so-called Biological Life Events (BLE) showed an inferior cognitive performance to that of healthy subjects without BLE 101. BLEs are defined as "those factors that are related to physical or mental health, experienced at any point in life and thought to be related to brain dysfunction, other than grossly impaing conditions like dementia and brain trauma". One of these BLE was anaesthesia, defined as "more than three operations under general anaesthesia with a short duration or one lasting more than 3 hours". The number of risk factors increased with age, with a substantial correlation between age and anaesthesia. The authors concluded that BLE-affected subjects were slower than healthy volunteers and that "the existence of risk factors for brain dysfunction may aggravate the effects of ageing even for subjects younger than 65 years".

Longitudinall studies of changing mental ability in old age show that abrupt declines in cognitive function are precursors of growing dependence on others, leading to loss of independence and withdrawal from studies $[1,13]$ or to death $[8,9]$.

\section{Awns and oulline of this thesis}

The main theme of this thesis is to study the effect of an operation under general anaethesia on cognitive functions, and the mediating role of age in this relationship. In this thesis, a distinction is made between surgery in general and open-heart surgery because of the differences in surgical techniques. Therefore, the first two chapters review the literature on the influence of general surgery on cognitive functioning and the influence of open-heart surgery on cognitive functioning (chapter 1 and 2). The other chapters present the results of empirical studies. In the next two chapters the effect of open-heart surgery on cognitive function is the central issue (chapter 3 and 4). This is followed by two chapters on the influence of general surgery on cognitive function (chapter 5 and 6). The main findings and the possible implications of the above-mentioned studies are discussed in the concluding remarks (chapter 7).

The main questions addressed in this thesis are:

\section{What is the infuence of an operation under general anaesthesia on cognitive functioning?}

In chapter 1, a review is presented of the results of clinical studies published from 1980 onwards, on the effect of surgery on cognitive functioning. Possible determinants for a change in cognitive function after an operation and methodological issues involved in this type of research are discussed.

\section{What is the impact of open-heart surgery on cognitive function?}

In chapter 2, the effects of open-heart surgery using cardiopulmonary bypass (CPB) on cognitive functioning are reviewed. The influence of CPB on the physiology of the brain and cognitive changes is discussed and interventions to reduce the incidence of cognitive deficits are mentioned. 
3. What is the infuence of age on cognitive recovery after cononary artery bypass graft (CABG) surgery?

In chapter 3 , a study designed to investigate the postoperative cognitive dysfunction in relation to age of patients who had undergone CABG surgery is described. The cognitive performance of middle-aged and elderly patients was compared pre and postoperatively. A distinction was made between short-term and long-term cognitive effects in order to test the hypothesis that older subjects require a longer recovery period after $\mathrm{CABG}$ surgery. The patients were compared with a control group before the operation to see whether there is a difference in cognitive performance before the operation, as heart disease might be a factor which negatively influences brain functioning.

\section{What is the most reliable way to estimate individual cognitive change after an intervention?}

In chapter 4, several approaches to estimate individual cognitive change in CABG patients and normal healthy controls are described and compared. Neuropsychological tests can be used to assess changes in cognitive function after a medical or psychological intervention. Besides comparing changes in group means, it is important to consider individual changes. Methodological issues involved in the estimation of individual cognitive change are discussed.

5. What is the severity and character of postoperative cognitive dysfunctions in the elderly? In chapter 5 , a study is described in which short-term and long-term changes in cognitive function after an operation under general anaesthesia were studied in a population aged over 60 years and were compared with the change in cognitive performance of normal healthy elderly.

\section{Is surgery a risk factor for age-related cognitive decline?}

In chapter 6, a large cross-sectional study is described in which a history of an operation under general anaesthesia and the interaction with age were assessed as predictors of cognitive decline. Additionally, duration of anaesthesia and number of operations in subjects with a history of an operation under general andesthesia were studied as risk factors.

\section{Concluding remarks}

In chapter 7 , a general discussion of the various findings and conclusion of this thesis is given.

\section{REFERENCES}

1. Baltes $P B$, Schaie KW, Nardi AH. Age and experimental mortality: A seven year study of cognilive behawiour. Developmental Psychology 1971; 5: 18-26.

2. Dyer CB, Ashton CM, Teasdale TA. Postoperative delirium: A review of 80 primary data-collection studies. Archives of Internal Medicine 1995: 155:461-5.

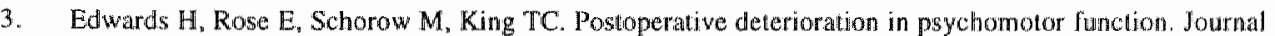
of the American Medical Association 1981;245:1342-3.

4. Flat JR, Birell PC. Hobbest A. Effects of araesthesia on some aspects of nonial functioning of 


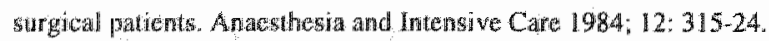

5. Hole $A$, terjeger $\mathrm{T}$, Aretwik $\mathrm{H}$. Epidural versus general anaesthesia for total hip arthroplasty in elderly

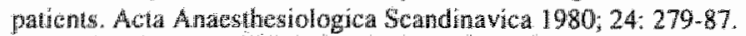

6. Houx $\mathrm{PJ}$, Veeling FW, Jolles $\mathrm{J}$. Age-associated cognitive decline is related to biological hife events. In: Igbal K. McLachan DRC, Winblad B, Wismewsk HM, ed. Alzheimer's Disease: Basic Mechanisms, Diagrowis and Therapeutic Stategles, Chichester, UK: John Wiley \& Sons Lid, 1991: 353-9.

7. Hou PI, Vheshing FW, Jolles I. Rugonous health scteening reduces age effech on menory scanning task. Britin and Cognition $1991 ; 15,246-60$

4. Jarwik LF, Falek A Intellecual stabiling and surwival in the aged Journal of Gerontology 1963;18:173-6.

9. Wlemen RW. Intellectual change in the senium. Proceding of the Social Statistics Section of the Anverican Statistical Society, 1962; 2905 .

1.0. Knil RL. Nowick TV, Novick BA, Sknner BA. Idiopathic postoperative delirium is associated with longterm cognitive impaiment. Canadian Joumal of Anaesthesia. 1991; 38: A54.

11. Parikh SS, Chung F. Pogtoperative delirium in the elderly. Anesthesia and Analgesia 1995; 80: $1217-22$.

12. Rabbiu PMA. A fresh look at changes in reaction times in old age. In: Stein A, ed. The psychobiology of aging problems and perspectives. Amsterdam: Elsewer North Holland, 1980:425-42.

13. Riegel KF, Regel RM, Meyer G. A study of the dropout rates in longitudinal research on aging and the predicition of death. Journal of Personality and Social Psychology 1967; 1: 342-8. 


\title{
The influence of surgery on cognitive functioning:
}

\author{
Possible determinants and methodological issues
}

\begin{abstract}
Studies published in the last 15 years on the effect of an operation on cognitive functioning are reviewed. In 38 of the 40 , studies the short-term effects (from 6 hours to 1 week) of an operation were studied. In 22 of these 38 studies a decline in cognitive function was reported as measured with psychometric tests. In 22 of the 40 studies long-term effects (from 3 weeks to 10 months) of an operation on cognitive functioning were studied, but in only 4 was a decline reported. Possible determinants for a short-term cognitive decline were age, general anaesthesia instead of local anaesthesia, pain, and the use of medication. Determinants for long-term cognitive dysfunctioning were hard to determine because these are seldom detected by using cognitive tests. The preoperative physical and mental condition of the patients are suggested to be important in this respect. Unfortunately, patients with a compromised physical or mental condition are often excluded from this type of research. The type of surgery does not seem to infuence cognitive functioning.

Different measurements have been used to assess changes in cognitive functioning, ranging from global rating scales to more specific speed-related tests. These tests can be grouped according to the different cognitive domains that are assessed, such as memory, attention, concentration, and speed of information processing. Cognitive dysfunctions after surgery seem not to be related to one specific cognitive domain but an overall deterionation is often reported.

The lack of an objective cognitive decline in the long term is in contrast with the subjective complaints these patients report. This discrepancy may partly be explained by the tests used in the assessment of cognitive functioning. Often no parallel versions were used or insensitive tests were used, which can obscure a learning effect. Moreover, only change in mean group performance was studied. It is possible that only a few patients show a cognitive decline which may be obscured by most patients showing no change or an improvement. Another explanation is that cognitive complaints are not based on cognitive decline as measured with psychometric tests. Other factors such as the degree of emotional support, coping style, personality, may be more important in influencing cognitive outcome and nervous system effects in the long term. More attention should be paid to these factors in future research.
\end{abstract}




\section{INTRODUCTION}

The studies reported in this chapter concern the influence of surgery on cognitive functioning, especially in the elderly. Many clinicians and family menbers can provide anecdotal evidence of eiderly patients whose cognitive function deteriorated and did not recover after surgery [3, 60. 811. An often-heard comment of family members is "he/she has never been the same after his/her operation". Also patients complain of recent memory loss (forgetting a close friend's name or their own telephone number), difficulty with simple arithmetic, or a poor concentration span that makes it difficult to follow the story line of a novel or television programme. Other common symptoms include poor handwriting, visual disturbances not corrected by their regular glasses, and poor judgement of distance in walking or driving. These examples suggest that an operation under general anaesthesia can cause a permanent change in cognitive abilities. For some patients who suffer from transient (weeks to months) cognitive impairments, the complaints may only be annoying, but for others they may constitute a serious crisis, especially if the impairments are permanent and result in the loss of job or, in the elderly, independence.

The present chapter contains a survey of the literature on the effect of surgery on cognitive functioning and discusses possible determinants and methodological issues involved. Impaired cognitive functions after an operation range from momentary postoperative confusion and delirium to permanent brain damage. Studies looking at momentary confusion and delirium are only briefly discussed because two rewiews have been published recently on this subject [31, 67]. The main focus of this chapter concerns the occurrence of subtle cognitive disturbances which still exist months after an operation. Brain surgery studies are not included in this survey, since the central nervous system complications of neurosurgery can produce confounding results.

No attempt has been made to evaluate differences between anaesthetic agents or between premedication agents in the extent to which they affect mental performance. Others have reported about the effects of these agents and, when relevant, these studies will be mentioned. An overview of anaesthetic techniques and anaesthetic risks in geriatric patients is given by Katz and Fagraeus [53]. They also describe the anatomy, physiology, and pharmacology of ageing related to anaesthetic practice. Studies investigating the effect of anaesthesia on the mental performance of non-patient volunteers ate also only mentioned when relevant, but are not the main issue here. Such laboratory research makes an important contribution to the area by isolating the effects of anaesthesia from the effects of surgery, but the interpretation of these studies is difficult because of methodological considerations such as bias in the selection of subjects (and hence limited generalisation of results) and the motivational effects on test performance inherent to the use of volunteers.

Cardiac surgery is also not reviewed in this chapter because cardiac surgery differs from other types of surgery in many aspects. A review of cognitive function after open-heart surgery can be found elsewhere $|4|$ and will be discussed in more detail in chapters 2, 3 and 4 . The main difference is the use of a heart-lung machine, which takes over the function of the heart and the lungs during surgery. This machine can give rise to additional problems which can have an impact on the brain. Two causative mechanisms, closely related to use of the heart-lung machine, are cerebral hypoperfusion and cerebral embolism. A higher incidence of neuropsychological dysfunction is reported in patients undergoing heart-surgery compared with other surgery $[1,9,40,72,80,921$.

It is now generally accepted that cognitive function declines with advancing age $[7,20,49,56]$. In this overview, a distinction will be made between a short-term cognitive effect and a long-term cognitive effect. A short-term cognitive change is defined as a change in cognitive 
function that is apparent immediately after the operation until discharge from the hospital (usually after 7-10 days). Long-term change is defined as the change in cognitive functioning during the follow-up assessment, which took place between 3 weeks and 10 months th the different studies. The study confines itself to a review of the literature from 1980 onwards. In the next part of this chapter, possible determinants of cognitive dysfunction, as found in the literature , will be discussed. Examples of these determinants are generall versus locall (epidural/spinal) anaesthesia and age. Finally, methodological problems occurring in this kind of research will be discussed.

\section{AGEING, COGNITION, AND ANAESTHESIA}

\section{Cognitive function and age}

There is a vast literature on the relationship between age and cognitive performance. It is now generally agreed that healthy individuals are characterised by cognitive decline in the later decades of adult life $[7,20,49,56]$. The acquisition of new information becomes less efficient, which, coupled with a diminished retention of this information, results in substantially poorer memory performance [49]. The ability to plan new activities, solve problems, and make complex decisions is noticeably diminished [73]. In addition, attention processes appear to be imvariably poorer in older patients than in younger patients [69]. Over a third of all individuals older than 60 years complain of sleep disorders [93]. Sleeping is closely related to arousal, which is also impaired in old age. In addition, there appears to be a general cognitive slowness that is especially apparent in the performance of tasks that have to be carried out under time pressure and/or in demanding situations. A general slowing down of central nervous system (CNS) functioning may be the cause of this problem [13]. A fruitful model for general slowing is provided by the notion of resources and resource reduction, as discussed by Salthouse [78]. Briefly, any cognitive activity requires resources, which may be time, space, or energy. A reduction of resources results in a diminished capacity to process information. For a thorough overview of the evidence on this issue, the reader is referred to the excellent surveys by Birren and Schate 8 i and La Rue [56]. While it is quite clearly established that elderly people (i.e. over 65 year's of age) show a deterioration in cognitive functioning or cognitive efficiency, there is also evidence that this deterioration may start in middle age (around the age of 40 years), at least in some categories of cognitive tests [45, 71]. Age-related cognitive problems may lie dormant for decades and only become gradually or suddenly apparent as the patient realizes that some aspect of his or her functioning is no longer what it used to be. Loss of neurons in the CNS may occur as early as the fourth decade of hife [41]. Problems that people aged 40 to 60 years experience may be caused by a deterioration of cognitive functions and abilities, giwing rise to defective memory function, decrease of cognitive energy, especially in demanding situations, and lack of concentration and attention. These problems often arise at work and can cause problems in family and other relationships, resulting in an increased use of the social security system, bealth care facilities, and medication. Although these problems are usually ascribed to social causes, they might also be the consequence of decreased cognitive functioning. Emotional change may occur in the elderly, either as a consequence of social or material loss ${ }_{\text {}}$ or as a consequence of the knowledge that many faculties have been lost or are diminished [13]. 


\section{An operation under general anasthesia as predictor for cogntitwe decline in the elderly}

Although it is generally accepted that cognitive function declines with advancing age, there are differences between individuals. Not everybody shows a decline in cognitive functioning al the same age. The cause of these individual differences in cognitive change with advancing age is probably not due to normal ageing alone, but also to other factors. Houx ef al. $[45]$ observed that health-felated factors can be risk factors for poor cognitive performance. These health-related factors were defined as "those factors that are related to physical or mental health, experienced at any point in life and thought to be related to brain dysfunction, other than grossly impairing conditions like dementia and brain trauma". Examples of these bealth-related factors are mild head trauma, a bistory of drinking, use of medication, and an operation under general anaesthesia. The latter was defined as more than three operations under general anaesthesia or one lasting more than 3 hours. The number of these factors increases with age, and there is a substantial correlation between age and an operation under general anaesthesia. People who have been through one or more of these events show a greater cognitive decline than people who have not; especially after the age of 60 [46]. Although people probably recover quite well after one of the above-mentioned events, it is not unlikely that the brain has suffered some functional damage which cannot be diagnosed directly but which becomes evident when one grows older: In a review, Satz [79] formulated a threshold theory for acquired brain injury. The theory addresses the concept of brain reserve capacity as a major factor in explaining differences in the onset of clinical symptoms or the expression of impaired test performance after acquired brain injury. Although this theory is about brain injury, it can also explain the differences in cognitive change (i.e., brain function) between patients after an operation under general anaestlesia. General anaesthesia is a possible determinant for an accelerated decline in cognitive functioning. Sotaniemi et al. [85] have shown that patients who had dieficits early after surgery and whose deficits disappeared later developed measurable deficits 5 years after surgery, suggesting that the neuronal damage incurred at surgery tended to manifest itself more as the years went by and the brain changed due to the natural ageing process.

\section{General anaesthesia as a risk factor for dementia}

Several authors have hypothesised that there is an association between prior exposure to general anaesthesia and Alzheimer disease (AD), although there is no experimental data to support this hypothesis. Paschalis et al. [68] studied the prevalence of a history of prior operations under generall ancesthesia in patients with dementia of Alzheimer type (DAT) and patients with multi-infarct dementia (MTD). No association was found between DAT or MID and past surgical events. A study of Corey Bloom et al. [25] tried to find clinical features that could distinguish patients with possible Alzheimer's disease (poAD), probable AD (prAD), and mixed $\mathrm{AD}$ (MIX). One of the features which could distinguish MDX from $\mathrm{AD}$ alone was an increased prevalence of cardiovascular disease and exposure to general anaesthesia. Bohnen and coworkers [12] evaluated prior exposure to general analesthesia as a potential risk factor for AD. They studied the difference in cumulative duration of anaesthesia and the total number of general anaesthetic exposures prior to the age of onset of dementia in patients with $\mathrm{AD}$ and matched controls. No difference in cumulative exposure to general anaesthesia, exposure to six or more episodes of general anaesthesia, or cumulative exposure to 600 minutes or more of general anaesthesia was associated with a increased risk of $A D$. Although one study found an association between MIX and exposure to general anaesthesia [25], most studies have not 
demonstrated that anaesthesia is a risk factor in the development of dementia. Dementias occurring after anaesthesia and surgery are probably related to prolonged and difficult surgery and to concomitant disease [52]. Although an operation under general anathesta is probably not a risk factor for the development of dementia, the literature slows that it does have an impact on brain functioning in some patients.

\section{INFLUENCE OF SURGERY ON COGNITION}

\section{History}

Although postoperative cognitive dysfunctions have been reported after a variety of surgical procedures, these changes are often assumed to be transient, with a return to baseline function being expected within 1 week [51]. In 1955, Bedford [3] reported serious cognitive changes in patients older than 50 years who underwent an operation under general anaesthesia. Although he mentioned that these patients were probably already vulnerable for some reason, he concluded that general anaesthesia was a trigger for brain damage. Hypotensive surgery was seen as being contra-indicated in the elderly. This study prompted many investigation. Simpson and colleagues $[81]$ studied 250 patients older than 65 years and did not find any postoperative cognitive decline. They explained their findings (contrary to Bedford (3] as reflecting progress in perioperative care and the exclusion of acute surgery. Rollason et al. [76] also found no cognitive decline postoperatively, not even in patients who were operated on under hypotensive conditions. The cognitive changes reported by Bedford are probably the result of undiagnosed perioperative events such as cerebral microembolisms, cerebrovascular accildents, and other causes of hypoxaemia.

Although the conclusion of Bedford's study can be questioned, anaesthesia is still considered a factor in postoperative changes in cognitive functioning [10, 14]. The studies published after 1980 on the influence of surgery on cognitive functioning are summarised in table 1.1 . Studies before 1980 were not reviewed because surgical techniques and anaesthesia procedures have changed over the years.

\section{Short-and long-term cogritive effects}

Of the studies mentioned in table 1.1,38 looked at short-term cognitive change. The first cognitive assessment occurred from 6 hours to 1 week after the operation in the different studies. Of these 38 studies, 22 reported a cognitive decline shortly after the operation. Several explanations were given for these short-term cognitive effects." general anaesthesia instead of local anaesthesia [22,33.44], inactivity, supine position, fasting, anaesthesia, sleep deprivation [32], postoperative fatigue $[52]$, tranquillizing drugs after the operation $[5,52,821$, halothane anaesthesia [87], history of mental depression [5], preoperative level of cognitive functioning [24, 82, 84], age [24, 65], postoperative pain [82], postoperative hypoxaemia [77], and poor preoperative physical condition [27]. The other studies were not able to demonstrate a cognitive decline shortly after the operation $[6,18,30,36,37,39,42,46,48,58-60,62,70,83]$. In these latter studies, cognitive performance was assessed from 2 days to 1 week after the operation. Prior and Chander [70] suggested that the finding of no change or improvement of mental function after anaesthesia is probably caused by preoperative nervousness and pre-occupation with the outcome of surgery which can lead to a tenseness, which makes concentration on such a test 


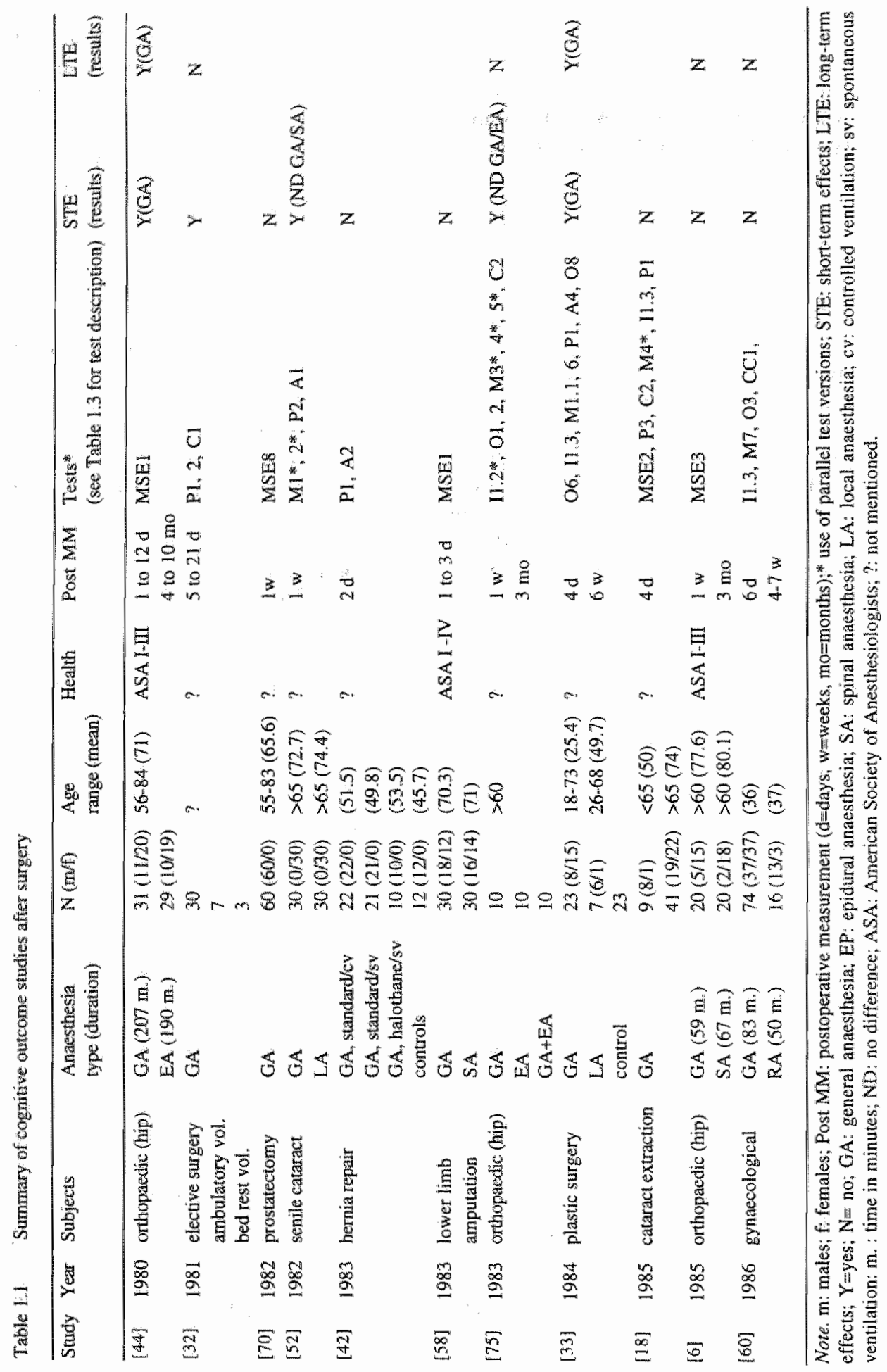


SURGERY AND COGNTION 19

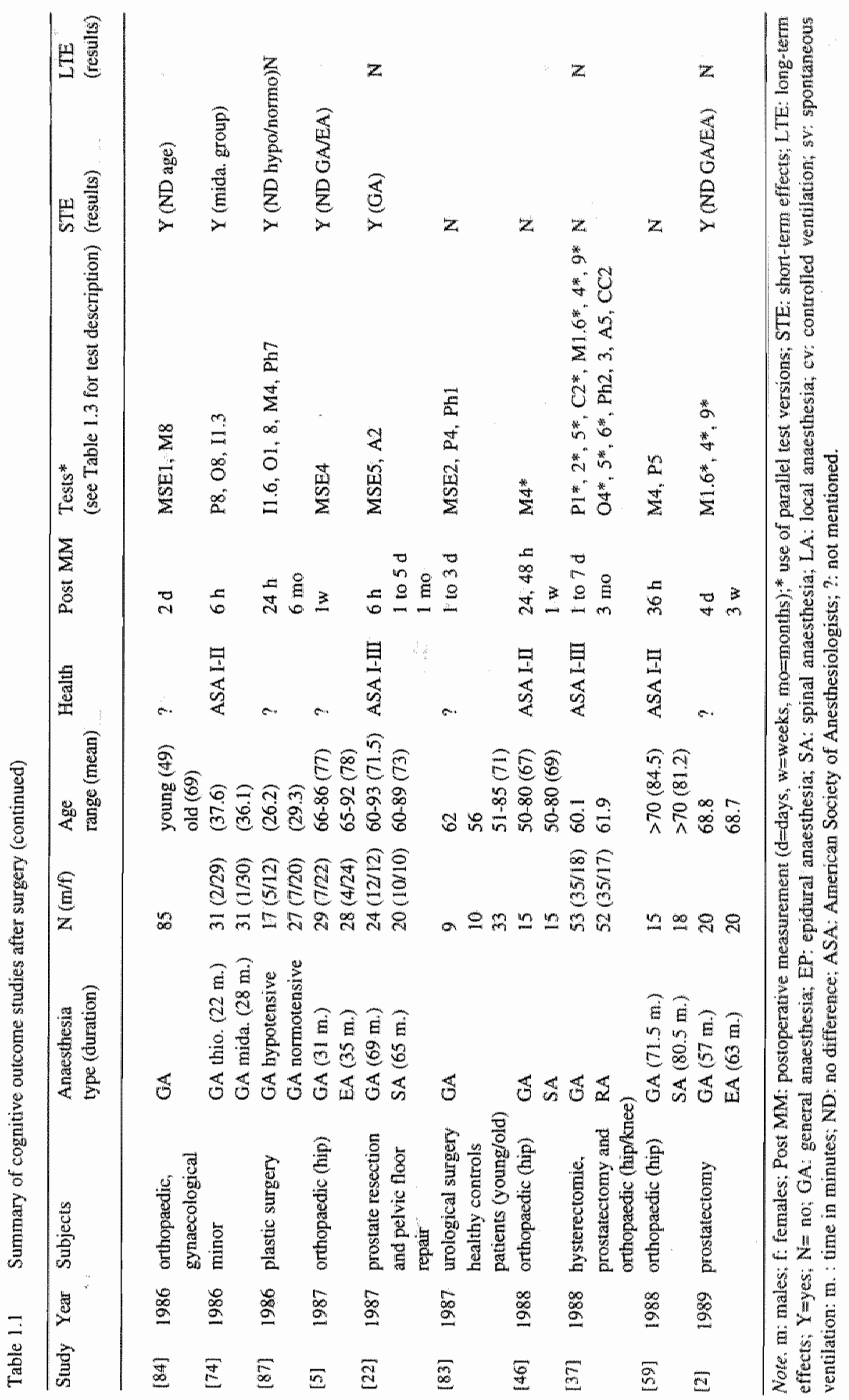




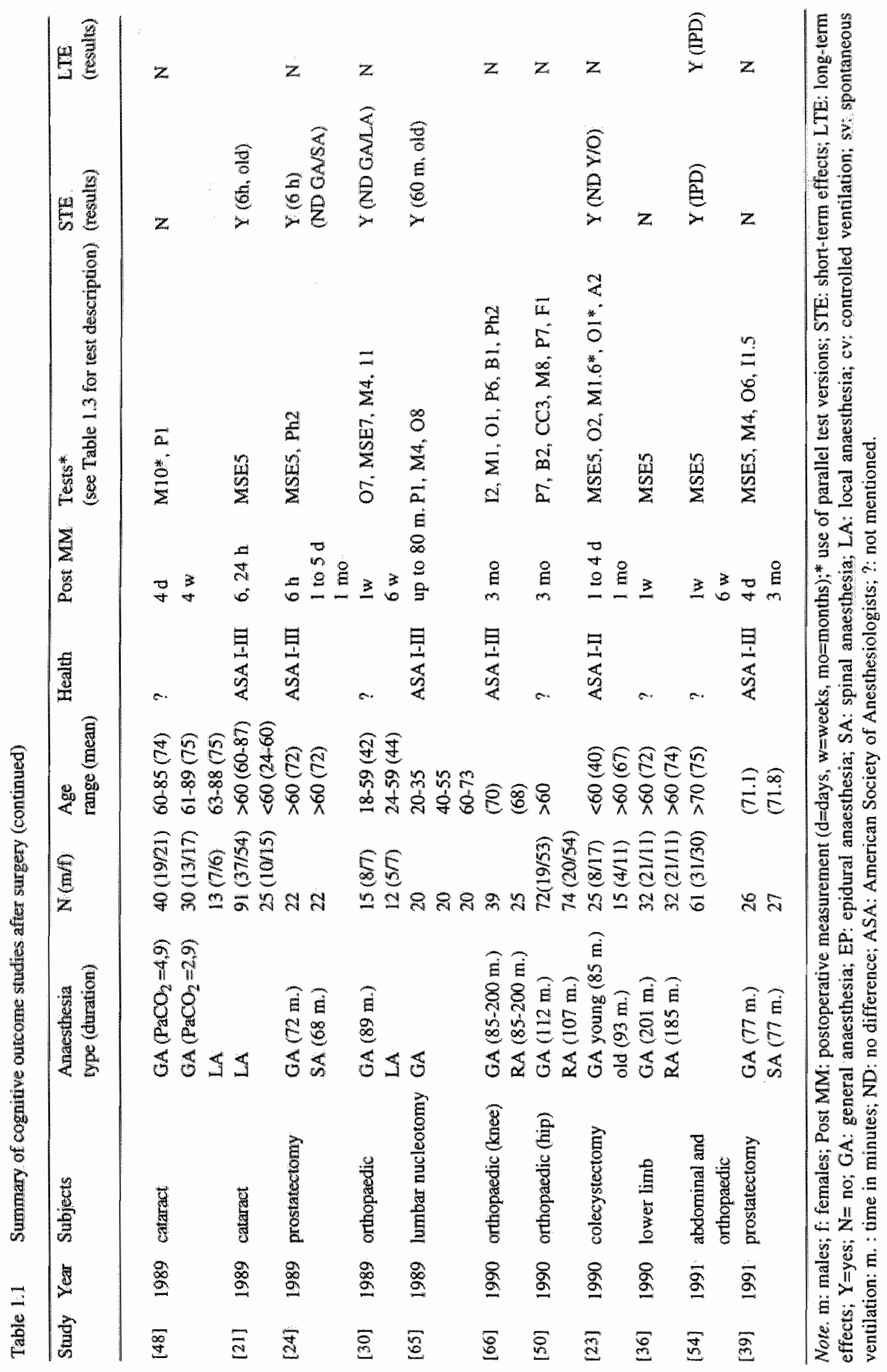


SURGERY AND COGNTION $\mid 2 I$

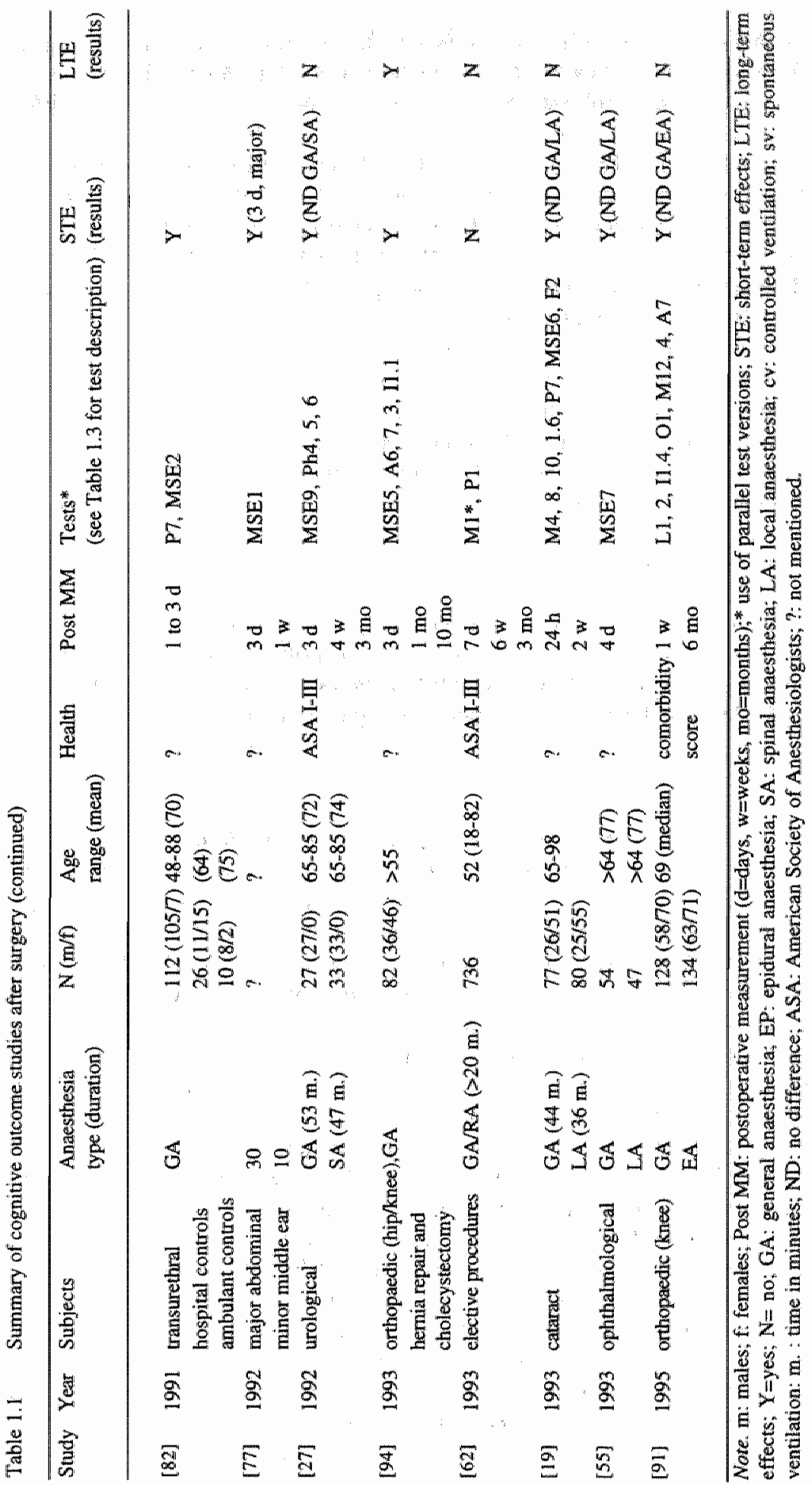


difficult. Afrer the operation, patients are more relaxed, thankful for a successful outcome of surgery, and looking forward to going home soon. Other explanations are practice effects on the cognitive measures and the use of tests that are not sensitive enough to measure cognitive change.

Twenty two studies looked at the long-term cognitive changes 3 weeks to 10 months after the operation. Only 4 of these reported a cognitive decline. Two of these studies compared general anaesuhesia with local anaesthesia and found a cognitive decline in the patients who underwent surgery under general anaesthesia [33,44]. One study reported that $10 \%$ of the patients who underwent surgery functioned below their preoperative level 3 weeks after the operation 132]; however a similar pattern of dysfunction was noted in volunteers on bed rest alone. Knill et al. [\$4] reported that $25 \%$ of the patients who developed delirium immediately after the operation showed a cognitive decline 6 weeks after the operation, as compared to only $2 \%$ of the patients without immediate postoperative delirium. The other 18 studies were not able to demonstrate a long-term decline in cognition functioning. The general conclusion is that cognitive decline shortly after an operation does occur but in the long term, patients generally recover or at least cognitive decline can not be measured by the psychometric methods used.

\section{Determinants of cognitive dysfunctions}

These studies differ in many respects: patient population (age, gender, size, inclusion criteria), methodology (time of assessment), type of surgery, type of anaesthesia (general versus local), duration of surgery, health status (physical condition) before surgery, and psychometric instruments used. The different determinants of cognitive decline mentioned in the literature will be discussed.

Age

The issue of the cognitive effects of surgery on older persons has been the subject of much conjecture but only limited systematic inquiry. The increased use of surgery as routine health care practice for people of advanced age has led to heightened speculation about phenomena such as post-surgical dementia and postoperative delirium within this patient population. In at metalualysiss Cryns et al. $[28]$ discussed the effects of surgery on the mental status of older people. The age range involved in this study was from 59 to 86 years with a mean age of 70 years. The databases of 18 empirical studies were combined into one comprehensive dataset and subjected to meta-analysis. They observed that surgery had a significantly decompensating impact on the mental status of older people and that for all mental status measures included (cognition, delirium, and affect), effect size appeared to be significantly moderated by a patient's age. They also found that a patient's sex was predictive of the type of mental impaiment that is most likely to occur, with women more often showing a delirious state and men cognitive decompensation. They reported only the magnitude and direction of the inmediate postsurgical recovery from surgery on a patient's mental status.

Although most studies mentioned in table 1.1 looked at the effect of surgery in the elderly, only four studies looked at the effect of age by studying both young and old patients undergoing an operation under general anaesthesia. Burrows and coworkers [18] found that both young and old patients undergoing cataract extraction had cognitively recovered by the fourth postoperative day. In a study by Smith and collegues [84] into the adverse cognitive effects of general anaesthesia in young and elderly patients undergoing orthopaedic, gynaecological, or general surgery, postoperative cognitive deficits in both young and elderly patients were found 
2 days after the operation. The elderly patients also demonstrated postoperative deficits of orientation and concentration. Nadlstawek et al. $[65]$ studied three age groups of patients, young, middle-aged, and elderly, who underwent lumbar mucleotomy. Sixty minutes after the operation a decline in cognitive performance was found in the middle-aged and the elderly patients but not in the young patients; by 80 minutes these differences were no longer found. Chung and coworkers $[23]$, who looked at cogntive recovery in elderly and young patients following intra-abdominal surgery (cholecystectomy), found that the postoperative cognitive deterioration was no greater in elderly patients than in young patients. Smith et al. 182 assessed whether age was a predictor of cognitive deterioration in patients who underwent transurethral procedures, but did not find that age contributed to the increased variability in reaction time. In the in study, Zucker-Goldstein et al. [94] studied elderly patients who underwent hip or knee replacement, hernia repair, and cholecystectony. The Mini Mental State Examination (MMSE) was used to estimate cognitive decline 3 days and 10 months after the operation compared with the preoperative score. The immediate postoperative MMSE score predicted postoperative cognitive decline 10 months later, but age did not contribute to this decline. From these studies, it seems that age plays a role in short-term cognitive recovery, in that elderly people need more time to recover, but in the long term age is not the most important factor in predicting whether cognitive deterioration occurs after an operation; other factors are probably more important in this respect (see also chapter 3 , this thesis).

\section{Preoperative physical condition}

As the population ages, surgery will be performed more frequently in progressively older patients. Given their higher prevalence of comorbid medical illness, cerebrovascular disease, and underlying cognitive dysfunction, elderly patients are at increased risk of structural changes in the brain. Corrective procedures to improve the quality of life in the elderly are becoming routine. Postponement or cancellation of anaesthesia and surgery in elderly patients with an operable malignancy, but a "weak" heart, places these patients on a descending path to in miserable death. "Expectant" treatment of an aged patient with a fractured hip because of " bad lungs" may place that patient on the same path. Similarly, the geriatric patient who has a relatively weak heart or bad lungs, but who dreads each day and each meal because of intractable oesophageal reflux because of a hiatal hernia may insist upon challenging the expertise of the surgeon and the anesthesiologist. Ageing brings many changes to the cardiovascular system, the respiratory system, the pulmonary system, renal function, nutritional state, and current compliance with drug therapy, changes which should be considered carefully before elderly undergo surgery. Ageing is an all-encompassing, multifactorial process involwing a decreased capacity for adaptation and a gradual decrease in functional reserve of all the body"s systems. Ageing itself is not truly a disease process but is instead an index of the probability of many disease states. Underlying disease is not always clinically evident in the elderly . Increased operative risk, when present, is attributable to identifiable disease, not simply to the angeing process $[39,54]$.

Crul et al. [27] studied the influence of type of anaesthesia on postoperative subjective well-being and mental function in elderly patients undergoing urological surgery. A supplementary group of patients with pre-existing cardiovascular and/or pulmonary disorders was included in the study to evaluate the influence of preoperative physical condition on postoperative mental function. In this group with pre-existing disorders, the decline in postoperative mental function and subjective sense of well-being was most pronounced. This was the only study that looked at the impact of physical condition on postoperative cognitive recovery. Interestingly, it was 
found that patients undergoing coronary artery bypass graft surgery had an inferior preoperative performance on a cognitive test battery when compared to carefully age-matched healthy controls (see chapter 3 , this thesis). This finding can be regarded as circumstantial evidence for the notion that patients who are going to be operated on may as a group-be characterised by an inferior condition (somatically and/or mentally) which increases the risk of the operation. These studies suggest that preoperative physical condition can have an impact on cognitive recovery after surgery. Only one study looked explicitly at the influence of physical condition on cognitive performance [27]. However, most studies have not mentioned the preoperative physical condition of the patients under study or have used these as exclusion criteria (see table 1.2).

Table 12 Medical and mental diseases used as exclusion criteria in the different studies

\begin{tabular}{ll} 
Medical diseases & Studies \\
\hline & \\
not mientioned & {$[27,28,34,35,38,41,444,52,61,67,76,84,85,86,89]$} \\
cardionespiratory problems & {$[19,22,24,46,72]$} \\
diabetes mellitus & {$[50,77]$} \\
sterold medication & {$[77]$} \\
anawsthesia in preceding 3 monttis & {$[2,39,57,77,93]$} \\
history of stroke & {$[18,22,24]$} \\
cancer & {$[6,64]$} \\
nearological disease & {$[2,6,19,56,57,62,68,79]$} \\
alcohol/drug abuse & {$[62]$,} \\
head trauma & {$[22,24]$} \\
visuallauditory problems & {$[19,23,39,48,50,93]$} \\
physical problems & {$[48]$} \\
vise of psychoactive medication & {$[24]$} \\
infective/metabolic disorder & {$[56]$}
\end{tabular}

Mental diseases $\quad$ Studies

$\begin{array}{ll}\text { abnornal mental status: } & {[5,22,24,46,48,54,60,62,96]} \\ \text { psychatric diseqse } & {[19,22,23,24,68,72,79,96]} \\ \text { dementis } & {[2,6,24,39,54,56]} \\ \text { low education } & {[39,79]} \\ \text { psychological disonder } & {[2]}\end{array}$

These exclusion criteria were used for obvious reasons. Investigators want to study a group of patients with no additional physical problems which could also affect cognition besides the operation they have to undergo. However, it is possible that these excluded patients are especially at risk of developing cognitive problems after the operation. This phenomenon could be an explanation for the fact that most studies have not found a decline in cognitive function after an operation. Several studies classified each patient according to the American Society of Anesthesiologists (ASA) status (see table 1.1). This is a 5-point classification to index a patient's physical condition: Status 1, patients without physical problems except the one they are operated on; Status 2, patients with minor to moderate physical problems such as hypertension or very young or old age; Status 3, patients with severe physical problems such as diabetes mellitus; Status 4, patients with life-threatening diseases; Status 5, patients who will die within 24 hours without an operation. Studies that classified their patients according to these 
criteria usually included patients with ASA status 1 to 3. Although the ASA status says something about the physical condition of a patient, it is only a global impression. No study that classified their patients according The ASA status looked at the effect of this physical status on cognitive recovery. The effect of preoperative physical condition on postoperative cognitive dysfunction is currently not clear. More research is needed in this area.

\section{Preoperative mental problems}

Some studies looked at the preoperative mental status of patients to see whether this was a predictor of cognitive outcome. Smith et al: [84] demonstrated a relationship between short-term postoperative deficits and preoperative level of cognitive functioning in patients who underwent orthopaedic, gynaecological, or general surgery. They found greater postoperative memory deficits in those patients who had a comparatively low preoperative memory score. They suggested that, given the relationship between cognitive impairment and the cholinergic system in normal ageing those patients who already show signs of cognitive deterioration are markedly affected by the anticholinergic agents used as premedication and for muscular relaxation. In a study by Berggren et al. [5]. elderly patients with femoral neck fracture were given epidural or halothane anaesthesia to see whether the anaesthetic technique influenced the incidence of postoperative confusion. They found that postoperative confusion was correlated closely with a history of mental depression and the use of anticholinergic medication. No difference in incidence of confusion between the two anaesthetic groups was found. Chung and collegues [21] studied young and elderly patients undergoing cataract operations. Mental function was assessed by using the MMSE pre- and postoperatively. The baseline score on the MMSE was found to be a significant predictor of the postoperative score. In a study into mental function after general anaesthesia for transurethral procedures [82], an increased variability of reaction time after the operation was predicted by a reduced score on a mental status test before the operation. From these studies it seems that a low preoperative mental function can be a determinant for postoperative cognitive deterioration. However, most studies excluded such patients (see table 1.2). So the same problem as with physical condition, as mentioned before, occurs with preoperative mental status. This could also be an explanation for the fact that most studies have not been able to demonstrate a deterioration in cognitive function after an operation because the patients at risk had already been excluded.

\section{General anaesthesia wersus local anaesthesia}

The early discussion about the effect of general anaesthesia on cognitive function in the eldlerly [3] led to the question whether local anaesthesia would preserve cognitive functioning in the elderly better. There are indications that local anaesthesia improves postoperative negative nitrogen balance and ameliorates the endocrine-metabolic stress response to surgery. There is also less postoperative blood loss and a lower incidence of postoperative thromboembolic complications [44]. Twenty-six of the 40 studies compared the effect of the two different procedures on changes in cognition in elderly patients $[2,5,6,19,22,24,27,30,33,36,37,39,44,46$, $48,50,52,55,58.60,66,70,75,911$. Only two studies $[33,44]$ reported a difference in cognitive outcome between the two procedures, both in the short term and the long term. These studies found a cognitive decline in some patients who underwent an operation under general anaesthesia. In the study of Hole and coworkers [44], no objective neuropsychological tests were used, but patients were interwiewed during their hospital stay and after 6 weeks they were sent a questionnaire. In Flatt's study [33]. objective neuropsychological measures were used but only 7 patients were operated on under local anaesthesia and 23 under general anaesthesia. 
Chung ef al. 22] demonstrated that short-term mental function was better following spinal anaesthesia than following general anaesthesia. There was a significant impairment of cognitive function 6 hourg after the operation, and some impaiment 3 days after the operation when general anaesthesia was used. They concluded that spinal anaesthesia may be a better choice in the elderly, as it causes less deterioration in mental function, a lower incidence of postoperative confusion, and a reduced risk of drug interactions. The other 23 studies could not demonstrate any difference in cognitive functioning between the two procedures. The mental impaiment occurring within the first postoperative week is probably caused by factors other than the agents used to induce general anaesthesia, the endocrine-metabolic response to surgery, or amount of blood loss. The type of anaesthesia does not seem to influence cognitive outcome after the operation in the long term, although shortly after the operation patients can be more confused after general anaesthesia. Dekhuijzen and de Lange [29] recently investigated the influence of general or local anaesthesia on the mental function of elderly patients. They reviewed eighteen papers, published between 1980 and 1990 , and concluded also that with both general anaesthesia and local andesthesia mental changes can be found in the immediate postoperative period, but not in the long term.

\section{Type of surgery}

Differences in the type of surgery, ranging from minor surgical procedures to extensive surgery, also make comparisons between different investigations problematic, since the relationship between mental function and the extent of the surgical trauma is unknown. Ten studies looked at the influence of orthopaedic (hip and knee) surgery $[5,6,30,44,46,50,59,66,75,91]$, four at the influence of prostatectomy $[2,24,39,70]$, five at the influence of cataract surgery $[18$, $19,21,48,52]$, one at the influence of amputation of the lower limb for vascular disease [58], two at the influence of plastic surgery $[33,87]$, one at the influence of lumbar nucleotomy $[65]$; one at the influence of cholecystectomy [23], one at the influence of lower limb surgery [36], one at the influence of urological procedures [27], and one at the influence of ophthalmological surgery [55]. Nine studies looked at a mixture of operations (orthopaedic, gynaecological, urological, and cataract) within one study $[22,37,60,62,77,82-84,94]$. In two studies the type of operation was not described $[32,74]$. From these studies it seems that type of surgery is not responsible for the change in cognition, as there is no specific operation in which a decline in cognitive performance is always or never found. The studies that looked at different types of surgery within one study support this notion because, in general, no differences were found between the different surgical procedures in terms of changes in cognition $[22,84]$.

The time after the operation when cognitive function was assessed also differs between the studies, and is dependent on the type of surgery. In short surgical procedures, cognition was assessed a fow hours after the operation. In more extensive surgical procedures, the first postoperative assessment took place several days after the operation. The general conclusion is that cognitive decline shortly after an operation does occur but that in the long term patients generally recover or at least cognitive dysfunctions cannot be measured. These findings seem to be independent on type of surgery.

\section{Phamacological deteninants}

The nervous system is the target organ for the pharmacological assault which produces a transient state of drug-induced coma referred to by the all-encompassing term 'general anaesthesia'. Thus, by definition, no plan for anaesthetic management, however meticulous its construction, can avoid extensive and profound disruption of the normal function of this vital 
organ. Studies evaluating the short-term effects of anaesthesia in healthy volunteers not subjected to surgery have shown that all agents used to induce and maintain anaesthesia have some deleterious effect on mental function. Even trace amounts of anaesthetic agents such as nitrous oxide, halothane, and enflurane have been shown to cause measurable decrements in performance in psychological tests $[16,17]$. The functions most sensitive to these minimal amounts of anaesthetic are immediate memory, as measured by a digit span test, and a combination of perception, cognition, and motor response, as assessed with a task requiring divided attention to simultaneous auditory and visual stimuli. These functions may be affected for up to 1 hour after exposure to the anaesthetic has ceased [51].

There has been much debate over the years as to whether anaesthesia causes prolonged and irrevocable deterioration in mental function. It is difficult to distinguish the effects of anaesthetic agents alone, after exclusion of other factors known to be present at the time of surgery and during the postoperative period. A wide variety of psychological and physiological tests administered to young volunteers anaesthetised with various agents revealed no detectable effects on mental function beyond 21 days [42]. Nor are there reports of subjective changes once the initial disturbances disappeared. It appears therefore that uneventful anaesthesia does not have a longterm effect on the cognitive function of fit, young patients beyond the first week or two after surgery:

Although function usually returns quickly and completely in daily clinical practice, the nervous system of an elderly individual differs both quantitatively and qualitatively from its younger counterpart. In addition, the disposition and pharmacokinetics of anaesthetic drugs in these patients is altered by ageing, and elderly patients have a significant prevalence of concomitant diseases. Elderly people are more likely to suffer from adverse drug interactions because they are often prescribed several drags at a time. The decrease in renal and hepatic function results in prolongation of drug elimination half-lives. The anatomy, physiology, and pharmacology of ageing in relation to anaesthesia has been thoroughly described by Katz and Fagraeus [53]. They also give an overview of anaesthetic techniques and anaesthetic risks in geriatric patients.

Two studies looked at the effect of pharmacological agents on cognitive performance. Reitan et al. [74] compared the effects of two anaesthetics on psychomotor skills and amnesia in patients undergoing minor elective surgery. In one group anaesthesia was induced with midazolam and in the other group with thiopental. Time to orientate postoperatively and to perform on a psychomotor test were longer with midazolam than with thiopental. Anterograde amnesia was evident in $84.8 \%$ of the midazolam-treated patients compared with $31.4 \%$ of the thiopental-treated patients. They concluded that midazolam was an effective agent for inducing anaesthesia, but that it delays recovery of psychomotor function compared to thiopental. In a study by Smith et al. [82], the use of postoperative sedative drugs contributed to an increased variability in reaction time after an operation in patients who had general anaesthesia for transurethral surgery.

Although not many studies looked at the effect of drugs on cognitive functioning in elderly patients undergoing surgery, drugs certainly do affect mental functioning, especially immediately after an operation. These residual drug effects disappear between 48 hours and 1 week after surgery [64].

\section{Hypoxaemia}

That cerebral hypoxaemia can result in subtle cognitive dysfunctions has been shown in studies outside of the operating theatre. For example, West ${ }^{[881}$ reported that healthy mountain climbers 
who suffered prolonged and severe hypoxaemia, experienced a decline in verbal learning and short-term menory and an impairment in expressive language. The most serious impairment was found in finger tapping speed. This abnormality was still present in thirteen of the sixteen subjects 1 year later. In this study subjects suffered prolonged and continuous hypoxaemia. In patients undergoing surgery, short episodes of hypoxaemia occur during the operation and in the nights that follow $[15,61,63]$. The impact of these short episodes of hypoxaemia on cognition is not clear, but intra- and postoperative hypoxaemia has been suggested to be a major risk factor for to postoperative cognitive dysfunction [e,g, $5 ; 44,77]$.

Four studies have looked at the association between cognitive functioning and postoperative hypoxaemia $[5,44,62,77]$. There was a significantly higher incidence of mental complications in patients undergoing elective hip replacement surgery who were anaesthetised with thiopental-fentanyl-nitrous oxide than in patients operated on under epidural analgesia [44]. The authors concluded that confusion was related to the degree of postoperative hypoxaemia in patients given general anaesthesia. In patients given halothane, early postoperative hypoxaemia was associated with confusion [5]. However, in contrast to the results of Hole et al. [44], there was a high incidence of postoperative confusion in patients who had been operated upon under epidural analgesia. Patients with confusion in the epidural group did not have any reduction in arterial oxygen tension postoperatively. Thus, hypoxaemia was not the only cause of the postoperative confusion in these patients. Rosenberg and Kehlet [77] studied patients who underwent major surgery and minor surgery and compared the occurrence of hypoxaemia during the second postoperative night and the mental test score in the two groups. The patients who underwent major surgery had a decreased mental test score on the third postoperative day, whereas those who had undergone minor surgery did not show an impaired cognitive functioning. This decreased cognitive function was correllated with the mean $\mathrm{SpO}_{2}$ on the second postoperative night following major surgery. The authors concluded that postoperative hypoxaemia is an important pathogenetic factor in postoperative cognitive dysfunction. Møller and coworkers [62] used perioperative monitoring with pulse oximetry to measure hypoxaemia and adjusted the oxygen supply in order to prevent a decrease in postoperative cognitive dysfunction. They studied two groups of patients, one of which one underwent pulse oximetry monitoring in the operating theatre and recovery room and the other not. They concluded that postoperative cognitive impairment was the same with or without perioperative monitoring with pulse oximetry.

In three of the four above-mentioned studies, psychometric tests were not used to assess mental function, but only a mental status test or interview $[5,44,77]$. These studies reported a change in mental score after the operation which was related to hypoxaemia. In two studies this relation was found for the short term only $[5,77]$. However, Hole and collegues [44] reported mental changes in four patients that reduced their quality of life months after the operation. One patient died, one suffered from complete dementia, one patient had amnesia for many weeks, and one patient complained of severely reduced memory and ability to concentrate: It is not clear whether these long-term mental changes are related to hypoxaemia. More research is needed in this area.

\section{Intraoperative determinants}

In 5 of the 40 studies mentioned, the main aim was to determine the effect of changing intraoperative variables on cognitive outcome.

Hypotension. Townes et al. [87] compared the effect of controlled hypotension during halothane anaesthesia on brain functions with that of non-hypotensive anaesthesia in patients 
undergoing plastic surgery. Hypotensive anaesthesia was not associated with greter postoperative impairment than normotensive anaesthesia: Both groups showed short-term postoperative impairments of memory and leaming. For at least the first 24 hours after administration of a general anaesthetic agent such as halothane, there was an interference with consolidation of memory. This impairment was not apparent in follow-up examinations 6 months later. Townes et al. concluded that hypotension during surgery does not seem to influence cognitive functioning postoperatively. The same results were found in a study by Rollason et al. [76]. They compared mental function in relation to hypotensive and normotensive anaesthesia in elderly patients and concluded that both groups of patients were equally at risk.

Additional oxygen. Prior and Chander [70] studied the effects of different anaesthetics on cognitive function in elderly patients undergoing prostatectony under general anaesthesia. The main question concerned the effect of receiving additional oxygen during and after the operation compared with patients who did not. No deterioration of cognitive function was found in either group 1 week after the operation.

Hypocapnic ventilation. In a study by Jhaveri [48] the effects of hypocapnic ventilation on cognitive function were studied in elderly patients who underwent cataract surgery. Four weeks after the operation, there were no differences in cognitive performance between the hypocapnicventilated group, the non-hypocapnic-ventilated group, and the group who received local anaesthesia.

Induction of anaesthesia. In a study by Herbert et al. [42], the duration of the impairment of mental functioning after anaesthesia was studied in patients undergoing hernia repair. The patients were divided into three groups in which the method of induction of anaesthesia (intravenous or inhalation) and ventilation (spontaneous or controlled) was varied. After considerable impairment initially the performance of all groups gradually returned to pre-operation levels, but patients breathing spontaneously during anaesthesia took longer to recover.

Additional medical complications. Forster et all. [36] studied the effects of general and local anaesthesia on brain functioning in elderly subjects undergoing elective surgery of the lower limbs. In four patients from the local anaesthesia group, the MMSE score decreased to pathological values postoperatively. This fall was associated with trans- and postoperative incidents (haemorrhage, cardiorespiratory arrest, confusion after receiving pethidine, cardiac decompensation). They concluded that alterations of higher brain functions are probably related to trans and postoperative incidents rather than to the type of anaesthesia administered.

\section{Postoperative determinants}

Although this is not the main issue here, delirium or immediate postoperative confusion has been mentioned, either directly or via its underlying cause, as a cause of permanent mental impairment in some patients [89]. Dyer et al: [31] reviewed 26 articles published between 1966 and 1992 on the incidence and risk factors of postoperative delirium. The overall incidence of postoperative dellirium was $36.8 \%$ (range $0 \%$ to $73 \%$ ). Parikh and Chung $[67]$ reported an incidence of $10 \%$ to $60 \%$ in their review. The incidence of postoperative confusion was $51.5 \%$ in another study into the predictors of acute confusional states in elderly patients [90]. Even non-surgical elderly patients who were admitted to the hospital developed confusion. Foreman. [35] reported an incidence of confusion of 38\% in 71 non-surgical patients older than 60 . Although these mental dysfunctions are often transient they have an important impact on the patient's health and therefore on health care costs. Mental dysfunction can result in increased morbidity, delayed functional recovery, prolonged hospital stay, and Iong-term mental impairment. Therefore early diagnosis and treatment is important to minimize the development of 
delinum after an operation.

Kmill et al. [54] assessed the cognitive outcome of elderly patients who suffered idiopathic postoperative delirim (IPD) after anaesthesia and surgery and compared it to the outcome of elderly surgical patients who did not. The patients who suffered IPD had normal preoperative MMSE scores, suggesting that IPD does not telate to preoperative cognitive dysfunction. One week after the operation, however, the IPD group had slightly reduced MMSE scores. Within this group, more patients had substantial decreases in MMSE scores, decreases which persisted up to 6 weeks. The magnitude of these decreases would not be expected to develop in normal elderly patients over a 6 -week period. This implies a link between IPD and the development of cognitive impaiment. Knill et al concluded that IPD is associated with persistent moderate decrements in cognitive performance in some elderly patients. The same was found in a study by Zucker-Goldistein and Fogel [94]. They studied cognitive change after elective surgery in non-demented older adults. They also found that immediate postoperative cognitive change, as measured by the MMSE, may predict later postoperative cognitive decline.

Apart from delitium, pain is a postoperative factor that may affect cognitive functioning. Smith and coworkers [82] found that postoperative pain contributed to an increased variability in reaction time after the operation in patients who underwent an operation under general anaesthesia for transturethral procedures. Future research should pay more attention to the relationship between pain and cognitive change after surgery because clinical impressions suggest that this is a relevant factor.

\section{Discussion}

The literature in general shows that shortly after an operation cognitive function can deteriorate, but in the long term this deterioration is seldom found. Age, general anaesthesia (versus local anaesthesia), and pharmacological determinants seem to affect short-term but not long-term cognitive performance: Older patients and patients who have general anaesthesia need more time to recover. Most medications administered to a patient, before, during and after an operation, have side-eflects which can cause short-term cognitive problems.

Preoperative physical condition and mental status might be determinants for cognitive change but this is hard to determine from the literature. Most studies excluded patients with a questionable mental status or physical condition. It is possible that this group especially is vulnerable to cognitive deterioration and that it is this group that reports cognitive complaints long after an operation. Another explanation for not finding long-term cognitive dysfunctions is selection bias. Patients who do not feel well physically or mentally before the operation, patients who are tired, depressed, or scared of the operation, are more likely to refuse to participate in a study. Patients who are feeling well, who are aware of the need for scientific research (high education) are probably more likely to cooperate. It is not unlikely that the first group is a risk group for postoperative cognitive decline and reports long-term cognitive complaints. More research is needed in this area.

The type of surgery does not seem to influence cognitive functioning per se In most studies, the time point when cognitive performance is assessed depends on the type of surgery. With minor surgical procedures cognition is tested few hours after the operation and with extensive surgery the first assessment is often within a week after the operation. After both minor surgery and extensive surgery short-term cognitive decline is found but not long-term decline.

Prolonged hypoxaemia can cause long-term cognitive deficits but it is not clear from the literature whether short episodes of hypoxaemia occurring postoperatively have the same effect. 
More research is needed to determine the effect of these short episodes of hypaxaemian cognitive function.

Some studies looked at the effect of intraoperative wariables such as hypotension during the operation, administration of additional oxygen during and after the operation, different methods of induction of anaesthesia, and the accurrence of medical complications on cognitive outcome. Short-term but no long-term effects were found, except for complications during the operation. These complications are probably due to existing underlying disease.

There are some indications that postoperative confusion can lead to long-term cognitive deterioration and that postoperative pain can lead to cognitive deterioration in the short term. Other complex factors such as the degree of emotional support, the patient's financial situation, and the degree to which the surgical procedure improves the elderly patient's social integration may influence cognitive outcome and nervous system effects in the long term 164l. Not much attention has been paid to these factors in the above-mentioned studies; so the importance of these factors is not clear.

\section{METHODOLOGICAL ISSUES}

\section{Measurements used in the assessment of cognitive change}

An increasing number of studies have addressed the issue of the cognitive sequelae of general anaesthesia, especially in the elderly. Doctors are confronted with their patients who complain of cognitive rest-effects which they ascribe to the operation and/or the anaesthesia. Cognitive complaints are usually measured by rating scales in which either the patient, his/her relatives, or the doctor rates the complaints of the subject. Recently, various rating scales for the assessment of cognitive complaints in the elderly have been validated (e.g., the MAC-questionnaires [25]. To dates these specific instruments have not been used in studies into anaesthesia and cognition, although more general rating scales have often been used for example, the Mini Mental Status Examination (MMSE) [e.g., 34]. The MMSE is a crude instrument which enables the differentiation of people who are clearly demented from those who are not, with a category in between with questionable cognitive dysfunction. The MMSE is -generally- not very sensitive to the effects of medical interventions. In pharmacological research, the MMSE is judged as too insensitive to assess the effect of drugs. Yet, many studies on anaesthesia and cognition have used the MMSE.

A great majority of studies have also used tests which have been developed either as a diagnostic test for use in neurological patients and other patients with putative brain dysfunction, or for the measurement of intelligence-related constructs in normal subjects and in patients. These tests were not devisedto evaluate medical and other interventions. The advantage is that they are well-known and belong to the standard measures of any psychological department in a general hospital. However, a number of disadvantages can be mentioned. In the first place, these tests generally do not exist in parallel forms (which is essential for evaluation of change). In the second place, they are quite crude, enabling the assessment of substantial deterioration but not of subtle changes which may substantially affect the quality of life. Tests of the Wechsler tradition, such as the Wechsler Adult Intelligence Scale or the Wechsler Memory Scales (WMS), and the Halstead Reitan tradition (see Lezak 1995 [57] are quite crude and insensitive, and were not devised for the evaluation of subtle change, which is needed in studies into cognitive after effects of interventions such as anaesthesia. It is also possible that 
these tests are too easy, so that people can reach an optimal performance without much effort. Even if people suffer from cognitive dysfunctions or complaints after an operation, they can still show an optimail performance on these tests.

Some studies used methods which assess not only the absolute performance in terms of the number of good/false responses, but also the speed of performance. Research in other fields of cognitive netropsychology indicate the importance of use of measuring the speed of performance. Both in cognitive pharmacological research [43] and in the assessment of light brain trama [eg, $]_{\text {, the }}$ the needed to perform a task appears more sensitive and reliable than the absolute performance.

The measurements used in the above-mentioned studies (see table 1.3) for the assessment of cognitive change differ greatly. Therefore, the results of these studies are difficult to compare and cannot easily be generalised to other patient populations. Most studies did not use parallel versions of the cognitive tests, which means that practice effects could obscure a decline in cognitive functioning. Furthermore, most studies did not use a control group, and patients were compared with their own preoperative performance. It is possible that a change in performance found will also be found in normal healthy subjects or in patients staying in the hospital without an operation. There is also a large inter-study variation in when cognitive performance was assessed, and this depended on the type of surgery. And, finally, most studies looked at change in cognitive performance by comparing changes in group means. It is possible that some individuals show a substantial decline in performance which can be obscured by a larger number of patients showing no change or an improvement (see chapter 6).

The tests to study cognitive change after an operation are reviewed below. After this, other methodological issues such as the use of parallel versions and control groups will be discussed in more detaill.

\section{Mini mental status evaluation (MMSE)}

Several studies on anaesthesia and cognition have used the MMSE or a comparable instrument to assess cognitive functioning $[5,6,21,22,24,27,36,44,54,55,58,70,77]$. This type of instrument is useful in screening for confusion or delirium but it is not suitable for measuring changes in cognitive functioning. No parallel versions exist, so with tepeated testing it is not likely that a decline will be found because patients still remember the answers. Although this is a crude instrument, some studies have used it to measure mental change postoperatively $[5,24,44,56,57$. 771. In these studies mental change was found 6 hours to 1 day postoperative in elderly patients, but not when the patients were discharged. With the MMSE and other comparable measures, it is possible to measure cross impairments like delirium or dementia, which is probably the case in these studies. Two studies $[44,54]$ detected mental changes with this instrument several months after the operation. In both studies the patients with mental impairment had a mean age above 70. Other factors, like ageing processes in the brain and additional diseases, are probably more responsible than anaesthesia for impairments measured by the MMSE.

\section{Psychometric tests}

In many of the studies mentioned in table 1.1 cognition was measured with more-or-less objective psychometric test (categories: $\mathrm{I}, \mathrm{L}, \mathrm{M}, \mathrm{P}, \mathrm{O}, \mathrm{C}, \mathrm{B}$, see table 1.3 ) $12,18,19,22,23,27$, $30,32,33,37,39,42,46,48,50,52,59,60,62,65,66,74,75,82-84,87,91,941$. Several studies assessed only one or two different cognitive domains (see table 1.1$)[2,22,32,42,46,48,52,59,60,62,65$, $74,82-84,941$. Extensive neuropsychological assessment was performed in the other studies [18, $19,23,30,33,37,50,66,75,87,91]$. The results found in the different cognitive domains were as 
follows:

Subtests of intellectual abilities (I). Only one study found an effect of operation on intellectual functioning. Williams-Russo ef al. 191 reported a decline in perfomance on the Digit Span and Digit Symbol Substitution Test (subtests of the WAIS) 1 week after the operation. Six months after the operation this decline was no longer found. Other studies that used these tests to assess cognitive change after the operation were not able to demonstrate a decline $116,33.39$, $60,66,74,75,87,94]$.

Verbal functions and language skills $(L)$. Two studies used tests assessing verbal functioning but could not demonstrate an effect of operation [66, 91].

Memory $(M)$. Most studies used some kind of memory test. Several studies demonstrated a decline in memory function shortly after an operation. The Wechsler Memory Scale (WMS) in whole or in part, was used in ten studies. Three of these studies found a decline in some aspects of performance shortly after the operation $[19,33,52,62]$. Other studies using the WMS could not demonstrate a decline in performance postoperatively $[2,23,37,65,65,77]$. Long-term effects were found in only one study. Flatt et al. [33] found a decline in performance on the Mental Control Test, a subtest of WMS, 6 weeks after an operation. In one study the Luria Memory Test was used [52] and detected a decline in performance shortly after the operation. In three studies a story recall test was used $[2,19,75]$. In one study a decline in performance on this test was found shortly after the operation but not after 3 months [75]. Several studies used some free verbal recall (immediate and delayed) and recognition test. In five studies a short-term decline $[19,65,75,87,91]$ was found with this test, whereas others could not demonstrate a decline in performance $[2,18,30,37,39,46,59]$. No study found a long-term decline with this test. Other memory tests used in which a short-term decline was found were: Picture Recognition Test 175], Rey Auditory-Verbal Learning Test 133], Object Learning Test 119. 841, Benton Visual Retention/Recognition Test [91]. No long-term effects were found with these tests.

Psychomotor functions $(P)$. Several studies used tests measuring psychomotor function to study the effect of an operation. In four studies a short-term effect was found. In two of these studies a decline in simple reaction time was found shortly after the operation 132, 33]. Campbell et al. [19] found a decline on a digit copying test 24 hours after the operation but after 2 weeks the effect could not be demonstrated. In a siudy by Reitan et al. 1741 a decline in performance was found on the Purdue Pegboard 6 hours after the operation. In one study a decline in performance on a simple reaction time test was found 6 weeks after the operation $\| 33 \rrbracket$. Others could not demonstrate a decline in psychomotor functioning after the operation $118,37,42,48,50$, $52,59,62,65,66,82,831$.

Orientation and attention $(O)$. Seweral tests measuring orientation and attention were used in the different studies. In four studies a short-term decline was found on the Trailmaking A and B and Symbol Digit Modality Test [23, 75], Digit Symbol Substitution Test [33] and a wigilance test [33, 65]. Others could not demonstrate a decline on these tests $[37,66,74,911$. In none of the studies was a long-term effect on orientation and attention found.

Conceptual functions (C) Few studies looked at the influence of an operation on conceptual functioning. In one study a symbol recognition test was administered and a decline shortly after the operation was found [32]. Three other studies used a card sorting test but did not find a decline postoperatively $[18,37,75]$. No long-term effects of an operation on conceptual functioning were found.

Tests for brain damage $(B)$. In two studies the two-point discrimination test and the Critical Flicker Fusion Test were used to see whether brain damage occurred after the operation 150,661 . Neither study found evidence of brain damage postoperativelly. 
Table 1.3 Cogrntive medsures used in the different sudices

Mental status examination (MSE)

1. Interview and guestionmare

$144,58,77,84]$

2. Cilton Assessment Procedures for Elderly (CAPE) [18,82, 83$]$

3. Abbrevated Mental Tes (AMT)

4. Organic Brain syndrome Scale (ORS)

[5]

5. Mini-Menal State (MMS)

6. Felix Post Unit Questionnaire (FPU)

$[21,22,23,24,36,39,94]$

7. Nurnberger Alters Inventar (NAD)

8. Memory Test of Postgatuate Institute Chandigarh [70]

9. Hospital Observalon LW (HOI)

Intellectual ability tests (l)

1. Wechster Adull Intelligenee scales (WAIS)
1. Similarties
2. Block Design
3. Digit Span
4. Digit Symbol Substitution Test
5. Object Assembly
6. Vocabulary

[75]

$[18,33,60,74,91]$

$[33.39,91]$

(39)

[.87]

[66]

2. WAIS-R (Sat -Mogel short form)

1. Boston Naming Test

2. Verbal Elluency

$[33,52,62,66]$

[66]

$[52,62]$

$[52,62]$

$[52,62,66]$

$[2,19,23,37,52,62,65,66,75]$

$[52,62,60]$

$[62,66]$

\52!

$[2,19,75]$

$[2,18,19,30,37,39,46,59,65,75,87,91]$

[75]

(33)

$600]$

$[10,39,50,84]$

$[2,37]$

[19.48]

[29]

[1911

$[18,32,33,37,42,48,62,65]$

[32, 37. 52]

[18] 
Table 1.3 Cognitive measures used in the different studies (continued)

Psychomotoric functions (P)
4. Choice Visual Reaction Time
$[50,82,83]$
5. Symbol Cancellation
6. Finger Oscillation Test
$[37,39]$
[66]
7. Digit Copying Test
$[19,50,82]$
8. Purdue Peg Board
174]

Orientation and attention (O)

1. Trail Making $A / B$

$[23,66,75,87,91]$

2. Symbol Digit Modality Test

$[23,75]$

3. Aufmerksamketisbelastungstest $\mathrm{d} 2$

4. Addition

[37]

5. Stroop Color-Word Interference Task

[37]

6. Digit-Symbol Substitution Test

7. Konzentrations-Leistungs-Test (KLT)

$[33,37,39]$

[29]

8. Vigilanze

$[33,65,74,87]$

Concepiual finctions (C)

1. Symbol Recognition [32]

2. Card Sorting Test

Test for brain damage $(B)$

1. Two-Point Discrimination [66]

2. Critical Flicker Fusion Threshold _. [50]

Affective state (A)

1. State "Trait Anxiety Inventory

2. Visual Analogue Scale (VAS)

3. Zung Self-Rated Anxiety Scale

4. Lovibonds's Self-Analysis Questionnaire

5. Symptom Checklist (SCL-90-R)

[37]

6. Brief Psychiatric Rating Scale (BPRS)

[37]:

7. Geriatric Depression Scale (GDS)

$[37,911$

Cognitive complaints ( $C C$ )

1. Cognitive Failure Questionnaire (CFQ) \60》

2. Metamemory Questionnaire [37]

3. The Cognitive Difficulties Scale $\$ 50 \rrbracket$

4. Questionnairre by mail 《62

\section{Physical healh (Ph)}

1. Geriatric Mental Status Examination (GEMS) [21, 22, 83]

2. Sickness Impact Profile (SIP)

3. Health Index

$[24,37,66]$

4. Subjective Loss of Condition (SLC)

5. Vigor and Intactness Scale

$[27]$

6. Checklist Subjective Physical Well-being

7. Self-rating of Discomfort

Functional activities $(F)$

1. The Functional Life Scale

2. Holbrook Activity Index (HAI) 


\section{Rating scales for affective state and physical health}

Performance on neuropsychological tests is dependent on the motivation of the subject. Affective state may influence motivation and performance on these tests. In several studies a questionnaire on affective state or physical health was administered. Several studies measured anxiety level and depressive symptoms experienced by the patients before and after the operation $[22,33,37,42,52,94]$. Spielberger and coworkers [86] demonstrated an elevated preoperative anxiety score in patients. However, none of these studies demonstrated a change in anxiety and depression experienced by the patient or an effect of mood on neuropsychological test performance.

A few studies looked at the change in subjective physical health. In a study of Townes et al. [87] patients were asked to rate discomfort. Twenty-four hours after the operation patients experienced more discomfort and grogginess than before the operation. Six months after the operation this was no longer apparent. Chung et al. $[22,24]$ used the Geriatric Mental Status Examination (GEMS). This is a standardised clinical interview schedule enquiring about physical health. They did not found a change in subjective physical health $\mathbb{1}$ month after the operation. In two studies the Sickness Impact Profile (SIP) was used [37, 66]. This is a behaviour-based measure of health status. Neither study found a change on this measure 3 months after the operation. Ghoneim and collegues [37] also used two other measures of physical health but failed to demonstrate a change in subjective health. Crul et al. [27] used a checklist for subjective physical well-being. Four weeks after surgery, no signs of mental deterioration were found; however, the subjective sense of physical well-being had not fully returned, especially in patients with a compromised preoperative physical condition. Three months after the operation physical complaints were no longer reported.

Two studies looked at the change in functional activities. Jones et al. [50] used the functional life scale, which covers the activities of daily living, home activities, and social interactions. Three months after the operation no change was found on this scale. Campbell et al. [19] used the Holbrook Activity lndex (HAI). This rating scale assesses the patient"s activity level and social functioning in his or her everyday life. Three months after the operation a small increase in social function and activity level was found.

\section{Subjective cognitive complaints}

Subjective complaints about memory and concentration failures after surgery are well documented in the literature $[3,47]$, but objective quantification of these memory and concentration failures has rarely been undertaken. In most studies, psychometric techniques, mostly pertaining to existing intelligence tests, were used. These subjective complaints of patients deal especially with long-term effects. In 1981, 1128 surgical subjects were questioned by mail about cognitive complaints after an operation [60]. Of these patients, 1000 were operated on under general anaesthesia and 128 under local anaesthesia. The latter group was seen as a control group to answer the question whether general anaesthesia was responsible for cognitive complaints or surgery in general. Of the patients operated on under general anaesthesia $53 \%$ sent back the questionnaire and in the local group this was $54 \%$. About a $33 \%$ of the patients operated under general anaesthesia reported cognitive failure weeks or months after the operation. Only $6 \%$ of the local anaesthesia group reported similar cognitive failure. These results have to be interpreted with care because they based based on self-report data. It is possible that these cognitive failures already existed before the operation but that patients only noticed them after being asked about them.

In four studies mentioned in table 1.1 some kind of subjective measurement of cognitive 
complaints was used to see whether patients experience more cognitive afficulties alter an operation. In the study by Meier et al. 1601 , the concentration and menory performance of patients undergoing surgery was measured. No impaiment of concentration and memory performance following general anaesthesia could be established. Nevertheless, $32.4 \%$ of the patients reported that they had experienced postoperative disturbances of memory up to 7 weeks. In another study a meta-memory questionnaire was used before and 3 months after the operation [37]. No change in memory failure was found 3 months after the operation. Jones et al. [50] reported that cognitive and functionall competence in elderly patients was not detectably impaired 3 months after an operation. However, 23 of the 146 patiants reported that their memory and concentration were worse than before the operation, but this was not confurmed by testing. In the study by Møller and collegues [62], patients were assessed before and 5 days aftirn operation with the WMS and a reaction time test. No change in performance was found 5 days after the operation. Patients were also asked to evaluate whether their cognitive abilities had changed since surgery with a short questionnaire sent by mail 6 weeks after surgery. Nine per cent of these patients thought that their mental functioning had deteriorated, but this perceiwed deficit was not confirmed by the objective tests.

\section{Use of parallel test versions and control groups in the measurement of change}

Most studies have the methodological drawback that they did not use parallel versions of cognitive tests. Patients who are tested with exactly the same test materials will probably show learning and practice effects which can obscure a change in cognitive functioning. Thus even though patients suffer from a deterioration in cognitive functioning, it is possible that their performance is the same after the operation because they still remember the tests and are able to perform at the same level. One solution to circumvent this problem is to use parallel versions of tests, which are less vulnerable to learning and practice effects, like most memory lests. However, even so it is still possible that learning effects are found due to procedural learning. The first time patients are confronted with tests, they do not know what to expect and are probably nervous. The second time they know what to expect, are less nervous, and will perform better. This problem can be dealt with in two ways. The first way is to make the patients familiar with the procedure before the actually measurement starts. This can be done by adding another preoperative measurement ("pretest"). The second way is to use a control group. This control group has to be tested with the same tests and with the same time intervals between the assessments. Only a few studies have used parallel tests over the different measurements $z_{\text {, }}$ $18,23,37,46,48,52,751$, but results were the same as those of studies that did not use parallel tests.

Perhaps a better way to avoid learning effects is to use a control group of subjects who are not having an operation, preferably patients who are also staying in hospital. These controls should be matched on to patients by age, sex, education, etc. Only a few studies used this kind of control group. Edwards et all. [32] compared patients undergoing elective surgery with ambulatory and bed rest volunteers. They found progressive impairment in psychomotor function during the first 4 to 5 days after elective surgery. The same findings were found in the bed. rest volunteers but the ambulatory volunteers showed an improvement. The authors suggested that inactivity and a supine position may have caused this decline. There were only 3 bed rest volunteers and 7 ambulatory volunteers who were compared with 30 patients. The study did not provide demographic data for the patients, so it is thard to draw conclusions from this study. Another study compared 55 patients undergoing hernia repair, who were divided 
into thee groups in which the method of induction of anaesthesia and ventilation was varied. $\mathrm{A}$ control group of orthopaedic patients in hospital who had not had an operation for at least 2 weks before testing was used [42]. There were no age differences between the groups. The patients" pertormance in a reaction time test was assessed for 2 days, four times a day, and compared with that of the controls, After considerable impairment initially, reaction times in all groups gradually returned towards control values in 2 days. In this study the control group had undergone strgery at least 2 weeks earlier. It is possible that these control patients were suffering from their operation because they were still in hospital. Orthopaedic surgery requires a longer recovery time than does hemia repair. The results of this study are therefore questionable. Another study used non-patients as the control group to control for the effect of practice on performance during repeated test administration [33]. Control subjects were matched in age and sex to patients receiving general anaesthesia for plastic surgery. However, with the use of non-hospitalised controls it is possible that differences found between the groups are due to the stay in a hospital or not, and are not due to the operation. Smith et al. [83] compared patients undergoing urological surgery with orthopaedic patients who served as controls and who had been operated on at least 12 days earlier. Twenty-four hours after the operation no difference in change of reaction time was found between patients and controls. It is possible that the control group had not yet recovered from their operation and therefore no decline was found.

\section{How to analyse cognitive change?}

Finally, all studies mentioned in table 1.1 compared change in group performance from one mensurement to the other. Some studies described change in terms of the percentage of patients showing a change, but this change in performance was based on arbitrary decisions. Flat and collegues [33] reported that the effects of general anaesthesia on mental functioning varied greatly between individuals and that some people appeared to be quite profoundly affected by anaesthesia and failed to return to a preoperative level of performance 6 weeks after anaesthesia. Most research assessing the effeet of anaesthesia on mental functioning in terms of mean group performances has largely found that such effects do not last for more than about 1 week after andesthesia. latt's findings appear to conflict with persistent reports from some patients that the effects of anaesthesia on cognitive functioning last well beyond the immediate postoperative period. Flatt et al. suggest that this apparent conflict can be explained by the large interindividual variation in the effects of anaesthesia on mental functioning. The only factor common to the three individuals who were most affected by general anaesthesia was the clinical impression that all three were highly stressed. The authors suggest that there may have been some interaction between preoperative stress level and the cognitive effects of general anaesthesia. Some studies reported postoperative mental decline based on an interview with the patient without using objective measures [ 5,44$]$. In a study by Nadstawek and coworkers [65], decline was defined as the percentage of patients being able to perform a test. Recovery of motor and mental functions was investigated up to 80 minutes postoperatively. This way of defining individual decline is useful when performance is measured immediately after an operation but not after a few days, when all patients will be able to do the tests. Chung et al. [21. 22] used the MMSE to measure cognitive impairment. A score lower than 23 was taken to indicate cognitive decline. Six hours after the operation they found a decline in $30 \%$ of the elderly patients and in $4 \%$ of the younger patients. At 24 hours after the opration both young and elderly showed the same performance as before the operation. In another study by Chung et al. [24], a decrease of more than two points on the MMS was considered indicative of cognitive decline. Six hours 
after the operation cognitive decline was detected but wot after 1 day. The MMSE is useful 6 hours after an operation but after a couple of days probably all patients will perform above a score of 23 or at least not show a decrease of two points, so this test is not useful for screening long-term cognitive decline. Møller and coworkers [62] reported that the distribution of the individual differences in total scores on the pre- and postoperative WMS varied widely. In $17 \%$ of the patients the postoperative ( 5 days) total Wechsler Memory Seale (WMS) scone was either 10 points higher or 10 points lower than the preoperative total WMS score. The patients whose WMS scores were 10 points lower after operation were included in a follow-up study 3 months after surgery. These patients were compared with control patients who were selected randonly from the patients with a normal postoperative WMS score 5 days after the operation. By 3 months after the operation the median WMS score had returned to the preoperative value. It seems that the effect of anaesthesia is not uniform across individuals: most patients show no change or an improvement in cognitive performance while some patients show a decline. For this reason more attention should be paid to changes in individual performance.

\section{Discussion}

The instruments used in the different studies to assess cognitive change after an operation can be divided in to the Mini Mental State Examinations and psychometric tests. The latter tests can be subdivided for the different cognitive domains. Although some studies were able to measure cognitive decline by using Mini Mental State Examinations, this is probably not the kind of subtle cognitive decline patients complaining of several months after an operation. The decline. assessed with this instrument is more serious and probably due to factors other than an operation alone. For most cognitive domains assessed by psychometric tests, short-term but not long-term effects are found. Anaesthesia does not have a uniform effect on the various aspects. of mental functioning. When a decline is found shortly after an operation, this affects various cognitive domains and not one particular domain. Several studies used some kind of rating scale to assess the amount of anxiety, depression, change in physical health and functional activities and cognitive complaints. Mood state did not change much from the pre- to the postoperative assessment and did not affect cognitive performance. A few studies have looked at the impact of an operation on physical health and functional activities. Although one study reported subjective complaints about physical well-being 1 month after an operation, most patients do not seem to have complaints about their physical health several weeks after an operation. Interestingly, three of the four studies found that a substantial number of the patients reported long-term cognitive complaints that were not detected with objective tests. Other studies have not determined whether patients suffer from cognitive complaints after discharge from hospital, so it remains unclear how many patients suffer from these complaints.

Although only a few studies used parallel wersions of tests, but these studies did not detect more cognitive impairment than tother studies. The lack of control groups in this kind of research is a problem. Even when a decrease in cognitive performance is found, one never knows whether this decrease is due to the operation, to the stay in hospital, or to normal fluctuat ions over time which also occur in normal healthy people.

Finally, all studies looked at change in group means, which can conceal important individual variations in performance. In the literature on heart surgery and cognitive functioning (see chapter 2 and 3), there is a tradition of evaluating individual change as well as group change. Although the assessment of individual change is complicated from a methodological point of view (see chapter 4), the advantage of this method is that individuals who are particularly 
wulnerable for an operation can be detected. This can have important implications for the treatment of these patients. Future research should pay more attention to these individual differences in vuluerability to an operation.

\section{CONCLUDING REMARKS}

The overall conclusion of this review is that it is difficult to study the effects of anaesthesia on mental function due to a large number of variables that may affect postoperative performance. These variables are: characteristics of patient population; type of the surgery and anaesthesia; events during anaesthesia such as hypotension and hypoxia; differences in the effect of anaesthetic agents; influences of different premedication agents; the effect of hospital environment on the motivation and well-being of patients; time of postoperative cognitive assessment; practice effects on repeated use of a particular test of mental function; and selection bias.

The available literature on prolonged postoperative mental dysfunction is sparse, flawed, and occasionally contradictory. Generally, studies in this area have suffered from methodical deficiencies, have tested only few mental functions, and/or have been based on a small number of patients.

It seems that shortly after an operation patients can show a deterioration in cognitive functioning but that such a deterioration is not detected in the long term. However, some studies have reported cognitive complaints several months after surgery. There is the possibility that some or all of the postsurgical complaints of cognitive functioning do not reflect deficits related to surgery or anaesthesia. Instead, surgery could trigger a number of psychological events in the patient, e.g., mild depression or awareness of age-related changes, which could lead to subjective feelings of cognitive dysfunction not associated with impaired performance on objective cognitive tests. Consequently, the alternative hypothesis of complaints without cognitive dysfunction must be carefully examined. Past studies have rarely examined both subjective reports and objective performance together. Any attempt to account for psychological and cognitive deficits following surgery must also take into consideration the physical and mental health status of the patient before, during, and after surgery. The immediate and very transient decline may be due to residual effects of anaesthetics, other administered medication, sleep deprivation, or underlying disease. The improvement in mental state is probably the result of improved physical state postoperatively, improvenent in function, diminished pain and discomfort, and some practice effect due to greater familiarity with the psychomotor and cognitive tests as they are repeated.

Most of the studies referred to above used psychometric techniques. A disadvantage of these tests is that when they are used repeatedly, a learning process leads to higher scores, which may mask a possible mental decline. Only a few studies used parallel tests or included control groups. Also, cognitive functions only were measured, and these are a small part of the wide range of mental abilities. It is questionable to what extent such testing of cognitive function is relevant for detecting behavioural dysfunction of patients reported by relatives and hospital staff.

Age does not appear to be the most important factor causing cognitive deterioration after surgery. However, ageing is an all-encompassing, multifactorial process involwing a decreased capacity for adaptation and a gradual decrease in functional reserve of all the body"s systems. Ageing itself is not truly a disease process but is instead an index of the probability of many disease states. This supports the opinion that biological age rather than calendar age influences 
the degree of postoperative mental decline:

Level of function and psychosocial variables, such as social network, need to be analysed in larger numbers of patients. Other factors which could influence postoperative cognitive deterioration are the coping style of the patient, personality, and expectations of the operation. The influence of these factors was not investigated in the reviewed studies. More attention should be payed to these factors in future research.

\section{REFERENCES}

1. Aberg T, Kihlgren M. Effect of open-heart surgery on intellectual function. Scandinavian Journal of Thoracic Cardiovascular Surgery. 1974; Suppl 5: 1-63.

2. Asbjørn J, Jakobsen BW, Pilegard HK, Blom $\mathrm{L}_{n}$, Ostergaard A, Brandt MR. Mental function in efderly men after surgery during epidural analgesia. Acta Anaestlıesiologica Scandinavica 1989; 33 : 369-73.

3. Bedford PD. Adverse cerebral effects of anaesthesia on old people. The Lancei 1955; 6: 259-63.

4. Benedict RHB. Cognitive function after open-heart surgery: Are postoperative neuropsychological deficits caused by cardiopulmonary bypass? Neuropsychology Review 1994; $4: 223-55$.

5. Berggren D, Gustafson $Y$, Eriksson B, et al. Postoperative confusion after anesthesia in elderly patients with femoral neck fractures. Anesthesia and Analgesia 1987; 66: 497-504.

6. Bigler D, Adelhøj B, Petring OU, Pederson NO, Buscls P, Kalhke P. Mental function and morbidity after acute hip surgery during spinal and general anaesthesia Anaesthesia 1985; 40:672-6.

7. Birren JE, Schaie KW, ed. Handbook of the psychology of aging. 3rd ed. New York: Van Nostrand Reinhold Company, 1990.

8. Birren JE, Schaie KW. ed. Handbook of the psychology of aging. 2ndt ed: New York: Van Nostrand Reinhold Company; 1985.

9. Blumenthal JA, Madden DJ, Burker EJ, et al. A preliminary study of the effects of cardiac procedures on cognitive performance. International Journal of Psychosomatics 1991; 38: 13-6.

10. Blundell E. A psychological study of the effects of surgery on eiglaty-six elderly patients. The British Journal of Social and Clinical Psychology 1967; 6: 297-303.

11. Bohnen N, Jolles J, Twijnstra A. Neuropsychological deticits in patients with persistent symptoms six months after mild head injury. Neurosurgery 1992; 30:692-6.

12. Bohnen $N$, Warner MA, Kokmen E, Beard CM, Kurland LT. Alzheimer's disease and cumulative exposure to anesthesia: a case-control study. Journal of the Americam Geriatric Society 1994; 42: 198. 201.

13. Botwinick J. Ed. Aging and Behavior. 3rd ed. New York: Springer, 1984.

14. Brander $\mathbf{P}$, Kjelsberg $M$. Tanmisto $T$. The effects of anaesthesia and general surgery on geriatric patients. Annales Chirurgiae el Gynaecollogiae Fenniae 1970; 59; 138-45.

15. Brown LT, Purcell GJ, Traugott FM. Hypoxaemia during postoperative recovery using continuous pulse oximetry. Anaesthesia Intensive Care 1990; 18: 509-16.

16. Bruce DL, Bach MJ. Psychological studies of human performance as affected by traces of enflurane and nitrous oxide. Anaesthesiology 1975; 42: 194-6.

17. Bruce DL, Bach MJ. Effects of trace anesthetic gases on behaviourall performance of wotunteers. Britiscti Journal of Anaesthesia 1976; 48:871 -5.

18. Burrows J, Briggs RS, Elkington AR. Cataract extraction and confusion in elderly patients. Journal of Clinical and Experimental Gerontology 1985; 7; 51-70.

19. Campbell DNC, Lim M, Muir MK, et al. A prospective randomised study of local versus general anaesthesia for calaract surgery. Anaesthesia 1993; 48: 422-8.

20. Charness NE. ed. Aging and human performance. Waterloo, Canada: John Wiley \& sons, Chichester, 1985.

21. Chung $F$, Lavelle $\mathrm{PA}, \mathrm{McD}$ onals $\mathrm{S}$. Cognitive impairment after neuroleptanalgesia in cataract surgery. Anesthesia and Analgesia 1989; 68: 614-8.

22. Chung F, Meier $R$, Lautensehlager $E$, Carmichael FJ, Chung A. General or spimal anesthesia: which is better in the elderly? Anesthesiology 1987; 67: $422-7$. 
23. Chung F, Scyone C, Dyck B, el al. Age-related cognitive tecovery after general anesthesia. Anesthesia and Analgesiat $0900 ; 71: 217.24$.

24. Chung $\mathbb{F}$, Chung A, Meier RH, Lauteruschlaeger E, Seyone C. Comparison of perioperative mental function after general anaesthesia and spinal anaesthesia witn intravenous sedation. Canadian Journal of Anitusthesia 1989; 36:382-7.

25. Corey-Bloon J, Galsko $\mathrm{D}$, Hofltetter $\mathrm{R}$, Jackson JE, Thal LJ. Clinical features distinguishing large cohorts with possible $A D$, probable $A D$, and mixed dementia. Journal of the American Geriatric Society 1993; $41: 31-7$.

26. Crook TH, Feher EP, Larrabee GJ. Assessment of memory complaint in age-associated memory impairment: The MACQ. International Psychogeriatrics 1992; 4 (2): 165-76.

27. Crul BJ.P. Hullstijn W, Burger IC Influence of the type of anaesthesia on post-operative subjective physical well-being and mental function in elderly patients. Acta Anaesthesiologica Scandinavica 1992; 39: 61520 .

28. Cryns AG, Gorey KM, Goldstein MZ. Effects of surgery on the mental status of older persons. A meta-analytic teview. Journal of Geriatric Psychiatry and Neurology 1990; 3:184-91.

29. Dekhuijzen LS, Lange JJ. De rol van algehele of locale anesthesie bij het ontstaan van cognitieve stoornissen bij oudere mensen. Tijdschrift Gerontologie en Geriatrie 1993; 24: 193-9.

30. Dierks Ventling VC, Gerhard U, Hobi V: Der Einfluss von Total- und Localanasthesie auf Konzentration und Gedachinis. (The effects of total- and local anesthesiat on concentration and memory). Schweizerische Zeitsehrift fur Psychologie 1989:48: 112-20:

31. Dyer CB, Ashton CM, Teasdale TA. Postoperative delirium: A review of 80 primary datamcollection studies. The Archives of Internit Medicine 1995; 155; 461-5.

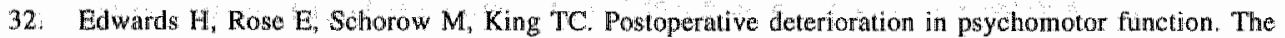
Journal of the American Medical Association 1981: 245: 1342-3.

33. Flat JR, Birell PC. Hobbest A. Effects of anaesthesia on some aspects of mental functioning of surgical patients. Anaesihesia and Intensive Care 1984; 12: 315-24.

34. Folstein MF, Folstein SE, Mchugh PR, "Mini-Mental State": A practical method for grading the cognitive state of patients for the clinician. Journal of Psychiatric Research 1975; 12: $189-98$.

35. Foreman MD. Confusion in the hospitalized elderly: incidence, onset, and associated factors. Research in Nursing \& Health 1989; 12: 221-29.

36. Forster A, Altenburger H, Gamulin Z. Conséquences de l'anesthésie sur les fonctions supérieures du sujet âge (Effects of anesthesia on higher brain functions in the elderly). La Presse Médicale 1990; 19 : 1577.81 .

37. Ghoneim MM, Hinrichs JV, O'Hara MW, al Comparison of psychologic and cognitive functions after general or local anesthesia. Anesthesiology 1988; 69:507-15.

38. Gibson JR, Mendentall MK, Axel NJ. Geriatric anesthesia: Minimizing the risk. Geriatric Clinics of North America 1985: 1: 311-21.

39. Hasn $J$, van KJ, Bloem $B R_{\text {s }}$ ot al Cognitive function after spinal or general anesthesia for tramsurethral prostatectomy in elderly men. Journal of the American Geriatrics Society 1991: 39: 596600 .

40. Hanmeke TH, Hastings IE. Neuropsychologic alterations after cardiac operation. The Journal of Thoracic and Cardiovascular Surgery 1988; $96: 326-31$.

41. Haug H. Are neurons of the human cerebral cortex really lost dering aging? In: Traber J, Gispen WH, ed. Senile Demential of the Alzheimer Type. Berlin: Springer, 1985: 150-63.

42. Herbert M. Healy TEJ, Bourke JB, Fletcher IR, Rose JM. Profile of recovery after general anaesthesia. The British Medical Journal 1983; 286: 1539-42.

43. Hijmain $R$, Jolles J, Verhoven WMA, Van Ree JM, Elderson A, De Wied de D. DesglycinarnideARG8-Vasopressin in five trials with memory-disturbed patients. Human Psychophamacology 1992; 7: $7 \times 23$.

44. Hole A, Terjesen T, Breivik H. Epidural versus general anaesthesia for total hip arthroplasty in elderly patients. Acta Anaesthesiologica Scandinavica. 1980; 24:279-87.

45. Houx Pr, Vreeling FW, Jolles J. Age-associated cognitive decline is related to biological life events In: Iqbal K, McLachlan DRC, Winblad B, Wisniewski HM, ed. Alzheimer's Disease: Basic Mechanimse Diagnosis and Therapeutic Strategies. Chichester, UK: John Wiley \& Sons Lid, 1991: 353-9.

46. Hughes D, Bowes JB, Brown MW. Changes in menory following general or spinal anaesthesia for hip anthroplasty. Anacsthesia 1988; 43: 114-7. 
47. James FM. The effects of cyclopropane anaesthesia without surgical operation on mental functions of normal man. Anesthesiology 1969:30: 265-71.

48. Thaveri RM. The effects of hypocapnic ventilation on mental function in elderly patients undergoing cataract surgery. Anaesthesin 1989; 44:635 40.

49. Jolles J. Cognitive, emotional and behavioral dysfunctions in aging and dementia. In: Swatb DF, Fliers E, Mirmirian M, Gool WA, Haaren FV, ed. Progress in brain research. Amsterdam: Elsevier Science Publishers, 1986.

50. Jones MJ, Piggott SE, Vaughan RS, et al. Cognitive and functional conpetence after anaesthesia in patients aged over 60: controlled trial of general and local anaesthesiat for elective hip or knee replacement. The British Medical Journal 1990; 300: 1683-7.

51. Jones MJT. The influence of anesthetic methods on mental function. Acta Chirurgica Scandinavica $1988 ; 550: 169-76$.

52. Karhunen U, Jonn G. A comparison of memory function following local and general anaesthesia for extraction of senile cataract. Acta Anaesthesiologica Scandinavica 1982;26:291-6.

53. Katz SM, Fagraeus L. Aresthetic considerations in geriatric patients. Clinics in Geriatric Medicine $1990 ; 6: 499-510$.

54. Knill RL, Novick TW, Novick BA, Skinner BA. Idiopathic postoperative delirium is associated with longterm cognitive impairment. Canadian Journal of Anaesthesia 1991; 38: A54.

55. Krier C, Bohrer $\mathrm{H}_{8}$ Polarz H, Schonstedt R. Cognitive function in geriatric ophthalmological patients following local versus general anesthesia. Ophthalmology $1993 ; 90: 367-71$.

56. LaRue A. Aging and Neuropsychological Assessment. New York: Plenum Press, 1992.

57. Lezak MD. Neuropsychological Assessment. 3rd ed. New York: Oxford university press, 1995.

58. Mann RAM, Bisset WIK. Anaesthesia for lower limb amputation: A comparison of spinal analgesia and general anaesthesia in the elderly. Anaesthesia 1983; 38: 1185-91.

59. Maurette P, Castagnera L; Vivier C, Erny P, Rêpercussions comparées de l'anesthesie générale et de la rachianesthésie sur les fonctions psychiques du sujet ägé (Psychological assessnent in the elderly after general and spinal anaesthesia). Ann Fr Anesth Reanim 1988; 7: 305-8.

60. Meier U, Trullinger E, Stoll F, Fassolt A. Zur Frage der Postoperativen Konzentrations- und Gedächtnisstörungen bei Chirurgische Patienten. Schweizerische Zeitschrift fur Psychologie 1986; 45: 103-18.

61. Møller JT, Johamnessen NW, Berg $\mathbb{H}$, Espersen K, Larsen LE. Hypoxaemia during anaesilhesia - an observer study. British Journal of Anaesthesia 1991; 66:437-44.

62. Møller JT, Svennild 1, Johannessen NW, et al. Perioperative monitoring with pullse oximetry and late postoperative cognitive dysfunction. British Journal of Anaesthesia 1993; 71: 340-7.

63. Moller JT, Wittrup M, Johansen SH. Hypoxemia in the postanesthesia care unit: an obserwer study. Anesthesiology 1990; 73: 890-5.

64. Muravchick S. Immediate and long-term nervous system efects of anesthesila in elderly patients. Clinics in Antaesthesiology $1986 ; 4: 1035-45$.

65. Nadstawek J, Hausmann D, Bartsch A, Födisch M, Stoeckel H. Rückkehr motorischer und mentaler Funktionen nach Enfluran-Stickoxidul-Narkose bei 1,3 MAC in verschiedenen Altersgruppen (Recovery of motor and mental functions after enflurane-nitrous oxide anaesthesia of 1.3 MAC at different ages). Anästhesiologie Intesivtherapie in Nolfallmedizine. 1989;24: $293-7$.

66. Nielson WR, Gelb AW, Casey JE, Penny FJ, Merchant RN, Manninen PH. Long-term cognitive and social sequelae of general versus regional anesthesia during arthroplasty in the elderly. Anesthesiology 1990; 73: 1103-9.

67. Parikh SS, Ching F. Postoperative delirium in the elderly. Anesthesia and Analgesia 1995; 80: 1217- 22.

68. Paschalis $C_{\text {, Polychronopoulos }}$, Lekka NP, Harrison MJ, et al. The role of head injury "surgical anaesthesia and family history as aetiological factors in dementia of Alzheimer type: A prospectiwe study. Dementia $1990 ; 1: 52-5$.

69. Plude DJ, Hoyer WJ. Attention and performance: Identifying and localizing age delicits. In: Charness $\mathbb{N}_{\text {, }}$ ed. Aging and human performance. Chichester, UK: Wiley, 1985: 47-99.

70. Prior FN, Chander P. Air as a vaporizing gas: Cognitive functions in elderly patents undergoing anaesthesia. British Journal of Anaesthesia 1982; 54: 1207-12.

71. Rabbitt PMA. Applied cognitive gerontology: Some problems, methodologies and data. Applied Cognitive Psychology 1990; $4: 225-46$.

72. Raymond M, Conklin C, Schaffer J, Newstadt G, Matloff JM, Gray RJ. Coping with transient 
intellectual dysfuntuon after coronary bypalss surgery. Heari \& Lung 1984; $13: 531-9$.

73. feese HW, Rodehater D. Problem solving and decision making, In. Birren JE, Schare KW, ed. Handtyok of the psychology of aging. New York: Van Nostrand Reirihold, 1985: 474-99.

74. Reitan IA, Porter W, Rraunstein M. Comparison of psychomotor skills and amnesia after induetion of anesthesta wh midarolan or thopental. Anesthesia and Analgesia 1986, 65, 933-7.

75. Wis $J$ Lombolit, Haxhold $O$, et al. Immediate amd long-term mental recovery from general versus epidural anesthesia in elderly patients. Acta Anaesthesiologica Scand inavica $1983,27,44-9$.

76. Rollason WW, Rothertson GS, Cordiner CM, Fall DJ A comparison of mental function in relation to hypoterisive and normotenstre anaesthesia in the elderly. Britust Jourral of Anaesthesia 1971; 43 : 561-5.

77. Rosenberg $\mathfrak{J}_{\text {. Kehlet }}$ H Postoperative mental confusion - association with postoperative hypoxemia (ASA altstrac). Anesthesiology $1992 ; 77: 315$

78. Salthouse TA. Resource reduction interpretations of cognitive aging. Developmental Review 1988; 8: 238.72

79. Salz P. Brain reserve capacity on symptom onsel after brain injury: A formulation and review of evidence for threshold theory. Neuropsychology 1993; 7:273-95.

80. Shaw PJ, Bates D, Carilidge NEF, Heaviside D, Julian DG, Shaw DA. Early neurological complications of coronary artery bypass surgery. The British Medical Journal 1985; 291: 1384-7.

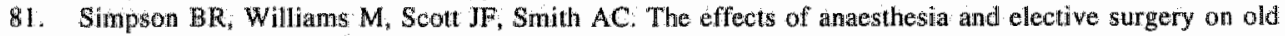
people. The Lancet $1961 ; 14 * 887-93$.

82. Smith $C$, Carter $M$, Sebel $P$, Yate P. Mental funetion after general anaesthesia for transurethral procedures. British Jountril of Anaesthesia 1991;67:262-8.

83. Smith CM, Carter M, Loughinan B, Marks R, Sebel PS, Yate PM. Effects of general anaesthesia on neaction time in elderly patients undergoing endoscopic urological surgery. British Journal of Anaesthesian $1987 ; 59: 1330 \mathrm{P}$.

84. Snth RJ, Roberts $\mathrm{NM}_{4}$ Rodgers $\mathbb{R J}$, Bennett $\mathrm{S}$. Adverse cognitive effects of general anaesthesia in young and elderly patients. International Clinical Psychopharmacology $1986 ; 1: 253-9$.

85. Sotaniemi KA, Mononen $\mathrm{H}_{\mathrm{k}}$ Hokkanen TE. Long-term cerebral outcome after open-heart surgery: A Five-year neuropsychological follow-up study. Stroke 1986: 17:410-7.

86. Spielberger GD, Wadsworth AP, Auerbach SM, Dunn TM, Taulbee ES. Emotional teactions to surgery. Journal of Consulting and Clinical Psychology 1973; 40: 33.

87. Townes BD, Dikmen SS, Bledsoe SW, Hornbein TF, Martin DC, Janesheski JA. Neuropsychological changes in a young, healthy population after controlled hypotensive anesthesia. Anesthesia and Analgesia 1986; 65: $955-9$.

88. West JB. Human physiology at extreme altitudes on mount everest. Science 1984: 223: 784.

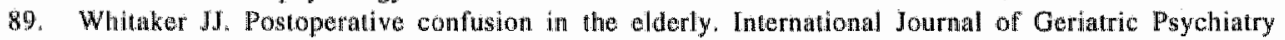
$1989: 4: 321-6.6$.

90. Williams MA, Campbell E, Raynor WJ, Musholt MA, Mlynarczyk SM, Laraine FC. Predictors of acute confusional states in hospitalixed elderly patients. Research in Nursing and Health 1985: 8: 31.40.

91. Williams-Russo $P$, Stutrock NE, Mattis $S$, Szatrowski TP, Charlson ME. Cognitive effects after epidurat ws general anesthesix in older adults. The Journal of the American Medical Association 1995; $274: 44-50$.

92. Willams Russo $\mathrm{PG}$, Szatrowski TP. Mattis S; et al. Post-operative cognitive deterioration in cardiac vs. non-cardiac surgical patients. Perfusion 1994; 9: 405-45.

93. Woodruff DS. Arousal, sleep, and aging. In: Biten JE, Schaie $\mathrm{KW}$, ed. Handbook of the psychology of agung. New York: Van Nostrand Reinhold, 1985: 26:-95.

94. Zucker-Goldstein M, Fogel BS. Cognitive change after electwe surgery in nondemented older adults. The American Journal of Geriatric Psychiatry 1993; 1: 118-125. 


\title{
Cardiopulmonary bypass (CPB) and cognitive function
}

\begin{abstract}
A review of studies published in the past 15 years on the influence of open-heart surgery on cognitive function is presented. Despite the many methodological problems inherent to this type of study, consistent findings have been reported. Cognitive deterioration is found shortly after the operation but not after several months, at least when changes in group means are studied. When individual change is studied, a decline of up to $35 \%$ after 1 year has been reported. This discrepancy is probably due to the very sensitive definitions for cognitive decline used in most studies and is probably an overestimation of the real decline. Studies that included a comparison group show that cognitive dysfunction is probably a sequela of open-heart surgery. Although a substantial proportion of variance in postoperative decline may be accounted for by the nonspecific aspects of general surgery, factors unique to open-heart surgery appear to have a minimal but measurable impact in short-term cognitive functioning. In the long term this is not so clear. Variables associated with a change in cognitive functioning after open-heart surgery can be divided into patient-related, surgery-related, and physiology-related variables. Examples of patient-related variables are age, the severity of cardiovascular symptoms or heart disease, education, and genetic predisposition. Mood and personality can also contribute to cognitive complaints after open-heart surgery. Mood state does not seem to affect objective cognitive performance but there is some evidence that it does have an impact on cognitive complaints. Examples of surgery-related variables with an impact on cognitive outcome are duration of bypass, blood pressure, acid-base management, and microembolic events. During the operation physiological changes occur which can cause brain damage. Biochemical markers and physiological techniques can detect cerebral damage earlier than cognitive measures can. There are indications that the damage found with these techniques is related to performance on cognitive tests. Possible interventions to reduce cognitive deterioration are hypothermic surgery, the use of arterial filters, the use of membrane oxygenators instead of bubble oxygenators, and the use of cerebral protective drugs.
\end{abstract}




\section{INTRODUCTION}

Since the early days of cardiac surgery attention has been paid to the impact of this type of surgery on brain functioning. It was apparent from the outset that the use of extracorporeal circulation (ECC) imposed widespread organ dysfunction which, at least in the early days, was associated with significant monality and morbidity. The use of ECC has steadily increased over the past four decades. This artificial perfusion procedure, most commonly referred to as cardiopulmonary bypass (CPB), is an essential component of cardiac surgery, as it permits the circulation and oxygenation of blood during cardioplegia, and in turn, the manipulation of a stationary heart under direct wision. The advent of CPB in 1954 led to rapid advances in cardiac surgery (44). Cardiac valve replacement/repair (CVR) is now routinely used to rectify the function of diseased or malformed cardiac valves (usually aortic or mitral valve). Coronary artery bypass grafting (CABG), which entails bypassing one or more segments of obstructed coronary artery using grafts from the patient's saphenous vein, has become the standard treatment for severe chronic angina pectoris. Although major improvements have occurred in cardiopulmonary techniques, the literature has continued to report cerebral dysfunction as a major continuing problem in modern cardiac surgical practice. An operation which relieves coronary artery stenoses, or replaces a diseased heart valwe, cannot nowadays truly be described as "successful" when the patient sustains cerebral injury during the operation, sufficient to moclify the patient's personality or intellectual performance postoperatively. As the mortality associated with coronary artery bypass grafting has fallen, morbidity has become an increasing concern. Postoperative quality of life, including the socio-economic concern of returning to gainful employment, is of supreme importance. It is in this regard that brain injury following $\mathrm{CPB}$ is devastating if it leaves the patient with persistent motor, sensory, behavioural, or intellectual deficiencies:

The same year (1954) in which Gibbon [44] reported the successful clinical use of the cardiopulmonary bypass, Fox and colleagues [41] reported sustained neuropsychological and psychological dysfunction in patients who underwent CVR. In the studies that followed, the association between cardiac surgery and a high incidence of cerebral injury was well estalshished, allthough the incidence rates varied considerably between the different studies. In 1965 Gilman $[45$ reported persistent cerebral dysfunction in $23 \%$ of patients, compared with $2 \%$ reported by Ehrenhaft et al. $[29]$ in 1961 . The patients in Gilman's study suffered from marked postoperative neurological signs, such as hemiplegia, visual field defect, or a constellation of higher cognitive deficits resembling transcortical sensory aphasia and/or agnosia. To the present day the reported incidence rates differ greatly. In the different studies that have prospectively examined neuropsychological dysfunction after CABG surgery, the incidence of impaired cognitive dysfunction shortly after the operation ranges from $24 \%$ to $79 \%$ and can persist for 12 months in up to $35 \%$ of patients $[$ e.g., 30, 52, 86, 106, 1.12, 119, 122, [24]. This discrepancy is dwe to several factors, the most important being the patient characteristics, large differences in the number of subjects studied, whether a comparison group was used or not, different approaches to statistical analysis, non-standardised procedures for CPB or psychometric testing, differences in time of assessment, and different tests used to identify cerebral dysfunction.

Possible causative mechanisms for cognitive dysfunction after CPB are embolism, inadequate brain blood flow, lack of pulsatile blood flow, cerebral ischaemia, normothermia versus hypothermia, absence of arterial line filters, failure to use membrane oxygenators, advanced age, duration of bypass time, previous neurological disease, and $\mathrm{PaCO}_{2}$ changes [e.g., 
$18,45,46,58.817$.

This chapter reviews the literature regarding the impact of CPB surgery on cognitive function. A distinction in CPB-supported cardiac surgery can be made between intracardiac operations, such as CVR, and extracardiac operations, such as CABG. Some of the reviewed studies compared postoperative outcomes of intracardiac and extracardiac surgery, and for the main part, between group differences in postoperative cogaitive function were not found $10 \%$, 116, 134]. When differences were reported, the data revealed only a minimal difference between group means, but with a more favourable outcome in extracardiac operations [14, 143]. Therefore, the data obtained from studies examining the impact of botla intra-and extracardiac surgery will be considered jointly. First a description of the procedure using heart-lung machine will be given, and then the potentially hazardous aspects of ECC that may place patients at risk for cerebral injury will be discussed. This is followed by an overview of the literature on cognitive change after CPB. Next, variables associated with cognitive change will be discussed. A distinction can be made between patient-related variables, such as age, surgery-related variables, such as the use of ECC, and physiological changes in the brain, as measured with biochemical markers and EEG and MRI. Several subject-related variables were already discussed in chapter 1 and will only be briefly discussed here. Subject-related factors especially related to cardiac surgery will be described more extensively. Finally, possible interventions reported in the literature to reduce cognitive disturbances after CPB will be discussed.

\section{CPB AND THE BRAIN}

Cerebral hypoperfusion and cerebral emboli, which are closely related to the use of the heartlung machine, are proposed to explain the cognitive changes after CPB. Brierley [17] already suggested in 1963 that emboli and prolonged reduction in cerebral perfusion might be aetiological factors in cognitive change. This notion was supported by later findings [45, 56]. The discussion about the importance of these mechanisms continues to this day [108, 114]. To aid understanding of these mechanisms a short description of the heart-lung machine will be given first, which is followed by a description of the pathophysiology inherent to cardiopulmonary bypass and its impact on cerebral physiology.

\section{The heart-lung machine}

The heart-lung machine consists of a pump and an oxygenator (see picture 1. 1). The bypass procedure begins with heparin being administered into the right atrium to prevent clotting while the patient's blood is routed through the heart-lung machine. Plastic cannulae are then inserted through the wall of the right atrium into the superior and inferior vena cavae. The pulmonary artery is then clamped, diverting cll venous blood to an extracorporeal venous reservoir. $A$ similar reservoir also collects suction return from the operative field and any blood remaining in the left ventricle. The blood is led from the venous side of the circulation to the oxygenator. In the oxygenator, oxygen is added to the blood and carbon dioxide is removed. The oxygen-rich blood is then drawn through filters to remove emboli consisting of air bubbles, platelet aggregates, or material from the oxygenator and pumped into the arterial side of the circulation, mostly in the aorta. With this technique the heart and lungs are shut out from the circulation. The oxygenator can also contro the temperature of the blood. Normally, the bloodflow is pulsatile, but with the heart-lung machine a continuous bloodflow is usually produced. Patients 
are only connected to the heart-lung machine when the heart is actually operated on so that the duration of ECC is as short as possible. During the operation, the body is cooled to a temperature of approxinately $28^{\circ} \mathrm{C}$ by the heart-lung machine, with rewarming being initiated during the anticipated final 30 minutes of surgery $[5,10,19]$.

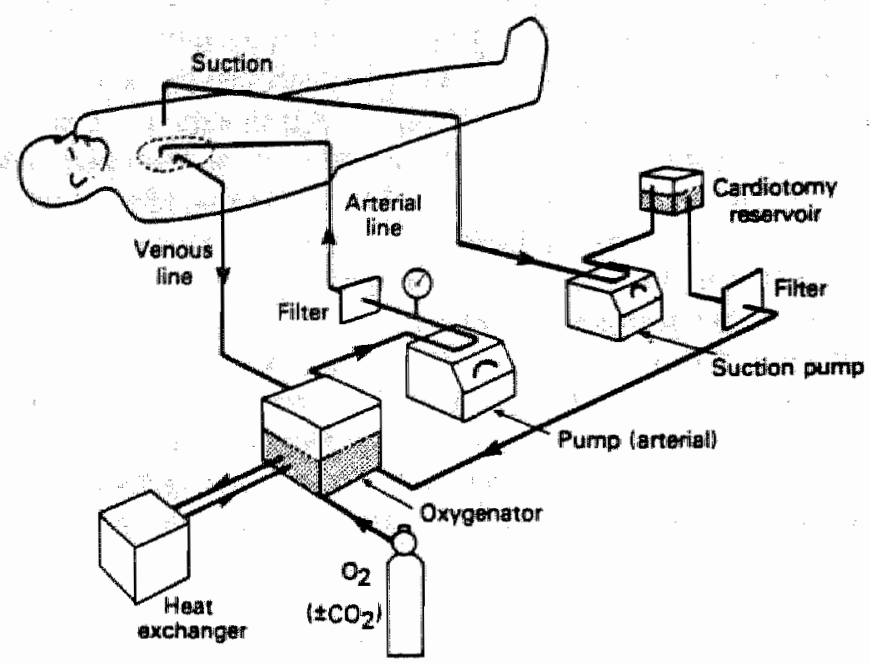

Picture 1.1 Schematic representation of blood circtation through a heart-lung machine [15]

\section{Pathophysiology of $C P B$}

The use of CPB during cardiac surgery imposes significant pathophysiological effects on haemodynamics, blood cell activation, and hypothermia. The changes in haemodynamics during $\mathrm{CPB}$ surgery concern the change in blood flow and the use of non-pulsatile perfusion. During CPB surgery the blood flow rate is lower than the normal physiological rate $[100.130$, 136|. This moderate flow perfusion represents a compromise because higher flows are believed to be associated with increased blood cell trauma. The use of moderate hypothermia during $\mathrm{CPB}$ surgery has led to even further reductions in blood flow rates because tissue oxygen requirements are decreased at a lower temperature [42]. Although pulsatile flow is probably more physiological, non-pulsatile perfusion became established as the routine mode of perfusion due to technical obstacles associated with pulsatile perfusion. Non-pulsatile perfusion results in progressive systemic vasoconstriction that continues for some hours into the postperfusion period [e.g., 66, 132. 140]. The pathological consequences of vasoconstriction include a reduced perfusion of peripheral organs, and an increased left ventricular load [121].

During CPB surgery, the patient's blood volume passes through the extracorporeal circuit. The components of the ECC are manufactured from synthetic materials, which can activate a whole series of cascades to produce a systemic inflammatory response [63, 103]. Leucocytes and platelets are activated and form microaggregates which pass through the circulation as microemboli. Microemboli have been demonstrated after CPB surgery in many vital organs including the lung, kidney, and most significantly, the brain [1], 104]. They can block small vessels, releasing vasoactive substances at the site of microvascular obstruction, which can lead 
to damage and disruption of the integrity of local vascular endothelium:

As was already mentioned, hypothermia reduces tissue oxygen requirements. This might be beneficial during a state of compromised blood flow during CPB surgery because it increases the safety margin and ischaemic thresholds in vital organs. However, when the management of gas exchange and acid-base balance is considered during hypothermic CPB surgery, the

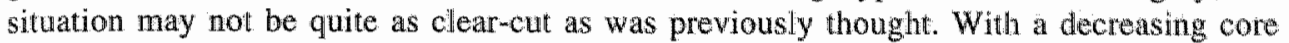
temperature, carbon dioxide solubility increases, and therefore the blood $\mathrm{PaCO}_{2}$ decreases: Until recently, it was believed that "normal' $\mathrm{pH}$ and $\mathrm{PaCO}_{2}$ levels should be maintained during hypothermic perfusion, so additional carbon dioxide was added to the bypass circuit in the hypothermic phase of CPB surgery. This regimen of acid-base balance is known as "pH-stat". The alternative approach, in which no additional carbon dioxide is added, is based on comparative physiology, and is known as the 'alpha-stat' regimen. This regimen stresses that electrochemical neutrality is the most important endpoint rather than the observed pH changes [98, 141]. With 'alpha-stat' a normal cellular metabolism during hypothermia is preserved at a reduced metabolic rate.

It is clear that CPB surgery can induce systemic pathological effects by causing inadequate blood supply, inflammatory/microembollic cellular damage, and metabolic disturbances. These pathologica] processes may also have an impact on the brain, and especially on cerebral blood flow and cerebral metabolism.

\section{The influence of $C P B$ surgery on cerebral physiology}

Brain function is dependent on glucose and oxygen for energy supply. As there is little storage of glucose in the brain, it is important to maintain the balance between metabolism and blood supply, with the blood supply being adjusted in such a way that the metabolic needs of the brain are fulfilled (cerebral autoregulation) [28]. Autoregulation ensures that there is a constant blood supply to the brain over a certain range of systemic perfusion pressures $(50-150 \mathrm{mmHg}$ ). During surgery, it is possible that fluctuation causes hypoperfusion. The perfusion pressure is then too low to maintain autoregulation and CBF becomes pressure-passive. Under these circumstances, blood supply is directly related to perfusion pressure [108]. Under nomal circumstances, the principal determinant of $\mathrm{CBF}$ is cerebral oxygen consumption $\left(\mathrm{CMRO}_{2}\right)$. The dependent relationship of $\mathrm{CBF}$ and $\mathrm{CMRO}_{2}$ is known as flow-metabolism coupling, and is rellected by the parallel reductions in $\mathrm{CBF}^{-}$and $\mathrm{CMRO}_{2}$ seen with most intravenous anaesthetics and with hypothermia. Carbon dioxide induces changes in CBF independent of changes in $\mathrm{CMRO}_{2}$. An increase in arterial $\mathrm{PaCO}_{2}$ levels increases $\mathrm{CBF}$. Excessively high $\mathrm{PaCO}_{2}$ levels are associated with complete loss of autoregulation, such that CBF becomes pressure passiwe. When cerebral perfusion is reduced below the lower limit of autoregulation, certain regions that lie along the boundary zones of the major cerebral arteries, e.g. the parieto-occipital area of the cerebral cortex [48], are particularly vulnerable to ischaemia and hypoxia. These boundary zones are sometimes referred to as 'watershed' areas and infarcts in these zones are referred to as 'watershed' infarctions 11311. Glucose metabolism is reduced in the posterior watershed zones in patients with severe coronary artery disease, and the reduction is not associated with a history of CABG surgery [68]. These findings suggest that patients with severe heart disease are already suffering from reduced cerebral blood flow and are therefore more vulnerable to cardiac embolisation, microembolisation, or hypoperfusion.

The insertion of cannulae into the aorta can cause macroemboli. The wall of the aorta often contains small clumps of fat and calcium and blood clots which can come off when the camnula 
is introduced. These emboli can enter the brain and block small arteries $[58,75]$. As was already mentioned, microemboli have been demonstrated in the brain after CPB surgery [108]. These emboli consist of air; fibrin, blood clots, and small parts of the pump-oxygenator system. Althowgh the uge of membrane oxygenators [12] and arterial filters [110] can decrease the incidence of microembolic events, these events are not eliminated.

Harris et 1 . [54] showed, by using MRI, that the brain is swollen immediately after an operation. This can be caused by microemboli or hypoperfusion during the operation and results in brain oedema caused by leakage of liquid from the blood stream to the brain. This swelling of the brain is not related to other procedures besides CPB surgery. Dob et al. [27] found brain swelling after abdominal aortic aneurysm repair but to a lesser extent than was found with CPB.

\section{The influence of changes in cerebral physiology on cerebral injury}

There is some evidence that a moderate reduction in total blood flow rates will reduce cerebral blood flow to dangerously low levels $[21,33,651$. But how low may flow rates be without really compronising cerebral perfusion? Some studies demonstrated no change in CBF in alpha-stat managed patients with a mean arterial pressure (MAP) as low as $30 \mathrm{mmHg}[50,77]$. The routine practice of maintaining a perfusion pressure higher then $50 \mathrm{mmHg}$ may not be necessary for most patients [125]. However, in patients with altered autoregulation (chronic hypertension, insulin-dependent diabetes), patients with severe cerebrovascular disease or elderly patients [82], the perfusion pressure at which changes in CBF occur is unknown.

The issue of non-pulsatile perfusion versus pulsatile perfusion has been discussed ever since cardiac surgery began. Non-pulsatile perfuision results in progressive systemic vasoconstriction that continues for some hours into the postperfusion period. This is due to the release of vasoconstrictive substances [e.g. 132]. Vasoconstriction wi]l lead to increased left ventricular load and reduced perfusion of the brain. It has been shown that pulsatile flow prevents or at least minimizes the metabolic and haemodynamic disturbances in the brain that are observed with non-pulsatile perfusion [70]. The hypothalamic-pituitary axis has been studied as a useful model for cerebral function duing open-heart surgery. The normal pattern of stress responses to surgical procedures is well established, but during cardiac surgery with non-pulsatile perfusion these reactions are not seen [58]. This is indicative of reduced cerebral perfusion leading to altered cerebral function and hence reduced hormone release.

Another mechanism is the cerebral tesponse to blood cell activation during CPB surgery. Cellular microaggregates appear to lodge in the microcirculation of vital organs during CPB surgery and have been demonstrated within the retinal circulation, which is part of the cerebrall circulation [111. Major cerebral embolism has always been recognised as an important, though relatively rare, complication of cardiac surgery, but microembolism is an almost inevitable conseguence of conventional CPB techniques. It is assumed that macroemboli are responsible for focal brain infarcts 1571 and that microemboli are responsible for changes in cognitive function $[1 \mid 4]$.

The changes in arterial carbon dioxide tension $\left(\mathrm{PaCO}_{2}\right)$ during $\mathrm{CPB}$ surgery, which are part of the overall acid-base strategy, appear to be involved in cerebral functioning. Two strategies of acid-base management can be followed during induced hypothermia: $\mathrm{pH}$-stat and alpha-stat. The two strategies have a different impact on cerebral functioning. Some studies reported cerebral hyperperfusion with $\mathrm{pH}$-stat management. Although cerebral hyperperfusion might initially seem to be beneficial, it may uncouple the flow/metabolism autoregulation within the 
brain, which can lead to a pressure-passive CBF. Studies that used the 'alpha-stat' regimen found that CBF was lower than with $\mathrm{PH}$-stat but that $\mathrm{CBF}$ changed in parallel with cerebral oxygen consumption [47,94]. This indicates that flow/metabolism coupling is preserved and that cerebral autoregulation is maintained.

Finally, the swelling of the brain after CPB surgery as found by Harris et all 154$]$ may also be a possible explanation for cerebrall injury [133], especially when the swelling is extensive and. prolonged.

\section{COGNITIVE CHANGES FOLLOWING CPB}

Estimates of the extent of cognitive impairment after cardiac surgery have ranged from 24\% 152 I to $79 \%$ [111]. This wide range is due in part to the diversity of cognitive tests used, varying follow-up intervals, differences in patient characteristics, and, most importantly, the definition of decline. Before an overview of the literature on cognitive change after CPB is given, several methodological issues will be discussed such as, the experimental design, selective attrition, selection of neuropsychological test, moderating factors, and definitions of decline. Studies published after 1980 and which included pre and post-surgery assessment of cognitive function after CPB surgery will then be discussed (see table 2.1). In most studies the preoperative assessment took place in the week before surgery and the postoperative assessment in the weeks, months or sometimes even years after surgery. In this rewiew, a short-term cognitive effect is defined as a change in cognitive performance measured within 7 to 10 days after an operation (as a rule: before disclharge from hospital). A long-term cognitive effect is defined as a change in cognitive performance measured several weeks to months after the patient has been discharged from hospital.

\section{Methodological issues}

First of all, this kind of research is restricted by the many procedural difficulties encountered when conducting behavioural research in hospital settings. Most studies have examined patients undergoing elective rather than emergeny cardiac surgery so that examinations can be planned in advance, and often only patients with relatively stable cardiac function have been included. Because of this selection bias, it is possible that patients at risk for cognitive decline, with for instance more severe cardiac disease, are not included.

In order to ensure that most of the sample will complete the cognitive examination and because limited time for testing most studies used a short test battery designed to detect the presence of brain injury rather than evaluate a wide range of specific cognitive functions. One obvious problem with using a limited cognitive battery is that not all relevant domains of cognitive functioning are assessed. Consequently, it is impossible to adequately identify specific areas that may be affected by CPB surgery. Table 2.2 gives an overview of the tests used in the different studies. Most studies have used tests assessing intellectual abilities, memory, and attention. Other cognitive domains, such as language skills, executive function and motor performance, construction and perception, have not often been assessed. Also, it is difficult to compare the results of the different studies as each study used different tests to assess cognition.

Because of the fact that $\mathrm{CPB}$ surgery is regarded as a life-saving intervention, the choice of potential research designs is limited. Withholding an operation for research purposes is 
unethical, so randomised subject assignment and controlled research designs with no-treatment or waiting-list comparison groups are not possible. Thus, outcome studies are often quasi-experimental, involving either normal healthy comparison groups, or comparisons with patients undergoing other types of surgery without CPB (see table 2.1).

Another important methodological consideration is the problem of selective attrition. In most studies patients were followed up over extended periods. Because patients do not randomlly drop out of studies, reporting data only on the subset of patients who return for follow-up may yield an inaccurate picture of the true rate of impairment over time [10]. Thus, the reported. incidence of cognitive decline after CPB surgery may underestimate the true level of impairment.

Finally, studies have used a variety of definitions of decline or change such as a decline of 1 standard deviation $(S D)$ or more on some number of tests, a decline of $20 \%$ or more on a number of tests, impairment ratings (IR), clinical ratings, or comparing change in group means (see table 2. 1). The results reported in the literature will be discussed against the background of these methodological issues.

\section{Thidence of cognitive changes after short and long follow-up periods}

Forty of the 54 studies conducted postoperative cognitive assessment during the early recovery phase, before discharge from the hospital (see table 2.1). Thirty-five of these studies reported a significant decline in cognitive performance. Five studies were not able to demonstrate a cognitive deterioration shortly after the operation $[23,36,37,43,49]$. In four of these studies a Mini Mental State Examination (MMSE) was used to estimate cognitive decline [23, 36, 43]. This type of test is probably not sensitive enough to detect cognitive change. One study did not mention which tests were used [49]. Considering that practice effects would be expected in a study design with a test-retest interval of about 2 weeks, the substantial deficits in performance found in the literature can be interpreted as evidence of cognitive decline after CPB surgery. This decline may be caused by patient-related variables such as the stress of having undergone a major operation, pain, worry and depression, fatigue, or the lingering effects of general anaesthesia or surgery-related variables such as duration of surgery, hypoperfusion or emboli. These issues will be discussed in more detail in the next paragraph.

Several studies have looked at cognitive performance after a longer time interval, ranging from 1 month to 5 years. Twenty-nine studies looked at the long-term effects of open-heart surgery. Eighteen studies could not demonstrate cognitive deterioration after discharge from the hospital, at least when group means were compared. In fact, there was either no significant change from baseline or improved performance (see table 2.1). Three studies found a decline in group or subgroup performance. Sotaniemi and colleagues [123, 124] examined patients four times during the year after cardiac surgery, and at a long-term follow-up after 5 years. As a whole, the cognitive performance of their sample improved steadily over the 5-year period. However, they identified a subgroup of patients with an unusually high incidence of postoperative neurological complications. In addition to longer operations and medical complications, this subgroup evidenced a significantly diminished rate of improvement in cognitive performance. Two other studies found a change in group performance from 6 weeks to 6 months after surgery $[55,84]$.

Besides comparing change in group means, several studies have also investigated individual change. In most of these studies, the criterion of deficit was a reduction of preoperative 
OPEN-HEART SURGERY AND COONITION 159

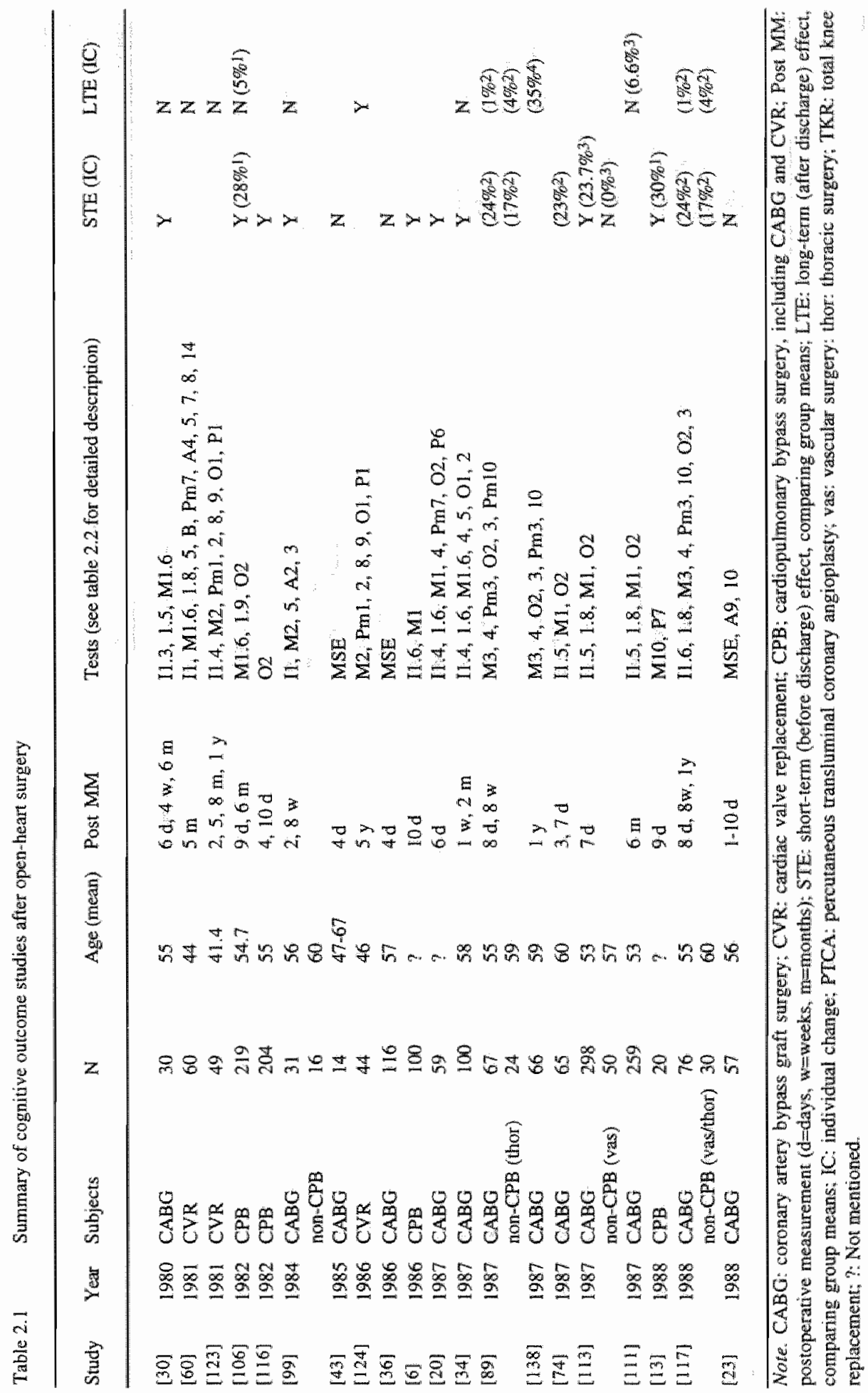




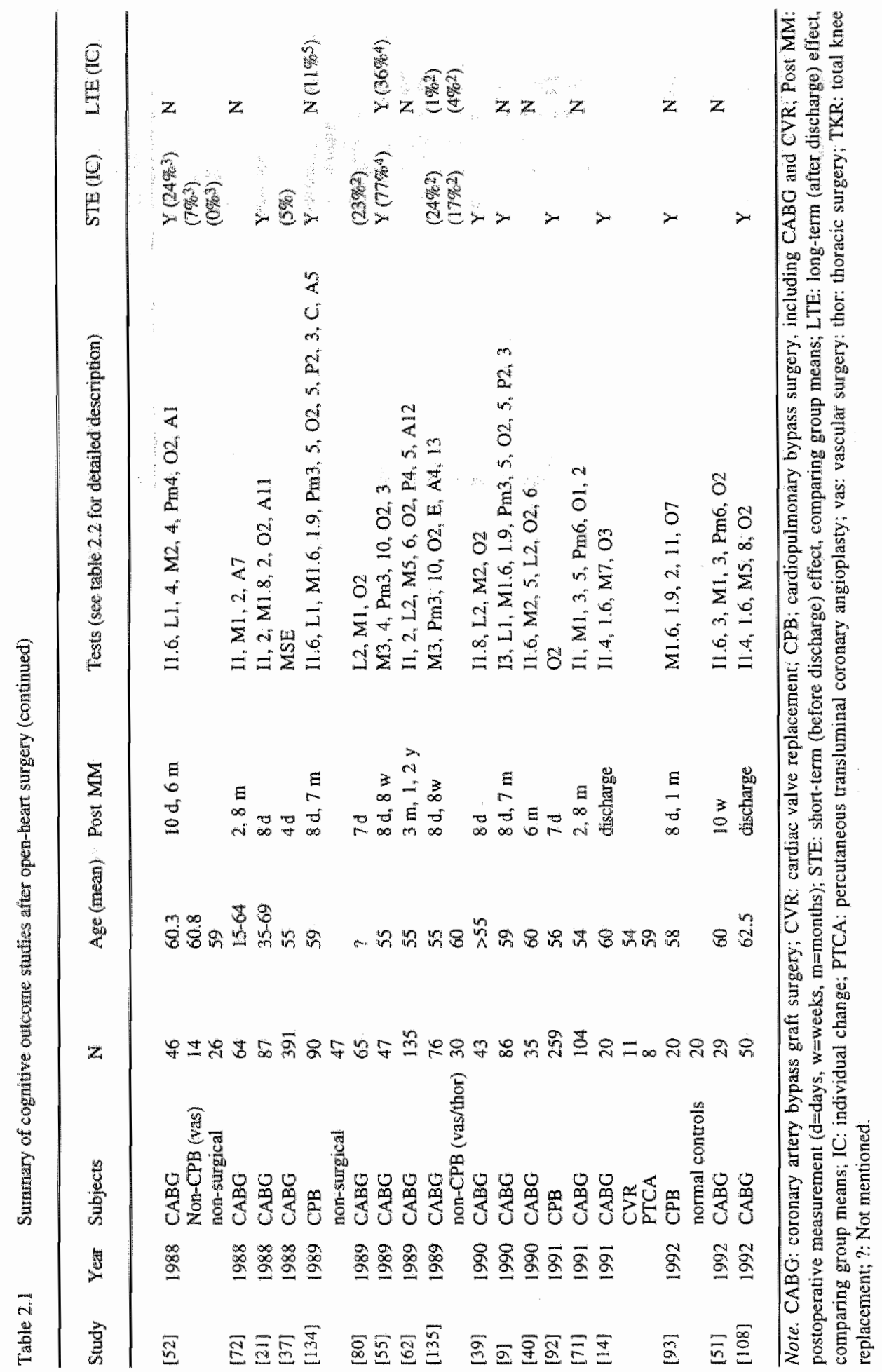


OPEN-HEART SURGERY ANO COGNITON I 55

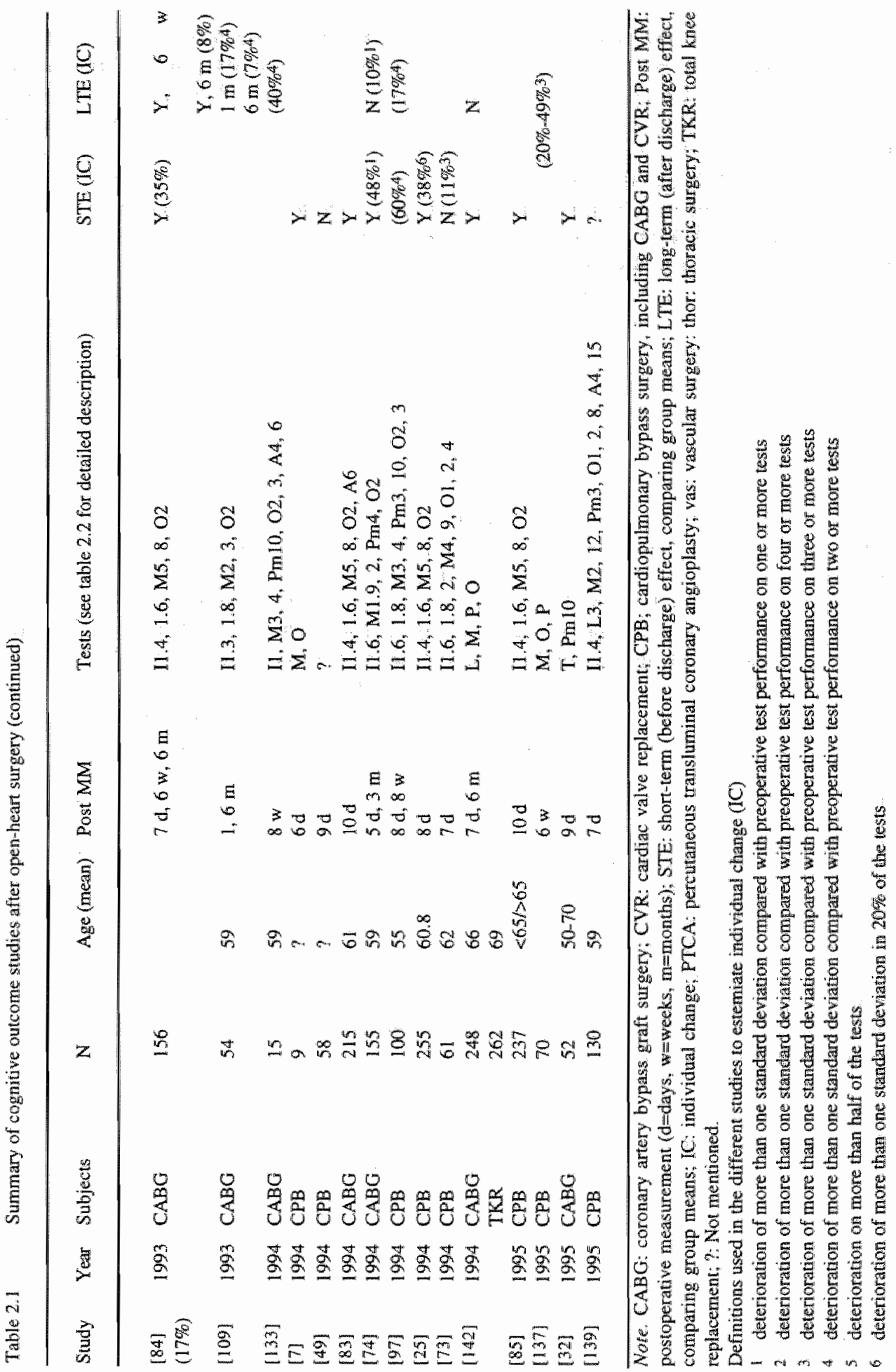


test performance of ISD on one or more tests, ats suggested by Newman and colleagues [86]. In most studies patients were classified as normal, moderately, or severely impaired, depending on the number of tests on which they showed a decline. The incidence of cognitive impairment ranged from $23 \%$ to $77 \%$ before discharge from hospital and from $1 \%$ to $49 \%$ after discharge from hospital (see table 2.1). Although these incidence rates are useful in estimating subgroups of patients who show deterioration after an operation, comparisons of these incidence rates between studies is difficult. The incidence of cognitive impairment is dependent upon the tests administerd, the SDs of the group means, the criteria used to distinguish normal from impaired performance, and the timing of assessments. This way of estimating individual cognitive change has never been used for normal healthy controls, so these fincings could also be due to a normal change in performance over time. It is possible that normal healthy subjects also show a change in cognitive performance of $1 S D$ after 1 month (see chapter 6 ). The incidence rate mentioned in these studies is probably overestimated because of the sensitive definitions used for a decline in cognitive performance.

\section{Controlled studies}

Several studies included a comparison group consisting of either normal healthy control subjects $[93,134]$, non-operated heart disease $[14,52]$, or medical patients undergoing an operation not requiring CPB surgery $[52,89.113,117.135]$. The inclusion of normal control subjects permits an evaluation of the degree of deficit in cardiac patients before and after surgery. Studies comparing cardiac patients with normal healthy controls found short-term cognitive impairments in the patients but these deficits were no longer apparent in the long term [93, 134]. In Townes" study [134], cardiac patients showed significant cognitive improvement in the long-term whereas there was no significant long-term change in normal subjects. O'Brien and coworkers [93] also found an improved performance in the patients but in their study controls showed an even a greater improvement. They suggested that this finding was probably due to a learning effect. Both studies found impaired neuropsychological performance prior to surgery in patients with cardiac disease but not after discharge from hospital.

These shont-lem neuropsychological deficits observed in cardiac patients may be the result of long-acting anaesthetic, emotional distress, pain, or other non-specific factors related to surgery. A surgical comparison group is needed to study the effect of these factors. Aberg and Kihlgren [1] compared cardiac patients with patients undergoing thoracic surgery. Cardiac patients showed significantly more impairment 8 days after surgery compared with the thoracic group. After 2 months, the cognitive performance of the cardiac patients was comparable with baseline performance although they performed at a significantly lower level than the thoracic group. Aberg and Kihlgren concluded that both operations have an impact on cognition, but that this impact is more severe in cardiac patients. Newman et al. 189$]$ also compared thoracic surgery patients with $\mathrm{CABG}$ surgery patients. In the short term, a higher percentage of deterioration was found in the CABG group than in the thoracic group, but after 2 months there was a higher percentage of deterioration in the thoracic group than in the CABG group. They suggested that cerebral dysfunction atso occurs with non-CPB surgery. In the studies of Smith et al. [117] and Treasure et al. [135] the same patient group was used as in Newman's study [89]. Williams-Russo and colleagues [142] compared the cognitive performance of CABG patients with that of patients who underwent total knee replacement (TKR), 1 week and 6 months after the operation. Cognitive impairment was not dramatically different between the two groups. The CABG patients showed greater mean impairment 1 week after the operation than the TKR 
patients, but this difference was no longer detectable after 6 months.

Although the comparison of thoracic surgery or TKR patients with CABG patients helps to control for at least some aspects of major surgery, there are physiological differences between the two groups which could influence the cognitive results. CABG patients are at higher risk for cerebrovascular disease, which could leave them more vulnerable to the effects of general anaesthesia, sleep deprivation, or other complications of major surgery. To study these effects a comparison group of patients with severe vascular disease who are scheduled for surgery without CPB is needed. Studies comparing CABG patients with vascular patients found a short-term deterioration in the CABG group and an improvement in the vascular group [99. 13$]$.

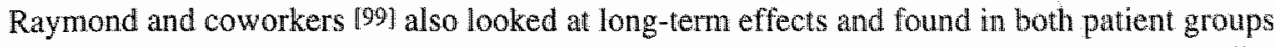
the same or improved performance compared with the baseline performance. From these studies it seems that the cognitive deficits of patients who have undergone open-heart surgery are related to exposure to the CPB circuit, at least in the short term.

The optimal study design would include both surgical and non-operated subjects for comparison with open-heart surgery patients. Hammeke and co-investigators $\$ 52\rfloor$ compared $\mathrm{CABG}$ patients with vascular surgery patients and non-operated patients with symptomatic coronary artery disease. Ten days after the operation, the $\mathrm{CABG}$ group showed a deterioration in cognitive performance and the non-operated group an improvement. The vascular surgery patients showed a performance between that of the CABG patients and the non-operated controls. After 6 months the CABG patients showed an improvement in cognitive performance but to a lesser degree than the patients in the two other groups. Blumenthal et al. $[14$ sludied the effect of three commonly performed cardiac procedures on short-term cognitive performance in patients undergoing cardiac surgical treatment (CABG surgery and valve repair) or a nonsurgical intervention, percutaneous transluminal coronary angioplasty (PTCA). They found that valve and $\mathrm{CABG}$ patients exhibited a declime in cognitive performance, whereas the performance of PTCA patients did not change.

These studies show that cognitive dysfunction is a probable sequela of open-heart surgery. Although a substantial proportion of variance in postoperative decline may be accounted for by non-specific aspects of general surgery, factors unique to open-heart surgery appear to have a minimal but measurable impact on cognition in the short-lem. In the long term this is not so clear. Some studies detected cognitive deficits as long as 5 years after surgery, while normal function was reported in several other studies after severall weeks.

\section{Cognitive domains studied}

The tests used to measure cognitive functioning in the studies mentioned in table 2. II range from general rating scallessuch as the MMSE, intelligence-related tests such as the WAIS, to tests measuring speed of performance. The different tests and questionnaires used are mentioned in table 2.2. In this section an overview of the cognitive measures used to study cognitive change after heart surgery and the results found for the different cognitive domains will be discussed.

Mini Mental Status Evaluation (MMSE) [38]. In four studies the MMSE was used to study cognitive change after heart surgery $[23,36,37,43]$. None of these studies was able to demonstrate a change in cognitive functioning shortly after the operation. This instrument is useful in screening for confusion or delirium but is probably not sensitive enough to measure changes in cognitive function.

Subtests measuring intellectual abilities (I). Several studies used intelligence-related measures to assess cognitive change after heart surgery. Most studies used one or more subtests 
Twble 22 Cognitive measures used in the different studies

Mental status examination (MSE)

Mni Menul state Examination.

Intellectwal abilities ( $)$

1. Wechsler Adull Intelligence Seales (WAIS :

\subsection{Information \\ 1.2. Arithmetic \\ 13 Similarities \\ 1.4 Digit Span \\ 1.s Vocabulary \\ 1.6 Digit Symbol \\ 1.7 Picture Completion \\ 1.8 Block Design}

1.9 Picture Arrangement

2. Raven Progressive Maurices

3. Shipley Institute of Living Scale

Verbal functions and langugige skills (L)

1. Aphasia Soreening Test

2. Word Fluency

3. Token Test part V

\section{Memory $(M)$}

1. Wechsler Memory Scale (WMS)

1.1 Information

1.2 Mental Control Test

1.3 Figurative Memory

1.4 Personal and Current Information

1.5 Orientation

1.6 Logical Memory

1.7 Digit Span

1.8 Paired-Associate Learning 1.9 Visual Reproduction

2. Verbal Learning Rest

3. Rey Auditory-Verbal Learning Test

4. Nonwerbal Memory Test

5. Benton Visual Retention/Recognition

6. Thactual Pertornance

7. Sternberg Menory Search Task

8. Randt Shori Story

9. StoryRrecall

10. Rivermead behavioural Menory Test

11. Baston Remole Memory Test

Psychomotoric functions ( $\left(P_{m}\right)$

1. Triangles

2. Maze Test

3. Purdue Pegboard
$[2], 36,37,43]$

[62, 71, 72, 99]

$[60,62,71,72,99]$

$[30,60,62,71,72,99,109]$

$114,20,21,25,34,60,62,71,72,83-85,108,123$.

$123,124,139]$

$[21 ; 30,43,58,62,71,72,79,111,113,1331$

$[6,14,20,21,25,34,40,51,52,60,62,71-74$,

$83-85,89,97,99,108,117,133-135,1381$

$160,62,71,72,133]$

$[21,39,55,60,62,71-73,89,97,99,109,111,113$

$117,133,135,4381$

$[60,62,71,72,99]$

$[21,62,73,99]$

[9., 51,134]

$[9,80,134]$

$[39,40,52,62]$

[139]

$[6,20,51,71,72,79,111,113]$

$[6,20,51,71,72,79,80,111,113]$

$[20,51,71,72]$

[51, 71, 72]

$[6,20,51,71,72,79,111,113]$

$[9,20,30,34,51,60,71,72,93,106,134]$

$[6,20,51,71,72,79,80,111,113]$

$16,20,21,51,60,71,72,79,80,111,113]$

$[9,20,51,71,72,73,79,80,93,106,111,113,114]$

$[21,39,40,52,74,93,99,109,123,124,139]$

$[51,55,71,89,97,109,117,133,135,138]$

$[20,34,52,55,73,89,97,117,133,138,1399$

$[25,34,38,60,62,71,72,83485,99,108]$

[62]

[14.]

$[25,83-85,108]$

[73]

[13]

[93]

[123, 124]

$[123,124]$

$[9,55,89,97,117,134,135,138,139]$ 
Table 2.2. Cognitive measures used in the differen studies (continued)

\section{Psychomotaric frunctions $\left(P_{m i}\right)$}

4. Lafayetle"s Grooved Pegboard

5. Finger Tapping

6. Bender-Gestal Test (Bi-G)

7. Symmetric Drawing

8. Kohs' Block Design

9. Choice Reaction Time Test

Orientation and attention (O)

1. Stroop Color-Word Test

2. Trail Making Test

3. Letter Cancellation Test

4. Number Cancellation Test

5. Digit Vigilance

6. Paced Auditoraly serial Addition Task

7. Contimuous Performance Test

8. Dot Cancellation

9. Line Bisection Test

\section{Perception $(P)$}

1. Recognition of Designs

2. Sensory Perceptual Examination

3. Visual Search

4. Speech Perception

5. Seashor Rhythrn

6. Figure Identification Task

7. Coding and Visual Perception Task

\section{Conceptual functions (C)}

The Wisconsin Card Sorting Test

\section{Tess battery $(T)$}

Syndrome Short Test (SST)

\section{Affective state and personality (A)}

1. Profile of Mood States (POMS)

2. Zung Depression Scale.

3. Taylor Mamifest Anxiety

4. Beck's Depression Inventory

5. Hamilton Anxiety/Depression Scale

6. Spielberger state/trait anxiety questionnaire [83, 133, 139]

7. Rorschach

8. Self Image Test

9. Millon Behavioural fnventory (MBHT)

10. Millon Clinical Multiaxial Inventory

11. Brief Psychiatric Rating Scale (BPRS)

12. MMPI-168

13. Clinical Interview Schedule

14. Self-image "Test
[52, 74]

$[9,51,60,62,71,134]$

$[20,60]$

[123. 124]

$1123,124]$

$[32,55,89,97,117,133,138]$

$[34,71,73,123,124,132)]$

$19,20,21,25,34,39,40,51,52,55,62,71$, $74,79,80,83-85,89,92,97,104,108,109$, 111. 113, 116, 117, 133-135, 138, 139$]$ $[14,32,55,89,97,117,133,138]$

[73]

$[9,134]$

[40]

[93]

[139]

[139]

[123, 124]

$[9,134]$

$[9,034]$

[62]

[62]

[20]

[13]

[32]

[52]

[99]

199]

$[60,133,135,139]$

$[60,134]$

$[60,72]$

$[60]$

[23]

[23]

[21]

$[60,62]$

[135]

[60] 
of the Wechsler Adult Intelligence Scales (WIAS) 1671. The most frequently used subscales were Digit Span, Digit Symbol, and Block Design. A deereased Digit Span performance was found shortly after the operation in some studies $[25,83]$ but others were not able to demonstrate this decline $14,20,321$. One study found a decreased performance on this test 5 months after open-heart surgery [60). Most studies that used the Digit Symbol Test demonstrated a decrease in performance shortly after the operation $[6,14,20,25,34,40,52,83,93,97,134]$. A clecline in performance on the Block Design Test was also demionstrated shortly after the operation [39, 97, 111]. One study mentioned a decline as assessed with the Vocabulary test [11]1. After discharge no decline in performance was found with any intelligence-related test (see table 2.1). In general, some intelligence-related measures were able to measure changes in cognitive functioning shortly after the operation, especially the Wechsler's Digit Symbol Test (measuring complex attention and psychomotor performance) and the Wechsler's Block Design Test (measuring construction abilities and wisual spatial organisation).

Verbal functions and language skills (L). Only a few studies assessed changes in verbal functioning and language skills after heart surgery. Three studies used an aphasia screening test $19,80,1341$. These studies could not demonstrate a decline shortly after the operation and found an improvement after 7 months. Three studies used a word fluency test $[39,40,62]$. Two studies looked at the short-term change in verbal fluency, one of which found a decline [39] whereas the other did not [52]. After discharge no decline in verbal function was found in these studies [40. $52,62]$. It seems that aphasia and speed and ease of verbal production are in general not affected by heart surgery.

Memory $(M)$. Changes of memory function was assessed in most studies. Different tests were used and different kinds of memory were assessed (see table 2.2). Several studies used the Wechsler Memory Scale (WMS) [67], in whole or in part. Shortly after the operation most studies found a decline in performance on this test $[6,9,20,30,74,93,104,111,134$, although there were some exceptions [21, 34]. After discharge no decline was found $[9,30,51,60,71,72,74$, 93, 104, 111, 124, 134]. Besides the WMS, several other tests were used to assess changes in memory function (see table 2.2). Independent on the type of memory assessed (verbal, nonverbal, immediate, recognition, etc) a decline was found shortly after the operation but not after discharge.

Psychomotor functions $\left(P_{m}\right)$. Psychomotor function was assessed in some studies by using different test (see table 2.2). Sotaniemi and coworkers [123, 124] could not demonstrate a change in performance in this function shortly after the operation and after 5 years. However, most studies found a decline in this function shortly after the operation but not at follow-up measurements after discharge $[52,55,74,97,134]$, using tests measuring manual dexterity. Four studies used tests assessing constructive performance, which combines perceptual activity with motor response and which always has a spatial component $[20,60,123,124]$. No decline was found with these tests in either the short term or the long term. In general, deterioration in psychomotor functions can be found shortly after the operation but not after discharge.

Ortentation and attention (O). Several tests measuring orientation and attention were used in the different studies. The Trailmaking Test was used the most often. Most studies using this test found a decline in performance shortly after the operation $[20,21,25,34,39,55,73,74,83,97,106$, 111. 1341. In none of the studies was a long-term effect found with this test. The same is true for the other tests that assess orientation and attention (table 2.2).

Conceptual functions ( $C$ ) Only one study looked at change in conceptual functioning after heart surgery by using the Wisconsin Card Sorting Test [52]. No change in performance was found after 10 days and 6 months. 
Perception (P). Only a few studies used a test measuring perceptive hunctioning. None of these studies could demonstrate a change in this function after heart surgery.

Test battery (T). Engelhardt et al: [32] used the Syndrome Short Test (SST) to detect concentration and memory disturbances in order to document a deterioration in cerebral function. The SST consists of nine subtests. Each subtest has to be completed within 60 seconds. In six of the nine subtests the time taken for each task was neasured. Mistakes have to be corrected, adding to the time needed. In three subtests the number of correctly recalled objects is counted. The results are transformed into a score taking age and verbal intelligence quotient into account. With this test Engelhardt et al. found a deterioration of cerebral function 1 week after CABG surgery.

\section{Variables associated with cognitive change}

Neurological and neuropsychological deficits have been observed in patients who have undergone open-heart surgery over the last 30 years. Several studies have tried to find determinants of these deficits so that patients at risk for cerebral injury can be identified. In this section the determinants reported in the literature will be discussed, namely, patient-related variables, surgery-related variables, and physiological changes in the brain associated with cognitive change.

\section{Patient-related variables}

Besides the use of the heart-lung machine, which is related to processes like hypoperfusion and emboli, there are several other factors which could influence cognitive function after the operation.

The influence of the factor age. Advancing age is the most frequently investigated subject characteristic to date, and with a few exceptions $[6,30,123]$, most studies have reported a relationship between advanced age and poorer neuropsychological outcome $120,33,35,88,91,93$, $106,107,116,134,138 \mathrm{~J}$. In these studies, a low mortality among elderly patients undergoing CABG has been reported, but all studies have reported high morbidity. Some studies tailed to find an association between age and postoperative outcome. However, one of these studies found very little evidence of cognitive impairment after surgery, thereby limiting the variance in the dependent measure that could be accounted for by preoperative factors [30\%. Other studies used younger samples [11] and an aging effect may not be detectlable until the sixth or seventh decade. In older patients, atherosclerosis is, in general, more severe than in younger patients and the regional CBF is less, due to changes in cerebro vascular antoregulation. So elderly people are probably more wulnerable to cerebrovascular disease, intracranial luemorthage, or inadequate perfusion during CPB surgery and therefore in greater danger of developing cognitive dysfunctions. Stump and colleagues [128] showed a significant association between increasing age and number of emboli during cardiac surgical procedures. To determine the mechanism of age-related cognitive dysfunction after CABG, Newman et al. 183] studied the contribution of age-related alterations in CBF autoregulation to cognitive impairment in cardiac surgical patients. They could not demonstrate an association between age-related changes in CBF autoregulation and cognitive decline, although the decline in cognitive function was greatest among the older patients. They concluded that cognitive dysfunction after CPB in the elderly cannot be explained by impaired CBF autoregulation, and that other mechanisms are probably more important. In a later study, they [85] llooked at the effect of mean arterial pressure (MAP) during hypothermic CPB surgery and the rate of rewarming from hypothermia on 
postoperative cognifive dysfunction. They found that the rate of rewarming and MAP were unrelated to cognitive decline. However, interactions associated with cognitive decline were foumd between age and an MAP of less than $50 \mathrm{mmHg}$, and between age and rewarming. Although MAP and rewarming were not the prmary determinants of cognitive decline, hypotension and rapid rewaming contributed to cognitive dysfunction in the elderly.

The influence of pre-exising (cardiac) vascular disease. The severity of cardiovascular symptoms or heart disease may also predispose patients to postoperative deficits $193,106,107$, 1.11. $\mathrm{Q}^{\mathrm{B}} \mathrm{Brien}$ et al. [93] found that severe cardiac disease and duration of illness were associated with lower memory test scores before CABG and a greater decline after surgery. Shaw et al. [111] demonstrated that a history of cardiac failure and angiographic evidence of left ventricle damage were significantly correlated with impaired cognition after surgery. Although it has been suggested that pre existing cerebrowascular disease could be a risk factor for neurological dysfunction after $\mathrm{CABG}\left[\mathrm{B}_{2}, 26 \mathrm{j}\right.$, this was not demonstrated in studies comparing the neuropsychological outcome after $\mathrm{CABG}$ of patients with normal and abnormal carotid arteries (assessed by means of digital subtraction angiography) [16,55].

The influence of education and gender. Other possible risk factors are years of education and gender. Newman et al. 83 f found that years of education was associated with less cognitive decline. The protective effect of education appears similar to that suggested in recent studies of Alzheimer's disease, but the mechanism by which this education-related protection occurs is unclear [126]. Whether education imparts a cognitive reserve, enhances test-taking skills, or imparts some improvement in neuronal homeostasis that makes these patients more resistant to neurological insult is unknown. Few studies have compared the neuropsychological outcome of $\mathrm{CABG}$ in men and women. This is because more men than womin undergo cardiac surgery. One study reported a less favourable outcome in terms of neuropsychological performance in women after valve surgery [123].

Genetic factors. In one study a genetic predisposition for cognitive decline after CABG was mentioned [129]. This study assessed several factors that could predict postoperative cognitive decline, such as preoperative cognitive score, age, years of education, and cerebral arteriovenous oxygen difference. Although a number of variables could predict cognitive decline, they condd only predict between $10 \%$ and $40 \%$ of the variance, so other factors must influence this decline as well. This inability to predict a significant percentage of the variance and similarities between cognitive decline after cardiac operation and the early cognitive changes in Alzheimer's disease led to investigation of the role of the apolipoprotein E-e4 allele, a known risk factor for the development of late-onset and sporadic forms of Alzheimer"s disease. This allele was studied as a predictor variable for cognitive dysfunction in patients undergoing CABG. In a multivariate linear regression analysis including preoperative score, age, years of eduction, apolipoprotein E-e4, and CPB time, a significant association was found between apolipoprotein Ere4 and decline in cognitive performance on several cognitive measures at discharge and 6 weeks postoperatively. Better educated patients were less susceptible to the decline in cognitive function associated with the allele. This study suggested that genotype is an irmportant predictor of cognitive dysfunction after CPB surgery. Certain individuals may be susceptible to cognitive decline after physiological stress as a result of a genetic impairment of neuronal mechanisms of maintenance and repair.

The influence of mood state. It has become common to assess mood states such as anxiety and depression, at the same time as neuropsychological assessments are performed to ensure that any observed changes in cognition are not due to changes in mood. This has made it possible to examine whether preoperative mood is associated with cognitive decline following 
cardiac surgery. In a small study using the MMSE, Folks ef al. Why found that preoperative depression increased the risk of immediate postoperative cognitive dysfunction. There is little other support for this finding in the literature. Vingerhoets et a1. 1139] studied the relationship between emotional variables (anxiety and depression) and cognitive test performance in patients undergoing open-heart surgery. They correlated the self-reported anxiety and depression scores with the performance on 11 neuropsychological tests at pre- and postoperative examinations. They found elevated emotional arousal in these patients, but this did not affect their cognitive performance. Although mood does not seem to affect objective cognitive pertormance, there is some evidence that it does have an impact on cognitive complaints. Newman at al, 187 found a relationship between anxiety, depression, and complaints of postoperative memory dysfunction in the absence of any measurable cognitive deficit. This suggests that depression following cardiac surgery results in feelings of hopelessness and self-deprecation, which includes a negative self-appraisal of intellectual skills. These findings are consistent with those obtained by Kareken et al. [61]. These authors conducted a survey regarding complaints of cognitive impair* ment 2 to 3 years after CABG and valve replacement procedures. They found that, in general, respondents did not report cognitive problems following cardiac surgery. Risk factors, such as number of arteries bypassed and age, did not correlate with reports of cognitive dysfunction, but psychological distress did. They concluded that many patients experience psychological distress after surgery and that this distress is partially expressed in the form of complaints about mild memory loss and cognitive inefficiency.

The influence of personality. Chandarane et al. [23] studied the relationship between personality variables and postoperative cognitive dysfunction in CABG patients. They found that, besides age, cognitive dysfunction after 10 days was significantly associated with a preoperative high score on 'neuroticism', 'dominant personality', and 'extraversion'. Strauss and coworkers [127] studied psychological and neurological reactions to $\mathrm{CABG}$. They identified three subgroups of patients with respect to their emotional status and life satisfaction. One group was characterised by high levels of anxiety, depression, and life dissatisfaction, whereas the other two groups could be described as either average or stable. At follow up after 2 years, the first group had depressive coping styles, a slightly higher degree of cognitive impairment, more neurological and psychopathological symptoms, a considerably lower return-to-work rate, more subjective physical complaints, and a poorer attitude towatd outcome. They concluded that the operation itself is of less importance for late postoperative adaptation than the patients' ability to cope with their heart disease and its consequences. These findings underline demands for an adequate psychological support, both before and after the operation, for patients under* going coronary surgery.

\section{Surgery-related variables}

Duration of bypass. Several studies have found that duration of bypass is related to the incidence of neuropsychological deficit $[89,107,117,120,123,124,138]$; however, there are some exceptions [20,52, 113]. Prolonged CPB surgery is often associated with more difficult cases and attendant advanced atherosclerotic disease or severe valvular calcification. This interrelationship of risk factors makes it difficult to identify the relative contributions of each.

Blood pressure. The role of cerebral hypoperfusion has likewise proved hard to assess. Some workers have suggested that cerebral deficits can be partly avoided by ensuring that the MAP exceeds $50 \mathrm{mmHg}[115]$, but most of the arguments for this policy are based on work in animals 1521 and may be of limited relevance to humans.

Aberg and Kihlgren [1] found that low arterial blood pressure during CPB surgery could 
distinguish between patients with good versus poor cognitive outcome. Nevin and collegues 791 compared the changes in cognitive performance of a group of patients undergoing $\mathrm{CABG}$ surgery with routine peroperative monitoring with patients in whom normocapnia $\left(\mathrm{PaCO}_{2}\right.$ 35-45 mim $\mathrm{m}$ ) was maintained during surgery. On the third postoperative day, psychometric deficits were observed in $71 \%$ of the first group and $40 \%$ of the second group. More than $50 \%$ of the first group proved to have been hypocapnic immediately before the onset of $C P B$ and those with postoperative deficits differed from the others in this group by having had greatier charges in $\mathrm{PaCO}_{2}$ after the onset of the bypass operation and lower cerebral perfusion pressures in the first 10 minutes of the operation. Other studies could not found such a relationship [20, 123]. There are some indications that older patients with a MAP of less than $50 \mathrm{mmHg}$ show a greater decline in cognitive function [82]. So elderly people may be more vulnerable to hypoperfusion.

Cerebral blood flow. Distubances in CBF have been examined as a possible causative factor in ehanges in cognitive function following $\mathrm{CPB}$ surgery. Some studies have reported short-term changes in $\mathrm{CBF}$ following $\mathrm{CPB}$ surgery but were unable to find any relationship between these changes and cognitive petformance $143.89,119]$. An alternative approach has been to examine $\mathrm{CBF}$ during surgery. The changes in paCO 2 during $\mathrm{CPB}$ surgery appear to be involved in changes in CBF 177,951 . Two strategies of acid-base management can be followed during induced hypothermia: alpha-stat and $\mathrm{pH}$-stat. Two studies have attempted to examine whether cognitive complications are more prevalent under alpha-stat or under $\mathrm{pH}-\mathrm{stat}[9,137]$. Bashein and co-investigators [9] did not find a difference in the incidence of cognitive dysfunction between two groups of patients managed with these acid-base protocols. However, Venn et al. [137] reported that a significantly higher proportion of patients in the $\mathrm{pH}$-stat group fared less well than in the alpha-stat group. Patients in the alpha-stat group experienced less disruption of cerebral autoregulation during hypothermic CPB surgery, and this was accompanied by a reduction in postoperative cognitive dysfunction. More research is needed to estimate the relationship between acid-base management and cognitive change:

Croughwell et al. [24] found jugular bulb haemoglobin desaturation during the warming phase of cardiopulmonary bypass. In a more recent study, they looked at the effect of this carebral venous desaturation on cognitive dysfunction [25]. Cerebral venous desaturation occurred in $17 \%$ to $23 \%$ of the patients and was associated with impaired postoperative cognitive test performance. They suggested that cerebral venous desaturation represents an imbalance in cerebral oxygen supply demand during normothermic CPB surgery, i.e., there is transient cerebral ischaenia. "The episodes of transient ischaemitare probably related to embolic events on failures in cerebral autoregulation in the setting of non-pulsatile CBF and are associated with impaired postoperative cognitive test performance.

The influence of wicroemboli. Microemboli have been implicated in the aetiology of newropsychological deficits after CPB. Two techniques can be used to detect microemboli: retinal fluorescein angiography and transcranial Doppler. In two studies retinal fluorescein angiography was used to deteet microemboli but could not demonstrate a relationship between detected microemboli and cognitive functioning 112,118$]$. Some studies examined the relationship between the incidence of microemboli, as detected by transcranial Doppler, and cognitive performance. There sure indications that individuals with a higher incidence of microemboli in surgery are more likely to have cognitive deficits [97].

\section{Physialogy-related variables}

Neuropsychological testing and neurological examination are common methods of assessing 
cerebral injury. These methods thave the disadvantage of being time-consuming and must often wail until the patient has recovered fully from the operation. Earlier diagnosis is of interest to select patients who may benefit from neuroprotective therapies. If the cognitive deficits observed after open-heart surgery reflect cerebral injury, then there should be other evidence of brain damage in patients with cognitive dysfunction.

Biochemical markers. Some studies have assessed biochemical and physiological measures of cerebral function in cardiac surgery patients. Aberg et al. [4] used the enzyme adenylate kinase (AK) in cerebrospinal fluid (CSF) as a biochemical marker for brain cell injury. Noncardiac operations do not evoke the release of AK into the CSF, whereas open heart operations evoke a significant increase [4]. The increase in CSF AK showed a weak but significant correlation with the psychometric test scores $[2,3]$. Because of the difficulty of obtaining permission for spinall fluid taps, other biochemical markers for brain cell injury had to be found. Two other biochemical markers for the prediction of postoperative neuropsychollogical dysfunction are S-100 and neuron-specific enolase (NSE). Sandstrom et al: [1051 measured a significant release of S-100 during CPB surgery but not during other types of surgery. Others demonstrated that S-100 and NSE levels after cardiac surgery are associated with neurological complications [59]. Backstrom et al. [7] found a correlation between elevated levels of S-100 and NSE in blood after open-heart surgery and the difference between pre- and postoperalive neuropsychological test performance up to 3 days after the operation. S-100 and NSE seem to be suitable biochemical markers for the detection and quantification of cerebral injury during cardiac surgery with ECC. These findings may be of value for the prediction of neuropsychological outcome, for early therapeutic interventions, and for the development of safer perfusion techniques.

EEG and MRI measures. Nevin et a]. [80] continuously monitored patients undergoing CABG surgery, using a cerebral function analyzing monitor (CFAM) which produces a detailed analysis of the EEG. They compared the results of peroperative cercbral monitoring with the neuropsychometric assessments. Seventy-six per cent of their patients with a neuropsychometric deficit after the operation also showed peroperative CFAM changes. The CFAM may prowide a practised obserwer with the opportunity of identifying cerebral insults as they occur.

To study cerebral functional outcome in cardiac surgical patients, Engelhardt et al. [32) used P300 mapping to see whether this measure was able to quantify cerebral dysfunction after $\mathrm{CABG} . \mathrm{P} 300$ is an endogenous potential and is a manifestation of cognitive processing invoked by given stimulus. P300 is present if the subject performs a task correctly and absent if he does not. In normal adults, the topography of P300 has been shown to be very stable on repeated measurements. One week after the operation a deterioration in cognitive performance, an increase in P300 latency, and an increase in mistake rate in counting the P300 target tone were found. The authors concluded that P300 can be used as an objective neurophysiological parameter for the quantification of cerebral function after $C A B G$.

Toner and coworkers [133] found that a large proportion of patients undergoing CABG have cerebral MRI abnormalities preoperatively. After surgery, new MRI changes were present in 4 of the 15 patients, all of whom also had cognitive deficits. They concluded that there is a close agreement between MRI changes and functional assessment. 


\section{INTERVENTIONS TO REDUCE COGNITIVE DEFICITS}

This section briefly describes the available evidence for relationships between proposed risk factors and cognitive deficits after open-heart surgery and interventions to prevent these deficits.

Hypothermia. The temperature at which patients are mantained during CPB surgery may affect the incidence of cerebral complications. Moderate hypothermia during CPB surgery is now standard practice. Graham et al. [49] and McLean et al, [74] compared the incidence of cerebral dysfunction in patients maintained at "mild" $\left(34^{\circ} \mathrm{C}\right)$ versus "moderate" $\left(28^{\circ} \mathrm{C}\right)$ hypothermia during $\mathrm{CPB}$ for $\mathrm{CABG}$. Neither study could demonstrate a difference in cerebral dysfunction after the operation between the two groups. However, Martin and colleagues [69] also compared patients undergoing $\mathrm{CABG}$ under warm cardioplegia with patients undergoing $C A B G$ under cold cardioplegia and found an increased rate of neurological complications in the warm cardioplegia group. No differences were noted between the two groups concerning neuropsychological dysfunction. From these studies, it seems that the neuroprotective effect of hypothermia is probably not as great as the literature suggests. One explanation for this is the fact that cooling of the body occurs after the patient is connected to the heart-lung machine. During connecting and disconnecting of the patient to the heart-lung machine, the body is not cooled and at this moment the risk of emboli is the greatest. The protective effect of cooling is then only partly true [90].

Filtration. Arterial line filters are used in an attempt to filter out microemboli that may occur during cardiac surgery. One study found little advantage of using a filter [6]. They compared the cognitive outcome of patients with and without an arterial line filter 10 days after CABG. The results indicated a similar number of patients with deficits in both groups. In contrast. Smith et al. [119] found that more subjects in the non-filtered group as opposed to the filter group had neuropsychological deficits 8 weeks after the operation. The difference between these two studies may be due to the length of follow-up. Smith showed a much clearer difference between the groups at the 8-week assessment, when the immediate effects of surgery had declined. Aris et al. [6] only followed up their patients for 10 days after surgery. Transcranial Doppler studies performed by Pugsley et al. [96, 97] showed a marked reduction in microemboli reaching the brain when a filter was placed in the arterial line. A neuropsychological test battery was applied, and it was shown that reducing the number of microemboli to the brain significantly reduced the degree of cerebral dysfunction after coronary artery surgery [97].

Oxygenation Over the years, the nature and form of oxygenators have changed considerably. Neuropsychological tests have been used to evaluate the differences between the oxygenators in terms of cognitive functioning. As early as 1973, patients on a bubble oxygenator were compared with patients who had a membrane oxygenator. Cognitive deterioration was found in $23 \%$ of those who had the membrane oxygenator and in $55 \%$ who had the bubble oxygenator [22]. Blauth et all. $[11,13]$ investigated the difference between bubble and membrane oxygenators in microembolic load to the cerebral circulation. The retinal microcirculation was investigated using fluorescein angiography. Retinal angiograms indicated a striking reduction in the extent of retinal microembolism when a membrane oxygenator was used. All patients in the bubble oxygenator group had abnormal retinal microvascular perfusion, in contrast to none in the membrane group. Although all oxygenators produce damage, it seems that bubble oxygenators do more damage to the constituents of blood and cause a greater denaturation of plasma proteins than do membrane oxygenators. These findings seem to suggest that the membrane oxygenator produces a lower frequency of cognitive disturbances.

Cerebroprotective drugs. Cerebral injury caused by CPB has a multifactorial aetiology. 
Although much of the injury may be ischemic in origin, possibly associated with hypoperfusion or emboli, some may also be associated with a general inflammatory response, the release of vasoactive substances causing endothelial damage, or generalised damage to cerebral integrity. There are therefore many ways in which potential cerebroprotective drugs can act. Barbiturate protection has frequently been noted as a pharmacological mechanism for brain protection [76]. Both sodium thiopental and propofol have been investigated as possible cerebroprotective agents, and presumably act by reducing the cerebral metabolic rate. One study compared two groups and reported some protection in the group receiving thiopental, but neuropsychological testing did not discriminate between the two groups [91]. Fish and collegues [34] compared one group of patients receiving prostacyclin prior to CPB surgery with patients who did not. No difference in neuropsychological performance was found between the groups. This suggests that prostacyclin does not prevent the deterioration in performance on neuropsychological tests after CPB surgery. Calcium channel blockers, which have a potent dilating effect on the cerebr* al vasculature, are considered to provide cerebral protection in cardiac surgery. One such blocker is nimodipine. Forsman et al. [40] compared CPB patients who received nimodipine with patients who did not. No significant differences in neuropsychological test performance were found between the groups, although a slight difference in favour of the nimodipine group was mentioned. Several new groups of cerebroprotective agents have received attention. Cerebral ischaemia results in a massive increase in the extracellular glutamate concentration, which is neurotoxic [102]. Glutamate is an excitatory neural transmitter and its actions are mediated by distinct types of receptors. If glutamate receptors are blocked; less focal cerebral ischaemia occurs and brain functioning is protected [64].

\section{CONCLUDING REMARKS}

Although CPB can cause changes in cerebral physiology which can lead to cerebral injury, the role of these alterations and the common occurrence of cognitive dysfunction is still not understood completely. Although most studies nowadays use arterial line filter, membrane oxygenators, and 'alpha stat' management on bypass, cognitive deterioration is still reported.

A major problem of this type of research is the methodological differences among studies. Studies have used different cognitive tests, different numbers of subjects, different nature of control subjects, different follow-up times, different approaches to statistical analysis, different experimental designs, etc. Robin at al: [101] compared these differences between the studies with the Babel effect described in the bible. "Babel, a city in Shinar, where Noah's descendants attempted to bulld a high tower reaching to heaven. For their presumptuous venture, God caused the builders to speak a variety of tongues. This caused utter confusion and prevented completion of the tower: The Babel Effect".

Perhaps a major step has been taken to solve this problem. The meeting 'CNS Dysfunction after Cardiac Surgery: Defining the Problem', was held in 1994. Its goal was to assemble leading investigators from the basic and clinical sciences who are interested in the field of cerebral physiology and outcome after cardiac operations. During this meeting, participants reached a statement of consensus on assessment of neurobehavioural outcome after cardiac surgery [78].

Despite the many methodological problems, there is some consistency across studies indicaling that deficits in cognitive performance do occur shortly after CPB. A substantial portion of the variance of this decline can be attributed to the effects of either the heart-lung bypass circuit 
and/or manipulation of atherosclerotic cardiac tissue during surgery. This is supported by the many studies demonstrating that open-heart surgery patients typically perform more poorly on postoperative examinations than do patients undergoing other major operations that do not involve CPB. Moreover, recent research has indicated that measures of the frequency of microembolic events are correlated with cognitive outcome. This implies that even uncomplicated open-heart surgery is associated with mild cognitive decline, independent of non-specific aspects of major surgery such as anaesthesia. Another consistent finding across studies is the return to baseline or improvement of cognitive performance on long-term follow-up examination. It can be concluded that while cerebral function is often compromised after surgery, most patients eventually experience substantial or complete recovery.

Data analysis restricted to group means may obscure cognitive decline in a subgroup of patients. In most studies, the variability in test scores was almost always substantially larger among surgery patients than controls. Such high variation could obscure differences in group means. Inwestigators should examine both individual changes and group changes. If a subgroup of patients is identified that demonstrates a decline after surgery, investigators should attempt to determine whether there are perfusion or surgery correlates of the postoperative deficits. When individual change is studied, investigators should also study a comparison group of normal healthy subjects to see whether the change could also be caused by normal fluctuations in performance over time. To date, there are a very limited number of studies that used this method in normall healthy people without surgery (see chapter 4 ).

It is clear that many patients with severe cardiac disease are impaired cognitively prior to surgery [93, 134]. Lockwood and col]egues [68] found evidence of reduced glucose metabolism in the posterior watershed zones in these patients, a decrease that was not associated with a history of CABG. These patients are probably already vulnerable to cardiac embolisation, microembolisation, or hypoperfusion well before any attempt at revascularisation. The cognitive functioning of cardiac disease patients may have less to do with the effects of surgery per se, than with the impact of the chronic, severe cardiac disease that brings them to the operating. theatre.

Finally, while the cognitive sequelae of open-heart surgery are remarkable, the impact of these impairments on day-to-day functioning is uncertain and has seldon been studied. To provide meaningfull advice about the problems such patients may experience, clinicians need ninore infonmation about the likely impact of specific deficits and combinations of deficits on activities that have practical importance. For example, the nature and degree of deficits that make it unsafe for a patient to drive a car, manage finances, or return to work would have considerable practical impact. One of the problems encountered in addressing such issues is obtaining criterion information about patients' everyday functioning that is reliable, comparable to that of other patients being studied, and meaningful in terms of the requirements of living situations of different individuals. One way to get this information is to question the patient. Only a fow studies surveyed self-reports of cognitive impairment among cardiac surgery patients. Shaw et al. [112] reported that $38 \%$ of their bypass patients were aware of some deterioration in intellectual function and that $10 \%$ judged themselves to be overtly impaired from observations of their day-to-day activities in the hospital. In a follow-up study 6 months later, Shaw et al. [111] found that $27 \%$ of their subjects stil] had mild complaints of forgetfulness, mental slowness, and decreased attention. Sotaniemi et al. [124] found that patients reported a general improvement in health, social ${ }_{\text {ind }}$ and leisure activities. However, 10 patients complained of mild memory impairment that did not affect their daily life activities. In a study of 16 patients, Elsass and Henriksen [31] found that patients complained of impaired memory and 
reduced motor speed in the presence of improved physical health. Another way to obtain criterion information is to use physician or family/spouse ratings. However, family ratings may be affected by feelings about the patient and by the perception of the purpose for the assessment. One way to obtain reliable criterion information is to use tests closely resembling relevant situations in everyday living. However, daily requirements for one person can be very different from those for another person. More research is needed to demonstrate that performance on specific neuropsychological instruments affects behaviour in certain areas of patients" everyday lives.

Although cognitive complaints after CPB have been reported, these subjective complaints do not seem to be related to objective cognitive test performance [87]. Patients with cognitive complaints did not show a decline in test performance and patients who showed a decline in test performance did not complain. Newman et al. [87] found that patients with cognitive complaints had higher levels of anxiety and depression. However, several CPB related-variables, such as emboli, seem to be related to objective cognitive test performance. When, for instance, a filter is used to prevent emboli from entering the brain, less decline in cognitive test performance is found. It seems that cognitive tests can be used to measure brain injury but not to measure cognitive complaints. Even if it were possible to perform surgery under the most optimal conditions without any sign of brain injury, a relevant subgroup of patients would probably still have complaints. These complaints are probably more related to mood personality, coping behaviour, and expectations. Future research should pay more attention to the correlates of these subjective cognitive complaints by developing intervention studies in this area.

Further study is necessary to define the population at risk and to determine whether adjustment of mood or surgical and perfusion techniques can minimize or reverse those factors that lead to cognitive dysfunctions and complaints.

\section{REFERENCES}

1. Aberg T, Kihlgren M. Effect of open-heart surgery on intellectual function. Scandinavian Journal of Thoracic and Cardiovasculan Surgery 1974; Suppl 5: 1-63.

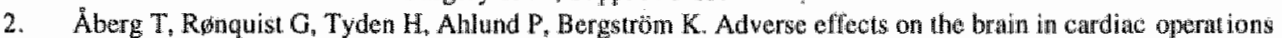
as assessed by biochemical, psychometric and radiological methods. The Journal of thoracic and Cardiovascular Surgety 1984; 87: 99-105.

3. Aberg $T$, Ronquist $\mathrm{G}$, Tyden $H$, Brunnkvist $S_{1}$ Bergstrom $K$. Cerebral damage during open theart surgery. Scandinavian Journal of Thoracic and Cardiovascular Surgery $1987 ; 21: 15963$.

4. Aberg T, Ronquist $G$, Tydén $H$, Ahlund $P J$, Bergstrom $K$, Release of adenylate kinase into cerebrospinal fluid during open heart surgery and its relation to postoperative untellectual funation. The Lancet $1982 ; 1 ; 1139-42$.

5. Aikenhead AR, Smith G. ed. Textbook of anaesthesia. 2nd. ed. New York: Churchill L.ivingstone, 1990: $629-643$.

6. Aris A. Solanes H, Camara ML, Junque C, Escartin A, Caralps JM. Arteriall line flltration during cardiopulmonary bypass: Neurologic, neuropsychologic, and hematologic studies. Journal of Thoracic and Cardiowascilar Surgery 1986; $91: 526-33$.

7. Backstrom M, Lundquist C. Stahl EO. Alling C, Johnsson PA. S-100 protein and neuron specific enolase (NSE) in blood after open heart surgery: Correlation to neuropsychological outcome. Preliminary findings. Perfusion 1994; 9:427-18.

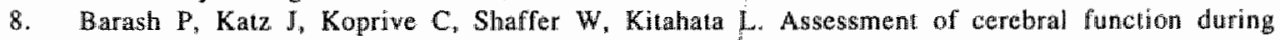
caridopulmonary bypass. Heart and 1 ing $1979 ; 8: 280.7$.

9. Bashein $\mathrm{G}_{\text {, Townes }} \mathrm{BD}$, Nessly $\mathrm{ML}_{\text {, }}$ ef al. A randomized study of carbon dioxide management during hypothermic cardiopulmonary bypass. Anesthesiology $1990 ; 72: 7,15$.

10. Benedict RHB. Cognitive function after open-heart surgery: Are postoperative neuropsychological 
deficils caused by cardiopulmonary bypase? Neuropsychology Review $1994: 4: 223-55$.

11. Blauth C, Kohner EM, Arnold I, et al. Recinal microembolism during cardiopulmonary bypass dernonstrated by flucreseein angiography. The Lancet 1986, ii $837-9$.

12. Blauth $\mathrm{C}$, Smith $\mathrm{P}$, Newman $\mathrm{S}$, al Retinal microembolism and neuropsychological deficit following clinical cardiopulmonary by pass: Conparison of a nembrane and bubble oxygenator. European Jounal of Cardiothoracic Surgery $1989 ; 3: 135-8$.

13. Blauth $\mathrm{Cl}_{\text {, Arnold } \mathrm{JV}}$ schulenberg WE, MoCartney $\mathrm{AC}$, Taylor $\mathrm{KM}$. Cerebral mieroembolism during cardiopulmonary bypass. Iournal of Thoracic and Cardiovascular Surgery 1988; 95: 668-76.

14. Bhumenthal JA, Madden DJ, Burker BJ, et al. A preliminary study of the effects of cardiac procedures on cognitive performance International Journal of Psychosomatics 1991; 38: 1-4.

15. Bosseher B, Heidanus $\mathrm{R}$, Cognitief funktioneren na een open hantoperate. Stageverslage en scriptie. Sectie Experimentele en Arbeldspsychologie, Rijksuniversiteit Groningen 1994.

16. Breslau $\mathrm{P}$, fell $\mathrm{G}$, Ivey T, Bailey W, Muller D, Strandess $\mathrm{K}$. Carotid artery disease in patients undergoing coronary anery bypass operations. The Thoracic and Cardiovascular Surgeon 1981; 82: $765-7$.

17. Brierley JB. Neuropathological findings in patients dying after open heart surgery. Thorax 1963; 18: $291-304$.

18. Brierley $\mathrm{JB}$. Brain damage complicating open-heart surgery: A neuropathological study of 46 patients. Proceedings of the Royal Society of Medicine 1976; 60:34-5.

19. Brillman 3. Central nervous system complications in coronary artery bypass graft surgery. Neurocardiology $1993 ; 11: 475-95$.

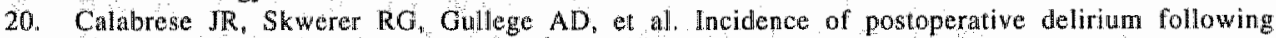
myocardial revascularisation. Cleveland Clinic Joumal of Medicine 1987; 54: 29-32.

21. Carella $F$, Travaini $G$, Contri $P$, et al Cerebral complications of coronary bypass surgery. $A$ prospective study. Acta Neurologica Scandinavica 1988; 77: 158-63.

22. Carlson $R$, Lande $A$, Landis $B$, at al. The lande-Edwards membrane oxygenator during heart surgery. The Journal of Thoracic and Cardiovascular Surgery 1973; 66: 894-905.

23. Chandarane PC, Cooper AJ, Goldbach MM, Coles JC, vesely MA. Perceptual and cognitive deficit following coronary artery bypas surgery. Stress Medicine 1988; 4: 163-71.

24. Croughwell ND, Frasco P. Blumenthal JA, Leon BJ, White WD, Reves JG. Warning during cariopulmonary bypass is associated with jugular bulb desaturation. The Annals of Thoracic Surgery 1992; 53:1702-8.

25. Croughwell ND, Newman MF, Blumenthal JA, of al. Jugular bulb saturation and cognitive dysfunction after cardiopulmonary bypass. The Annals of Thoracic Surgery 1994; 58: 1702-8.

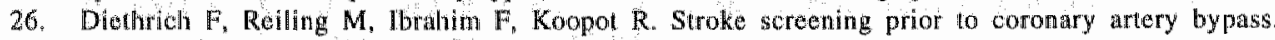
Bulletin of the Texus Hear Institute 1977; $4: 262$

27. Dop DP, Harris DNF, Standfield NJ. Brain swelling after abdominal aortic aneurysm repair. Perfusion 1994; $9: 405-55$.

28. Drummond JC, Shapiro HM. Cerebral physiology. In: Miller RD, ed. Anesthesia. 3rd ed. New York: Churchill Livinstone, 1990: 627.9.

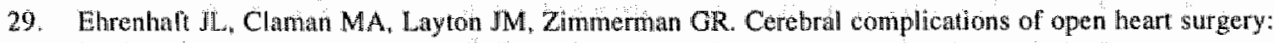
Furiher obserwations. The Journal of Thoracic and Candiovascular Surgery $1961: 42: 514-26$.

30. Ellis RJ, Wisnicwski $A_{2}$ Potts $R$, et al. Reduction of flow rate and arterial pressture at moderate hypothermia does not result in cerebral dysfunction. The Journal of Thoracic and Cardiovascular Surgery 1980; 79: $173-80$.

31. Elsuss $P$, Henriksen L. Acute cerebral dysfunction after open-heart surgery; A reaction-time study. Scandinavian Joumal of Thoracic and Cardiovascular Surgery 1984; 18: 161-5.

32. Engelhardt W, Dierks T, Pause M, Sold M, Hartung E, Silber R. P300-mapping: A neurophysiological tool to quantify cerebral dysfunction after coronary artery bypass grafting. European Journal of Cardio- Thoracic Surgery 1995: 9: 12-7.

33. Fish KJ, Helins K, Sarnquist FH, Tinkleberg J, Miller DC. Neuropsychological dysfunction after cononary artery surgery. Anesthesiology 1982; 57: A.55.

34. Fish $\mathrm{KJ}$, Hellms $\mathrm{KN}$, Sarnquist $\mathrm{FH}$, et al A prospective, randomized study of the effects of prostacyclin on neuropsychologic dysfunction after coronary artery operation. Journal of Thoracic and Cardiovascular Surgery 1987; 93:609-15.

35. Folks DG, Blake DJ, Fleece L, Sokol RS, Freeman AM. Quality of life six months after coronary 
antery bypass surgery: A preliminary report. Southern Medical Journal 1986; 79: 397-9.

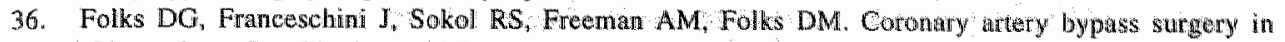
older patients: Psychiatric morbidity. Southern Medical Journal 1986; 79: 303-6.

37. Folks DG, Freeman AM, Sokol RS, Govier AV, Reves JG, Baker DM. Cognitive dystunction after coronary artery bypasss surgery: A case-controlled study. Southern Medical Iouninal 1988; 81: $202-6$.

38. Folstein MF; Folstein SE, McHugh PR. "Mini-Mental State": A practical method for grading the cognitive state of patients for the clinician. Journal of Psychiatric Research 1975; 12: 189-98.

39. Foreest $M$. Neuropsychological functioning following cardiopulmonary bypass. In: Willner AE, Rodewald $\mathrm{G}$, ed. Impact of cardiac surgery on the quality of life. New York: Plenum Press, 1990 181-9\%.

40. Forsman M, Olsnes BT, Semb G, Steen PA. Effects of nimodipine on cerebral blood flow and neuropsychological outcome after cardiac surgery. British Journal of Anaesthesia 1990; 65: 514-20.

41. Fox HM, Risso ND. Gifford S. Psychological observations of patients undergoing milral surgery. Psychosomatic Medicine 1954; 16: 186-208.

42. Fox LS, Blackstone EH, Kirklin IW, et al. Relationship of whole body oxygen consumption to perfusion flow rate during hypothermic cardiopulmonary bypass. The Journal of Thoracic and Cardiovascular Surgery 1982; 83:239-48.

43. Freeman AM, Folks DG, Sokol RS, et al. Cognitive function after coronary bypass surgery: Effect of decreased cerebral blood flow. The American Journal of Psychiatry 1985; 142:110-2.

44. Gibbon JH. Application of a mechamical heart and lung apparatus to cardiac surgery. Minnesota Medicine 1954: $37: 171-85$.

45. Gilman S. Cerebral disorders after open heart operations. The New English Journat of Medicine 1965; 272: 489-98.

46. Govier AV. Central nervous system complications after cardiopulmonary bypass. In: Tinker JH, ad. Cardiopullmonary Bypass: Current Concepts and Controversies. Philadelphia, PA: W..B. Saunders Company, 1989.

47. Gowier AV, Reves JG, McKay RD, et al. Factors and their influence on regional cerebrall blood flow during nonpulsatile cardiopulmonary bypass. Thoracic Surgery 1984; 38: 592.

48. Graham DG, Brierly JB. Vascular disorders of the central nervous system. In: Adams J, ad, Neuropathology. London: Eward Arnold, 1984: 125-207.

49. Graham JS, Heyer EJ, Delphin E, et al. Neurologic ontcome after CABG at mild versus moderate hypothermia. Perfusion 1994; 9: 418-9.

50. Greeley WI, Ungerleider RM, Kern FH, et al. Effects of cardiopulmonary bypass on cerebral blood flow in neonates, infants and children. Circulation 1989; 80: 1209-15.

51. Grote $C L$, Shanahan PT, Salmon P, Meyer RG, Barrett C, Lansing A. Cognitive outcome after cardiac operations. The Journal of Thoracic and Cardiovascular Surgery 1992; 104 (5): 1405-9.

52. Hammeke TH, Hastings JE. Neuropsychologic alterations after cardiac operation. The Journal of Thoracic and Cardiovascular Surgery 1988; 96: 326-31.

53. Harper AM. Cerebral blood flow and cerebrovascular disease. Science Basis Clinical Neurology 1985; 37 : 518-32,

54. Harris DNF, Bailey SM, Smith PLC, Taylor KM, Oatridge A, Bydder GM. Brain swelling in lirst hour after coronary artery bypass surgery. The Lancet 1993; 342: 586-7.

55. Harrison $\mathrm{MJG}_{\mathrm{n}}$ Schneidau A, Smith PLC. Newman S, Treasure T. Cerebrovascular disease and functional outcome after coronary artery bypass surgery. Stroke 1989:20:235-7.

56. Hill JD, Aguilar MIJ, Baranco A. Neuropathological manifestations of cardiac surgery. The Annals of Thoracic Surgery 1969; 7: 409-19.

57. Hise JH, Nipper ML, Schmitker JC. Stroke associated with coronary artery bypass surgery. The American Journal of Neuroradiology 1991; $\| 2 ; 811-14$.

58. Hornick P. Smith PL, Taylor KM. Cerebral complications after coronary bypass grafting. Current Opinion in Cardiology 1994; $9: 670-9$.

59. Johnson $P$, Lundquist $C$, Lindgren $A$, et al. Cerebral dysfunction after cardiac surgery: Assessment by two biochemical markers in blood, Sw100 and NSE. Perfusion 1994; 9:427.

60. Juolasmaa A, Outakoski J, Hirwenoja $R$, Tienari P, Sotaniemi $K$, Takkunen J. Efrect of open heart surgery on intellectual performance. Journal of Clinical Neuropsychology 1981; 3: 181-97.

61. Kareken DA. Williams JM, Mutchnick MG, Harter $G_{\text {, Torres }} \mathbb{1}$, George WE. Self-report of cognitive function after cardiac surgery. Neuropsychology 1992; 6: 197-209. 
62. Konof $\mathrm{H}$, Clark $\mathrm{C}$, Kavanagh-Griy $\mathrm{D}$, Mizgala $\mathrm{H}$, Munro L. Two-year follow-up study af coronary bypass sungery. The Joumal of Thotacic Cardiovascular Surgery 1989: 97: 78-85.

63. Kiuft $C$, Doiuewaard $G$, Emeis 11. Role of the contact system in fibrinolysis. Seminars in Thrombosis and Hemostasis $1987,13,50-68$.

64. Koehar A, Zinin IA, Lyden PD, Marzarella V. Glutamate antagonist therapy reduces meurologic deficits produced by focal central nervotis system ischaemía Anchives of Neurology 1988 ; 45: 148-53.

65. Kolkka R, Hiberman M, Neurologic dysfunction following cardiac operation with low-flow, lowPressure pressure cardiopulmomary bypass. The Journat of Thoracic and Cardiovascular Surgery 1980; 79: 4327.

66. Lewine FH, Philbin DM, Kono $K$, et al. Plasma vasporessin levels and urinary sodium excretion during cardispulmonary bypass with and without pulsatile flow. The Annals of Thoracie Surgery 1981; 32,637 .

67. Lezak MD. Neuropsychological Assessment. 3ro ed. New York Oxford University Press, 1995.

68. Lockwood AH, Benedict RHB, Murphy BW, et al: Cerebral metabolic and neurobehavioral abnormalities in patients: with cononary artery disease. In: Hartnian $A_{*}$ Hearse DJ; Kuschinsky W, ed. Cerebral Ischemia and the Heart, 1994.

69. Martin TD, Craver JM, Gott JP, et al. Prospective, randomized trial of retrograde warm blood carioplegia: Myocarial benefit and neurologic threat. The Annals of Thoracic Surgery 1994; 57 : 298 304.

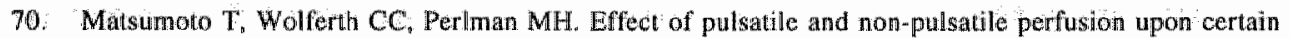
cerebral and conjunctival circulation in dogs. The American Surgeon 1971; 37: 61-4.

71. Mattlar $C_{*}$ Engblom $\mathbb{E}_{\text {, Vesala }} P_{\text {, Vantinen }} E_{\text {, Knuts }} \mathrm{L}$. The proportion of patients with cognitive impairment alter coronary artery bypass surgery: An 8-month follow-up study. Psychotherapy and Psychosomatics 1991; 55: 145-50.

72. Mattlar CE, Engblom E, Vanttinen E, Knuts LR. Neuropsychological findings and personality Structure associated with coronary artery bypass surgery (CABS). Journal of Clinical and Experimental Neuropsycholegy 1988; 10:329.

73. McDaid CM, Lowis SA, MoMurray LT, Phillips SA. Heart surgery: What are the neuropsychological consequences? The Irish Journal of Psychology 1994: 15: 1:10-25.

74. Mclean RF. Wong BI, Naylor CD, et al. Cardiopulmonary bypass, temperature, and central nervous system dysfunction. Circulation 1994; 90: 11-250-5.

75. Mills SA. Cerebral injury and cardiac operations. The Annals of Thoracic Surgery 1993; 56: S86-91.

76. Mitchenfelder JA. A valid demonstration of barbiturate-induced brain protection in man. Anesthesiology $1986 ; 64: 140-2$.

77. Murkin JM, Farra JK, Tweed WA, el al. Cerebral autoregulation and flow/metabolism coupling during eardiopulmonary bypass: "The influence of $\mathrm{PaCO}_{2}$. Anesthesia and Analgesian 1987; 66: 825-32.

78. Murkin JM, Newnan SP, Stump DA, Blumenthal JA. Statennent of consensus on assessment of neurobehavioral onteomes after cardiac surgery. The Annals of Thoracic Surgery 1995; 59: 1289-95.

79. Novin M, Colchester ACR, Adams S, Pepper JR. Evidence for involvement of hypocapnia and bypoperfusion in aetiology of neurological deficit after cardiopulmonary bypass. The Lancet 1987; 26: $1493-5$

80. Nevin M, Colchester ACF, Adams S, Pepper JR. Prediction of neurologica damage after cardiopulmonary bypass surgery. Amaesthesia 1989; 44:725-9.

81. Newman M, Frasco P, Kern F. Central nervous system dysfunction after cardiac surgery. Advances in Cardiovascular Surgery 1992; 3: 243-84.

82. Newman MF, Croughwell ND, Blumenthal JA, et al. Predictors of cognitive decline after cardiac operation. The Arnils of Thoracic Surgery 1995; 59: 1326-30.

83. Newman MF, Croughwell ND, Blumenthal JA, et al. Effect of aging on cerebral attoregulation during cardiopulmonary bypass: Association with postoperative cognitive dysfunction. Circulation 1994: 90: II243-9.

84. Newman MF, Schell RM, Croughwell $N$, et al. Pattern and time course of cognitive dysfunction following cardiopulmonary bypass. Anesthesia and Analgesia 1993; 76: $\$ 294$.

85. Newman MV, Kramer D, Croughwell ND, et al. Differential age effects of mean arterial pressure and rewarming on cognitiwe dysfunction after cardiac surgery. Anesthesia and Analgesia 1995; 81:236-42.

86. Newiman $S$. The incidence and nature of neuropsychological morbidity following cardiac surgery. Perfusion 1989; 4: 93-100. 
87. Newman $S$, Klinger $L$, Ven $G$, Smith $P$, Harrison M, Treasure T. Subjective reports of cegnition in relation to assessed cognitive performance following coronary artery bypass surgery. Journal of Psychosomatic Research 1989; 33: 227-33.

88. Newman $S$, Kninger $L$, Venn $G$, Smith $P$, Harrison $M$, Treasure $T$. The persistence of Neuropsychological deficits twelve months after coronary artery bypass surgery, and reports of cognitive change, mood state and assessed cognition following corronary artery bypass surgery. In: Wilner $A_{\text {, }}$ Rodewald G, ed. Impact of Cardiac Surgery on the Quality of Life. New York: Plenum, 1990.

89. Newman S, Smith P. Treasure T. Joseph P, Ell P, Harrison M. Acute neuropsychological consequences of coronary artery bypass surgery (Health Psychology): Current Psychological Research \& Reviews, 1987; 6: 115-24.

90. Nussmeier NA. Neuropsychiatric complications of cardiac surgery. Journal of Cardiothoracic Vascular Anesthesia 1994; 8 (Suppl 1): 13-8.

91. Nussmeier NA, Arlund C, Slogoff S. Neuropsychiatric complications after cardiopulmonary bypass: Cerebral protection by a barbiturate. Anesthesiology 1986; 64: 165-70.

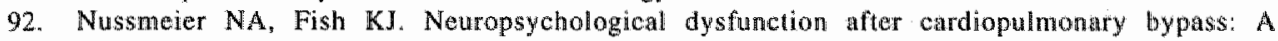
comparison of two institutions. Journal of Cardiohoracic Vascular Anesthesia 1991; 5:584-8.

93. O'Brien DJ, Bauer RM, Yarrandi H, Knauf DG, Bramlett P, Alexander IA. Patient memory thefore and after cardiac operations. The Journal of Thoracic and Cardiovascular Surgery 1992; 104; 11 16-24.

94. Prough DS, Stump DA, Roy RC, et al. Response of cerebral blood flow to changes in carbon dioxide tension during hypothermic cardiopulmonary bypass. Anesthesiology 1986; 64: 576 .

95. Prough $\mathrm{DS}_{4}$ Stump DA. Troost $\mathrm{BT} . \mathrm{PaCO}_{2}$ management during cardiopulmonary bypass: Intriguing physiologic rationale, conwincing clinical data, evolwing hypothesis? [comment]. Anesthesiology 1990; 72: 3-6.

96. Pugsley $W$. The use of doppler ultrasound in the assessment of microemboli during cardiac surgery. Perfusion 1989; 4: 1115-22.

97. Pugsley $W$, Klinger L, Paschalis $C$, Treasure $T$, Harrison $M$, Newman $S$. The inpact of microemboli during cardiopulmonary bypass on neuropsychological functioning. Stroke 1994; 25: 1393-9.

98. Rahn H. Body temperature and acid-base regulation. Pneumologie 1974; 151:87.

99. Raymond M, Conklin C, Schaffer J, Newstadt G, Matloff JM, Gray RJ. Coping with transient intellectual dysfunction after coronary bypass surgery. Heart \& Lung 1984; 13:531-9.

100. Replogle RL, Gross RE. Renal function during extracorporeal circulation. Journal of Surgery Res $1961 ; 1: 91-6$.

101. Robin ED, McCauley RF, Notkin $\mathbb{H}$. Long-term cognitive abnormalities associated with cardiopulmonary bypass (CPB) and the Babel Effect. Chest 1994: 106: 278-81.

102. Rothman SM, Olney JW. Glutamate and the pathophyslology of hypoxic-ischaemic brain damage. Annals of Neurology 1986; 19: 105-11.

103. Royston D. Blood cell actiwation. Seminars in Thoracic and Cardiovascular Surgery 1990; 2: 341-57.

104. Royston DJ, Fleming JS, Desai JB, et al. Increased production of peroxidation products associated With open-heart surgery: Evidence for free radical generation. The Journal of Thoracic and Cardiovascular Surgery 1986:91: 759-66.

105. Sandstrom $\mathrm{E}_{\mathrm{p}}$ Karlsson K. Kskinen LO, Rabow L, Stigbrand T, Äberg T. S-100 a biochernical marker for cerebral injury during cardiac surgery. Perfusion 1994; $9: 426$.

106. Savageau JA. Neuropsychological dysfunction following elective cardiac operation II. A six-month reassessment. The Journal of Thoracic and Cardiovascular Surgery 1982; 84: 595-600.

107. Savageau JA, Stanton B, Jenkins CD. Klein MD. Neuropsychological dysfunction following elective cardiac operation. I: Early assessment. The Journal of Thoracic and Cardiovaseular Surgery 1982; 84: 595-600.

108. Schell RM, Kern FH, Greeley WJ, et al. Cerebral bloodflow and metabolism during cardiopulmonary bypass. Anesthesia and Analgesia 1993; 76: 849-65.

109. Sellman M, Holm $\mathbb{L}$, Ivert T, Semb BKH. A randomized study of neuropsychological function in patients undergoing coronary bypass surgery. The Thoracic and Cardiovascular Surgeon 1993; 41: 349-54.

110. Semb BKH, Pedersen $T$, Hatteland $K$, et al. Doppler ultrasound estimation of bubble removal by various arteriall line filters during extracorporeal circulation. Scandinavian Journal of Thoracic and. Cardiowascular Surgery 1982; 16:231-40.

111. Shaw PJ, Bates D. Cartlidge EF, et al. Long-term intellectuall dysfunction following coronary artery 
bypass graft surgery: A six month follow-up stwdy. Quarterly Journal of Medicine 1987, 62:259-68.

112. Shaw PI, Bates D, Cartidge NEF, et al: Early intellectual dysfunction follwing coronary bypass surgery. Quarterly Jowmal of Medicine 1986, $225,59-68$.

113. Shaw PJ, Butes D, Carlidge NEF, et al Neurologic and neuropsychological morbidity tollowing major surgery. Comparison of coronary artery bypass and peripheral vascular surgery. Stroke 1987; 18 : 7007 .

114. Shaw PJ, Bates D, Cartlidge NEF, Heaviside D, Julian DG, Shaw DA. Early neurological complications of cononary artery bypass surgery. British Medical Journal 1985; 291: 1384-7.

115. Simpson I. Cerebral perfusion during cardiac surgery usingt cardiac bypass. In. Longmore DB, ed. Towards safer candiac suitgeny. Lancaster: MTP, 1981: 287-92.

116. Slogeff $\mathrm{S}$, Girgis $\mathrm{KZ}$, Keats A. Ettologic faetors in neruopsychiratric complications associated with cariopulmonary bypass. Anesthesila and Analgesia 1982; 61:903-11.

117. Simith PL. The cerebral complications of coronary antery bypass surgery. Annalls of the Royal College of Surgeons of England 1988; $70,212-6$.

118. Smith PLC Cerebral microembolism and neuropsychological outcome following coronary artery bypass surgery (CABS) with either a membrane or a bubble oxygenator. In Willner $A$, Rodewald $G$, ed. Impact of Cardiac Surgery on the Quality of Life. New York: Plenum, 1990:

119. Smitl PLC, Newman $\mathrm{S}$, Treasure $\mathrm{T}$, et al. Cerebral consequences of cardiopulmonary bypass. The Lancet 1986: 1: 823-4.

120. Smith RJ, Roberts NM, Rodgers RJ, Benmett $S$. Adverse cognitive effects of general anaesthesia in young and elderly patients. International Clinical Psychopharmacology 1986; 1: 253-9.

121. Sonnenblick EH, Downing SE. Afterload as a primary determinant of ventricular performance: American Journal of Physiology 1963: 204: 604-8.

122. Sotaniemi KA. Brain damage and neurological outcome after open-heart surgery. Journal of Neurology, Neurosurgery and Psychiatry 1980; 43: 127-35.

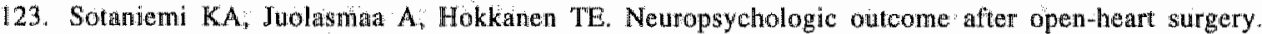
Archives of Neurology 1981; 38:2-8.

124. Sotaniemi KA, Mononen H, Hokkanen TE, Long-term cerebral outcome after open-heart surgery: A five-year neuropsychological follow-up study. Stroke 1986; 17: 410-7.

125. Stanley TE, Smith LR, White WD, et al . Effect of cerebral perfusion pressure during cardiopulnionary bypass on neuropsychiatric outcome following coronary artery bypass grafting. Anesthesiology 1990; 73 : A93.

126. Stern $Y$, Gurland $B_{*}$, Tatemichi $T$, Tang $M$, Wilder $D$, Mayeux $R$. Influence of education and occupation on the incidence of Alzheimer's disease. The Journal of the American Medical Association 1994: 271: 1004-10:

127. Strauss B, Paulsen G, Strenge H, Graetz S, Regensburger D, Speidel H. Preoperative and late Postoperative psychosocial state following cotonary artery bypass surgery. The Thoracie and Cardiovasculat Surgeon 1992; 40:59-64.

128. Stump DA, Tegeler CH, Newman SP, Wallenhaupt S, Roy RC. Older patients have more emboli during coronary artery bypass graft surgery. Anesthesiology 1992; 77: A.52.

129. Tardiff B. Newman M, Saunders A, et al. Apolipoprotein E. allelle frequency in patients with cognitive deficits following cariopulmonary bypass: Circulation 1994:90 (suppl 1): 201.

130. Tarhan S, Moffit EA. Anaesthesinand supportive care during and after cardiac surgery. The Annals of Thorac Surgery 1971:11:64-89.

131. Taylor KM. Cardiac surgery and the brain: An introduction. In: $\$$ mith $\mathbf{P}$, Taylor $\mathrm{K}$, ed Cardiac surgery and the brain. London: Hodder and Stoughton Publishers, 1993: 1-14.

132. Taylor KM, Bain WH, Morton JJ, et al. The role of angiotensin II in the development of peripheral vasoconstriction during open-heart surgery. Annals of Heart Jourial 1980; 100: 935-7.

133. Toner $\mathrm{I}_{\text {" Peden }} \mathrm{CJ}$, Hamid SK, Newman S, Taylor KM, Smith PL. Magnetic resonance imaging and netropsychological changes after coronary artery bypass graft surgery: Preliminary findings. Jourmal of Neurosurgical Anesthesiology 1994; 6(3): 1163-9.

134. Townes BD Bashein G. Hornbein TF el al. Neurobehavioral outcomes in cardiac operations. The Journal of Thoracic and Cardiovascular Surgery 1989; 98 : 774-82.

135. Treasure $T$, Stnith PLC, Newman $S$, et al. Impairment of cerebral function following cardiac and other major surgery. European Journal of Cardio-Thoracic Surgery 1989;3;216-21.

136. Vasko JS, Dearing JP. Techniques of cardiopulmonary perfusion. In: Norman JC, ed. Cardiac Surgery. 
New York: Appleton-Century-Crofts, 1972.

137. Venn GE. Patel $\mathbb{R L}$, Chambers DJ. Cardiopulmonary bypass: Perioperative edrebral blood flow and postoperative cognitive deficit. The Annals of Thoracic Surgery 1995: 59: 1326-30.

138. Venn J, Klinger $L_{s}$ Smith $P$, Harrison $M$, Newman $S P$, Treasure $T$. Neuropsychological sequelae of bypass twelve months after coronary artery surgery. Proceedings of the British Cardiac Society 1987: $564-565$.

139. Vingerhoets $G$, De Soete $G$, Jannes $C$. Relationship between emotional variables and cognitive tost performance before and after open-heart sugery. Clinical Neuropsychology 1995; 2: 198-202.

140. Watkins DM, Peterson MB, Kong DL, et al. Thromboxane and prostacyclin changes during cardiopulmonary bypass with and without pulsatile flow. The Journal of Thoracic and Cardiovascular Surgery 1982; 84: 250-6.

141. White FN. A comparatiwe physiological approach to hyothermia. The Journal of Thoracio Cardiovascular Surgery 1981; 82: 821-8.

142. Williams-Russo PG, Szatrowski TP, Mattis S, et al. Post-operative cognitive deterioration in cardiac ws. non-cardiac surgical patients. Perfusion 1994: 9:405-45.

143. Wolman RL, Kanchuger MS, Newman MF, Roach GW, Nussmeier NA. Adverse neurologic outcome following intracardiac versus extracardiac surgery. Perfusion 1994:9:406-7. 
त $\quad 3$

$\cdots$

$\therefore \quad \therefore$

$\therefore \quad$ 


\title{
The influence of age on postoperative cognitive recovery after coronary artery bypass graft surgery
}

\author{
Dijkstra JB, Houx PJ, Langemeijer JM*, Ackerstaf RGA**, and Jolles J
}

\begin{abstract}
There are indications that older people have a higher risk of cognitive dysfunctions after coronary artery bypass graft (CABG) surgery. This study investigates the possible effect of age on cognitive dysfunctions after CABG surgery. Twenty-one middle-aged (age $<61$ years) and 20 elderly (age $\geq 61$ years) patients were compared. A cognitive test battery was used on four occasions, two times before and two times after surgery. In addition, the patient group was compared to individually matched healthy controls at the first testing session. The restilts indicate that patients had an inferior memory performance before the operation and were slower on a reaction time task than the controls. Short-term cognitive impairments were found in the patients 10 days after the operation. The older patients had an impaired performance on a learning task compared to the younger patients. After 6 weeks, most patients were back at their preoperative performance level when group means were considered. However, when assessed on an individual basis, $40 \%$ of the patients still had an impaired performance on one or more tasks, irrespective of age. The degree of impairment was usually mild. The results do not support the notion that age plays an important role in susceptibility to postoperative cognitive dysfunction, although elderly patients need more time for recovery of their short-term learning ability.

The relevance of the present findings is that cognitive impairments were seen at a time when patients were judged fit to be discharged. Although quite healthy and relatively young patients were studied, the majority of subjects showed a netropsychological dysfunction. For this reason, patients should be warned that some change in mental function can be expected for several weeks to months after the operation. It could be that failure to give such a warning is a causal factor in the development of cognitive complaints and worries in the postoperative months.
\end{abstract}

* Department of Anesthesiology, St. Antonius Hospital, Nieuwegein

** Department of Neurophysiology, St. Antonius Hospital, Nieuwegein 


\section{INTRODUCTION}

Although major improvements have taken place in cardiopulmonary techniques, the literature on cardiac surgery continues to report postoperative cerebral dysfunction as a major problem in moden cardiac surgical practice. An operation which relieves coronary artery stenoses cannot be described as successiul when the patient sustains cerebral dysfunction afterwards. The two major mechanisms which are thought to contribute to these cerebral deficits are gaseous or solid particle embolisation and reduced cerebral blood flow due to hypotension [5]. The incidence of cerebral injury after coronary artery bypass graft (CABG) surgery varies between studies, and this variation may be caused by differences in methodology, psychometric instruments used, and the characteristics, including age, of the patient populations studied. Several studies have prospectively examined cognitive function both before and after CABG surgery, and have documented definite postoperative impaiment in some patients, especially the elderly $[8,15]$. In older patients atherosclerosis is generally more severe than it is in younger patients, and the reglonal cerebral blood flow is reduced due to changes in autoregulation of the system compared with younger patients. This may imply that the elderly are more at risk of embolisation and hypoperfusion and as a result to develop cognitive dysfunctions,

The importance of cognitive dysfunction after $\mathrm{CABG}$ surgery lies in the possible long term effects. Sotaniemi et al. [12] found that, even after the acute postoperative changes had disappeared, individuals with short-tern cognitive dysfunction were more likely to show dementia 5 years later. This prompts the hypothesis that perioperative cerebral damage, even when its clinical effects are reversible, involves some neuronal loss which may make an individual more vulnerable to age-dependent cell loss in the future. This is of importance in view of recent findings that operations under general anaesthesia can act as a risk factor for age-related cognilive decline. Houx et al. [6] found that general anaesthesiat is a possible predictor for an inferior performance on cognitive tests in subjects aged 60 and older. This could indicate that an effect of CABG surgery can be expected especially in patients older then 60 years.

The present study was designed to investigate postoperative cognitive dysfunction in relation to age in patients undergoing $\mathrm{CABG}$ surgery. The cognitive performance of middie-aged and elderly patients was compared pre- and postoperatively. A distinction was made between shortterm and long term cognitive effects in order to test the hypothesis that older subjects require a Ionger recovery period after CABG surgery, Short-term effects can last up to 2 weeks and long-term effects can last up to months or even years. The patients were also compared with a control group to see whether there was a difference in cognitive performance before the operation, as heart disease might be a factor which negatively influences brain functioning 131.

\section{MATERIALS AND METHODS}

\section{Subjects}

Forty-one male patients ( 41 to 78 years) who underwent elective CABG surgery in the St. Antonius Hospital in Nieuwegein (The Netherlands) consented to participate in the study. The study was approved by the Medical Ethics Committee, and informed consent was obtained from the patients. Patients with major psychiatric disease, disease of the CNS (recent meningitis or encephalitis, tumors, major degenerative diseases, and cardiovascular accident, and re-operations were excluded. The patients were assigned to two groups, middle-aged $(<61$ 
years, $N=21$ ) and old ( $\geq 61$ years, $N=20$ ). There were no differences in the level of education between the two groups. Level of education was measured on an 8-point scalle, ranging from primary education to higher vocational training and university [17]. Table 3.1 summarizes the patient characteristics.

In a subgroup of these patients the number of emboli was measured. The effect of these microembolic events (MEE) during surgery on cognitive function after surgery were analysed post-hoc. The results of this preliminary study are described in the appendix.

Table 3.1 Patient characteristios: For each variable mean $(S D)$ levels are displayed

\begin{tabular}{lrrrrr}
\hline Variable & Middle-aged $(N=21)$ & \multicolumn{1}{c}{ Eilderly $(N=20)$} \\
\hline & & & & \\
& & & & \\
age $(M \pm S D)$ & 115.7 & $(11.9)$ & 117.8 & $(15.0)$ \\
$I Q(M \pm S D)$ & 41.9 & $(74.4)$ & 87.4 & $(99.7)$ \\
duration of heart disease $(M \pm S D)$ months $)$ & 4.1 & $(1.3)$ & 4.1 & $(1.1)$ \\
number bypasses $(M \pm S D)$ & 4.0 & $(1.7)$ & 3.4 & $(2.0)$ \\
education $(M \pm S D)$ & & & & & \\
\hline
\end{tabular}

A control group of 41 healthy male vollunteers was drawn from a larger population who participated in a study on risk factors for cognitive decline in the elderly [7]. These control subjects were matched to the individual patients for age and level of education. Twenty-one middle-aged controls were used (mean age $=53.0$ years, $S D=6.5$ ) and 20 old controls (mean age $=68.6$ years, $S D=4.1)$. The level of education was $4.7(S D=1.3)$ and $4.4(S D=1.5)$ for the middle-aged and elderly subjects, respectively. Although the control group had a slightly higher education, this difference was not statistically significant (middle-aged: $t=-1.6, p=\mathrm{ns}$; elderiy: $t=-1.74, p=\mathrm{ns}$ ).

\section{Ancesthetic management}

All patients were premedicated with morphine and haloperidol, give intramuscularly. After arrival at the operating theatre an intravenous catheter and an radial artery catheter for invasive blood pressure monitoring were placed. The EEG leads already placed on the ward were connected to the EEG computer. Anaesthesia was then induced with diazepam $0.2 \mathrm{mg} / \mathrm{kg}$, fentanyl $10 \mathrm{mcg} / \mathrm{kg}$ and intubation was facilitated with pancuronium $0.1 \mathrm{mg} / \mathrm{kg}$. Following tracheal intubation, two central venous catheters were placed in the right internal jugular vein. One served as a central venous pressure line. Repeated doses of fentanyl and diazepam were given when thought appropriate. Blood pressure was regulated with sodium nitroprusside. The transcranial Doppler (TCD) probe was then placed on the right temporal bone and the signals from the right middle cerebral artery were scanned. Patients were heparinised with heparin 3 $\mathrm{mg} / \mathrm{kg}$. Extra-corporeal circulation was performed according to the alpha-stat principle at 2.4 $\mathrm{V} / \mathrm{min} / \mathrm{m} 2$ at normal temperature, using a membrane oxygenator. Mild hypothermia $\left(28^{\circ} \mathrm{C}\right)$ was used. Blood pressure during ECC was kept between 40 and $60 \mathrm{mmHg}$. 


\section{Measuremesits}

Visual Verbal Leaming Test (VVLT). This is a computerised, visual version of a test of secondary memory. In live consecutive trials, a list of 15 words has to be memorised and reproduced. The dependent variables are the total number of words recalled over the five trials (VVLTTOT), delayed recall (VVLTDEL) and recognition (VVLTREC) after 20 minutes, thus enabling measurement of memory storage and retrieval 161 .

Stroop Color Word Test (SCWT). The SCWT has often been used to test selective attention, mental speed, and interference susceptibility 161. The test involves three cards displaying forty stimuli each colour names (SCWT I), coloured patches (SCWTL), and colour names printed in incongruously coloured ink (SCWT III). The dependent variables are the time needed to read (SCWT D), or to name the colour of the patches (SCWT II) or printed ink (SCWT III).

Concept Shifting Test (CST). This test is derived from the Trail Making Test, which has long been used to measure the ease of shifting between concepts in ongoing behaviour [6]. It consists of fouf parts. On each test sheet, 16 small circles are grouped in a larger circle. In the first part, empty circles have to be crossed out as fast as possible (CSTO). In the other three parts the circles contain numbers, letters, or both (CSTC), appearing in a fixed random order. Subjects are requested to cross out the items in the right order. The dependent variables are the time needed for the CSTO and the CSTC.

Motor Choice Reaction Test (MCRT). This test is a computer test, in which reaction times are studied as a function of the complexity of the task requirements. Dependent variables are the movement time in a simple task condition (MCRTM) and the initiation time in comlex task condition (MCRTI) [6].

Mood assessment. Anxiety and depression were measured with the Spielberger State-Traite Anxiety Inventory 191 and the Zung Self Rating Scale for Depression [19], in order to assess whether cognitive function is negatively influenced by anxiety or depression.

\section{Procedure}

The cognitive test battery was administered on four occasions: 6 weeks (baseline) and 2 days preoperatively, and 10 days and 6 weeks postoperatively. On each occasion, a parallel version of the test battery was used to reduce learning effects. Demographic data, together with medical, surgical, and social histories, and medication used; were collected by means of questionnaires sent to the patients at home before they came to the hospital for the first assessment. Anxiety and depression were assessed on each occasion. The cognitive functioning of the historical controls was only assessed once and took place about 2 years before the present study [7]. These control subjects considered themselves healthy; a formal evaluation of mood was not pertiormed.

\section{Data analysis:}

The baseline performance of the patients and the performance of the matched controls on the cognitive tests were compared to see whether the patients performed systematically worse than the matched controls. A distinction was made between short-term and long-term cognitive effects. A short-term cognitive effect was defined as the change in performance from 2 days preoperatively to 10 days postoperatively, and a long-term cognitive effect as the change occurring from 2 days preoperatively to 6 weeks postoperatively. The first assessment was 
performed in order to reduce practice effects since these are most obvious from the first to the second assessment [4].

In addition to changes in the mean scores, it is important to consider individual changes as described by Shaw et al. [11]. A neuropsychological deficit was considered to be present when a patient's postoperative performance for the 10 main variables deteriorated by at least one standard deviation ( $S D$ of the patients on the second preoperative measurement) from his preoperative performance. The deterioration was considered mild when there was a decline in performance on one or two test variables and moderate-to-severe when there was a decline on three or more test variables.

Formal analysis with the Kolmogorov-Smirnov test for normality was done to determine the normality of the dlata distribution. Group differences on categorical demographic variables (employment, education, individual change) were analysed by using the Chi-square statistic. Continuous variables were tested by analysis of variance with repeated measurements (ANOVA), except for the comparison between the patients and controls on the first assessment. Although the control group had a slightly higher education, no differences in results were found when education was used as a covariate. Therefore the data for the analyses without education as covariate are reported. P-values lower than 0.05 were regarded as significant.

\section{RESULTS}

\section{Differences between patients and controls before the operation.}

In some aspects, the cognitive performance of the patient group was significantly worse than that of the control group (table 3.2). A two-way ANOVA (group $x$ age) showed significant group effects on immediate (VVLTTOT) and delayed recall (VVLTDEL) performance and for movement time (MCRTM). Significant age effects were found on the concept shifting (CSTC) and interference scores (SCWT III), in that the elderly subjects performed less well than the middle-aged subjects. There were no significant interactions between group and age.

\section{Short-term cognitive effects}

Group means for short-term test performance are summarised in table 3.3. With respect to learning performance, there was a significant decline in performance for recognition memory after the operation (VVLTREC) but not for immediate (VVLTTOT) and delayed recall (VVLTDEL). A similar main effect of the operation was found for all the other variables, except movement time (MCRTM). In addition, age effects were found for the concept shifting task (CSTO) and interference (SCWT III), in that the elderly subjects performed less well than the middle-aged subjects. Interestingly, there was an interaction effect for immediate recall (VVLTTOT), showing that the change in learning performance from the preoperative measurement to the first postoperative measurement was significantly greater in the elderly group than in the middle-aged group. No interaction effects were found on any of the other cognitive variables.

The results for the test performance of individual subjects are summarised in table 3.4 . Thirty-three of the 41 patients $(80 \%)$ had poorer scores on one or more tests 10 days after the operation. Of these 33 patients, 19 showed mild deterioration and 14 showed moderate-tosevere deterioration of cognitive function. Age did not have a significant effect on the extent of the individual deterioration, as determined by using a chi-square test. 


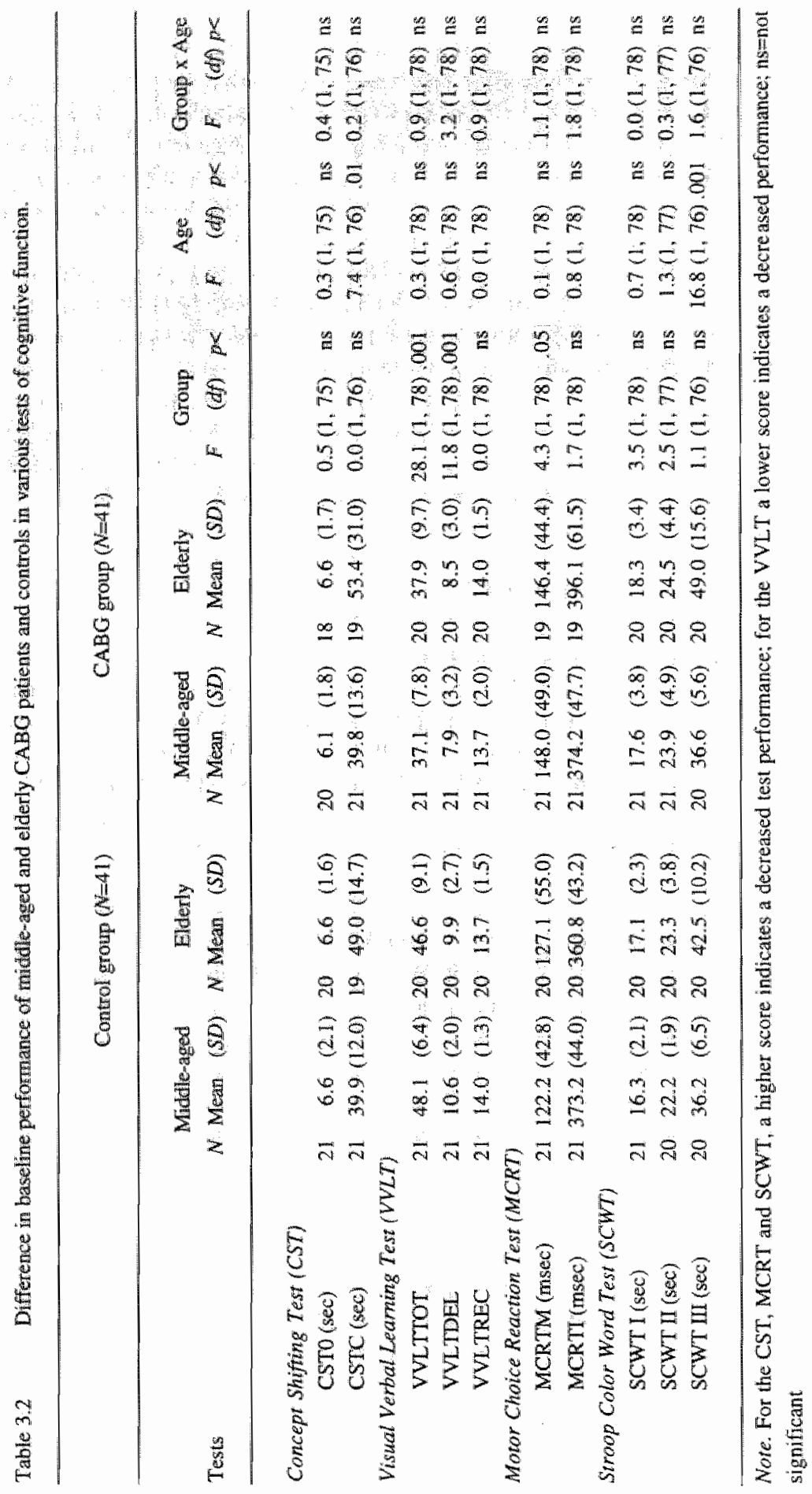




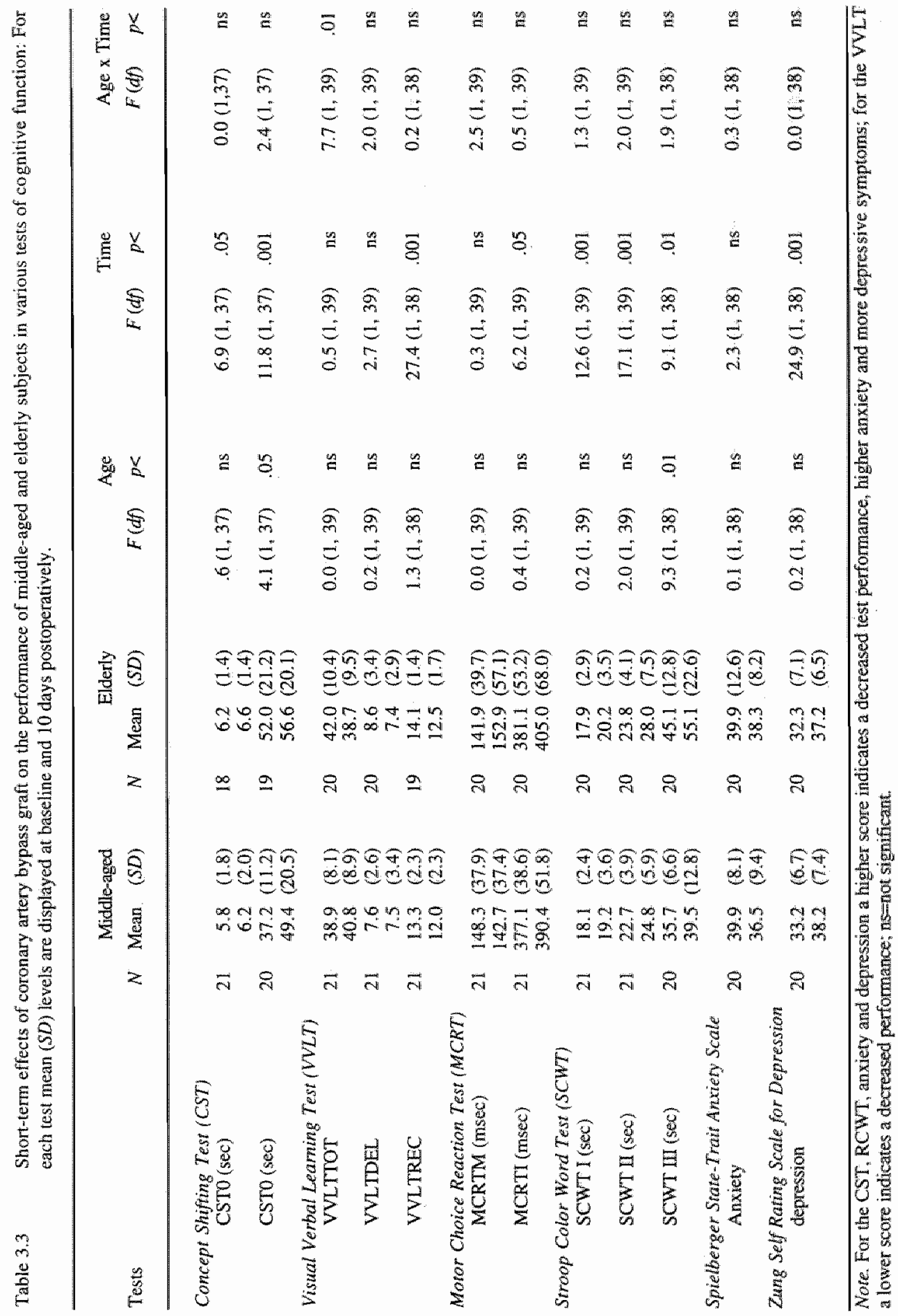




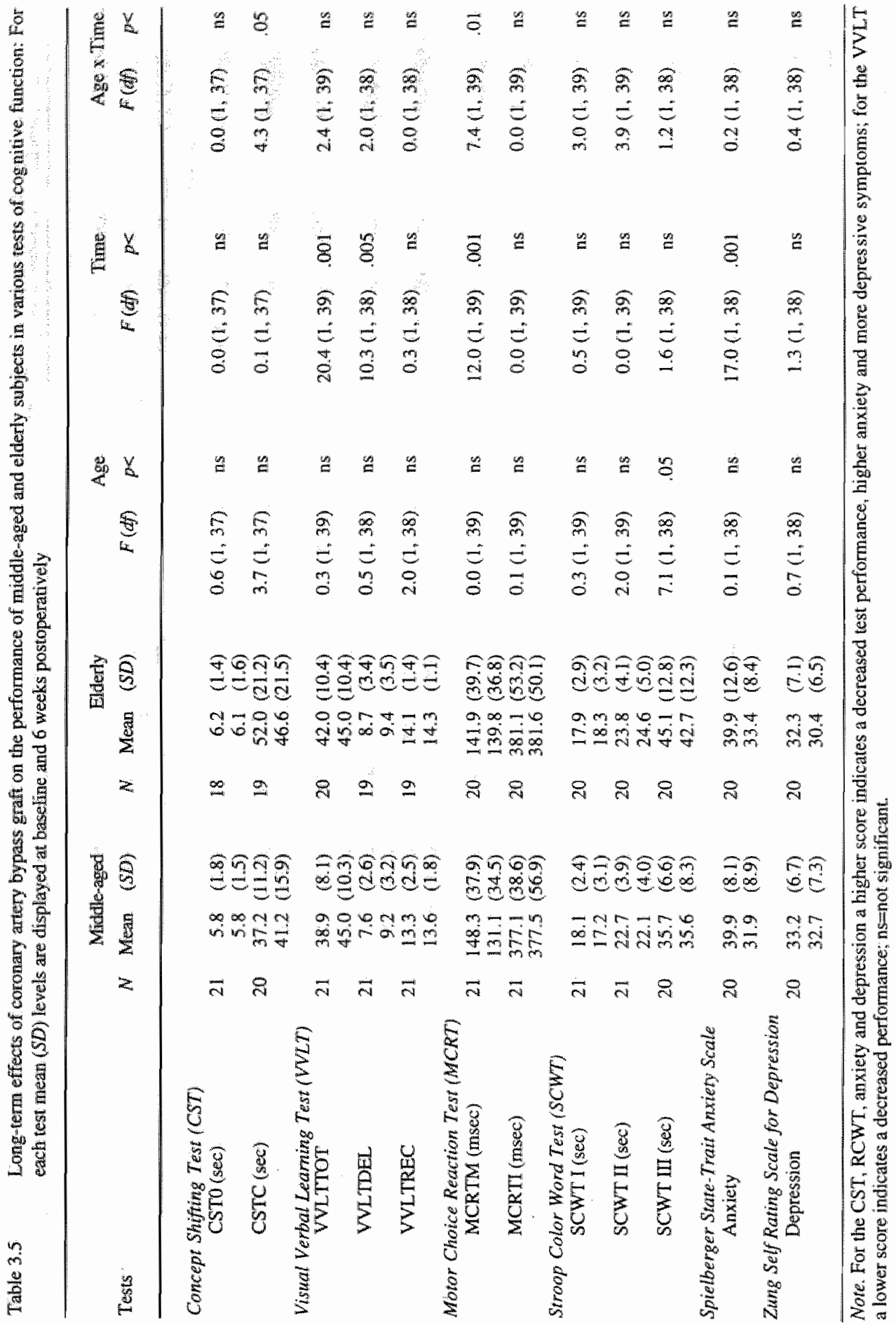




\section{Long-tern cognitive effects}

After 6 weeks most patients showed the same or even improved performance compared to their preoperative performance. As shown in table 3.5, when group means were considered, main long-term operation effects were found for immediate recall (VVLTTOT), delayed recall (VVLTDEL), and movement time (MCRTM): performance improved from 2 days preoperatively to 6 weeks postoperatively. A significant main effect of age was found only for the interference score (SCWT III): the elderly subjects were slower than the middle-aged subjects. Interaction effects were found for the shifting speed (CSTC): the performance of the older group improved more than that of the middle-aged group. Another significant interaction was found for the movement time (MCRTM), whereby the older group improved less than the middle-aged group.

Six weeks after the operation, 17 of the 41 patients (41\%) still had a poorer performance on one or more tests than before the operation. Of these patients, 16 showed mild deterioration and 1 showed moderate-to-severe deterioration of cognitive function. Again, age did not have a significant effect on the extent of the individual deterioration (table 3.4).

Table $3.4 \quad$ Neuropsychological dysfunction

\begin{tabular}{|c|c|c|c|c|c|c|}
\hline Severity of deterioration & $\begin{array}{l}\text { Short-term } \\
\text { Middle-aged } \\
\%(N)\end{array}$ & $\begin{array}{l}\text { Elderly } \\
\%(N)\end{array}$ & $\operatorname{cht}^{2}(p)$ & $\begin{array}{l}\text { Long-term } \\
\text { Middle-nged } \\
\%(N)\end{array}$ & $\begin{array}{l}\text { Ellderly } \\
\%(N)\end{array}$ & $\operatorname{cht}^{2}(p)$ \\
\hline$\therefore$ & \\
\hline No change or improvement & $24(5)$ & $15(3)$ & 2.1 (ns) & $52(11)$ & $65,(13)$ & $1.4(n s)$ \\
\hline Mild (on 1 or 2 tests) & $52(11)$ & $40(8)$ & & $43(9)$ & $35(7)$ & \\
\hline Moderate-to-severe $(>2$ tests) & $24(5)$ & $459)$ & & $5(1)$ & $0(0)$ & \\
\hline
\end{tabular}

Note. Individual neuropsychological dysfunction at 10 days (short-term) and 6 weeks (longterm) after operation "compared with neuropsychological performance 2 days before the operation for the middle-aged $(N=21)$ and the elderly patients $(N=20)$.

\section{Mood changes}

With respect to affect, more depressive complaints were reported 10 days after the operation than 2 days before the operation. By 6 weeks the scores had returned to the level measured 2 days before the operation. The anxiety score was lower 6 weeks after the operation than 2 days before the operation. No significant cornelations were found between the pre- and postoperative anxiety and depression scores and the pre-and postoperative results on the neuropsychological tests.

\section{DISCUSSION}

The results show that the patients who underwent CABG surgery thad an inferior learning performance before the operation and were slower on a reaction time task than individually matched controls. The older patients did not have a poorer performance than the younger patients. A clear-cut cognitive impairment was found 10 days after the operation, immediately before the patients were discharged from the hospital. These short-term postoperative cognitive 
defects were evident for the majority of the cognitive variables examined. The elderly patients showed an impaired performance on a leaming task compared to the younger patients, who showed an improvement In contrast to these short-term effects, no long-term postoperative cognilive defects were found, at least when group means were considered: all scores had rewerted to preoperative levels or were even improved. When short-term and long-term cognitive effects were analysed on an individual basis, $80 \%$ of the patients appeared to be impaired on one or more variables after 10 days, and this proportion was still $40 \%$ after 6 weeks. The degree of imparment was mostly mild. After 10 days $34 \%$ of the patients showed a moderate-to-severe deterioration and only $2 \%$ of the patients had a moderate-to-severe imparment 6 weeks after the operation.

Thus, the present clata provide evidence that older subjects are somewhat more vulnerable than younger subjects to the effects of CABG surgery, as the older group had a greater impairment of immediate memory 10 days after the operation when compared with the younger group. This difference disappeared 6 weeks after the operation. Thus elderly patients need more time to recover after $\mathrm{CABG}$ surgery, but 6 weeks after the operation no differences were found anymore between the younger patients and the elderly patients. The same findings were reported by Stump et al. [14]. When group means were compared, cognitive dysfunctions were found in the short term but not in the long term, whereas individual analysis showed that $40 \%$ of the patients still had a decreased performance on at least one test 6 weeks after the operation. These findings are similar to those of Shaw et al. [11], After 7 days they found a 79\% incidence of neuropsychological dysfunction. compared to $80 \%$ in the present study. After 7 months they found that $57 \%$ of the patients still showed dysfunction, compared to $41 \%$ in our study after 6 weeks. Ellis et al. [3] reported a similar incidence $(75 \%)$ of early postoperative nearopsychological dysfunction in 30 patients undergoing $C A B G$ surgery. Our results and those reported by others can be taken to indicate that there is individual variability in the vulnerability to CABG surgery and that this variability is obscured when only group means are taken into consideration. Although the deterioration found after a couple of weeks is in general mild, it is important to know which individuals are performing less well. These findings are generally in line with earlier research and underline the relevance of analysing changes on an individual, rather than group, basis $[15,16]$. In our study age did not seem to modify individual deterioration. Future research must be directed at investigating the sources of wariability in more detail. "Age', "somatic condition", and "psychosociall factors" may be relevant in this respect.

As has already been mentioned, the individual deterioration found after 6 weeks was mild. Individual changes in normal healthy controls over the same time period should be determined to svaluate the clinical relevance of these findings.

Although the patients had a higher score on the depression scale 10 days after the operation and a higher anxiety score immediately before the operation, it is unlikely that these emotional variables influenced their cognitive performance. No correlations were found between the preoperative and postoperative anxiety and depression scores and the preoperative and postoperative results on the neuropsychological tests. The same results were reported in a study of Vingerhoets et al. [18]. who found that an elevated anxiety and depression reported by patients undergoing open heart surgery did not affect cognitive performance.

In contrast to other studies $[8,15]$, in this study age did not play an important role in susceptibility to postoperative cognitive dysfunction. This may be due to the relatively "healthy" and "young' elderly in this study. The strict exclusion criteria prevented inclusion of elderly with a high risk of cognitive dysfunction due to organic causes. Aging itself is probably not responsible for the cognitive dysfunction after $\mathrm{CABG}$ surgery but is instead an index of the 
probability of many disease states. Increased operative risk, if present, is atributable to utem iffable disease, not merely to the aging process. Our elderly subjects had a mean age of 67 years. It has been reported that patients in the 6th and 7th decade of life are most vulnerable to cognitive deficits after $\mathrm{CABG}$ [1]. If more patients in this age group had been included, whit probably more severe arteriosclerosis and concomitant diseases, perhaps the findings would have been more significant. It is also possible that our patients are not representative of thes patient population typically undergoing $C A B G$ surgery. The selection of quite healthy and relatively young patients who are scheduled for elective surgery raises questions about the generalisation of findings. In addition, the small sample size limits the power to detect differences between age groups. This alone could account for the absence of an age effect in this study.

Patients had an inferior neuropsychological performance compared to that of the matched control subjects. The difference between the controls and the patients with respect to education was not statistically significant, and when education was added as covariate the results were not different. It is thus unlikely that the slightly higher education of the control group was responsible for the inferior performance of the patients at baseline. Another explanation is that the patients were suffering from life-threatening disease, in need of surgery and a stay in hospital. They were probably more anxious and worried than normal healthy controls, which could easily affect cognitive performance even before surgery. Coronary artery disease may be a marker for diffuse atherosclerosis. These patients are more likely than healthy controls to have significant stenosis in their cerebral vascular circulation. Thus heart disease as such can be a risk factor or vulnerability factor for cognitive dysfunction. These findings are in line with those reported by others [1, 13].

In the present study, learning and movement times improved 6 weeks after the operation compared with the preoperative scores. It is possible that these improvements are dre to a learning effect. Although four parallel versions and two preoperative measurements were used to minimize learning effects, subjects could still be familiar with the tests and for this reason attain higher scores. Thus a postoperative deterioration in test performance could be obscured by the fact that performance increased from test session to test session. This phenomenon could be the reason why there is sometimes no objective perfomance deficit after an operation even though a patient has cognitive complaints [10]. This improvement might also be explained by the fact that patients are no longer in hospital and experience less stress, because both the middle-aged and the elderly subjects had a significantly lower score on the anxiety scale compared to their score 2 days before the operation. Although there was no correlation between anxiety and test performance, the experience of less stress can be an explanation for the improvement on these tests. This hypothesis can be tested by assessing the performance of a comparison group tested on the same occasions with the same tests. A postoperative performance deficit could then be determined by comparing the change in performance for the patient group and the control group.

The relevance of the present findings is that very clear-cut impairments of memory and of simple and complex speed parameters were seen at a time when the patients were judged fit to be discharged. Although quite healthy and relatively young patients undergoing elective surgery wếre studied, the majority of subjects showed a neuropsychological dysfunction, and for this reason patients should be warned that some impairment of memory, concentration, and reaction time can be expected for several weeks to months after the operation. It could be that failure to give such a warning is a causal factor in the development of cognitive complaints and worries in the postoperative months. Bed rest, sleep deprivation, sedation, and general illness have all 
been thought of as possible causes of postoperative fatigue and imparment in memory and psychomotor skills. These factors could affect patients differently and as such explain why the postoperative period can have a different course in different patients.

\section{REFERENCES}

1. Benedict $\mathbb{R H B}$ Cognitive function after open-heart surgery: Are postoperative neuropsychological deficits caused by cardiopulmonary bypass? Neuropsychology Review 1994; 4: 22.3-55.

2. Chandarane PC, Cooper AJ, Goldbach MM, Coles JC, Vesely MA. Perceptual and cognitive deficit following coronary artery bypas surgery. Stress Medicine 1988; 4: 163-71.

3. Ellis $\mathrm{RJ}$, Wisniewski $\mathrm{A}_{\text {; }}$ Potts $\mathrm{R}_{\text {, }}$ et al. Reduction of flow rate and arterial pressure at moderate hypothermia does vot result in cerebral dysfunction. Thoracic and Cardiovascular Surgeon 1980; 79: 173. 80 .

4. Hijman $R$, Jolles $J$, Verhoeven WMA, Van Ree JM, Elderson A, De Wied D. Desglycinamidle-ARG8vasopressin in five trials with memory-disturbed patients. Human Psychopharnacology 1992; 7: 7-23.

5. Hornick P, Smith PL, Taylor KM. Cerebral complications after coronary bypass grafting. Current Opinion in Cardiology 1994, 9: 670.9.

6. Houx PJ, Jolles J. Vulnerability factors for age-related cognitive decline. In: Isaacson $\mathbb{R L}$, Jensen KF, ed. The Vulnerable Brain and Environmental Risk. New York: Plenum Press, 1994: 25-41.

7. Houx PJ, Vreeling FW, Jolles J. Rigorous health sereening reduces age effect on memory seanning task. Brain and Cognition 1991; 15: 246.60.

8. Nussmeier NA, Fish KJ. Neuropsychological dysfunction after cardiopulmonary bypass: A comparison of two institutions. Journal of Cardiothoracic Vascular Anesthesia 1991; 5: 584-8.

9. Ploeg HM van der, Defares P, Spielberger CD. Handleiding bij de Zelfbeoordelingswragenlijst ZBV. Lisse: Swets \& Zweitlinger 1980.

10. Sanders LD. Recovery of psychological function after anesthesia. Internationall Anesthesiology Clinics 1991; 29: 105-15.

11. Shaw PJ, Bates $\mathrm{D}$, Cartlidge $\mathrm{EF}$, et al. Long-term intellectual dysfunction following coronary artery bypass graft surgery: A six month follow-up study. Quarterly Journal of Medicine 1987; 62: 259-68.

12. Sotaniemi KA, Mononen H, Hokkanen TE. Long-term cerebral outcome after open-heart surgery: A fiveyear neuropsychological follow-up study. Stroke 1986; 17:410-7.

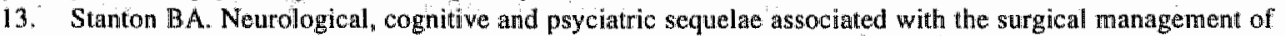

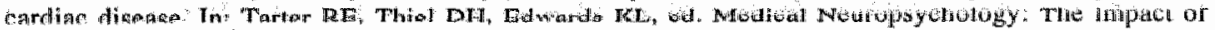
disease on behavior. New York: 1988: 27-70.

14. Stump DA, Newman SP, Coker LH, Hibawi HR, Rogers AT. Age is a risk factor for acute but not persistent neuropsychological deficits after cardiac surgery [Abstract]. Anesthesiology 1994;81: A59.

15. Townes BD. Neurobelavioral outcomes in cardiac operations. Journal of Thoracic Cardiovascular Surgery 1989: 98: 774-82.

16. Treasure $T$, Smith PLC, Newman S, et al. Impairment of cerebral function following cardiac and other major surgery. European Journal of Cardio-thoracic Surgery $1989 ; 3: 216-21$.

17. Verlage F. Intelligentie en leeftijd (Intelligence and Age). [doctoral dissertaion]. Assen, The Netherlands: 1964.

18. Vingerhoets $G$, De Soete $G$, Jannes $C$. Relationship between emotional variables and cogntive test performance before and after open-heart sugery. Clinical Neuropsychology 1995; 2: 198-202.

19. Zung WWK, Durham NC. A self-rating depression scale. Archives of General Psychiatry 1965; 12:63-70. 


\title{
How to assess individual cognitive change after an operation
}

\author{
Jeanette B. Dijkstra, Jos H.H.J. Prickaerts, and Jellemer Jolles
}

\begin{abstract}
Neuropsychological tests can be used to assess changes in cognitive function after a medical or psychological intervention. Besides comparing changes in group means it is important to consider individual changes. Methodological issues involved in the estimation of individual cognitive change are discussed in this chapter. Three different approaches to estimate individual cognitive changes after coronary artery bypass (CABG) surgery were compared in 30 patients. As a control, 30 normal healthy subjects were studied in the same way. The results show that the use of a control group is important for estimating individual change. Instead of studying change in performance in separate tests, it appears to be more reliable to study the change in a compound score for these tests. With this compound score, both improvement and deterioration within one patient and the inter-patient performance variability are taken into consideration. If no control group is available, a change of 1 or more standard deviation in at least $30 \%$ of the tests should be used as a criterion of cognitive impairment. The present results may be applicable to future intervention studies.
\end{abstract}




\section{INTRODUCTION}

Neuropsychological tests can be used to assess and evaluate changes in cognitive functioning over time. An important application of neuropsychological tests in this respect is the evaluation of change after an intervention, be it a medical (e.g., drug treatment, surgery) or psychological intervention (e.g., neuropsychological rehabilitation). However, there are methodological concerns with respect to the use of these tests for this purpose.

One way to look at changes is to test before and after the interwention and to determine whether the mean score on a test changes. It is possible that the mean test score of a group does not change after the intervention, whereas individual scores decline or improve substantially. As a result, no changes in performance are found after the intervention for the group as a whole, thus obscuring the fact that sometimes a large number of- individuals do respond to the intervention. For instance, if approximately $20 \%$ of a group of patients show some deterioration after major surgery, and approximately $60 \%$ show some improvement and the remaining $20 \%$ show no change, then the overall change will be towards some improvement 19]. Most studies of cognitive change after coronary artery bypass graft (CABG) surgery have demonstrated an overall improvement when group means are studied [e.g., 5], but there is little information about individuals with deficits. In order to identify individuals who are performing at a lower or higher level than before the intervention, a different type of analysis is required. The most obvious way to overcome this difficulty is to exarnine the change in individual performance before and after the intervention, i.e an experimental design in which each individual is his or her own control. This method, however, is not without its problems.

A major problem is to determine exactly what amount of change has to be considered as reflecting a deterioration in a particular test. Blumemthal et al. [1] recently reported that a variety of definitions of decline are used in studies looking at individual cognitive impairment after cardiac surgery. He compared three different ways to estimate cognitive decline: decline of one level in global impairment rating; decline of 1 standard deviation (SD) on $20 \%$ of tests; and $20 \%$ drop on $20 \%$ of tests. When these three methods were compared, not much agreement between the methods was found as to which patients showed a decline in performance and which did not. In a study into the effect of heart surgery on cognitive performance, deterioration was defined as a decrease in performance greater than $\mathbb{S} S D$ of the preoperative group performance in a test (see chapter 3 ). Additionally, mild individual deterioration was defined as a decline in one or two tests and a moderate-to-severe individual deterioration as a decline in three or more tests. This way of studying individual change is consistent with that of other studies [e.8, 8, 10, 11. 131. However, several methodological problems may occur when these definitions for mild and modersite-to-severe deterioration are used.

Firstly, these definitions have never been used in a normal healthy control group to see whether a proportion of these people also shows changes in performance during repeated testing. It is possible that the performance of normal healthy individuals changes more than I $S D$ over time. Due to the lack of a control group, one never knows what the 'normal' variance of change in individual performance is. "The variance of change of normal healthy controls reflects fluctuation over time and not a real change because no intervention has taken place. The change in performance that patients show besides this "normal' change can be interpreted as an effect of the intervention. Thus, it is important to use these definitions for deterioration in controls too. In our previous study (see chapter 3), the $S D$ of the patient group was much larger than the $S D$ of the control group. So, it is also important to consider which $S D$ value of the preoperative group performance should be used to estimate change. One could use the $S D$ value 
of the patients for the patients and the $S D$ value of the controls for the controls or the $S D$ value of the total group or the $S D$ value of the controls for comparison of cognitive change. Up till now, this potentially relevant issue has not been investigated.

Another issue pertains to the question in how many tests must the patient have an abnormal score after the intervention in order to be rated as impaired or improved? Several studies have used a battery of eight to ten tests. Can the patient's performance be considered as impaired after the intervention when there is a drop of $1 S D$ on one test, two tests, or three tests? The usual decision has been that an impaired performance in at least two tests is enough to classify the patient as impaired [9]. Typically, no rationale is offered as to why two tests were chosen rather than, for example, one or three tests.

A third methodological issue -in studies evaluating the effect of surgery-is that most studies did not take improvement into consideration. The same definition used for deterioration can also be used for improvement. It is not unlikely that some patients show an improvement in performance after an intervention such as surgery. Another possibility is that patients show a decline in some tests and an improvement in others. When decline and improvement are both taken into consideration, the conclusion could be that there was no overall change. By making one standardised (compound) score for the different cognitive tests, it is possible to estimate change in a more general way. This procedure is often used in neuropsychological assessment for diagnostic purposes, e.g., in the estimation of an IQ score with the Wechsler Adult Intelligence Scale [6] or level of cognitive impairment with the Halstead Reitan Impairment Index [6]. With this method information for each separate task and function is لost but an advantage is that this measure is less vulnerable to fluctuations in the separate tests.

In the fourth place, there seems to be a considerable variability between patients in that they do not show changes in performance on the same tests [2]. If one patient shows a decline in a memory test and another patient shows a decline in a simple reaction time test, can this be interpreted as the same amount of deterioration? The only conclusion that can be drawn is that a proportion of patients show a deterioration on different tests. By using a compound score this problem can also be solved.

Fifth and finally, the choice of $1 S D$ seems quite arbitrary. Perhaps it is better to take a $S D$ value that yields an optimal discrimination in performance between patients and controls, presuming that the intervention does have an effect on cognitive functioning.

The present paper describes several approaches to estimate cognitive change in individual patients and controls and compares the different approaches introduced above. The purpose of this study was to find the most reliable approach to estimate individual cognitive change from one measurement to another. For this study, the data of 30 patients who underwent coronary artery bypass surgery (CABG) surgery and 30 normal healthy control subjects, matched for age and education, were used. The relevance of the study lies in the possible application of our findings to treatment studies (drugs, neuropsychological rehabilitation, psychotherapy) and studies in which non-specific change due to the passage of time is tested in patients, elderly people or children.

\section{MATERIALS AND METHODS}

\section{Subjects}

Thirty male patients (55 to 78 years) who underwent elective CABG in the St. Antonius Hospital in Nieuwegein (The Netherlands) participated in the study. The study was approved 
by the Medical Ethics Committee and informed consent was obtained. Excluded were patients with major psychiatric disease, disease of the central nervous system (recent meningitis or encephalitis, rumours, major degeneratiwe diseases and cerebrovascular incidents), re-operations; and an $1 \mathrm{Q}$ score below 90.

A control group of thisty volunteers ( 57 to 75 years) was recruited by an advertisement in a local newspaper ( 17 male and 19 female). These subjects were drawn from a larger sample of healthy subjects who could be matched individually to the CABG patients. Control subjects were matched with the patients for age and level of education (measured with the scoring system proposed by Verhage, 1964 [14], Table 4.1 summarizes the demographic details of the patients and the controls.

Table 4.1 Demographic details: For each variable mean (SD) levels are displayed.

\begin{tabular}{llll}
\hline Variable & Control group (30) & Patient group (30) & T-value (p) \\
& & & \\
Sex (malefremale) & $17 / 13$ & $30 / 0$ & $22(\mathrm{~ns})$ \\
Age $(M \pm S D)$ & $64.4(4.9)$ & $64.1(5.7)$ & $.52(\mathrm{~ns})$ \\
Education $(M \pm S D)$ & $3.8(2.0)$ & $3.6(2.0)$ & \\
\hline
\end{tabular}

\section{Procedure}

A cognitive test battery (see below) was used on four occasions: 6 weeks (measurement 1 ) and 2 days preoperatively (measurement 2), and 10 days (measurement 3 ) and 6 weeks postoperatively (measurement 4). On each occasion, a paralle] wersion of the test battery was used to reduce learning effects. The control group was assessed with the same time intervals between the four measurements. The first mensurement was assessed in order to reduce practice effects because these are most obvious from the first to the second measurement [3]. Hence, data from the first measurement were not used in the final analysis. To compare the different approaches for the assessment of individual change, the change in performance between the second and the third measurement (short-term change) was studied. Finally, changes in performance between the second and the fourth measurement (long-term change) were evaluated.

\section{Measurements}

The following tests were used: 1) The Concept Shifting Test is derived from the Trail Making Test, which has long been used to measure the ease of shifting between concepts in ongoing behaviour [4]. It consists of four parts. On each test sheet, 16 small circles are grouped in a larger circle. In the first part empty circles have to be crossed out as fast as possible. In the other three parts the circles contain numbers, letters, or both, appearing in a fixed random order. Subjects are requested to cross out the items in the correct order. "The dependent variables are the time needed for each part. 2) The Stroop Color Word test has often been used to test selective attention, mental speed, and interference susceptibility [4]. The test involves three cards displaying forty stimuli each: colour names (card D), coloured patches (card II), and colour 
names printed in incongrwously coloured ink (card III). The dependent warables are the time needed to read, or to name the colour of the patches or printing ink. 3) The Letter Digit Substitution Test (reading and writing) is a modification of the procedurally identical SymbolDigits-Modalities Test (SDMT; see Lezak [4,7]. It is used to measure the speed of processing of general information. The dependent variables were the number of letters written and read in 1 minute. 4) The Visual Verbal Learning Test is a computerised, visual version of a test of secondary memory. In three consecutive trials, at list of 15 words has to be memorised and reproduced [4]. The dependent variable is the total number of words remembered in the three trials.

\section{Assessment of individual changes}

Three different approaches to determine individual change in cognitive performance were compared with each other. For the first two approaches, three different $S D$ valwes were used to estimate change in performance, namely, the $S D$ values of the subgroups (patients or controls), the $S D$ valiue of the total group (patients and controls), and the $S D$ value of the control group.

\section{Approach 1: Individual changes on the separate tests}

Change was defined as a decrease or an increase in performance on a test by at least $1 . S D$ from the second to the third measurements. Changes for each test were calculated for the control group and the patient group and the groups were compared in the number or percentage, of individuals who showed a short-term change. Firstly, patients and controls were studied separately with this method. In this subgroup analysis, the SD of the patients on measurement two was used for the patients and the $S D$ of the controls on measurement two was used for the controls to estimate change. This approach has been used in other studies to estimate individwal change in patients [e.g., 8, 10, 11, 13] but has never been applied to study individual change in nornal healthy controls.

In the total group analysis, the $S D$ of the total group on the second measurement was used to estimate change in both patients and controls. This approach is based upon the assumption that both groups are initially drawn from one population of subjects who can be regarded as normal and healthy with respect to brain functioning before the operation. In the control group analysis the $S D$ of the control group on the second measurement was used to estimate change. With this approach, the variance occurring in the control group is considered as nomal variance. When patients or controls change more than this normal variance, they show a clecrease or increase in performance.

For all three sub-approaches, a change on one or two tests was defined as a mild change and a change on more than two tests as a moderate-to-severe (great) change, in agreement with earlier studies which used this criterion $[\mathrm{e}, \mathrm{g}, 8,10,11,13]$,

\section{Approach 2: Individual changes on the compound score}

The second approach consists of the use of compound scores. The use of compound scores is potentially superior to the use of a battery of individual scores because of the scatter in the performance on separate tests: an individual subject may improve on several test variables and deteriorate on others. The compound score takes this scatter into consideration. In the present study, a cognitive compound score was callculated as follows: $Z$ scores were calculated for each test variable for the second and third measurements. To compute this standardised score, the mean and the $S D$ of the total group on the second measurement for each test was used. For both 
measurements, the $Z$ scores of the ten test variables were added and divided by ten to calculate a compound score Next, the changes in this compound score were calculated. Again, change was defined as a decrease or increase in performance by at least $1 S D$ of the compound score on the second measurement and was used in the subgroup, total group, and control group comparisons as described above. Change was thus evaluated on all tests together and not in one particular test or cognitive function.

\section{Approach 3. Effect of changing SD value}

Finally, instead of defining decline and improwement as a change of more than $1 . S D$ in performance scores, it may be more reliable to use a $S D$ value that allows for the best distinction between patients and controls. The effect of changing the $S D$ value (values ranging from 1 to $0.4 S D$ ) of the compound score on measurement two, to determine the change in performance in the patients and the controls, was studied ad hoc. The proportion change in patients and controls was studied for the total group and the control group comparison.

\section{Statistics}

The Kolmogorov-Smirnov test was used to test whether data were normally distributed. Sex differences in test performance in the control group were analysed by using unpaired t-tests on the separate test scores and the compound score for measurement 2 and 3 separately, and on the change score for both measurements. The differences in change in performance between the patients and controls for the three approaches described above were analysed by using a Chisquare test.

\section{RESULTS}

No differences in test performance (on the separate test variables and compound score) were found between males and females in the control group, on both measurements and on the change in performance over both measurements. Hence, the total control group can be compared with the patient group.

\section{Approach 1: Individual changes on the separate tests}

In the subgroup comparison, about $50 \%$ of the subjects in both the patient and control groups showed a mild deterioration. A moderate-to-severe deterioration was only found in the patients $(27 \%)$. Thirty per cent of the patients and $47 \%$ of the controls showed a mild improvement. No moderate-to-great improvements were found. A group difference was found in deterioration (Chi-square: $p<.01$ ) but not in improvement (table $4.2 \mathrm{a}$ ).

In the total group comparison, a mild deterioration in both patients and controls, $40 \%$ and $23 \%$ respectively, was found. Only the patients showed a moderate-to-severe deterioration (37\%). A mild improvement was found in $27 \%$ of the patients and $23 \%$ of the controls. No moderate-to-great improvements were found. Again, a group difference in deterioration was found (Chi-square: $p<.001$ ) but not in improvement (table $4.2 \mathrm{~b}$ ).

When the control group comparison was used, $23 \%$ of the patients and $57 \%$ of the controls showed a mild deterioration. Fifty-seven per cent of the patients showed a moderate-to-severe deterioration compared with none in the control group. Mild improvements were found in the 
Table $4.2 \mathrm{a}$ Indiwidual change in the separate tests: subgroup comparison

\begin{tabular}{|c|c|c|c|}
\hline Change & $\begin{array}{l}\text { Parients } \\
N(\%)\end{array}$ & $\begin{array}{l}\text { Controls } \\
N(\%)\end{array}$ & $\mathrm{ch}^{2}$ \\
\hline \multicolumn{4}{|l|}{ Deterioration } \\
\hline No change or improvement & $7(23)$ & $13(43)$ & $9.9 *$ \\
\hline Mild deterioration & $15(50)$ & $17(57)$ & \\
\hline Moderate-to-severe deterioration & $8(27)$ & 0 & \\
\hline \multicolumn{4}{|l|}{ Improvement } \\
\hline No change or decline & $21(70)$ & $16(53)$ & 1.8 \\
\hline Mild improvement & $9(30)$ & $14(47)$ & \\
\hline Moderate-to-great improvenzent & 0 & 0 & \\
\hline
\end{tabular}

Table $4.2 \mathrm{~b}$ Individual changes in the separate rests: total group comparison

\begin{tabular}{|c|c|c|c|}
\hline Change & $\begin{array}{l}\text { Patients } \\
N(\%)\end{array}$ & $\begin{array}{l}\text { Controls } \\
N(\%)\end{array}$ & $\operatorname{chi}^{2}$ \\
\hline \multicolumn{4}{|l|}{ Deterioration } \\
\hline No change or improvement & $7(23.3 \%)$ & $23(76.7 \%)$ & $20.9^{*}$ \\
\hline Mild deterioration & $12(40 \%)$ & $7(23.3 \%)$ & \\
\hline Moderate-to-severe deterioration & $\| \Perp(36.7 \%)$ & 0 & \\
\hline \multicolumn{4}{|l|}{ Improvement: } \\
\hline No change or decline & $22(73.3 \%)$ & $23(76.7 \%)$ & 0.1 \\
\hline Mild improvement & $8(26.7 \%)$ & $7(23.3 \%)$ & \\
\hline Moderate-to-great improvement & 0 & 0 & \\
\hline
\end{tabular}

Note. $p<.001$

Table $4.2 \mathrm{C}$ Individual changes in the separate tests: control group comparison

\begin{tabular}{|c|c|c|c|}
\hline Change & $\begin{array}{l}\text { Patients } \\
N(\%)\end{array}$ & $\begin{array}{l}\text { Controls } \\
N(\%)\end{array}$ & $\operatorname{ch}^{2}$ \\
\hline \multicolumn{4}{|l|}{ Deterionation } \\
\hline No change or improvement & $6(20)$ & $13(43)$ & $23.8 *$ \\
\hline Mild deterionation & $7(23)$ & $17(57)$ & \\
\hline Moderate deterioration & $17(57)$ & 0 & \\
\hline \multicolumn{4}{|l|}{ Improwement } \\
\hline No change or decline & $17(57)$ & $16(53)$ & 1.2 \\
\hline Milld improwement & $12(40)$ & $14(47)$ & \\
\hline Moderate improvement & $1(3)$ & 0 & \\
\hline
\end{tabular}

Note. * $p<001$ 
patients and the controls, $40 \%$ and $47 \%$ respectively. One parient showed a moderate-to-great improvement (3\%). With this approach a group difference was found for deterioration (chisquare: $p<.001$ ) but not for improvement (table $4.2 \mathrm{c}$ ).

Based on these findings, it was decided to re-define change. A decrease or increase on one or two tests was defined as no deterioration or improvement because this definition showed no plain difference between patients and controls. Thus, two categories for deterioration and improvement were left, i.e. "no change or deteriorated" and "no change or improved'. The results concerning deterioration are summarised in table $4.2 \mathrm{~d}$.

Table $4.2 d \quad$ Deterioration in the separate tests

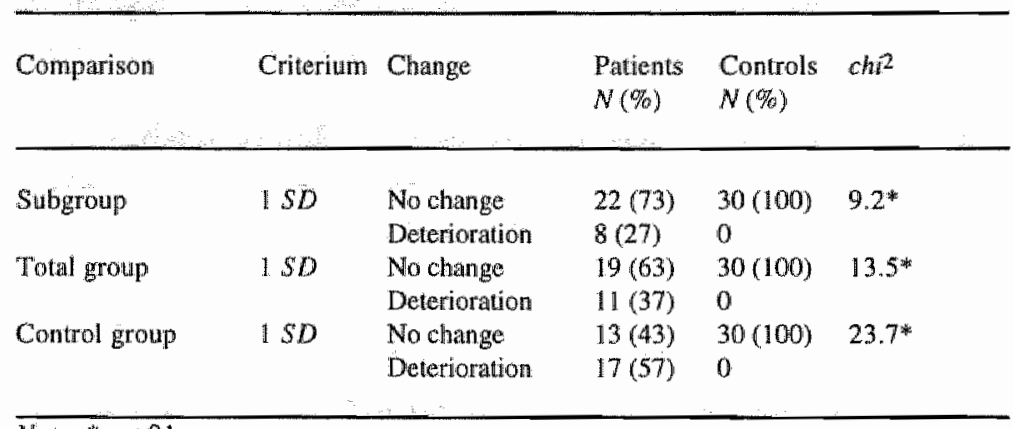

Note $p<01$

In conclusion, in the subgroup comparison, $27 \%$ of the patients showed a deterioration compared with none in the control group. In the total group comparison, this was $37 \%$ compared with none in the control group. When the control group comparison was used, $57 \%$ of the patients showed a deterioration and none in the control group. In the subgroup comparison, the total group comparison, and the control group comparison a group effect was found for deterioration.

\section{Approach 2: Indvidwal changes on the compound score}

The results for deterioration on the compound score are summarised in table 4.3. Two categories were defined in view of the results found with approach $\perp$ (above). Again "change in performance was compared with the $S D$ for the subgroups, for the total group, and for the control group.

With the subgroup, tolal group, and control group comparisons, $13 \%, 27 \%$ and $33 \%$ of the patients, respectively, showed a deterioration and none of the controls. Group effects were found in both the subgroup comparison, the total group comparison, and the control group comparison. In none of the groups was an improvement found.

\section{Approach 3: Effect of changing the SD value}

Changing the $S D$ value from 1 to 0.4 shows that the smaller the $S D$ the greater the decline in performance in both patients and controls. A SD value of 0.6 allowed the best distinction between patients and controls in the total group comparison. In the control group comparison, the optimal discrimination was found with a $S D$ value of 0.8 . Results are summarised in table 4.4 . 
Table 43 Deterioration on the compound score

\begin{tabular}{|c|c|c|c|c|c|}
\hline Comparison & Criterium & Change & $\begin{array}{l}\text { Patients } \\
N(\%)\end{array}$ & $\begin{array}{l}\text { Controls } \\
N(\%)\end{array}$ & $d t^{2}$ \\
\hline Subgroup & $1 S D$ & $\begin{array}{l}\text { Na change } \\
\text { Deterioration }\end{array}$ & $\begin{array}{l}26(87) \\
4(13)\end{array}$ & $\begin{array}{l}30(100) \\
0\end{array}$ & $4.3 *$ \\
\hline Total group & $1 S D$ & $\begin{array}{l}\text { Nachange } \\
\text { Deterioration }\end{array}$ & $\begin{array}{l}22(73) \\
8(27)\end{array}$ & $\begin{array}{l}30(100) \\
0\end{array}$ & $9.2^{*}$ \\
\hline Control group & $1 S D$ & $\begin{array}{l}\text { No change } \\
\text { Deterioration }\end{array}$ & $\begin{array}{l}17(57) \\
13(33)\end{array}$ & $\begin{array}{l}30(100) \\
0\end{array}$ & $16.66^{2}$ \\
\hline
\end{tabular}

Note. * $*<.05 ; * 0<01$

Table 4.4 Deterioration on compound score: Effect of SD

\begin{tabular}{|c|c|c|c|c|c|c|}
\hline \multirow{2}{*}{$\begin{array}{l}\text { Criteria } \\
\text { Change }\end{array}$} & \multicolumn{3}{|c|}{ Total group comparison } & \multicolumn{3}{|c|}{ Control group comparison } \\
\hline & $\begin{array}{l}\text { Patients } \\
N(\%)\end{array}$ & $\begin{array}{l}\text { Controls } \\
N(\%)\end{array}$ & chit & $\begin{array}{l}\text { Patients } \\
N(\%)\end{array}$ & $\begin{array}{l}\text { Controls } \\
N(\%)\end{array}$ & $\operatorname{ch} i^{2}$ \\
\hline \multicolumn{7}{|l|}{$>0.4 S D$} \\
\hline No change & $9(70)$ & $27(90)$ & $22.5 *$ & $8(27)$ & $25(83)$ & $19.5 *$ \\
\hline Deterioration & $21(30)$ & $3(10)$ & & $22(73)$ & $5(17)$ & \\
\hline$>0.5 S D$ & & & & & & \\
\hline No change & $11(37)$ & $29(97)$ & $24.3^{*}$ & $9(30)$ & $26(87)$ & $19.8 *$ \\
\hline Deterionation & $19(63)$ & $1(3)$ & & $21(70)$ & $4(13)$ & \\
\hline \multicolumn{7}{|l|}{$>0.6 S D$} \\
\hline No change & $16(53)$ & $30(100)$ & $18.3^{*}$ & $9(30)$ & $27(90)$ & $22.5 *$ \\
\hline Deterioration & $14(47)$ & 0 & & $21(70)$ & $3(10)$ & \\
\hline \multicolumn{7}{|l|}{$>0.7 \mathrm{SD}$} \\
\hline No change & $20(67)$ & $30(100)$ & $12.0^{*}$ & $11(37)$ & $29(97)$ & $24.3^{*}$ \\
\hline Deterioration & $10(33)$ & 0 & & $19(63)$ & $13)$ & \\
\hline \multicolumn{7}{|l|}{$>0.8 S D$} \\
\hline No change & $20(67)$ & $30(100)$ & $12.0 \%$ & $11(37)$ & $30(100)$ & 27.8 \\
\hline Deterioration & $10(33)$ & 0 & & $19(63)$ & 0 & \\
\hline \multicolumn{7}{|l|}{$>0.9 S D$} \\
\hline No charuge & $21(70)$ & $30(100)$ & $10.6^{2}$ & $6(53)$ & $30(100)$ & $18.3^{*}$ \\
\hline Deterioration & $9(30)$ & 0 & & $14(47)$ & 0 & \\
\hline \multicolumn{7}{|l|}{$>1.0 S D$} \\
\hline No change & $22(73)$ & $30(100)$ & $9.2 *$ & $7(57 \%)$ & $30(100)$ & $16.6^{*}$ \\
\hline Deterioration & $8(27)$ & 0 & & $13(43)$ & 0 & \\
\hline
\end{tabular}

Note. $p<01$

\section{Individual changes in the long term}

When long-term individual changes were studied in the separate tests with the three different approaches, no differences in deterioration or improvement were found between the patients and controls. The same results were found when a compound score was used. When $0.6 S D$ was used in the total group comparison for the long term, no differences were found between 
patients and controls, and no difference was found between the two groups when 0.8 SD was used in the control group companison.

\section{DISCUSSION}

Three different approaches to estimate individual change were compared. Firstly, we studied the change on the separate test variables. After redefining change as a decrease or increase on three or more variables rather than an increase or decrease in two test variables, differences between the patients and the controls were found for deterioration but not for improvement. Secondly, a compound score was calculated. Group differences in deterioration were found but not in improvement. Thirdly, changing the $S D$ value from 1 to 0.4 showed that for the total group comparison the optimal discrimination between the two groups was found with a $S D$ value of 0.6 and for the control group comparison with a $S D$ value of 0.8 . Several considerations are of importance when deciding which approach is the most reliable one and whether one should use the subgroup, total group or control group comparisons.

First of all, the data show that for the separate tests (and functions), a decrease or increase of at least $1 S D$ on three tests or more (out of ten) was indicative of a real change because a change on one or two tests was also seen in the control group. To put it in a more general way, a change of more than $30 \%$ in the total test performance can be taken as a deterioration or improvement. Other investigators who studied individual change in patients $[\mathrm{e}, \mathrm{g}, 8,10-13]$ have interpreted deterioration as a decrease in performance of $1 S D$ on two or more tests. Therefore the percentage deterioration reported in these previous studies is probably too high.

Secondly, when individual change was studied per test the results were not consistent. Patients showed a decrease in performance in different tests, which is hard to interpret. This inter-patient performance variability has also been reported by Hammeke and Hasting [2], but most studies have not considered this problem. It is also possible that one patient shows a decline in some tests and an improvement in others. To deal with these problems, a compound score can be used to study deterioration in a more general way. With the compound score a lower percentage deterioration was found. This is due to the higher vulnerability of the separate tests for change. The compound score is a more solid measure and less vulnerable to change.

Thirdly, the last approach showed that the use of $1 S D$ is quite arbitrary and should be reconsidered. With a $S D$ value of 0.6 or 0.8 (total group, control group respectively) the specificity of the compound score in measuring change stayed the same (100\%) and the sensitivity was greater compared with the use of $1 S D$. This approach makes it possible to attain fin optimal discrimination between patients and controls.

Finally, which comparison should be used to estimate cognitive change; the subgroup, the total group or the control group comparison? The data show that the percentage deterioration. varied between the different comparisons. When there is no initial difference in $S D$ between the groups, it does not matter which comparison is chosen, but when there is a difference, one should consider this choice carefully. The present findings suggest that total group comparisons should be used. The estimation of change is somewhat more conservative than when the control. group comparison is used. However, the subgroup analysis is too conservative because change is defined only in relation to the subgroup.

On the basis of the results, it was concluded that a control group should be used, even when individual change is studied in which individuals are used as their own control. With a control group one is able to consider normal change over the different measurements, that is change that 
is not due to surgery (or any other intervention), and one can estimate which SD value should be used to determine a deterioration. If no control group is avallable, a change of $1 S D$ in test performance in at least $30 \%$ of the tests could be used to determine change. The results also show that the use of a compound score solves the problem of improvement and deterionation within one patient and the problem of large inter-patient performance vatiability. The findings in the present study suggest that differences between patients and controls are quantitative: there are control subjects who improve or deteriorate from measurement to measurement, but the magnitude of change is far less than in the patient group. Discrimination between the groups is improved by reducing the $S D$ criterion, indicating that $1 S D$ is too conservative. For this reason, future intervention studies should use a control group in order to decide which $S D$ criterion should be used.

The results obtained in the present study may prove applicable to other intervention studies, e.g., treatment studies (drugs, neuropsychological rehabilitation, psychotherapy) and studies in which non-specific change due to the passage of time is tested in patients, elderly individuals, or children.

\section{REFERENCES}

1. Blumenthal JA, Mahanna EP, Madden DJ, White WD, Croughwell, ND, Newman ME "Menhodological issues in the assessment of netropsychologic function after cardiac surgery. The Aninals of thotac Surgery 1995; $59: 1345-50$.

2. Hammeke TH, Hastings JE. Neuropsychologic alterations after cardiac operation Journal of Thoracic and Cardiovascular Surgery 1988; 96:326-31.

3. Hijman $R_{3}$ Jolles J, Verhoeven WMA, Van Ree JM, Elderson A, De Wied D. Desglycinamide ARGswasopressin in five trials with memory adisturbed patients. Human Psychopharnacology 1992; 7: 7.23.

4. Jolles J, Houx PJ, Van Boxtel MPJ, Ponds RWHM. The Maastricht Aging Study: Determirnants of cognitive aging 1995.

5. Klonoff H, Clark C, Kavanagh-Gray D, Mizgala H, Munro I. "Twowear follow-up study of coronary bypass surgery. The Joumal of Thoracic and Cardiowascular Surgery 1989; 97: 78-85.

7. Lezak MD. Neuropsychological Assessment. 2nd ed. New York: Oxford University Press, 1983.

8. Lezak MD. Neuropsychological Assessment. 3rd ed. New York: Oxford university pesss, 1995.

9. Nevin $M$, Colchester $A C^{*}$, Adams $S$, Pepper JR. Evidance for involvement of lnypocapoia and hypoperfusion in aetiology of neurological deficit after cardiopulmonary bypass. The Lancet 1987; 26:1493-5.

10. Newman S. Neuropsychological and psychological changes. In: Smith P, Taylor Ked. Cardiac surgery ard the brain. Boston: Hodder and Stoughton Publishers, 1993: 34.54.

11. Newman $S$, Smith $P$, Treasure $T$, Joseph $P$, Ell P. Harrison M. Acute neuropsychological bonsequences of coronary artery bypass surgery (Health Psychology). Curnen Psychological Reseanch \&e Revicws, 19B7; 6: $115-24$.

12. Savageau JA. Stanton B, Jenkins CD, Klein MD. Neuropsychological dysfunction following elective cardiac operation. I: Early assessment. The Journal of Thoracic and Candovascular Surgery 1982; 84:595600 .

13. Sellman $M$, Holm $L$, Ivert T, Semb. B KH. A randomized study of neuropsychological function in patients undergoing coronary bypass surgery. The Thoracic and Cardiovascular surgeon $1993 ; 41: 349-54$.

14. Shaw $\mathrm{PI}$, Bates $\mathrm{D}$, Cartlidge EF, el al, Long-term intellectual dysfunction following conomary artery bypass graft surgery: A six month follow-up study. Quarterly Jourmal of Medicine 1987 ; Mew Series 62 : 259.268.

15. Verhage F. Intelligentie en leefijd (Intelligence and Age). [doctoral disgertation]. Masen, The Netherlandis: 1964. 


\title{
The influence of an operation under general anaesthesia on cognitive functioning in the elderly*
}

\author{
Jeanette B. Dijkstra, Peter J. Houx, and Jellemer Jolles
}

\begin{abstract}
There is some evidence that especially older people have a higher risk of cognitive dysfunction after an operation under general anaesthesia. The present paper investigates the severity and character of postoperative cognitive dysfunctions after an operation under general anaesthesia in patients older than 65 years. Cognitive functions were assessed before and I week (short term) and 3 months (long term) after the operation. "The cognitive performance of the patients was compared to that of healthy control subjects who were also subjected to repeated cognitive measurements. After 1 week the patients had a poorer performance on tests measuring sensorimotor speed when compared with the controls, but not on tests measuring cognitive flexibility or memory. Three months after the operation both patients and controls showed an improved cognitive performance when compared to the first measurement. With respect to cognitive flexibility, the patients showed more improvement than the controls and with respect to general information processing the patients showed less improvement than the controls. Thus the present resullts show that an operation under general anaesthesia in older people does lead to short-term cognitive deficits. When group means are considered, there is not a long-term decrease in cognitive performance. No difference between the patients and controls was found with respect to short and long-term individual cognitive change. Fourteen of the 48 patients (31\%) reported having experienced a change in mental abilities after discharge from hospital, and 8 of these 14 patients (18\%) still experienced these mental changes after 6 months and reported "not being the same since the operation". Long-term subjective cognitive complaints do not seem to be related to objective cognitive impairment. This discrepancy between objective test performance and subjective complaints needs further study.
\end{abstract}

\footnotetext{
* This project is part of the multi-centre study 'International Study on Post-Operative Dysfunctions' (ISPOCD) and has been financed by the "Profileringsfonds' of the University Hospital Maastricht.
} 


\section{INTRODUCTION}

Postoperative cognitive dysfunction is not uncommon in elderly patients. It can significantly impair their quality of life and constitutes a burden to society when telderly patients prematurely lose their independence. The magnitude of this social burden is difficult to estimate.

Many clinicians have described patients who underwent an uncomplicated operation under general anaesthesia, but who complained postoperatively for weeks to months of psychological dysfunction [1, 8, 19]. For some patients who suffer only transient (weeks to months) cognitive impairments, the complaints may only be annoying; for others they may constitute a serious crisis, especially if the cognitive impairment is permanent and results in the loss of their job or, in the elderly, loss of independence.

Several papers describe early and short-lasting cognitive dysfunctions in postoperative patients (well summarised by Parikh and Chung [21] and Dyer et al. ${ }^{49]}$ ), whereas long-term (weeks to months) cognitive effects were seldom found. However, a substantial number of the patients do have cognitive complaints for a long period after an operation [8, 19]. The discrepancy between subjectively reported cognitive complaints and objectively measured cognitive function might be caused by the methodological weaknesses of previous studies. Most studies have used fairly insensitive tests such as the Mini Mental State Examination (MMSE) [12]. Although the MMSE is generally not very sensitive to the effects of medical interventions, it has been used in quite a few studies on anaesthesia and cognition [e.g. 6, 12, 24].

Another issue is that many studies did not use parallel versions of the cognitive tests, the same test version being administered before and after the operation. This means that postoperative deterioration in test performance could be obscured by learning effects, i.e. performance inproves from test session to test session. This could be why there is sometimes no decline in test performance after an operation even though a patient has cognitive complaints [7].

Finally, the majority of studies have used tests which have been developed either for diagnostic use in neurological patients or for the measurement of intelligence-related constructs in normal subjects and in patients. These tests were never devised for the evaluation of medical or other interventions. The advantage is that they are well known and belong to the standard measures of psychological departments of general hospitals. However, they have a number of disadvantages. These tests generally do not exist in parallel forms and are quite crude, enabling the assessment of serious deterioration, but not subtle changes which can still change the quality of life considerably. Tests of the Wechsler tradition and of the Halstead Reitan tradition are among the tests which are crude and insensitive for the purpose of evaluating change in cognitive performance [17]. Yet, several studies have used these tests and failed to find change in cognitive performance after an operation, or differences between spinal versus general anaesthesia [ 14,201 , or differences between young and elderly patients [4]. With these tests only the absolute performance in terms of the number of good/false responses is measured, but not the speed of performance, which is probably more sensitive in this respect. Both in cognitive pharmacological research [15] and in the assessment of mild brain trauma [2] cognitive performance which is measured in terms of the time needed to perform a task appears more sensitive and reliable than the absolute performance.

The principal aim of the present study was to evaluate the severity and character of cognitive dysfunctions after an operation (short and long term), by using parallel test versions that have proven to be sensitive in measuring change. Also, several predictors such as duration of anaesthesia and hospitalisation time were studied as possible risk factors for the development of cognitive dysfunctions. The study was performed within the framework of the International 
Study on Postoperative Cognitive Dysfunctions (ISPOCD), which is part of a Bioned European concerted action programme in European countries and the USA involving 1400 elderly subjects who have undergone an operation under general anaestlhesia. The present study involved an analysis of the first 56 subjects (out of a total of 104) in Maastricht.

\section{MATERIALS AND METHODS}

\section{Subjects}

Fifty-six patients older than 60 years who underwent an operation under general anaesthesia in the Academic Hospital in Maastricht (The Netherlands) participated in the study. The main surgical procedures included in the study were vascullar surgery, abdominal surgery, urological surgery, and gynaecologic surgery. The study was approved by the Medical Ethics Committee, and informed consent was obtained from the patients. Excluded were patients with major psychiatric disease, disease of the central nervous system (recent meningitis or encephalitis, tumors, major degenerative diseases and cardiovascular accident), patients on major tranquillizers and antidepressants, patients undergoing neurosurgery or cardiac surgery patients unable or unwilling to abide by the protocol, patients who could not follow procedures or who had poor comprehension of the Dutch language, patients with severe visual or auditory disorder/ handicaps, clinically significant Parkinson's disease, a current diagnosis of alcoholism or drug dependence, patients not expected to be discharged from hospital alive and with an expected postoperative hospital stay shorter than 4 days. Patients also scored higher than 23 on the Mini Mental State Examination (MMSE). In total 48 patients were used in the final analysis: 3 patients died shortly after the operation, 2 patients were too ill to perform the neuropsychological tests postoperatively, and 3 patients refused to participate after the operation.

Table 5.1 Subject characteristics

\begin{tabular}{|c|c|c|c|}
\hline & Paticnts (48) & Controls ( 50 ) & $i$ \\
\hline Age $(M \pm S D)$ & $682(5.8)$ & $64.5(5.3)$ & $3.29^{*}$ \\
\hline Years of education (MtSD) & $92(2.9)$ & $11.2(3.3)$ & -3.15 d \\
\hline $\operatorname{Sex}(M / T)$ & $13 / 35$ & $27 / 23$ & $7.35 * 1$ \\
\hline Andesthesia time (min. $M \pm S D)$ & $164.3(66.8)$ & & \\
\hline Day of discharge $(M \pm S D)$ & $10.4(5.7)$ & & \\
\hline \multicolumn{4}{|l|}{ Sergical procedure: } \\
\hline abdominal surgery & 16 & & \\
\hline vascular surgery & 8 & & \\
\hline urollogical surgery & 7 & & \\
\hline gynaecological surgery & 6 & & \\
\hline orthopaedic surgery & 4 & & \\
\hline breast & 2 & & \\
\hline other & 5 & & \\
\hline \multicolumn{4}{|l|}{ Reason of drop-out: } \\
\hline death & 3 & & \\
\hline too ill & 2 & & \\
\hline refusal & 3 & & \\
\hline
\end{tabular}

Note. *p<01; $1=\operatorname{ch}^{2}$ 
A control group of 50 healthy volunteers was recruited by an advertisement in a local newspaper. The same inclusion criteria were used for the control group as for the patients, yet the controls were on average 4 years younger and had 2 years more education. There were also fewer women in the control group than in the patient group. Table 5.1 summarizes the subject characteristics.

\section{Measurements}

Visual Verbal Learning Test (VVLT). This is a computerised, visually version of a test of secondary memory: In three consecutive trials, a list of 15 words has to be memorised and reproduced. The dependent variable is the total number of words recalled over the three trials (VVLTTOT). The VVLT also involves delayed recall after 20 minutes, thus enabling measurement of memory retrieval (VVLTDEL) [16].

Stroop Color Word Test (SCWT). The SCWT has often been used to test selective attention, mental speed, and interference susceptibility [16]. The test involves three cards displaying forty stimuli each: colour names (SCWT I), coloured patehes (SCWT II), and colour names printed in incongruously coloured ink (SCWT III). The dependent variables are the time needed to read (SCWT I), or to name the colour of the patches (SCWT II) or printing ink (SCWT III).

Concept Shifting Test (CST). This test is derived from the Trail Making Test, which has long been used to measure the ease of shifting between concepts in ongoing behaviour [16]. It consists of four parts. On each test sheet. 16 small circles are grouped in a larger circle In the first part emply circles have to be crossed out as fast as possible (CSTO). In the other three parts the circles contain numbers (CSTA), letters (CSTB), or both (CSTC), appearing in a fixed random order. Subjects are requested to cross out the items in the right order. The dependent variable is the time needed for each part.

Letter Digit Substitution Test (LDST). This test is a modification of the procedurally identical Symbol-Digit-Modalities Test (SDMT; $[17,18$ ). The subjects are supplied with a code at the top of a page where a digit corresponds to a letter. They then have a short time to fill in blanks which correspond to the correct codes. The test is used to measure the speed of processing of general information. "The dependent variable is the total number of letters written correctly in 1 minute (LDSTTOT).

Mood assessment. Depression was measured with the Zung Self Rating Scale for Depression [27], in order to assess whether cognitive function is negatively influenced by depression.

Cognitive Failure Questionnaire [3]. This questionnaire measures self-reported failures in perception, memory, and motor function.

The cognitive measurements assess the following theoretical underlying cognitive constructs: memory (VVLTTOT, VVLTDEL), cognitive flexibility (CSTC, SCWT III), sensorimotor speed (CSTO, CSTA, CSTB, SCWT I and II), and general information processing (LDSTTOT) (see [18] and Chapter 6).

\section{Procedure}

The cognitive test battery was administered on three occasions: 1 day preoperatively (baseline), and 7 days and 3 months postoperatively. Demographic data, together with medical, surgical and sociall histories, and medication used, were collected by means of an interview with the patients before the operation. Depression was assessed on each occasion to correct for the 
influence of a depressed mood on test performance. Complaints about cognitive functioning were assessed with a questionnaire at baseline and 3 months after the operation Six months after the operation patients were asked to evaluate whether their cogritive abilities had changed since surgery. A short structured interview was conducted by telephone. During this interview the patient was asked whether he/she had experienced changes in mental abilities after discharge from the hospital and for how long. The control group underwent the same procedure: they were tested with the same time intervals between the cognitive measurements. These subjects considered themselves healthy; a formal evaluation of mood changes and cognitive complaints was not performed. The period of inclusion of patients was one year; the inclusion of controls was completed in a period of four months.

\section{Data analysis}

The comparison of patients and controls was done in order to control for the effect of repeated testing. In order to study the initial differences between the two groups on the ten test variables a t-test was used. A distinction was made between short and long-term cognitive effects. A short-term effect was defined as a change in performance from baseline to 7 days postoperatively, and a long-term effect as a change from baseline to 3 months postoperatively. A multiple regression analysis for each measurement with age, years of education, and sex showed an effect of age and years of education on test performance but no effect of sex; accordingly, sex was not analysed as a separate factor. For the statistical evaluation of the effect of the medical intervention on cognitive performance, age and years of education were used as covariates in order to correct for the effect of these on test performance. "The short and longterm cognitive effects were tested by an univariate analysis of covariance with repeated measurements (ANCOVA).

In addition to changes in the mean scores, it is important to consider individual changes as described by Shaw et al. [21]. Variability in test scores is almost always substantially larger among surgery patients than controls and such high variances could obscure differences in group means (see also chapter 4, this thesis). A cognitive deficit was considered to be present when a subject's postoperative performance for the ten main variables deteriorated by at least one population-based (patients and controls) standard cleviation (SD) from his/her baseline performance. Deterioration was defined as decline in performance on more than two test variables.

To decide which intra-individual factors might contribute to change in performance in the patient group, age, years of education, sex, change on the depression scale, duration of andaesthesia, and days spent in hospital after the first postoperative measurement were entered in a stepwise hierarchical multiple regression model. Days spent in hospital after the first postoperative measurement was taken as a measure of the severity of illness after the operation. It was assumed that patients who had to stay in the hospital for a long period after their operation were more ill than patients who had left the hospital before the first postoperative measurement. This variable was used to study the effect of medical condition on change in cognitive performance. The day of discharge was subtracted from the day of the first postoperative measurement. A positive score indicates a stay in hospital after the first postoperative measurement, at negative score indicates that the patient had left hospital before the first postoperative measurement.

In the first step of the regression analysis age, year of education, and sex were entered, in the second step change on the depression scalle, and in the third step duration of anaesthesia and days spent in the hospital. Dependent variables were the short and long-term change score for the cognitive variables and change assessed with the cognitive complaints questionnaire. These 
change scores were calculated for each dependent variable in such a way that a negative difference indicated a decline (or more cognitive complaints) and a positive difference an improvement (or less cognitive complaints). Both absolute change (in raw test score) as relative change (percentage change) were computed and analysed. Pvalues lower than 0,05 were regarded as significant:

\section{RESULTS}

The baseline performance of the patients was worse than that of the controls for seven of the ten cognitive test variables (see table 5.2). These initial differences between the groups might be caused by differences in age and education (see table 5.1). An analysis of covariance with age and education as covariates was used to study the differences in test performance after adjustment for these variables. Table 5.2 shows that patients still performed worse on three of the ten test variables and perform better on one of the ten test variables after adjustment for age and years of education.

Table 5.2 Difference in baseline performance of patients and controls in varions tests of cognitive function on raw test scores (t-iest) and test scores adjusted for age and years of education (ANCOVA)

\begin{tabular}{|c|c|c|c|c|}
\hline Testis & $\begin{array}{l}\text { Patients }(N=48) \\
M(S D)\end{array}$ & $\begin{array}{l}\text { Controls }(N=50) \\
M(S D)\end{array}$ & $\begin{array}{l}\text { I-test } \\
\text { t-yalue }\end{array}$ & $\begin{array}{l}\text { ANCONA } \\
F(d f)\end{array}$ \\
\hline \multicolumn{5}{|l|}{ Concept Shiffing Test } \\
\hline $\operatorname{CSTO}$ & $8.2(2.6)$ & $6.4(1.2)$ & $4.2^{*} * *$ & $7.1 .(1,94)^{* * 4}$ \\
\hline CSTA & $25.5(7.3)$ & $21.6(5.1)$ & $3.0 * *$ & $0.6(1,94)$ \\
\hline CSTB & $32.2(10.9)$ & $25.5(5.8)$ & $3,8 *$ & $5,6(1,94)^{*}$ \\
\hline $\mathrm{cstr}^{\circ}$ & $43.7(15.7)$ & $34.5(10.6)$ & 3.4 * & $3.2(1,93)$ \\
\hline \multicolumn{5}{|c|}{ Wiswal Verbal Ledming Test } \\
\hline VNLTTOT & $25.1(6.0)$ & $26.8(5.1)$ & -1.5 & $3.8(1,93)$ \\
\hline VVLTDEL & $7.5(3.1)$ & $9.2(2.5)$ & $-2.8 *$ & $1.7(1,93)$ \\
\hline \multicolumn{5}{|c|}{ Stroop Color Word Test } \\
\hline SCWT I & $17.0(3.0)$ & $18.1(2.9)$ & -1.8 & $7.0(1.94)^{*}$ \\
\hline SCWT II & $23.5(4.2)$ & $22.7(3.5)$ & 1.0 & $0 . \Perp(1,92)$ \\
\hline SCW $\mathrm{T} 11 \mathrm{I}$ & $55.8(20.1)$ & $37.5(8.2)$ & $5.8^{*}$ & $21.0(1,93)^{*}$ \\
\hline \multicolumn{5}{|c|}{ Letrer Digit Swbstifution Test } \\
\hline LDSTTOT & $26.2(7.4)$ & $31.6(7.2)$ & -3.7 *3 & $2.7(1,94)$ \\
\hline
\end{tabular}

Note * $p<05 ; * 0<01$

\section{Short-term cogninive effects}

The effect of the medical intervention on cognitive performance was tested by using ANCOVA with repeated measurements. There were significant group effects on six of the ten variables (see table 5.3). Patients performed worse than controls on tests measuring sensorimotor speed (CSTO, CSTB, SCWT I), memory (VVLTDEL), interference susceptibility (SCWT III), and the processing of general information (LDSTTOT). A time effect between the two measurements was found on one test of interference susceptibility (SCWT III). Both groups showed 
improved performance. Interaction ffects (group $x$ time) were found in tests measuring sensorimotor speed (CSTO, SCWT I and II) and general information processing (LDSTTOT). Patients showed a decline in performance and controls an improwement or no change.

The results for the test performance of individual subjects are summarised in table 5.4. "Three of the 48 patients $(6 \%)$ had poorer scores on more than two test variables 1 week after the operation compared with 1 subject $(2 \%)$ in the control group. This measure of individual change was not different between the groups.

\section{Long-term cognitive effects}

ANCOVA with repeated measurements revealed significant group effects on five of the ten variables (see table 5.5). Patients performed worse than controls on tests measuring sensorimotor speed (CSTO, SCWT I), memory (VVLT, delayed recall), interference susceptibility (SCWT III), and processing of general information (LDSTTOT). A time effect was found on sensorimotor speed (CSTO, SCWT II), memory (VVLTTOT, VVLTDEL), interference susceptibility (SCWT III), and processing of general information (LDSTTOT). Both groups showed improvement over time for all tests mentioned. Interaction effects were found on cognitive flexibility (CSTC, SCWT III) and processing of general information (LDSTTOT). As to cognitive flexibility, both groups improved but the patients improved more than the controls. The patients improved less than the controls when it came to processing of general information. Three months after the operation, 3 patients $(6.2 \%)$ still had a poorer performance on more than two test variables compared with $2(4 \%)$ controls. This difference was not significant (table 5.4 ).

Table 5.4 Short-term and long-term indiwidual cognitive dysfunction

\begin{tabular}{|c|c|c|c|c|c|c|}
\hline \multirow{2}{*}{ Severity of deterioration } & \multicolumn{3}{|c|}{ Short term } & \multicolumn{3}{|c|}{ Long term } \\
\hline & $\begin{array}{l}\text { Pathents } \\
\%(N)\end{array}$ & $\begin{array}{l}\text { Controls } \\
\%(N)\end{array}$ & $\begin{array}{l}\operatorname{ch}^{2}(p) \\
\%(N)\end{array}$ & Pationts & $\begin{array}{l}\text { Controls } \\
\%(N)\end{array}$ & $\operatorname{ch}^{2}(p)$ \\
\hline No change & $94(45)$ & $98(49)$ & $1.13(\mathrm{~ns})$ & $94(45)$ & $96(48)$ & $0.26(178)$ \\
\hline Modente to sewere ( $>2$ tests) & $6(3)$ & $2(1)$ & & $6(3)$ & $4(2)$ & \\
\hline
\end{tabular}

Note. cognitive dysfunction at 7 days (shortermy) and 3 months (long terin) wher operaion compared with oognitiwe performance / day before the operation for patients $(N=48)$, and controls $(N=50)$.

\section{Mood changes"}

With respect to mood, no change in depressive symptoms was found in the patient group 1 week and 3 months after the operation compared with baseline $(t=-1.49$, ns and $t=-.58$, ns, respectively).

\section{Cogritive complaints}

No change in cognitive complaints as measured with the cognitive faillure questionnaire was found 3 months after the operation compared with baseline $(t=1.04$, ns). After 6 months, 14 patients ( $31 \%$ ) reported that they had experienced a worsening of mental abilities after discharge from hospital, and $8(18 \%)$ of these patients still experienced these mental changes. 


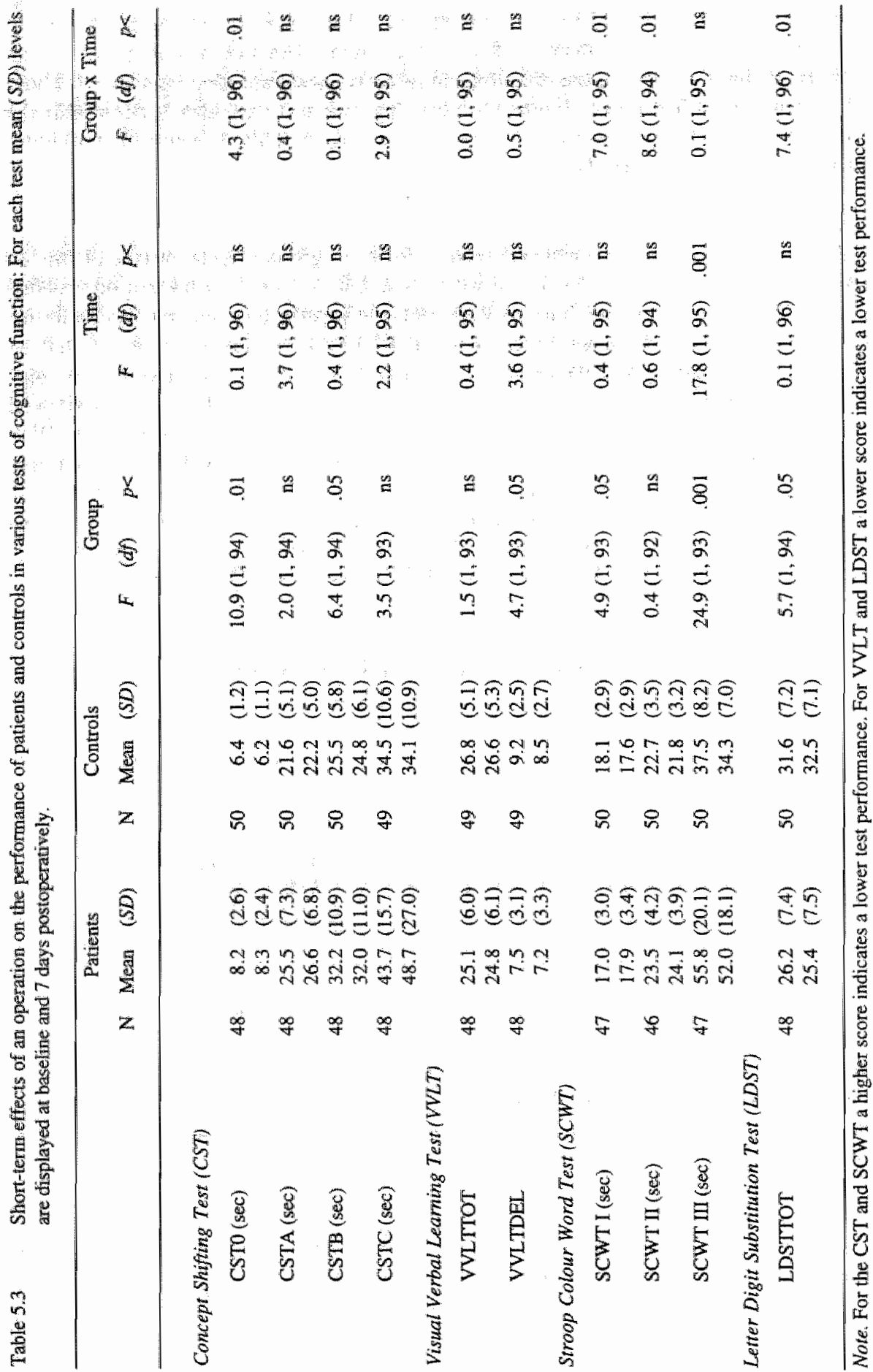




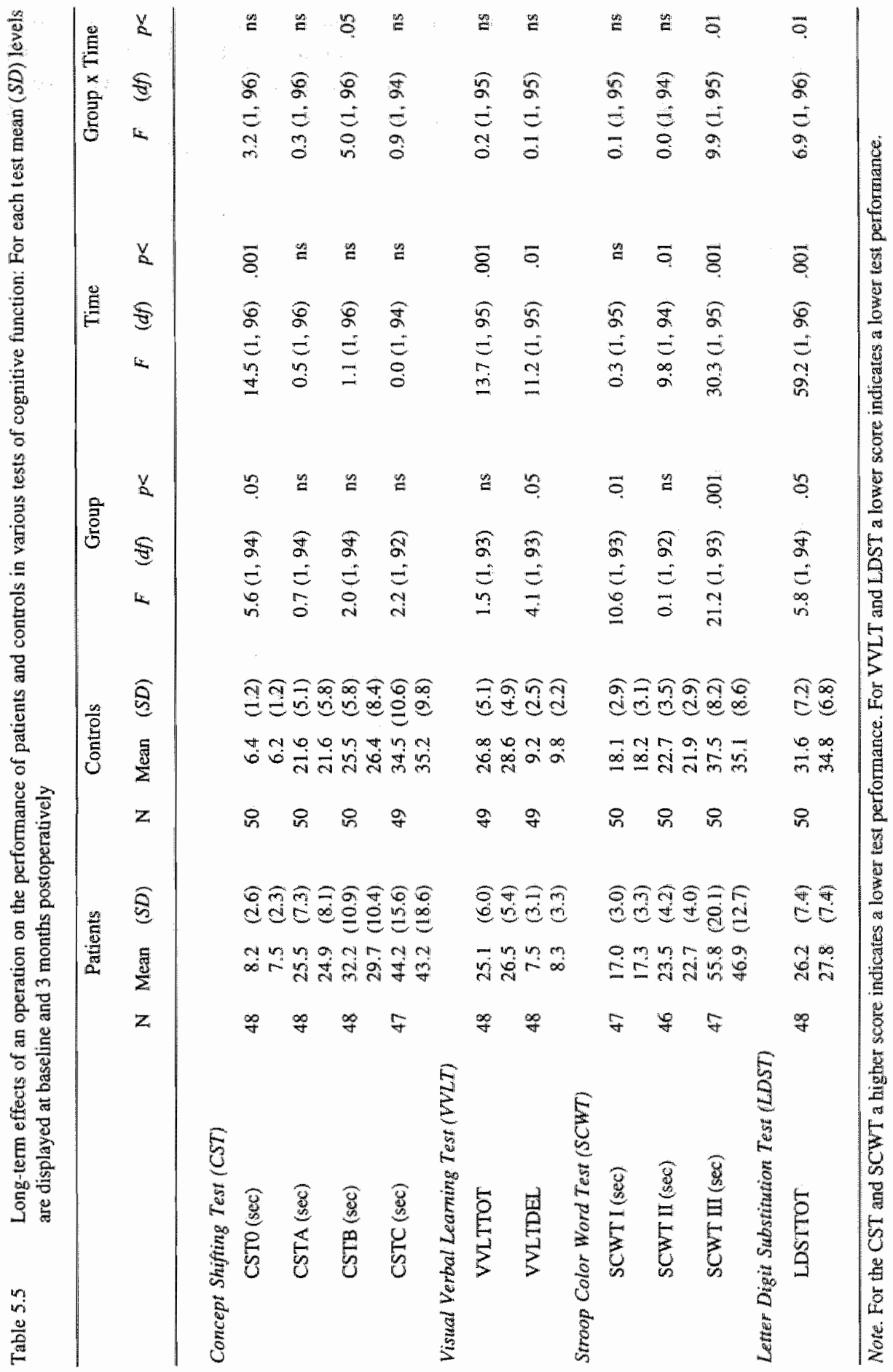




\section{Regression analysis}

The results of the regression analysis showed a significant contribution of change on the $Z$ Zung depression scale to the change in performance in the Concept Shifting Test (CSTO) 3 months after the operation, indicating a poorer performance with higher Zung scores. As shown in table 5.6, the various factors (age, years of education, sex, change on depression scale, duration of anaesthesia, and days spent in hospital after the first postoperative measurement) did not make a statistically significarit contribution to the total explained variance in the dependent variables. The table gives the results of the analysis of the absolute differences. Similar results were obtained for the analysis of the relative change (data not shown) and for the regression analysis of the short-term cognitive effects (data not shown).

Table 5.6

Results of regression analysis of several background variables on performance change from baseline to 3 months (long-term) after surgery.

\begin{tabular}{|c|c|c|c|c|c|c|c|c|c|}
\hline \multirow[b]{2}{*}{ Long-kerm change } & \multicolumn{3}{|c|}{ Step 1} & \multirow{2}{*}{$\begin{array}{l}\text { Step } 2 \\
\text { Zung }\end{array}$} & \multicolumn{2}{|l|}{ Step 3} & \multicolumn{3}{|c|}{$\mathbb{R}^{2}$, after step } \\
\hline & Edu & Age & Sex & & Dif & Dur & 1 & 2 & 3 \\
\hline CSTO & .01 & .02 & 31 & $.42^{*}$ & -.14 & .23 & .020 & $.177 *$ & .217 \\
\hline CSTA & .02 & .15 & -.34 & -.07 & .08 & -.40 & .023 & .026 & .128 \\
\hline CSTB & .13 & .09 & -.02 & .17 & -18 & -.10 & .018 & .042 & .08 \\
\hline CsTC & .14 & -.22 & $\therefore .09$ & .04 & .14 &. .18 & .079 & .082 & .111 \\
\hline VVLTTOT & .10 & -.13 & -.07 &. .16 & -.18 & -.17 & .052 & .080 & .142 \\
\hline VVLTDEL & .10 & .07 & .12 & -.12 & -.17 & .10 & .035 & .051 & .078 \\
\hline SCWT & .18 & -.19 & .20 & .03 & -.116 & 32 & .066 & .066 & .136 \\
\hline SCWT II & .06 & .06 & .11 & .04 & .09 & .04 & .015 & .017 & .026 \\
\hline SCWT III & -.21 & -.12 & .26 & .25 & -.17 & .22 & .059 & .112 & .158 \\
\hline LDSTTOT & -.02 & .21 & .28 & .06 & -.11 & -.16 & .146 & 148 & .186 \\
\hline $\mathrm{CFQ}$ & -.05 & .23 & -.09 & .21 & .16 & .08 & .081 & .118 & .140 \\
\hline
\end{tabular}

Note. Change scores were calculated in such a way that a negative score indicates a decline in: cognitive performance (or an increase in cognitive complaints on depressive symptoms) and a posilive score indicates an improvement in cognitive performance (or a clecrease in cognitive complaints or depressive symptoms). Chronological age, sex $(m=1 . \quad[=2)$, and years of education (Edu) were chtered in step one, chinge in score on the depression scale in step two, and duration of anaesthesia (Dur) and days spent in the thospital after the first postoperative measurement (Dif: a positive score indicates stay in hospital after the first postoperative measurement, negative score indicates discharged before postoperative measurement) in the final step). Shown are standardised regression coefficients (Beta) in the final model, and the explained variance $\left(\mathrm{R}^{2}\right)$ after each step, for long-term cognitive change. ${ }^{*}<0.01$. 


\section{DISCUSSION}

Patients performed worse than the controls in several cognitive tests even before the operation (table 5.2). In addition, the groups differed in short and long-term change, 1.e the difference between first and second, and first and third measurements in several cognitive tests. One week after the operation, the patients had a poorer performance than the controls in tests of sensorimotor speed and processing of general information, but not in tests of cognitive flexibility and memory. In contrast to this short-term decline in the patients, no long-term decline was found: all scores had returned to preoperative levels or had even improved. Differences in improved performance between the patients and controls were found in tests measuring cognitive flexibility (SCWT III), sensorimotor speed (CSTB) and processing of general information (LDSTTOT). The patients showed a greater improvement in sensorimotor speed and cognitive flexibility than the controls, and the controls showed a greater improvement in processing of general information. When short and long-term cognitive effects were analysed on an individual basis, 3 patients $(6 \%)$ of the patients appeared to be impaired on more than two test variables after 1 week, and this proportion was the same after 3 months. The three patients who showed a short of a long-term deterioration were not the same individuals. No difference concerning individual change was found between the paients and the controls. Thus, the present data provide evidence that cognitive dysfunctions, as measured with psychometric tests, do occur shortly after an operation but not in the long tern. Duration of anaesthesia, days spent in hospital after the first postoperative measurement, age, sex, years of education, and change of score on the depression scale could not predict short or long-term change in cognitive performance in these patients. There was one exception, namely, an increase in depressive symptoms contributed significantly to a decreased performance on the CSTO. Although this was an isolated finding, the change is in the predicted direction as an increase in depressive symptoms was expected to correlate with a decreased performance.

The patients did not report no more depressive symptoms 1 week and 3 months after the operation, nor more cognitive complaints 3 months after the operation than before the operation, as measured with a cognitive failure questionnaire. However, 6 months after the operation $18 \%$ of the patients still reported a decrease in general mental abilities. This finding has to be interpreted with caution because the changes reported by the patients were subjective in nature. It is possible that these cognitive complaints already existed before the operation but that patients only noticed them after being asked about them. In a cross-sectional panel study of the Maastricht Aging Study (MAAS), 1,986 normal healthy subjects aged 24 to 86 years were asked "do you consider yourself as being forgetful"?", and "how much do you worry about your forgetfulness?". In this study $41.5 \%$ of the subjects aged $55-65$ years, and $52 \%$ of the subjects aged 70-85 years, considered themselves forgetful, and $64 \%$ and $62 \%$ out of the people who considered themselves forgetful were worried to some extent about their forgetfuiness 17]. This indicates that normal healthy subject also have memory complaints when they are specifically asked about them. Yet, the finding that nearly $20 \%$ of the operated patients reported feelings of a general decline in mental abilities is of importance from a health care point of view. Furthen research should be directed at evaluating the nature of the discrepancy between objective test performance and subjective results. It is still possible that cognitive testing does not reveal what is really happening after an operation.

Despite the adjustment for age and years of education, the patients still had a poorer performance than controls on several cognitive test variables at baseline. We found a similar difference between patients (heart surgery) and historical controls in an earlier study (see chapten 3 ). 
Vartous explanations are possible. Of course; slight changes in brain functioning could be caused by general physical competence and/or decteased brain circulation in the patient group. This notion awaits careful scientific evaluation. In the second place, the difference could be due to a higher level of stress because of the stay in hospital It is possible that coming back to the hospitall after 3 months triggers the same feelings and thereby affects cognitive performance. Other explanations for the overall differences between the groups have been reported by others [11].

Few studies have compared patients with heathy controls in order to correct for repeated testing. Most studies have used controll groups consisting of ambulatory patients, patients undergoing other kinds of surgery, or patients who had their operation under local anaesthesia. The difference in performance at baseline between the patients and controls did not affect the main aim of the study, which was to examine performance trends across the three test occasions.

The decreased performance of the patient group on speed-related cognitive tests I week after the operation is probably due to lingering effects of anaesthetic drugs, postoperative analgesics, of other factors, all of which can contribute to postoperative fatigue. Bed rest, inactivity, and the supine position have all been shown to have a deleterious effect on sensorimotor function, and in the early postoperative period, fasting and sleep deprivation are other factors that must be considered [9]. Although both groups showed the same or an improved performance after 3 months, the patients showed more improvement than the controls in tests measuring cognitive flexibility and sensorimotor speed and less improvement in a test measuring processing of general information. The relatively greater improvement of the patients on two test variables may be due to the fact that they experience less stress and pain and had recovered in the 3 months. The relatively smaller improvement of the patients on one test variable could be an indication for a decline because the same or a relatively greater improvement than the controls would be expected. In general, long-term cognitive impairment after an operation under general anaesthesia has seldom been found $[5,22,25$, see also chapter 1$]$. However, it is possible that an improvement should be interpreted as a decline if healthy control subjects show a greater improvement over repeated measurements than the patient. Due to the lack of such a control group in most studies, no difference in performance or an increased performance of patients is always interpreted as no change or an improvement. Future studies into this area should pay more attention to the use of normal healthy subjects as a comparison group. We studied too few patients to determine the order of extent of the lack of improvement of the patients. This must be analysed on a much larger sample, which will be performed on the 1400 elderly patients who are subjects in the International Study on Postoperative Cognitive Dysfunction (ISPOCD).

Although the present study showed no increase in cognitive complaints, as assessed with a questionnaire, 3 months after the operation, a substantial proportion of the patients reported a decline in mental abilities. The discrepancy between subjective complaints and objective performance has also been found in other studies [8, 19]. It appears that these long-term cognitive complaints can not be confirmed with cognitive tests. Although these subjective complaints are often mentioned, the objective quantification of such memory and concentration complaints has, however, rarely been undertaken. The questionnaire we used asked the patients about specific cognitive dysfunctions whereas complaints that patients reported rather vague. This might be an explanation for the different results found with the questionnaire and with the interview.

These cognitive complaints are perhaps related to factors other than objective test performance on cognitive tests. Wallace [23] studied the effect of a special preparatory booklet designed to reduce stress in surgical patients. "This intervention had an effect on patients' knowledge, reported information, and worries about surgery. The patients in the control group (without preparatory booklet) had more misconceptions about the surgical procedures and more often. 
reported anxiety. Wallace found that patients who had more knowledge about sungery had fewer worries and recovered faster. It is possible that patients with more knowledge about the operation and about what to expect afterwards will have fewer cognitive complatints.

Thus, it is possible that complaints are more related to other factors such as the availability of information about the operation and what to expect after the operation, personality traits, anxiety and coping style. Future research should pay more attention to cognitive complaints and their determinants.

Although this preliminary report suggests that there are no long-term cognitive effects of general anaesthesia, it is possible that the ISPOCD study as a whole will be able to demonstrate long-term cognitive effects. Likewise, it is not unlikely that there are differences between countries concerning the anaesthetics and the surgical procedures used which may reveal differences in the impact of an operation under general anaesthesia on cognitive functioning.

\section{REFERENCES}

1. Bedford PD. Adverse cerebral effects of anaesthesia on old people. The Lancet 1955; 6; 259-63.

2. Bobmen N, Jolles J, Twijnstra A. Modification of Stroop Color Word Test improves differentiation between patients with mild head injury and matched controls. The Clinical Neuropsychologist 1992; 6:178-84.

3. Broadbent DE Cooper PF. FitzGerald P, Parkes KR. The cognitive Failures Questionnaite (CFQ) and its correlates. British Journal of Clinical Psychology 1982; 21: 1-16.

4. Chung F, Lavelle PA, McDonals S. Cognitive impairment after neuroleptanalgesia in catarad surgery. Anesthesia and Analgesia 1989; 68: 614.8.

5. Chung $F$, Seyone $C$, Dyck $B$, et al. Age-related cognitive recovery after general anesthesia. Anesthesia and Analgesia 1990; 71:217:24.

6. Chung F, Chung A, Meier RH, Lautensehlaeger E, Seyone C. Comparison of perioperatiwe nnental function after general anaesthesia and spinal anaesthesia with intravenous sedation. Canadian Jonrnal of Anaesthesia $1989 ; 36: 382-7$.

7. Commissaris CJ, Ponds RW, Jolles J. Subjective menory problems and people's need for education and intervention. In: The Maastricht Aging Study: Deterninanis of cognitive aging. ed. Jolles J, Houx PJ, Boxtel MP. Ponds RW, 1995; 79-84.

8. Dierks-Venting VC, Gerhard U, Hobi V. Der Einfluss von Total und Regionalamastheste auf Komzentration und Gedachtnis. (The effects of total-and local antesthesia on concentlation and memory. Schweizerische Zeitschrift fur Psychologie 1989; 48: 112-20.

9. Dyer CB, Ashton CM, Teasdale TA. Postoperative delirium: A review of 80 primary dutameollechion studies. Archives of Internal Medicine 1995; 155: 461-5.

10. Edwards H, Rose E, Schorow M, King TC. Postoperative deterioration in psychomotor function. The Jourmal of the American Medical Association 1981; 245* 1342-3.

11. Flat JR, Birell PC, Hobbest. A. Effects of anaesthesia on some aspects of mental functioning of surgical patients. Anacsthesia and Intersive Care 1984; 12:315-24.

12. Folstein MF, Folstein, SE, McHugh PR. "Mini-Mental State": A practical method for grading the cognitive state of patients for the clinician. Journal of Psychiatric Research 1975; $12: 189-98$.

13. Forster A, Altenburger H, Gamulin Z Consequences de l'arnesthésie sur les fonctions superieures du sujet age (Effects of anesthesia on higher brain functions in the elderly). La Presse Médicale 1990; 19:1577.81.

14. Haan $J_{\text {, van }} \mathrm{KJ}$, Bloem $\mathrm{BR}$, et al. Cognitive function after spinal or general anesthesia for transurethral

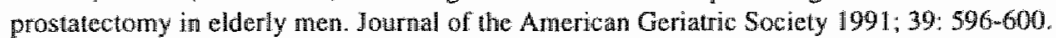

15. Hijman R, Jolles J, Verhoeven WMA, Wan Ree JM, Elderson A, Wied de D. Desglyoinamide-ARG8vasopressin in five trials with memory-disturbed patients. Human Psychopharmacology 1992; 7: 7-23.

16. Houx PJ Jolles J. Vulnerability factors for age-related cognitive dechine. In: Isacson RL, Jensen KR, ed. The Vulnerable Brain and Environmental Risk. New York: Plenum Press, 1994: 25-41.

17. Jolles J, Houx PJ, Van Boxtel MP, Ponds RW. The Maastricht Aging Study: Determinants of cognittive aging. Neuropsych Publishers, Maastricht 1995. 
18. Lezak MD. Neuropsychollogical Assessment. 3rd ed. New York: Oxford uniwersity press, 1995.

19: Meier $U$, Trullinger $\mathrm{E}$, Stoll $F$, Fassolt $\mathrm{A}$. Zur Frage der postoperativen konzentrations- und. gedalchunisstorungen bei chirurgische patienten. Schwevzerische Zeitschrift fur Psychologie 1986; 45: 10318.

20. Nielson WR, Gelb AW, Casey IE, Peniny FJ, Merchant RN, Mamninen PH. Long-term cognitive and social sequelae of general wersus regional anesthesia during arthroplasty in the elderly. Anesthesiology $1990,73,1103-9$.

21. Parikh S6, Chung F. Postoperative delirium in the elderly. Anesthesia and Analgesia 1995; 80: 1217-22.

22. Ruts $\mathrm{J}$, Lomholt $\mathrm{B}$, Haxholdr $\mathrm{O}$, et al. Immediate and long-term mental recowery from general versus epidural anesthesia in elderly patients. Acta Anaesthesiologica Scandinavica 1983;27:44-9.

23. Shaw PJ, Bates D, Cartlidge EF, et al. Long-term Intellectual Dysfunction following Coronary Artery Bypass Graft Surgery: a six month follow-up study. Quarterly Journal of Medicine 1987; New Series 62. 259-68.

24. Wallace LM. Communication variables in the design of pre-surgical preparatory information. British Journal of Clinical Psychology 1986; 25:111-8.

25. Williams-Russo $P$, Sharrock NE, Mattis S, Szatrowski TP, Charlson ME, Cognitiwe effects after ep idural vs general anesthesia in oider adults. The Journal of the American Medical Association 1995; 274:44-50.

26. Zucker-Goldstein $\mathrm{M}_{\text {s }}$ Fogel BS. Cogmitive change after elective surgery in nondemented older adults. The American Journal of Geriatric Psychiatry 1993; 1: 118-25.

27. Zung WWK, Durham NC, Richards CB, Coral Gables FLA, Short MJ. Self-rating depression seale in an outpatient clinic. Archives of General Psychiatry 1965; 13:508 15. 


\title{
An operation under general anaesthesia as a risk factor for age-related cognitive decline:
}

\section{Results from a large cross-sectional population study}

Jeanette B. Dijkstra, Peter J. Houx, Martin P.J. Van Boxtel, and Jellemer Jolles

\begin{abstract}
This study evaluates the factor "operation under general anaesthesia" as a possible risk facton for age-related cognitive decline. A history of an operation under general anaesthesia, age, and other health-related factors were estimated in a large-scale population study involving 1257 normal healthy subjects aged 24-86 years. Cognitive performance, subjective health and subjective memory were measured. A history of an operation under general anaesthesia, duration of anaesthesia, number of operations, and the interaction with age of these three factors were studied as possible predictors. Out of the 1257 healthy subjects 946 subjects appeared to have undergone at least one operation under general anaesthesia. It appeared that a bistory of an operation under general anaesthesia, number of operations, and duration of anaesthesia could not predict cognitive performance or memory complaints but significantly contributed to the number of subjective health-related complaints. Subjects with a history of an operation under general anaesthesia felt less healthy than subjects who had never undergone an operation under general anaesthesia. No interactions with age were found, indicating that there is no difference in the effect of an operation under general anaesthesia on cognitive performance between younger and older subjects. A possible high-risk group of subjects was selected in order to assess whether the effect of operation under general anaaesthesia is confined to this group. This group was characterised by advanced age ( $>66$ years) and an operation under general anaesthesia which had lasted longer than 3 hours in the last 15 years. This group was compared with matched subjects who had never been operatedon under general anaesthesia. Cognitive performance, subjective health, and memory were assessed. A history of an operation under general anaesthesia, number of operations, and duration of anaesthesia could not predict cognitive performance, experienced health or subjective memory, not even when a potentially high-risk group was selected. The present study found no support for the notion that a history of an operation under general anaesthesia is a determinant or risk factor for accelerated agerelated cognitive decline.
\end{abstract}




\section{INTRODUCTION}

It is well established that the average individual experiences a decline in virtually all cognitive functions as he or she grows older [2]. Although this nay be the case, there is also considerable evidence that not all functions decline at the same tate [16]. Furthermore, it is by no means clear whether all normal, non-diseased, and non-demented individuals suffer age-related decline in cognitive abilities to the same extent. In fact, in recent years evidence has been presented to show that there may be substantial individual differences. It has been argued that, for a given biological or cognitive function, normal individuals may show successful ageing, involving little or no decline, as well as usual ageing with some or conisiderable decline [17,21]. In earlier studies (The Maastricht Memory Study; MMS), 16,81 it was demonstrated that certain health-related events might explain some of the considerable differences that can be found in cognitive test performance, especially in elderly individuals. These events were described as "Biological Life Events" (BLE) and were defined as health-related factors, experienced at any time in life, that may affect brain functioning in otherwise "mormal' people. Examples are repeated mild head injuries, prolonged (but not current) use of psychotropic medication, or surgical interventions under general anaesthesia. In medical practice, these factors are typically regarded as having no long-term effect on memory or other cognitive functions. In a sample $(N=262)$ of healthy subjects of warious ages, these health-related factors accounted for a major part of the individual variation in test performance, comparable to the effect of age. Moreover, the difference due to these health-related factors was greater in the older subjects, which suggests that these lactors may aggravate the age-related cognitive decline. They can be thought of as lowering the threshold for the development of small functional deficits by reducing 'brain reserve capacity', a concept put forward by Satz [18].

In the above-mentioned studies [6], these health-related factors were studied in general. The effect of the separate health-related factors was not studied because the number of subjects affected by one single factor was too small. The cognitive performance of subjects who experienced at least one health-related factor was compared with that of age peers who were entirely unaffected by these health-related factors. However, the number of operations under general anaesthesia appeared to be most closely related (inversely) to cognitive performance.

The present study investigated the effect of 'operation under general anaesthesia' on cognition. In the last two decades several papers have been published concerning the influence of general anaesthesia on cognitive functioning $13,13,14.19,231$. In general, the conclusions are that mental changes can be found in the immediate postoperative period but not in the long term. However, Sotaniemi and coworkers [20] found that, even after the acute postoperative cognitive changes had disappeared, affected individuals were more likely to show early dementia 5 years later. This prompts the hypothesis that perioperative cerebral damage, even when its clinical effects are reversible, involves some neuronal loss which may make an individual more vulnerable to age-dependent cell loss in the future. Thus an operation under general anaesthesia may be a 'vulnerability factor' for age-related cognitive decline. Most studies did not monitor their patients over long periods of times, so comparisons with other studies cannot be made. Nevertheless, Sotaniemi and coworkers" findings suggest that an operation under general anaesthesia might be a factor which can negatively influence cognitive functioning in the long term. In the present study, a history of an operation under general anaesthesia and the interaction with age were studied as predictors of cognitive performance, subjective health, and subjective memory. Additionally, duration of anaesthesia, number of operations under general amaesthesia, and the interaction with age of these two factors were studied as predictors. 
Finally, a putative 'high-risk group' of subjects selected. These subjects had, in the last 15 years, undergone an operation under general anaesthesia that had lasted longer than 3 hours. This group was compared with matched subjects who had never been operated on under general anaesthesia. Cognitive performance, subjective health, and memory were assessed. This study was conducted as part of arge cross-sectional study into biological and psychological determinants of successful and pathological cognitive ageing, which was carried out witlin the Maastricht Aging Study (MAAS [9])

\section{MATERIALS AND METHODS}

\section{Subjects and procedure}

Heaithy subjects were recruited from the patient registers of general practices in the region of Maastricht in the Netherlands [12]. This register contains all relevant past and current medical morbidity as documented by the general practitioners. Subjects with previous or actual medical conditions with known impact on cognitive and/or motor functions were excluded from the selection. Exclusion criteria were overt cerebrovascular disease, chronic neurological pathology (e.g., dementia, epilepsy, parkinsonism), mental retardation, chronic cardiovascular or pulmonary disease, and psychotropic drug use. All subjects were thus normal and healthy. The subjects who were eligible for the study answered a postal questionnaire and participated in an extensive neuropsychological investigation. The standlardised postal questionnaire yielded a subjective report on medical history and demographic information, such as age, sex, education, and health-related factors with a possible impact on the brain. Educiational level was measured by a Dutch scoring system [1], which consists of an 8-point scale, ranging from unfinished primary education (level 1) to university education (level 8).

Subject sampling was stratified by 12 discontinuous age classes ( 25 years $\pm 1,30$ years \pm 1 , 35 years $\pm 1, \ldots, 80$ years \pm 1 ) and sex. In total 1257 subjects underwent neuropsychological investigation. The factor 'operation under general anaesthesia' was split up into three cattegories, as indicated by Houx et al. [7]: 1) subjects who had never been operated on under general anaesthesia (category 1: 311 subjects); 2) subjects who had had three or fewer operations under general anaesthesia and never with a duration exceeding 3 hours (category 2 : 739 subjects); 3) subjects who had had at least one operation under general anaesthesia lasting 3 hours or more, or at least four shorter episodes of general ancesthesia (category 3: 207 subjects). Additionally a putative high-risk group was selected. Twenty-three subjects who had had an operation lasting longer than 3 hours were pair-wise matched for age, sex, education, and a history of other health-related factors (health) with subjects who never had an operation under general anaesthesia. These other health-rellated events were treatment by a neurologist (present or past), brain trauma, use of medication, alcohol abuse, systemic disease, and treatment by a psychiatrist. Fourteen of these 23 subjects had undergone open heart-surgery, 7 had undergone other vascular surgery, 1 had undergone orthopaedic surgery, and 1 subject had undergone splenectomy. Subject characteristics are summarised in table 6.1.

\section{Measurements}

Visual Verbal Learning Test (VVLT). This is a computerised, visual version of a test of secondary memory. In five consecutive trials, 15 words are to be memorised and reproduced. 
Table 6. Demographic detals

\begin{tabular}{llllll}
\hline & $N$ & Age & Education & Sex \\
Mean $(S D)$ & $\begin{array}{l}\text { Mealth } \\
\text { Mean }(S D)\end{array}$ & N/Y \\
\hline Totall group & 1257 & $50.1(16.2)$ & $3.6(1.9)$ & $651 / 606$ & $585 / 672$ \\
$\quad$ Category 1 & 311 & $46.4(16.4)$ & $4.1(1.9)$ & $191 / 120$ & $177 / 134$ \\
$\quad$ Category 2 & 739 & $50.6(16.1)$ & $3.5(1.8)$ & $375 / 364$ & $341 / 398$ \\
$\quad$ Category 3 & 207 & $53.9(15.0)$ & $3.4(1.8)$ & $85 / 122$ & $67 / 140$ \\
Operated group & 946 & $51.3(15.9)$ & $3.5(1.8)$ & $460 / 486$ & $408 / 538$ \\
High risk group & 23 & $65.9(10.3)$ & $3.3(1.9)$ & $21 / 2$ & $2 / 21$ \\
High risk control group 23 & $63.9(9.6)$ & $3.4(1.7)$ & $21 / 2$ & $2 / 21$ \\
\hline
\end{tabular}

Note. Health: the experience of other health-related events $\left(\mathrm{N}=\mathrm{no}_{*} \mathrm{Y}=\right.$ yes); Category 1: newer operated under general anaesthesia; Category 2: three or fewer operations under general anaesthesia and never with a duration exceeding 3 hours; Category 3 ; anaesthesia lasting 3 hours or more, or at leasit four shorter episodes of general anaesthesia; Operation: all subjects with an history of an operation under general anaesthesia; Risk group: subjects with an operation exeeding 3 hours; Control group: subjects matched with the risk group but who had never had an operation under general anaesthesia.

The clependent variables are the total number of words recalled over the five trials (VVLTTOT) and the maximum score on one of the trials (VVLTMAX). The VVLT also involves delayed recall (VVLTDEL) after 20 minutes, enabling the measurement of memory storage [9].

Stroop Color Word Test (SCWT). The SCWT has often been used to test selective attention, mental speed, and interference susceptibility [9]. The test involves three cards displaying forty stimuli each: colour names (SCWT I), coloured patches (SCWT II), and colour names printed in incongruously coloured ink (SCWT III). The dependent variables are the time needed to read (SCWT D), or to name the colour of the patches (SCWT II) or printed ink (SCWT III).

The Concept Shifting Test (CST). This test is derived from the Trail Making Test, which has long been used to measure the ease of shifting between concepts in ongoing behaviour [9]. It consists of four parts. On each test sheet, 16 small circles are grouped in a larger circle. In the first part empty circles have to be crossed out as fast as possible (CSTO). In the other three parts the circles contain numbers (CSTA), letters (CSTB), or both (CSTC), appearing in a fixed random order: Subjects are requested to cross out the items in the right order as fast as possible.

Letter Digit Substitution Test (LDST). This test is a modification of the procedurally identical Symbol-Digit-Modalities Test (SDMT; see Lezak, 110], (pp. 554-55). Subjects are required to reproduce, within 60 seconds, as many digits as possible in blank boxes beneath randomly generated letters according to a coding scheme for pairing letters with digits.

The VOEG-2l (inventory of subjective health; [4]) was included as an index of subjective health. It has been used in several Dutch surveys to determine subjective health status and it probes health complaints of a somatic and psychosomatic nature.

The abridged Dutch Meta-memory in Adulthood (MIA) [15]. This questionnaire was used to evaluate subjective memory functioning. Four subscales of this questionnaire were used; perceived memory capacity (Capacity), perceived change in memory functioning (Change), perceived feelings of stress and anxiety related to memory performance (Anxiety), and perceived sense of control over memory (Locus). 


\section{Data reduction and analyses}

To limit the number of dependent variables and to improve the robustness of the underly ing cognitive construct, we clustered most of the raw test scores into three compound performance indices, labelled Memory, Cognitive Flexibility, and Sensorimotor Speed [22]. Raw scores were transformed to standardised $\mathrm{Z}$ scores for the total group. Next, the average was taken of $\mathrm{Z}$ scores from tests that were included in the compound performance index: the Memory score was derived from the total, maximal and delayed recall scores of the VVLT; the Cognitive Flexibility score included the C version of the CST and subtask III of the SCWT; and Sensorimotor Speed was calculated from the 0 , A and B versions of the CST, and subtask I of the SCWT. Thus, in formula: Memory $=\left(Z_{\text {VVLTTOT }}+Z_{\text {VVLTMAX }}+Z_{\text {VVLTDEL }}\right) / 3$, Cognitive Flexibility $=-\left(Z_{\text {CSTC }}+Z_{\text {SCWT III }}\right) / 2$, and Sensorimotor Speed $=-\left(Z_{C S T 0}+Z_{C S T A}+Z_{C S T B}+\right.$ $Z_{\text {SCWT } 1} / 4$. The signs of the speed and flexibility scores were inverted to make them reflect above average performance when positive and below average performance when negative. LDST outcome was not included in the compound scores as performance on this test is not domain specific

Performance on cognitive measures, subjective health, and subjective memory were predicted using multiple hierarchical regression analysis. Three different models were tested to answer three different questions. In the first model, the effect of a history of an operation under general anaesthesia on the dependent variables was studied. In the second model, the effect of duration of anaesthesia was studied, and in the third model the number of operations. In the three different models chronological age, sex, education, and health were always entered in the first step. The second and third steps were dependent on the separate models which were used to predict outcome on the dependent variables.

In the first model, the factor "an operation under general anaesthesia" and the interaction with age of this factor were entered as predictors in the second step. To get higher contrasts and to increase the chance of detecting possible effects, only data from subjects in operation categories 1 and 3 were used in this model. The final block of variables involved terms testing interactions between an operation under general anaesthesia and sex, education, and health. In the second model, the duration of the operation and the interaction with age were entered as predictors in the second step. All subjects who underwent an operation under general angesthesia were used in this model (i.e. categories 2 and 3). For each operation a duration code was given ranging from one (less than 30 minutes) to four (more than 3 hours). When a subject underwent more than one operation, the duration codes of the different operations were summed. In the last step, the variables involved terms that tested interactions between duration of operation and sex, education, and health. In the third model the number of operations was entered as predictor in the second step and the interaction between age and this predictor. Again the interaction of the main predictor with sex, education, and health was entered in the third step.

In order to see whether a relatively recent operation which lasted more than 3 hours might be a more clear-cut risk factor, we selected subjects. who had undergone an operation in the last 15 years under general anaesthesia with a duration of more than 3 hours. Twenty-three subjects fulfilled these criteria. "They were matched for age, sex, educational level, and health with subjects who had never undergone an operation under general anaesthesia. Between-group differences were tested with paired t-tests. 


\section{RESULTS}

Zero-order correlations between predictor variables for the separate models were computed. For the first model, which studied the effect of a history of an operation under general anaesthesia, the cognitive outcome measures, subjective health-related measures, and subjective memory measures are presented in table 6.2 .

Table 6.2 Zero-order correlations between age, education, sex, health, anaesthesia (categories $\mathbb{1}$ and 3 ) and cognitive perforinance; subjective health and subjective memory.

\begin{tabular}{|c|c|c|c|c|c|}
\hline & Age & Dadication & $\operatorname{se} x$ & Health & Anaesthesia \\
\hline Age & 1.00 & $-0.32 * *$ & $-0.12 *$ & $0.33 *$ & $0.23 *$ \\
\hline Educration & $-0.32 *$ & 1.00 & $-0.06 * *$ & -0.21 * * & $-0.17 *$ \\
\hline $\operatorname{sex}$ & $-0.12 *$ & -0.06 & 1.00 & -0.00 & $0.20^{*}$ \\
\hline Health & $0.33 * *$ & $-0.21 * *$ & -0.00 & $\llbracket .00$ & 0.24 \\
\hline Andesthesia & $0.23 *$ & $-0.17 * *$ & 0.20 綿 & $0.24 *$ & 1.00 \\
\hline LDST & -0.66 & $0.45^{*}$ & $0.11 *$ & $-0.22 * *$ & $-0.12 * *$ \\
\hline Cogntive flexibility & 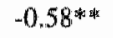 & $0.46 *$ & 0.08 & $-0.19 * *$ & $-0.16 *$ \\
\hline Memory & $-0.39+4$ & $0,21 *$ & 0.28 에 & $-0.13 * *$ & -0.04 \\
\hline Sensorimotor speed & $-0.60^{* * * 4}$ & $0.45 * *$ & 0.04 & $-0.22 *$ & $-0.21 *$ \\
\hline Subjective health & $0.15^{* k}$ & -0.29 w & $0.17 *$ & $0.29 * *$ & 0.27 皮 \\
\hline Anxiety (MIA) & $0.27 *$ & $-0,33^{* *}$ & $0.09 *$ & $0.24 * *$ & $0.09 *$ \\
\hline Capacity (MIA) & $-0.34 *$ & $0.14 * *$ & $0.11 * *$ & $-0.177 *$ & -0.02 \\
\hline Locus (MIA) & 0.01 & -0.09 & 0,02 & -0.05 & -0.01 \\
\hline Change (MIA) & $-0.52^{* * * k}$ & $0.25 *$ & 0.03 & $-0.29 *$ & -0.15 \\
\hline
\end{tabular}

Note. Age: chronological age; Edwcation: level of education ranging from 1 (low) to 8 (high); Sex: male=1, fennale $=2$; Health: other health-related events, $N=0$, $\mathrm{Y}=1$; Anaesthesia: subjects from category $\mathbb{1}(=0)$ and $3(=2)$; LDMT: Letter Digit Substitution Test; M1A: Meta-memory in Adulthood questionnaire; ${ }^{*} p<.05$; *th $p<01$

The four cognitive parameters were highly negatively correlated with age $(-.39$ up to -.66$)$, and $_{\text {, }}$ to a lesser extent, with objective health $(-13$ up to -.22$)$. They were positively correlated with ducation (.21 up to .46). This indicates that older subjects, less healthy subjects, and subjects with a lower education performed less well on the cognitive tests than did younger, healthy and, highly-educated subjects. Relatively high correlations between cognitive parameters and age may in part be explained by the -.32 correlation between age and education and the 33 correlation between age and objective health.

The total score on the general health scale (VOEG-21) correlated positively with age, sex, abjective health, and an operation under general anaesthesia (.15 up to .29), and megatively with education $(-.29)$. This indicates that older subjects, females, less healthy subjects, and less educated subjects felt less healthy. These correlations may partly be explained by the high correlations with age and these predictors ( -.12 up to .33).

The four subjective memory parameters on the Meta Memory in Adulthood Questionnaire (MIA) showed different correlations with the predictor variables per subscale. The subscale 
anxiety was positively correlated writh age $(27)$ and objective health $(24)$, and negatively correlated with education ( -33 ), indicating that older, less healthy, and lower educated subjects had more subjective memory problems related to higher anxiety. The subscale capacity was positively correlated with education $(.14)$ and sex $(.11)$, and negatively correlated with age $(-34)$ and objective health (-.16), indicating that older, lower educated, male subjects, and less healthy subjects had more subjective memory problems related to capacity problems. There were no high correlations between the subscale locus and the predictor variables. The subscalle change was positively correlated with education (.25) and negatively correlated with age (-.52), objective health $(-28)$, and an operation under general anaesthesia $(-15)$, indicating that older, lower educated, less healthy subjects, and subjects with an operation under general anaesthesia experienced a change in subjective memory.

Zero-order correlations between the predictor variables, subjective health and memory, for the second and third models are not presented here, but were in general identical to those of the first model.

Multiple hierarchical regression analyses were undertaken to evaluate the predictive power of a history of an operation under general anaesthesia and the interaction between age and the four cognitive scores, subjective health, and subjective memory. The results are summarised in table 6.3. Age, sex, education, and health were entered block-wise in step $\mathbb{1}$. An operation under general anaesthesia and the interaction with age were entered in step 2. In step 3 interactions between sex, education, health, and a history of an operation under general anaesthesia were entered to see whether these interactions could explain additional variance after step 2 . A main effect of an operation under general anaesthesia was found on the total score of the VOEG-21 $($ Bet $a=15, t=3.5, p<.001), 2.3 \%$ of the variance was explained by step 2 (see table 6.3). No main effects of an operation under general anaesthesia or an interaction with age were observed on the cognitive variables. Step 3 did not contribute to an explanation of the variance in any measure. This indicates that an operation under general anaesthesia affected subjective health but not cognitive performance or subjective memory. Subjects who had experienced at least one episode of general anaesthesia lasting 3 hours or more, or at least four shorter episodes of general anaesthesia, felt less healthy than subjects who had never experienced an operation under general anaesthesia. In general ${ }_{b}$ the same results were found with the two other models in which, instead of an operation under general anaesthesia, duration of anaesthesia and number of operations were studied as main predictors, and the interaction between age and these predictors

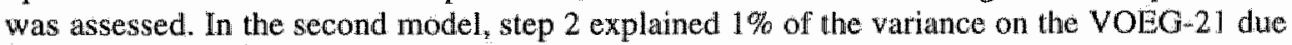
to the predictor duration of anaesthesia $(B e t a=.07, t=2.0, p<.05)$. Subjects who had undergone a relatively long operation felt less healthy than subjects who had undergone a relatively short operation. In the third model, step 2 explained $1 \%$ of the variance on the VOEG21. due to the predictor number of operations under general anaesthesia (Beta $=10, t=3.2, p$ $<.01$ ). In the third model, step 2 also explained $0.5 \%$ of the variance on the LDMT due to the number of operations $(B e t a=.07, t=2.7, p<.01)$. Subjects who had undergone more operations felt less healthy and performed worse on the LDMT than did subjects who had undergone fewer operations. In the second and third models, step three did not contribute to an explanation of the variance in any measure.

The first model, which was fitted for a history of an operation under general anaesthesia, showed that the predictors in step 1 explained $22 \%$ (memory) up to 50\% (LDMT) of the variance in the cognitive measures mainly due to the factors age and education, $16 \%$ of the variance in subjective health mainly due to the factor health, and $15 \%$ (capacity) up to $29 \%$ (change) of the variance in subjective memory mainly due to the factor age. There was no 
noticeable change in the size or direction of the observed effects when the entry of blocks was reverged and age was entered in the last block of variables. Table 6.3 summarizes the regression results for the first model. Results for the second and third models are not shown here, but were virtually identicall.

Table 6.3 Results of regression analysis of several background warables on cognitive performance. subjective health (VOEG-21), and subjective menory of 518 subjects (category 1 and 3 ).

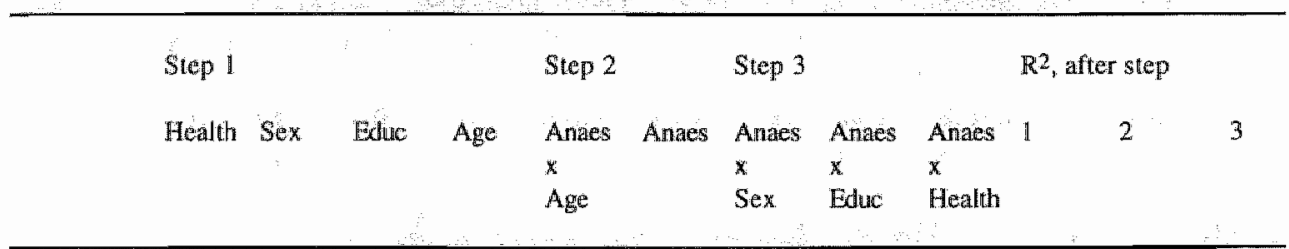

Cognibie measures

\begin{tabular}{|c|c|c|c|c|c|c|c|c|c|c|c|c|}
\hline LDMT & .02 & 04 & .28 和 & $-.58 *$ & -.05 & .06 & -.05 & 29 & .01 & $.501 * *$ & .505 & .507 \\
\hline Flexibility & .03 & 05 & 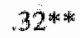 & -48 的 & -06 & .00 & -.01 & .03 & -.01 & $.419 * *$ & .423 & .425 \\
\hline Mennory & -00 & 25 米 & $12^{*}$ 林 & $-32^{\text {w和 }}$ & -.05 & .00 & .01 & -.03 & .03 & $.216 *$ & .218 & .219 \\
\hline Speed & .01 & .01 & $.29 *$ & -50 & -.06 & -.05 & -.02 & -02 & .04 & $.432 * 3 k$ & .435 & .437 \\
\hline
\end{tabular}

Sibjective healh

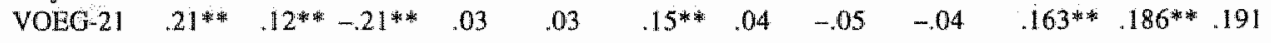

Subjective memory (MIA)

\begin{tabular}{|c|c|c|c|c|c|c|c|c|c|c|c|c|}
\hline Anxiey & $.16 *$ & $.10^{*}$ & $-23 *$ & $.16^{\text {\% * }}$ & .03 & -.03 & -.03 & -.01 & -.02 & $.160^{* * *}$ & .162 & .163 \\
\hline Capacity & -07 & .07 & .05 & $-34 *$ & .01 & .07 & -.01 & .04 & -.00 & $.146 *$ & .149 & .150 \\
\hline Locus & -.07 & .03 & -.09 & -0.04 & .08 & -.04 & .03 & .04 & .06 & .012 & .019 & .024 \\
\hline Change & $-15^{*}$ & -.01 & .07 & -.44 & -.01 & .00 & -.00 & .03 & .06 & $.290^{* *}$ & .290 & .294 \\
\hline
\end{tabular}

Note. Health: the existence of other heallh-related factors, $N=0, \mathrm{Y}=1$; Sex $(\mathrm{m}=1, \mathrm{f}=2)$; Educ: educational level; Anacs: subjects from category $1(=0)$ and $3(=2)$. Shown are standardised regression coefficients (Beta) in the final

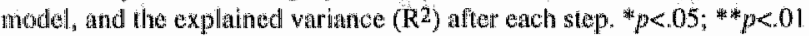

In terms of explained variance, the contribution of an operation under general anaesthesia, duration of operation, and number of operations was small and only affected the subjective health measure but not cognitive performance and subjective memory. The interaction between age and a history of an operation under general anaesthesia could not explain any wariance. In step 3, the interaction terms sex, education, and objective health with an operation under general anaesthesia, duration of anaesthesia or number of operations did not contribute to the explained variance.

In order to see if a potential high-risk group performed differently on cognitive, subjective health and subjective memory outcome measures, 23 middle-aged and older subjects subjects with a relatively recent operation lasting longer than 3 hours were matched with subjects who had never been operated on under general anaesthesia, whille controlling for age, sex, education, and the absence or presence of other health-related factors. Raw cognitive scores of this subgroup were again transformed to individual $Z$ scores and compound scores, using the abowe described formulae. Both groups are contrasted in table 6.4. Paired t-tests revealed no 
difference in cognitive, subjective health, and subjective memory outeome measures. This indicates that subjects who had undergone extensive surgery did not perfom differently from subjects who had never been operated on.

Table 6.4 Paired-timtests between athigh-risk" group and controls

\begin{tabular}{|c|c|c|c|}
\hline Control & $\begin{array}{r}P(N=23) \\
M(S D)\end{array}$ & $\begin{array}{r}\text { Operation group }(N=23) \\
M(S D)\end{array}$ & T-walue $(p)$ \\
\hline LDMT & $26.2(6.5)$ & $27.2(7.6)$ & 0.68 (ns) \\
\hline Cognitive flexibility & $-.35(.85)$ & $-.71(.99)$ & $1.46(\mathrm{~ms})$ \\
\hline Memory & $-.48(.84)$ & $-46(.99)$ & $-0.11(\mathrm{~ms})$ \\
\hline Sensorimotor speed & $-.26(.66)$ & $-.49(.85)$ & 1.24 (ns) \\
\hline Subjective health & $3.8(3.2)$ & $5.5(5.2)$ & -1.27 (ns) \\
\hline Anxiety (MIA) & $33.9 \cdot(7.5)$ & $33.1(7.1)$ & $0.38(\mathrm{~ns})$ \\
\hline Capacity (MIA) & $35.2(7.1)$ & $33.8(5.6)$ & $0.79(\mathrm{~ns})$ \\
\hline Locus (MLA) & $21.1(2.6)$ & $21.5(2.2)$ & -0.76 (ns) \\
\hline Change (MIA) & $28.8(6.0)$ & $28.0(6.8)$ & $0.44(\mathrm{~ns})$ \\
\hline
\end{tabular}

Note. $\mathrm{ns}=$ not sigmificant

\section{DISCUSSION}

This study investigated the predictive value of a history of an operation under general anaesthesia and the interaction between age and cognitive performance, subjective health, and subjective memory. Additionally, the number of operations and the duration of anaesthesia and their interaction with age were studied as predictors of cognitive performance, subjective health, and subective memory. None of these variables could predict cognitive performance or psychological functioning, not even when a putative high-risk group was selected. No interactions with age were found, indicating that there is no evidence of a difference in the effect of a history of an operation under general anaesthesia on cognitive performance between younger and older subjects. A history of an operation under general anaesthesia, duration of the operation, and number of operations significantly contributed to the score on the VOEG-21, at measure of subjective health. These findings are not surprising, because these subjects had been ill and had had one or more operations, so when they are asked about their health they would score higher on health-related measures.

These findings indicate that the earlier findings of Houx and Jolles $[6,5]$ are not corroborated for the factor 'operation under general anaesthesia'. It remains possible that the earlier findings are not explained by the factor 'operation under general anaesthesia' but by other health-related factors such as repeated mild head trauma or use of psychotropic medication. The predictor "health" (presence or absence of other health-related factors) used in the present study is identical to the measure used in the study by Houx and Jolles, except that a history of an operation under general anaesthesia was not included in this measure but was studied separately. The predictor "health" did not contribute to the explained variance in cognitive performance. The present study found no evidence for the notion that an operation under 
general anaesthesia is a risk factor or vulnerability factor for cognitive decline in older age. It remains to be judged whether brain trauma or other health-rellated factors which were considered in the study of Houx et al. constitute risk factors when studied separately.

Another explanation for the discrepancy between the results of this study and the study of Houx and Jolles may be the difference in the procedure of subject recruitment. In the latter study, subjects were recruited by an advertisement, whereas in the present study, a database of family practice patients was used, Possibly, the latter subjects were less motivated to perform well. It is also possible that the former subjects were more intelligent. The data on the health-related factors were also gathered differently: in the earlier study " an experienced neurologist carried out a semi-structured interview with the subjects, whereas in the present study the data were collected by means of a postal survey. The overall test performance of the subjects tended to be lower in the present study. This is in accordance with the notion that the composition of the present sample is different from the earlier sample, at least with respect to motivation and/or general ability.

In conclusion, the present results are not in line with the notion that a history of an operation under general anaesthesia may affect cognitive performance in the long run. This finding is in line with the literature, which has never been able to demonstrate persistent cognitive dysfunctions months after an operation but only short-term effects (days or weeks). However, it is clear that there are subjects who have subjective cognitive complaints for a long time after the operation, but these complaints have has not been objectified by using cognitive tests. From this study it is clear that subjects with a history of an operation under general anaesthesia report more subjective health-related complaints, but do not show a difference in cognitive performance or subjective memory, when compared with subjects who have never been operated on under general anaesthesia.

\section{REFERENCES}

1. Bie SE. Standaardvragen 1987. Voorstellen voor uniformering van vraagstellingen naar achtergrondkenmerken en interview [Standard questions 1987. Porposal for uniformisation of questions regarding background variables and interviews]. Leiden: The Netherlands: Leiden Universily Press, 1987.

2. Birten JE, Schaie KW. Ed. Handbook of the psychology of aging. 2nd ed. New York: Van Nostrand Reinhold Company, 1985.

3. Chung $F$, Seyone $\mathrm{C}$. Dyck $\mathrm{B}$, et al. Age-related cognitive recovery after general anesthesia. Anesthesia and Analgesia 1990; $71: 217-24$.

4. Dirken JM. Het meten van 'stress' in industriele situaties [Measurement of stress in industrial situations》. Groningen: The Netherlands: Wolters, 1967.

5. Houx PJ, Jolles J. Age-related decline of psychomotor speed: Effects of age, brain health, sex and education. Perceptual and Motor Skills 1993: 76: 195-211.

6. Houx PI, Jolles J. Vulnerability factors for age-related cognitive decline. In: Isaacson RL. Jensen KF, ed. The Vulnerable Brain and Environmental Risk. New York: Plenum Press, 1994: 25-41,

7. Houx PJ, Vreeling FW, Jolles J. Age-associated cognitive decline is related to biological life events. In: Iqlual $\mathrm{K}_{\text {, McLachlan DRC }}$ Winblad B, Wisniewski HM, ed Alzheimer's Disease: Basic Mechanisms, Diagnosis and Therapeutic Strategies. Chichester, UK: John Wiley \& Sons Ltd, 1991: 353-9.

8. Houx PJ, Vreeling FW, Jolles $\int$. Rigorous health screening reduces age effect on memory scanning task. Brain and Cognition $1991 ; 15: 246-60$.

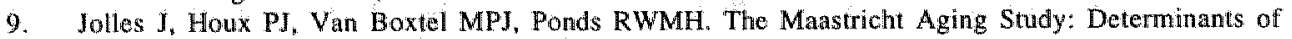
cognitive aging. Neuropsych Publishers, Maastricht 1995.

10. Jolles J, Houx PI, Vreeling FW, Verhey FRJ. Cognitive aging, biological life events and primitive reflexies. Neuroscience Research Communications 1993; 13: \$47-\$50.

11. Lezak MD. Neuropsychological Assessment. 3rd ed New York: Oxford University Press, 1995. 
12. Metsemakers JFM, Hoppener P, Knotmerus JA, Kocken RJJ, Limonard CBG. Computerized health information in the Netherlands: A registration network of family practices. British Journal of General Practice 1992: 42: 102-6.

13. Mgller JT, Svennild II, Johannessen NW, et al. Perioperative monitoring with pulse oximetry and late postoperative cognitive dysfunction. British Journal of Anaesthesia 1993; $71: 340-7$.

14. Nielson WR, Gelb AW, Casey JE, Penny FJ, Merchant RN, Manninen PH. Longeterm cognitiwe and social sequelae of gemeral versus regional anesthesia during arthroplasty in the elderly. Anesthesiology 1990; 73: 1103-9.

15. Ponds RWHM, Jolles J. The abridged Dutch Metamenory in Adulthood (MIA) questionmaire: Structure, and effects of age, sex, and education. Psychology and Aging 1996; 11: 324-32.

16. Rabbitt PMA. Applied cognitive gerontology: Some problems, methodologies and data. Applied Cognitive Psychology 1990; 4: 225-46.

17. Rowe JW, Kahn, RL. Human aging: Usual and successful. Science 1987; 237: 143-9.

18. Saiz $\mathbb{P}$. Brain reserve capacity on symptom onset after brain injury: A formulation and review of evidence for threshold theory. Neuropsychology 1993; 7:273-95.

19. Smith RJ, Roberts NM, Rodgers RJ, Bennett $\mathrm{S}$. Adverse cognitive effects of general anaesthesia in young and elderly patients. International Clinical Psychopharmacology 1986; 1:253-9.

20. Sotaniemi $\mathrm{KA}$, Mononen $\mathrm{H}$, Hokkanen TE. Long-term cerebral outcome after open-heart surgery: A fiveyear neuropsychological follow-up study. Stroke 1986; 17: 410-7.

21. Stones MJ, Kozma A. Hannah TE. The measurement of individual differences in aging: The

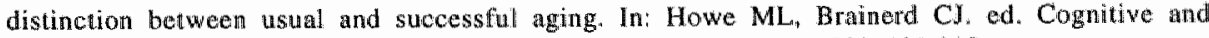
Behavioral perfornance factors in atypical aging. New York: Springer. 1990: 181-218.

22. Van Boxtel MPJ, Langerak K, Houx PJ, Jolles J. Sellf-reported physical activity, subjective health and cognitive performance in older adults. Experimental Aging Research 1996; 22:363-379.

23. Williams-Russo P, Sharrock NE, Mattis S, Szatrowski TP, Charlson ME Cognitive effects after epidural vs general anesthesia in older adults. The Journal of the American Medical Association 1995: 274: 44-50. 



\section{VII}

\section{Concluding remarks}

The main topic of this thesis is the influence of an operation under general anaesthesia on cognitive ageing. Most studies looking at the effect of surgery on cognitive functioning, as assessed with psychometric tests, demonstrated a short-term cognitive decline but seldom at long-term cognitive decline. This finding is discrepant with the subjective complaints reported by patients in the long term. This discrepancy may partly be explained by selection bias, the use of insensitive tests, the lack of parallel test versions and healthy control groups, and studying group changes instead of individual changes. Another possible explanation is that subjective cognitive complaints are not based on cognitive decline but on other factors.

The results of the empirical studies in this thesis confirm the notion that there is a decline in cognitive performance shortly after an operation and that performance, as measured by psychometric tests, is normal in the long term. Thus patients undergoing coronary artery bypass graft surgery showed a decline in cognitive functioning 10 days after the operation but 6 weeks after the operation their performance was equal to or improved when compared with their preoperative level. Although elderly people needed more time to recover from their short-term learning dysability, no interactions were found between age and cognitive functioning 6 weeks after the operation (chapter 3). Elderly patients undergoing an operation under general anaesthesia also showed a decline in cognitive function 1 week after the operation when compared with healthy control subjects. After 3 months no change or improvements were found on psychometric tests when compared with the preoperative cognitive performance. With respect to cognitive complaints, however, 6 months after the operation about $31 \%$ of the patients reported having experienced a decline in mental abilities after discharge from hospital. About $17 \%$ still experienced this mental decline at the moment of the evaluation (after 6 months). In the long term, there seems to be a discrepancy between objective cognitive test performance and cognitive complaints (chapter 5). Similary, negative findings with respect to cognitive dysfunction after an operation under general anaesthesia were found in a large cross-sectional population study. A medical history including an operation under general anaesthesia, number of operations, and duration of these operations were studied as risk factors for age-related cognitive decline, yet none of these variables could predict cognitive performance. Even a potentially high-risk group of subjects had a cognitive performancenot different from that of subjects who had never been operated on. Therefore, an operation under general anaesthesia appears not to be a risk factor or determinant for an accelerated cognitive decline with advancing age (chapter 6 ). This is the major finding in the present thesis, which needs to be discussed in somewhat more. detail. The following points will be addressed in this chapter:

1. Short-and long-term cognitive effects of surgery and possible determinants.

2. Discrepancy between objective test performance and cognitive complaints in the long term.

3. Psychologicall explanations for the discrepant findings in the long term.

4. The effect of age on cognitive outcome after surgery.

5. Anaesthesia as a possible risk factor for accelerated cognitive decline with advancing age. 
Short-and long-term cognitive effects of surgery and possible determinants

Despite the many methodological differences between studies investigating the infuence of an operation under general anaesthesia on cognitive function, there is some consistency in that deficits in cognitive performance have been found shortly after surgery (before discharge from the hospital) by using psychometric tests (chapter 1 and 2). There are various reasons for these performance deficits. The immediate and very transient cognitive decline may be due to reversible or irreversible brain dysfunctions that can be ascribed to anaesthesia. This is the main notion which is addressed in the present thesis. However, simpler explanations are also possible, for instance, the residual effects of anaesthetic drugs, other administered medication, complications during surgery, pain, sleep deprivation, age, or underlying disease. Type of operation, time of cognitive assessment, and mood do not seem to influence this short-term cognitive decline. This transient cognitive impairment may be annoying for patients, but eventually most patients will experience a substantial or complete cognitive recovery.

Although Jong-term cognitive effects of surgery were seldom found, several studies investigating the influence of open-heart surgery on cognitive functioning have reported a substantial percentage of patients showing cognitive decline several months after the operation. This decline is often based on individual change and is possibly overestimated because the definitions used to calculate this decline are in general too sensitive. In addition, these studies usually did not include healthy control groups assessed in the same way. Likewise, improvements in test performance after an operation is often not considered (see chapter 4).

Discrepancy between objective cognitive test performance and cognitive complaints in the long. tern

Although cognitive decline in the long term is seldom found by using psychometric tests, a substantial proportion of patients complain about a decline in mental abilities. This was demonstrated in chapter 5 and has also been reported by others $[4,5]$. These complaints especially involve long-term effects. Thus a discrepancy is found between objectively measured cognitive functionityg and cognitive complaints reported in the long term. If one assumes that cognitive complaints are caused by cognitive dysfunctions, there are several explanations for this discrepancy. One explanation is selection bias. Most studies excluded patients with questionable mental status and physical condition. Also patients who do not fee] well, physically or mentally, before an operation are more likely to refuse to participate in a study. The same applies to patients who are tired, depressed, or scared of the operation. Patients who are feeling well and who are aware of the need for scientific research (high education) are more likely to agree to cooperate. Nevertheless, the patients who are not included in scientific evaluation studies do undergo surgery under general anaesthesia. It is not unlikely that this group is at risk for long-term postoperative cognitive dysfunctions and will report cognitive complaints. However, such a selection bias does not explain the discrepancy between cognitive complaints and test performance within a selected patient group such as described in the present thesis (chapter 5).

Other explanations are the use of insensitive tests, the lack of parallel test versions and heallhy control groups, and studying group changes rather than individual changes. The types of test used in most studies are perhaps not sensitive enough to measure subtle cognitive change in the long term, changes which can affect the quality of life considerably and cause cognitive complaints. In the studies described in chapters 3 and 5 , tests were used which have been 
proven to be sensitive to subtle change. Nevertheless, these studies were also not able to demonstrate a change in cognitive performance 6 weeks or 3 months after surgery. $\mathrm{So}$, the sensitivity of tests is probably not an explanation for the discrepancy. A learning effect could have obscured a decline in test performance because most studies have not used parallel test versions or a healthy control group to correct for the effect of repeated testing on cognitive performance. Thus in most studies "no change or an "mprovement in performance" is interpreted as "no decline", but it is possible that a healthy control group would have shown an even greater improvement so that the performance of patients is impaired when compared to that of controls. In the studies described in chapters 3,4 , and 5 parallel test versions were used and in chapters 4 and 5 a healthy control group was used to correct for the effect of repeated testing on cognitive performance. However, no long-term cognitive decline was found, indicating that the lack of a healthy control group and the use of parallel test versions cannot explain the discrepancy between objective test performance and subjective complaints in the long term. Most studies have only looked at the change in mean performance. It is possible that there is a small subgroup of patients who are at risk for cognitive decline after surgery and that they are not detected when only change in mean group performance is considered. Perhaps this subgroup is suffering from cognitive dysfunctions and reports cognitive complaints. Although both group change and individuall change were studied in this thesis, no substantial differences were found between these two methods for assessing short- and long-term cognitive dysfunction. Thus the above-mentioned possible causes are unable to explain the discrepancy between subjective reported complaints and objective test performance.

A final possibility, which needs further consideration (and study), is that not much time is available for cognitive assessment. It is possible that the patients are able to perform quite well during a short period, by putting much effort into their performance, but that their daily functioning is compromised and gives rise to cognitive complaints. In other words, the patients are able to mobilize cognitive resources for a short time during the testing session, but they are not able to sustain this for a prolonged period. This hypothesis will be tested in follow-up research.

\section{A possible psychological explanation for the discrepant findings in the long term}

There is a possibility that some or all of the postsurgical complaints of cognitiwe functioning do not reflect cognitive deficits. The patients ${ }^{\circ} \mathrm{s}$ operation could trigger a number of psychological events, e.g., mild depression or awareness of age-related changes, which could leald to subjective feelings of cognitive dysfunction not associated with impaired performance on cognitive tests. The experience of an, unexpected, cognitive decline shortly after the operation, may worry patients and lead to cognitive complaints. If this is true, patients should be given information about what to expect after an operation. Medical psychological or neuropsychological interventions could be of importance in this respect. Wallace $[8]$ demonstrated that a preparatory booklet designed to reduce stress in surgical patients had an effect on patients" knowledge, reported information, and worries about surgery. He found that patients who had more knowledge about surgery had fewer worries and recovered faster.

Earlier studies rarely examined both subjective reports and objective performance together. One study examined whether patients who reported cognitive deterioration after coronary artery bypass surgery (CABS) showed cognitive dysfunctions as assessed with cognitive tests $\llbracket 77$. They found that the patients who considered that aspects of their cognitive function had deteriorated were not found to have reduced functions as assessed with cognitive tests 12 
months after the operation. When mood state was examined it was found that patients who reported deterioration tended to thave higher levels of depression and anxiety. The authors concluded that subjective teports of cognitive dysfunction following CABS do not reflect actual changes in cognitive functioning but rather appear to be related to mood Vingerhoets and coworkers [8] found that elevated emotional arousal (anxiety and depression) in patients scheduled for open-heart surgery had no relevant effect on their cognitive performance. Although levels of anxiety and depression seem not to affect cognitive test performance, they can have an impact on cognitive complaints. Other complex factors, such as the degree of emotional support the patient's financial condition, and the degree to which the surgical procedure improves the elderly patient's social integration, may influence cognitive outcome and nervous system effects in the long term too [6]. Also preoperative level of function, psychosocial variables such as social network, coping style, personality, and expectations of the operation need to be analysed in larger studies. Not much attention has been paid to these factors, so their importance is not clear. Again, follow-up studies have been planned to investigate these issues in more depth.

\section{The influence of age on cognitive outcome after surgery}

Our results indicate that age is not the most important factor causing cognitive deterioration after surgery. However, ageing is an all-encompassing, multifactorial process involving a decreased capacity for adaptation and a gradual decrease in functional reserve of all the body's systems. Ageing itself is not a disease process but is instead an index of the probability of many disease states. This supports the opinion that biological age rather than calendar age influences the degree of postoperative mental decline.

\section{Anaesthesia as a possible risk factor for accelerated cognitive decline}

A medical history of an operation under general anaesthesia, duration of operation, and number of operations and their interaction with age were not found to be predictive of cognitive performance. In the studies reported in this thesis, a history of an operation under general anaesthesia couldi not predict cognitive performance (chapter 6). Even a potentially high-risk group of subjects had a cognitive performance similar to that of subjects without a history of an operation under general anaesthesia. No interaction of an operation under general anaesthesia with age was found, indicating that an operation under general anaesthesia had a similar effect on cognitive performance in younger and older subjects. These findings do not corroborate the hypothesis put forward by Houx and Jolles: $[1,2,3]$ about the negative effect of anaesthesia in elderly subjects. In short these investigators found that healthy elderly subjects who had undergone one or more of the so-called Biological Life Events at some point in their life were characterised by inferior neurocognitive functioning. Because of the relatively small number of healthy subjects $(247)$, they were not able to differentiate the possible effect of general anaethesia from that of mild head injury, use of alcohol, psychtropic medication, and other health-related events. Thus it is possible that the earlier findings are not explained by an operation under general anaesthesia but by the other health-related factors, such as repeated mild head trauma or use of psychotropic medication. However, in the present study, health-related factors other than a history of an operation under general anaesthesia did not contribute to the explained variance in cognitive performance.

An explanation for the discrepancy between the results of this study and Houx and Jolles' 
study is the difference in subject recruitment. In the Maastricht Memory Stady subjects were recruited by an advertisement, and in the present study they were recruited from a database of family practice patients. Possibly, the latter subjects were less motivated to perform well. It is also possible that the former subjects were more intelligent. The data on the health-related factors were also gathered differenty: in the earlier study, an experienced neurologist carried out a semi-structured interview with the subjects whereas in the present study the data were collected by means of a postal survey. The overall test performance of the subjects tended to be lower in the present study. This is in accordance with the notion that the composition of the present sample is different from the earlier sample, at least with respect to motivation and/or general ability.

\section{Conclusion}

An operation under general anaesthesia does not affect objective cognitive performance in the long run. This is in agreement with findings in the literature of no long-term cognitive dysfunctions but only short-term deterioration. However, a subgroup of patients do report cognitive complaints long after an operation. The initial idea that these findings were caused by methodological issues such as selection bias, the use of insensitive tests, learning effects, studying group change instead of individual change, and the lack of healthy control groups could not be substantiated. However, it is clear that there are patients who have cognitive complaints long after an operation even though these complaints cannot be measured with cognitive tests. It is possible that, due to the relatively short period for cognitive assessment, patients are able to perform quite well by putting much effort into their performance, but that their daily functioning is compromised and gives rise to cognitive complaints. This is difficult to investigate in a hospital setting. Other factors are probably responsible for these cognitive complaints. Future research should pay more attention to the discrepant findings in the long term between objective cognitive test performance and cognitive complaints. Relevant topics in this respect are the effect of educating patients before and after an operation about what to expect after the operation in terms of cognitive performance and complaints; the effect of psychosocial factors such as social network, coping style, and personality on long-term cognitive performance and complaints; the effect of emotional support and financial situation on long-term cognitive performance and complaints.

Although most patients recover from an operation under general anaesthesia, there is a subgroup of patients who suffer from long-term cognitive complaints. Identification of these patients at risk and possible interventions to reduce these complaints should be the main goal of future research. The apparent negative findings concerning objective cognitive test performance can have positive implications for possible interventions to reduce or prevent these long term cognitive complaints.

\section{REFERENCES}

1. Houx PI, Jolles I. Age-related decline of psychomotor speed. Effects of age, brain health, sex and education. Perceptual and Motor Skils 1993; 76; 195-211.

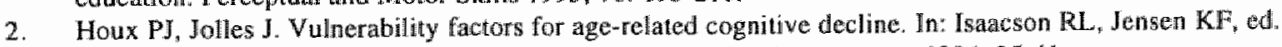
The Vulnerable Brain and Envirormental Risk. New York: Plenum Press, 1994: 25-41.

3. Jolles J, Howx PJ, Vreeling FW, Verhey FRU. Cognitive aging, biological life ovents and primitive reflexes. Neuroscience Research Communications, 1993; 13: S47-\$50. 
4. Meier U, Trullinger E, Stoll F, Fassoll A. Zur Frage der postoperativen Konzentrations- und Gedachtnisstorungen bei chirurgische Patienten. Schweizerische Zeitschrift fü Psychologie 1986; 45: 103-18.

5. Møller JT, Svennild I, Johannessen NW, et all. Perioperative monitoring with pullse oximetry and late postoperative cognitive dysfunction. British Journal of Anaesthesia 1993; $71,340-7$.

6. Muravehick $\$$. Immediate and long-term nervous system efects of anesthesia in elderly patients. Clines in Anaesthesiology 1986, 4. 1035-45.

7. Newman $S$, Klinger $\mathbb{L}$, Venn $G$, smith $P$, Harrison $M$, Treasure $T$. Subjectiwe reports of cognition in relation to assessed cognitive performance following coronary artery bypass surgery. Journal of Psychosomatic Research 1989, 33: 227-33.

8. Vingerhoets $G$, De Soste $G$, Jannes $C$. Relationship between emotional wariables and cognitive test performance before and after open-heart surgery. Clinical Neuropsyehology 1995; 2: 198-202,

9. Wallace LM. Communication variables in the design of pre-surgical preparatory information. British Journal of Clinical Psychology 1986; $25: 111-8$. 


\title{
Appendix
}

\section{The influence of microembolic events on neuropsychological outcome after CABG surgery}

Jeanette B. Dijkstra, Peter J. Houx, and Jellemei Jolles

\begin{abstract}
The occurrence of microemboli is thought to be an important causative factor for the neuropsychological deficits observed in patients who have undergone coronary artery bypass graft (CABG) surgery. In 23 patients the number of microembolic events (MEE) was measured by using Trans Cranial Doppler (TCD). This appendix shows the results of post-lioc analysis of the possible effect of microembolic events (MEE) during surgery on cognitive function after surgery. Results showed that the number of MEE did not affect the change in cognitive performance in either the short term or the long term.
\end{abstract}




\section{INTRODUCTION}

Microemboli have been implicated in the aetiology of neuropsychological deficits after coronary bypass surgery. Microembolic events (MEE) particularly occur at the time of cannulation and during introduction of the bypass 4.61 (see also chapter 2, paragraph 2.2). Two techniques can be used to detect microemboli: retinal fluorescein angiography and trans-cranial Doppler (TCD). In two studies retinal fluorescein angiography was used to detect microemboli but could not demonstrate a relationship between detected microemboli and cognitive functioning $\mathbb{1 1}, 8]$. Studies which investigated the incidence of microenboli as detected by TCD found indications that individuals with a higher incidence of microemboli in surgery are more likely to have cognitive deficits [6*7]. Pugsley et al. [7] examined the frequency of MEE in relation to neuropsychological outcome in 100 patients undergoing routine elective coronary artery bypass graft (CABG) surgery. A TCD was used to detect high-amplitude flow disturbances during the course of surgery. Pugsley et al. found a relationship between the frequency of microembolic events and neuropsychological outcome 8 weeks after surgery. Four groups were identified. In group 1, there were fewer than $200 \mathrm{MEE}$ during $\mathrm{CABG}$, in group 2 between 201 and 500 MEE, in group 3 between 501 and $1000 \mathrm{MEE}$, and in group 4 more than $1000 \mathrm{MEE}$. In group 1, only $9 \%$ of patients showed neuropsychological deficits after CABG but in group 4, as many as $43 \%$ of the patients showed neuropsychological deficits after the operation. They concluded that the more MEE during CABG, the higher the percentage of neuropsychological deficits.

In a subgroup of patients undergoing $C A B G$ surgery we measured the number of $M E E$ by using the TCD technique. Patients with fewer than $200 \mathrm{MEE}$ were compared with patients with more than $200 \mathrm{MEE}$ in terms of cognitive change 10 days and 6 weeks after the operation.

\section{METHODS}

Twenty-three male patients underwent CABG surgery during which MEE were counted with a TCD. Assessment with a neuropsychological test battery took place before the operation, 10 days after the operation, and 6 weeks after the operation. This battery consisted of tests measuring functions such as memory, speed of information processing in memory, initiation of movements, sensori-motor speed, attention, and the ability to shift between concepts in ongoing behaviour. Two groups were formed on the basis of the number of MEE occurring during surgery: one with fewer than $200 \mathrm{MEE}$ and one with more than $200 \mathrm{MEE}$. Change in cognitive. performance was compared in these groups. Table 1 summarizes the demographic details.

\begin{tabular}{lll}
\hline & $\begin{array}{l}\text { Group 1 (<200 MEE) } \\
(N=11)\end{array}$ & $\begin{array}{l}\text { Group 2 } \\
(N=12)\end{array}$ \\
\hline & & \\
MEE, Mean (Range) & $76(25-191)$ & $495(239-1000)$ \\
Age, Mean (SD) & $61.2(10.5)$ & $55.8(8.7)$ \\
IQ. Mean (SD) & $121(10.2)$ & $109(10.3)$ \\
\hline
\end{tabular}


Deterioration was defined as a decline in cognitive performance by at least 1 standard deviation from the preoperative performance. Deterioration was considered mild when there was decline in performance on one or two test variables and moderate-to-severe when there was decline on three or more test variables.

Group differences in age and IQ were analysed by using paired t-tests and group differences in change in test performance were analysed by using Chi-square statistics.

\section{RESULTS}

Two groups were formed, based on the number of MEE that occurred during CABG. Table 1 summarizes the demographic details and the amount of deterioration. Paired t-tests showed no age differences $(t=1.35, d f=19.5)$ between the groups but patients of group 1 had a significantly higher IQ $(t=2.71, d f=20.8, p<05)$. The two groups were compared with respect to short- and long-term individual cognitive change (none, mild, severe) by using Chi-square statistics. No differences in individual cognitive change between the groups were found (see table 2).

Table 2 short and long-tern cognitive deterioration

\begin{tabular}{|c|c|c|c|}
\hline Deterioration & $\begin{array}{l}\text { Group } 1(<200 \mathrm{MEE}) \\
(N=11)\end{array}$ & $\begin{array}{l}\text { Group } 2(>200 \mathrm{MEE}) \\
(N=12)\end{array}$ & $c h h^{2}(p)$ \\
\hline \multicolumn{4}{|l|}{ Short-term effect } \\
\hline none. & 1 & 4 & $5.32 \mathrm{~ns}$ \\
\hline mild & 8 & 3 & \\
\hline moderate to severe & 2 & 5 & \\
\hline \multicolumn{4}{|c|}{ Long-term effect } \\
\hline none & 6 & 9 & $2.85 \mathrm{~ns}$ \\
\hline mild & 5 & 2 & \\
\hline moderate to severe & 0 & 1 & \\
\hline
\end{tabular}

Note. MEE: microembolic events; ns: not significant

\section{DISCUSSION}

The number of MME a patient experienced during surgery did not affect the individual change in cognitive performance. MEE were detected in all patients in whom TCD was used. Thus it seems that MEE inevitably occur during CABG surgery, as was mentioned by others [2, 51. In none of our patients were more than 1000 MEE detected. Pugsley et al. [7] found the greatest percentage decline in cognitive function in patients with more than $1000 \mathrm{MEE}$. This discrepancy may be because our patients showed a relatively low frequency of MEE and we investigated only a small number of patients. The low frequency of MEE in this study compared with that of Pugsley et al. [7] might be due to the anaesthetic management. The use of the alpha-stat principle, a membrane oxygenator, mild hypothermia, and a low blood pressure in the present 
stidy could bave protected the brain from MEE. In Pugsley and coworkers' study a bubble oxygenator was used. It has been demonstrated that fewer emboli are detected when membrane axygenators are used instead of bubble oxygenators [3, 81. Moreover, Pugsley et al. regullated perfusion pressure pharmacologically and maintained a mean pressure between 60 and 100 mmHg. The risk of MME increases with such a relatively high mean arterial pressure.

Although MEE were detected in patients undergoing $C A B G$ surgery; the number of MEE did nol seem to affect cognitiwe performance.

\section{REFERENCES}

1. Blauth $C, 3$ mith $P$, Newman $S$, et al. Retinal microembolism and neuropsychological deficit following clintcal cardiopulmonary bypass. Comparison of a membrane and bubble oxygenator. The Eupopean Joumal of Cardiothotacic Surgery $1989,3: 135-9$.

2. Blauth Cl, Amold IV, Schulenberg WE, McCartney AC. Taylor KM Cerebral microembolism during cardiopulmonary bypass. Journal of Thonacic and Cardiowascular Surgery 1988, 95: 668-76.

3. Padayachee TS, Parsons $\$$, Teiobald $R$, Linley $J$, gosling $R$, Deverall $P$. The detection of microemboli in the middle cerebral artery during cardiopulmonary bypass: A transcranial Doppler ultrasound investigation using membrane and bubble oxygenators. Annals of Thoracic Surgery 1987; 44: 298-302.

4. Pugsley $W$. The use of doppler ultrasound in the assessment of microemboli during cardiac surgery. Perfussion 1989; 4: 115-22.

5. Pugsley W. Assessment of microembolic load during cardiopulmonary bypass by tramscranial doppler

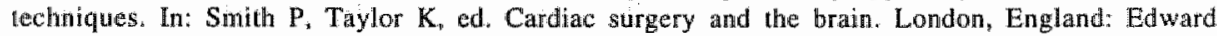
Armold Publisherd, 1993: 159-64.

6. Pugsley W, Klinger L, Paschalis $C$, al, Microemboli and cerebral impairment during cardiac Surgery Journal of Vascular Surgery 1990; $24: 34 \cdots 43$.

7. Pugsley W, Klinger $L$, Paschalis $C$. Treasure $T$, Harrison M, Newman $S$. The impact of microemboli during cardiopulmonary bypass on neuropsychological functioning. Stroke 1994: $25: 1393-9$.

8. Smith PLC, Blauth C, Newman S, Amolld J Siddons F, Taylor KM. Cerebral microembolism and neuropsychological outeome following coronaryatery bypass surgery (CABS) with either a membrane or a

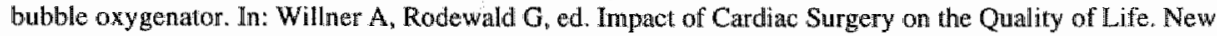
York, Plenum, 1990; 337-42. 


\section{SUMMARY}

This thesis describes the effect of an operation under general anaesthesia on cognitive aging. With advancing age, cognitive functioning tends to decline. Elderly people complain more about diminished memory function, difficulty to concentrate, slowness of thinking, and a diminished ability to do things simultaneously. Not all individuals suffer age-related decline in cognitive abilities to the same extent. The cause of these individual differences in cognitive decline with advancing age is probably not due to aging alone, but also involves other factors. A recent theory states that certain health-related factors can constitute risk factors for age-related cognitive decline: Examples of these health-related factors are mild head trauma, a history of drinking; use of medication, and an operation under general anaesthesia. The latter was defined as several operations under general anaesthesia of short duration or one operation lasting more than 3 hours. There is an increased prevalence of these health-related factors with higher age, and a large cross-sectional study into cognitive aging has provided experimental evidence that people who have been through one or more of these life events show a greater cognitive decline than people who have not, especially after the age of 60 . Although people probably recover quite well from one of the above-mentioned events, it is possible that the brain has suffered some functional damage which cannot be diagnosed directly but which becomes evident as the individual ages.

The question whether an operation under general anaesthesia is a determinant of an accelerated cognitive decline with advancing age is the main topic of this thesis. The short and long-term cognitive effects of an operation under general anaesthesia have been studied. Other factors which may interact with the effect of an operation under general anaesthesia are age, nature and duration of the operation, anaesthesiological variables, physical and mental condition of the patient, mood, personality and coping style. The first two chapters give an overview of the literature in this field, namely, the influence of an operation in general and the influence of open-heart surgery on cognitive functioning. The other chapters deal with experimental research.

Chapter 1 gives an overview of the literature of the last 15 years on the effect of an operation on cognitive functioning. The results of 40 studies are summarised and discussed. In 38 of the 40 studies the short-term effects (before discharge from the hospital) of an operation were studied, with cognitive assessment occurring between 6 hours and 1 week after the opration. In 22 of these 38 , studies a decline in cognitive function was reported , as measured with psychometric tests. In 22 of the 40 studies, long-term effects (after discharge from the hospital) of an operation on cognitive functioning were studied, with cognilive assessmet occurring between 3 weeks and 10 months after the operation. Only 4 of these 22 studies were able to measure a decline in cognitive functioning. Possible determinants for a short-term decline are age, general anaesthesia instead of local anaesthesia, pain, and the use of medication. Determinants for long term cognitive deterioration are hard to identify because these are seldom detected by using cognitive tests. The preoperative physical and mental condition of the patients might be important in this respect. Unfortunately, patients with a compromised physical or mental condition are often excluded from this type of research. The type of surgery does not seem to influence cognitive decline. There are indications that hypoxaemia occurs in the nights following the operation. Further research is needed to determine whether these short periods of 
hypoxamia have an impact on cognitive deterioration. Finally, there are some indications that postoperative confusion or delirium is associated with long-term cognitive deterioration.

For the assessment of change in cognitive functioning, different measurements have been used, ranging from global rating scalles to more specific speed-related tests. These tests can be categorised according to the different cognitive domains that are assessed such as, memory, attention, concentration, and speed of information processing. Cognitive deterioration after surgery does not seem to be related to one specific cognitive domain but overall deterioration is often reported.

In addition to cognitive measurements, several studies have also used methods to estimate the level of anxiety and depression and change in physical health to assess whether these have an impact on change in cognitive performance. Although most studies reported an increase in anxiety and depressive symptoms before the operation, this does not seem to influence change in cognitive performance.

The lack of a long-tern cognitive decline is in contradiction with the cognitive complaints. many patients report. This discrepancy may partly be explained by the tests used to assess of cognitive decline. Often no parallel versions or insensitive tests have been used, and learning effects on the tests used may have obscured the detection of changes in performance due to the operation. Moreover, only change in mean group performance has been studied. It is possible that only a small percentage of patients show a cognitive decline which is thus obscured because the majority of patients show no change or an improvement. Another explanation for this discrepancy is that subjective cognitive complaints are not based on cognitive decline. Other factors may be responsible for these cognitive complaints. Thus, the degree of emotional support, coping style, personality, and the degree to which the surgical procedure improves the elderly patient's social integration may influence cognitive outcome and nervous system effects in the long term. Up till now, not much attention has been paid to these factors in relation to cognitive complaints.

In chapter 2 the literature of the last 15 years on the influence of open-heart surgery on cognitive function is reviewed. In open-heart surgery the function of the heart and lungs is taken over by a heart-lung machine. However, use of this machine is associated with physiological changes in the body and the brain. Two causative mechanisms related to the heartlung machine proposed to explain the cognitive changes after coronary bypass surgery (CPB) are hypoperfusion and cerebral emboli. To understand these mechanisms, a short description of the heur--lung machine and the pathophysiology inherent to cardiopulmonary bypass and its impact on the cerebral physiology is given.

Despite the mary methodological problems such as selection bias, the use of short test batteries, the difference between studies concerning cognitive measures, limited choice of research designs, selective attrition, and the variety in definitions used to assess cognitive decline, consistent findings have been reported. Cognitive deterioration is found shortly after the operation but not after several months, at least when change in group means is studied. When individual change is studied, a decline in cognitive performance of up to $35 \%$ has been reported. Studies that included a comparison group show that short-term cognitive dysfunction is a probable sequela of open-heart surgery. The long-term effect of open-heart surgery compared with other surgery is not so clear.

Variables associated with a change in cognitive functioning after open-heart surgery can be divided into patient-related-, surgery-related-, and physiology-related variables. Examples of patient-related variables are age, severity of cardiovascular symptoms or heart disease, high 
education, genetic predisposition for cognitive dechne, mood and personality. Surgery-related variables can have an impact on cognitive outcome, for instance duration of surgery, blood pressure during the operation, strategies of acid-base management (alpha-stat or pH-stat), and microemboli during surgery. During the operation physiological changes occur which can cause brain damage. This damage can be measured with biochemical markers and physiological techniques. These techniques detect cerebral damage earlier than can cognitive measures. There are indications that the damage detected with these technigues is related to performance on cognitive tests. The implications of these findings are that patients can be diagnosed earlier when they have sustained damage and that they can be treated immediately.

Different interventions are possible to prevent or reduce cognitive disturbances after openheart surgery. Hypothermic surgery has always been seen as protective for the brain because it reduces cerebral metabolism and brain oxygen demands. However, a relationship between hypothermia and cognitive functioning has not been reported. One explanation for this is that cooling of the body accurs after the patient is connected to the heart-lung machine. During the period in which the patient is connected and disconnected to the heart-lung machine, the body is not cooled and at this moment the risk of emboli is the highest. The protectire effect of cooling is then only partly true. Although the use of arterial filters is not standard practice, there are indications that the number of microemboli going to the brain is reduced and that this is associated with less cognitive deterioration. Comparison of bubble and membrane oxygenators shows that the use of membrane oxygenators is associated with less cognitive disturbances. No relationship between cerebral protective drugs and cognitive performance has been found.

All these variables can affect short-term changes in cognitive functioning after surgery. Their effect in the long term is not clear. Although long-term cognitive impairments as measured with psychometric tests are seldom found, a small group of patients report cognitive complaints which cannot be measured by these tests. In future research more attention should be paid to these cognitive complaints and to factors related to these complaints.

In chapter 3, the results of a study into the effect of open-heart surgery (i.e. CABG) on cognitive functioning are reported. Forty-one male patients, divided into two age groups, one younger than 61 and one older than 61 , participated in this study. The patients were assessed with cognitive tests two times before the operation (6 weeks and 2 days) and two times after the operation ( 1 week and 6 weeks). Additionally, the patient group was compared to individually matched healthy controls at the first testing session. The results indicate that the patients had an inferior memory performance before the operation and were slower on a reaction time task than the controls. Ten days after the operation cognitive impairments were found in the patients. The older group had an impaired learning performance compared to the younger patients. Six weeks after the operation most patients were back at their preoperative performance level when group means were considered. No interaction with age was found. However, when assessed on an individual basis, $40 \%$ of the patients still had an impaired performance on one or more tests 6 weeks after the operation, irrespective of age. The degree of impairment was usually mild. The results do not support the notion that age plays an important role in susceptibility to postoperative cognitive dysfunction, although elderly patients need more time to recovery from their short-term learning dysability.

In chapter 4, different ways of estimating individual change are discussed. Psychometric tests can be used to assess cognitive change after an intervention. If, for instance, a small percentage of patients show a change but the remainder do not, no effect of the intervention will be found 
when change in group mean is analyzed. Besides analyzing change in mean group performance, it is umportant to study individual change to see whether a subgroup of patients is affected by an intervention. The methodological problems in estimating individual change are discussed in this chapter.

Three different approaches to estimate individual cognitive change after open-heart surgery were studied in 30 patients, who were compared with a control group of 30 normal healthy subjects studied in the same way and who were matched in age and education. The results showed that the use of a control group is important in the estimation of individual change. The control group alse showed a substantial change over the different measurements. This change cannot be attributed to an intervention but may be caused by fluctuation over time. Cognitive changes in a group after an intervention may be wrongly interpreted when changes in a control group without an intervention are not considered. The results showed that some patients have an improved performance in one test and a deterioration in another. In addition, the patient group showed a great variance concerning the different cognitive tests. The results suggest that instead of studying change in performance in separate tests, it may be more reliable to study the change by means of a compoundscore for these tests. With this compoundscore, both improvement and deterioration within one patient (intra-patient variability) and the inter-patient performance variability is taken into consideration. If no control group is available, a change of 1 or more standard deviation in at least $30 \%$ of the tests should be used if change on separate tests is to be studied.

In chapter $\mathbf{5}$, the results are described of a study in which the effect of an operation under general anaesthesia on cognitive functioning in patients older than 60 years was investigated. The severity and character of the postoperative cognitive dysfunction and possible predictors for these dysfunctions, such as duration of surgery and stay in hospital, were investigated. Cognitive function was assessed before the operation ( 1 day) and after the operation ( 1 week and 3 months) and compared with the performance of controlls who were also tested on four occasions with the same time intervals between the assessments. One week after the operation the performance of patients in tests measuring sensorimotor speed had deteriorated but not in tests measuring cognitive flexibility and memory. After 3 months, the patients were back at their preoperative performance level or showed an improved performance. Additionally, individual change was studied but revealed no differences between the patients and the controls. Duration of surgery and stay in hospital could not explain the variance in change on the dependent variables. After 6 months patients were itnerviewed by telephone, about whether they had experienced change in mental abilities after discharge from hospital. Fourteen of the 50 patients reported a change in mental abilities after the operation and 8 of these 14 still reported "not being the same since surgery". This decline could not be detected by using objective psychometric tests. This discrepancy between objective test performance and cognitive complaints needs further study. The fact that there are more patients with complaints than patients with objective cognitive dysfunctions may have implications for medical psychological care, and possible interventions.

In chapter 6 , the results of a large cross-sectional population study are described. This study was part of the so-called Mastricht Aging Study (MAAS). In this study, a history of an operation under general anaesthesia, number of operations, and duration of anaesthesia in interaction with age were studied as predictors for an accellerated cognitive decline in 1257 subjects aged 25-80 years. Additionally, a high-risk group was selected that consisted of 
subjects who, in the last 15 years, had underonge at least one operation under general anaesthesia that lasted Ionger than 3 hours. The cognitive performance of this high-risk group was compared with that of a group of matched subjects who had never been operated on under general anaesthesia.

The results showed that a history of an operation under general anaesthesia, number of operations, and duration of anaesthesia could not predict cognitive performance or cognitive complaints, not even in a potentially high-risk group. No interactions with age were found. A history of an operation under general anaesthesia could predict the score on a rating scale of subjective health. This finding is not surprising because these subjects had been ill and had undergone surgery, so when they are asked about their health they would score higher on health-related measures. These findings are not in line with the notion that an operation under general anaesthesia is a determinant for an accelerated cognitive decline with advancing ange. A more definite conclusion with respect to this hypothesis can only be obtained in a longitudinal study in which healthy subjects with and without operation are compared. Such a study is currently being performed within the framework of MAAS.

In chapter 7, the various findings and conclusions of this thesis are discussed. An operation under general anaesthesia can affect short-term cognitive performance but long-term cognitive effects are seldom found when measured with cognitive tests. This is in agreement with the literature, which has never been able to demonstrate persistent cognitive dysfunction months after an operation. These findings do not seem to be dure to methodological issues such as the cognitive tests used, learning effects, studying group change instead of individual change, and the lack of control groups. However, it is clear that there are patients who have persistent cognitive complaints long after an operation but that these complaints can not be measured with cognitive tests. Other factors are probably responsible for these cognitive complaints. Future research should pay more attention to the discrepant findings in the long term between objective cognitive test performance and cognitive complaints. Relevant topics in this respect are the effect of educating patients before the operation about what to expect after the operation in term of long-term cognitive complaints; the effect of psychosocial factors such as social network, coping style, and personality on long-term cognitive complaints; the effect of enotional support and financial situation on long-term cognitive complaints.

Although most patients recover well from an operation under general angesthesia, there is at subgroup of patients who suffer from long-term cognitive complaints. Identification of these patients at risk and possible interventions to reduce these complaints should be the main goal of future research. The apparent negative findings concerning objective cognitive test performance can have positive implications for psychological interventions in order to reduce or prevent these long-term cognitive complaints. Neuropsychological rehabilitation and psycho-education may be relevant in this respect, by preparing the patient for the short-term and medium longterm neurocognitive sequelae of an operation. 



\section{SAMENVATTING}

Vryjwel alle cognitieve functies gaan achteruit met het ouder worden. Tevens nemen klachten toe over geheugenachteruitgang, verminderde concentratie, tragheid van denken, of onvermogen meerdere dingen tegelijk te doen. De mate warin cognitieve achteruitgang als gevolg van veroudering optreedt, verschilt tussen mensen. Deze verschillen hangen wellicht samen met een aantal gezondheid-gerelateerde factoren, die in verband gebracht kunnen worden met gestoorde hersenfuncties. Een mogelijke factor is én langdurige of meerdere kortdurende periodes van algehele anesthesie. Andere factoren zijn geboortecomplicaties, lichte hersentrauma"s, overmatig alcohol-en/of medicijngebruik, blootstelling aan neurotoxische stoffen en neurologische en/of psychiatrische ziektes. Dergelijke factoren kunnen een 'kwetsbaarheidsfactor' ('vulnerability factor') zijn voor het optreden van cognitieve problemen bij het ouder worden. Ze kunnen ervoor zorgen dat de relatief 'normale' cognitieve veroudering op jongere leeftijd begint, of een ernstiger vorm heeft: De betreffende factoren kunnen al geruime tiju eerder in het leven plaats hebben gevonden, maar zich pas uiten bij het ouder worden.

In welke mate algehele anesthesie een bepalende factor is voor het ontstaan van cognitieve stoornissen en klachten op latere leeftijd, wordt in dit proefschrift onderzocht. Hierbij is gekeken naar zowel korte als lange termijn effecten van een operatie onder algehele anesthesie op het cognitief functioneren. Factoren die hierbij een rol kunnen spelen zijn leeftijd, lichamelijke conditie, gemoedstoestand, persoonlijkheid en de wijze waarop de persoon omgat met de eisen die aan hem/haar worden gesteld (coping). Mogelijk spelen ook factoren als soort en duur van de operatie en anesthesiologische parameters een rol.

In de eerste twee hoofdstukken wordt een overzicht gegeven van de literatuur over de invloed van een operatie in het algemeen, en de invloed van open-hart chirurgie op veranderingen in het cognitief functioneren. In de daarop volgende hoofdstukken worden de experimenten beschreven die in het kader van dit proefschrift zijn uitgevoerd. De bevindingen en conclusies van dit proefschrift worden in het laatste hoofdstuk besproken.

Hoofdstuk 1 geeft een overzicht van 40 studies die in de afgelopen 15 jaar (wanaf 1980) zijn uitgevoerd naar het effect van algehele anesthesie op het cognitief functioneren. In 38 wan deze 40 studies is gekeken naar een verandering in het cognitief functioneren vlak ta de operatie (variërend van 6 utr tot 1 week). Van deze 22 toonden 38 studies een cognitieve achteruitgang aan op de korte termijn. Lange termijn effecten (variërend van 3 weken tot 10 maanden) zijn in 22 van de 40 studies onderzocht. Slechts 4 van deze 22 studies constateerden een achteruitgang in het cognitief functioneren.

Determinanten voor cognitieve achteruitgang op de korte termijn zijn: leeftijd, algehele (in plaats van locale) anesthesie, pijn en medicijngebruik. Determinanten voor een cognitieve achteruitgang op de lange termijn zijn moeilijk te bepalen omdat deze zelden is geconstateerd. Fysieke en mentale conditie vóór de operatie spelen hierbij mogelijk een rol. Helaas worden patiënten met fysieke en mentale beperkingen vaak uitgesloten van deelname aan onderzoek. Het type operatie leek niet bepalend te zijn voor het optreden van een cognitieve achteruitgang. met uitzondering van operaties waarbij men een harl-long machine gebruikt (zie hoofdstuk 2). Wel is aangetoond dat, tijdens het slapen, na een operatie periodes van zuurstoftekort kunnen optreden. Of deze periodes al dan niet van invloed zijn op het cognitief functioneren is nog onduidelijk. Tenslotte blleek dat werwardheid v]ak na de operatie een mogelijke determinant is 
voor een cognitieve achteruitgang op de lange termijn.

Veranderingen in het cognitief functioneren zijn in de verschillende studies met uiteenlopende psychometrische tests gemeten. Deze tests kunnen onderverdeeld worden naar de verschillende functies die ze meten, zoals geheugen, aandacht, concentratie en de snelheid wan de informatieverwerking. Indlien er aantoonbare cognitieve effecten van een operatie waren, bleken deze zich niet te beperken tot een specifieke functie, maar waren aantoonbaar op meerdiere cognitieve functiegebieden.

In veel studies $\mathrm{z} j \mathrm{j}$, nalast de eognitieve tests, ook vragenliysten gebruikt die de mate van angst, depressie, gezondheid en cognitieve klachten meten. Op deze manier kan men de invloed van deze factoren op de cognitieve prestatie bepalen. Alhoewel in de meeste studies een verandering in de mate van angst en depressie werd aangetoond, leek deze niet van invloed te zijn op een verandering in de cognitieve prestatie.

De overwegend negatieve bevindingen, met betrekking tot cognitieve achteruitgang op de lange termijn, $z$ jn tegenstrijdig met de cognitieve klachten die mensen rapporteren. Deze discreparitie zou toegesehreven kunnen worden aan de tests die cognitieve achteruitgang meten. Vaak Zijn geen parallelle testversies gebrukt waardoor een mogelijk leereffect achteruitgang maskeert. Verder is er in de meeste studies gekeken naar een cognitieve achteruitgang van de totale groep. Het is mogelijk dat van de totale groep een paar mensen cognitief achteruit gaan, maar dat er bij het merendeel geen verandering of zelfs verbetering platatsvindt. De groep mensen die we] achteruit gaat wordt hierdoor niet gevonden. Een andere verklaring voor deze negatieve bevindingen is dat de cognitieve klachten die mensen hebben niet op cognitieve achteruitgang berusten. Andere factoren spelen hierbij mogelijk een grotere rol; emotionele steun, financiële situatie van de patiënt en de mate waarin de operatie de sociale integratie van de patiènt verbetert. Tot op heden is er aan deze factoren in relatie tot cognitieve klachten, weinig aandacht besteed.

Hoofdstuk 2 geeft een overzicht van de onderzoeken die er in de afgelopen 15 jaar zijn uitgevoerd naar het effect van open-hart chirurgie op het cognitief functioneren. Bij open-hart neemt een hart-long machine de functie van deze organen gedurende de operatie over. Hierdoor treden fysiologische veranderingen op in de hersenen die de cognitiewe stoornissen mogelijk kunnen verklaren, zoals hypoperfusie en cerebrale embolieẻn. Om meer inzicht te geven in deze processen, is een beschrijving wan de werking van de hart-long machine gegeven.

Ondanks de vele methodologische problemen, zoals selectiebias, gebruik wan korte testbatterijen, verschil in testmethoden, beperkte keuze in onderzoekdesigns, selectieve uitval en verschillende definities van cognitieve achteruitgang, zijn er toch consistente bevindingen gedaan. Vlak na de operatie was er sprake van een cognitieve achteruitgang maar op de lange termijn werd deze verandering, in de gemiddelde groepsprestatie, niet meer aangetoond. Wanneer men echter keek naar de individuele achteruitgang, werd eén jaar na de operatie toch nog een cognitieve achteruitgang tot $35 \%$ gerapporteerd. De studies waarbij tevens een controlegroep is bestudeerd, tonen aan dat een cognitieve achteruitgang op de korte termijn vaker voorkomt na het gebruik van een hart-long machine. Op de lange termijn is dit effect van openhart chirurgie, in vergelijking tot andere ingrepen, niet zo duidelijk.

Verschillende variabelen worden in verband gebracht met een verandering in het cognitief functioneren na open-hart chirurgie. Deze variabelen kunnen onderverdeeld worden in patiëntgerelateerde, operatie-gerelateerde en fysiologie-gerelateerde variabelen. Voorbeelden van patient-gerelateerde variabelen zijn: leeftijd, ernst van cardiovasculaire symptomen, opleiding, erfelijke componenten, gemoedstoestand en persoonlijkheid. Voorbeelden van operatie-gerela- 
teerde variabelen zijn: duur van de operatie, bloeddnak, zuur-base evenwicht en micro-embolieen. Gedurende de operatie vinden fysiologische veranderingen plaats die schade aan de hersenen kunnen veroorzaken. Om deze fysiologie-gerelateerde variabelen te meten, kumnen biochemische en electro-fysiologische technieken gebruikt worden. Met deze technieken is men in staat cerebrale schade sneller aan te tonen dan met cognitieve taken Er zijn aanwijzingen dat de schade, die met behulp van deze technieken wordt gevonden, gerelateerd is aan cognitieve testprestatie. Dit impliceert dat, met behulp van deze technieken, patienten eerder gediagnosticeerd en behandeld kunnen worden na een aangetoonde beschadiging.

Verschillende interventies zijn mogelijk om cognitieve stoornissen na een open-hart operatie te beperken. Hypothermie tijdens de operatie is altijd beschouwd als een bescherinende factor voor de hersenen, omdat hierdoor het cerebrale metabolisme vermindert en de hersenen minder zuurstof nodig hebben. Onderzoeken toonden echter geen verband aan tussen hypothermie en het cognitief functioneren. Een verklaring hiervoor zou kunnen zijn dat de koeling wan het lichaam pas plaatsvindt als de patiènt al is aangesloten op de hart-long machine. Tijdens het aanen afkoppelen is het lichaam niet gekoeld, terwijl juist op die momenten de kans op embolieen het grootst is. De beschermende werking van hypothermie is dus maar beperkt. Alhoewel het gebruik van een anterieel filter niet standaard is, zijn er aanwijzungen dat bij gebruik hiervan het aantal micro-embolieën naar de hersenen vermindert en er minder cognitieve complicaties optreden. Tevens bleek dat membraan-oxygenatoren, vergeleken met bubbel-oxygenatoren, tot een vermindering van de cognitieve achteruitgang leiden. Tenslotte is er geen verband gevonden tussen substanties die een mogelijk beschermend effect op de hersenen hebben ("neuroprotective drugs") en cognitieve prestatie na open-hart chirurgie.

Bij open-hart operaties zijn er derhalve veel factoren die het cerebrale functioneren kunnen beînwloeden. Met name op de korte termijn wordt er een relatief grotere cognitieve achteruitgang geconstateerd in vergelijking tot andere operaties. Cognitieve achteruitgang op de lange termijn wordt zelden gevonden, alhoewel een kleine groep patiënten wel cognitieve klachten heeft die niet met cognitieve taken (kunnen) worden aangetoond. Toekomstig onderzoek zou meer aandacht moeten besteden aan deze klachten en de factoren die hiermee verband houden.

Hoofdstuk 3 beschrijft de resultaten wan een onderzoek naar de effecten van open-hart chirugie op het cognitief functioneren. Er is onderzoek gedaan bij patienten die een Coronary Artery Bypass Graft (CABG) operatie moesten ondergaan. In deze studie zijn 41 mannelijke patiènten onderzocht, onderverdeeld in twee leeftijdsgroepen: jonger of ouder dan 61 jaar. Dexe patiènten zijn zowel tweemaal voór ( 6 weken en 2 dagen) als na ( 10 dagen en 6 weken) de operatie neuropsychologisch onderzocht. Daarnaast is de cognitieve prestatie van de patiènten op het eerste meetmoment vergeleken met die van gezonde controles. De resultaten lieten zien dat de patiënten 6 weken vóór de operatie slechter presteerden op een geheugentaak en langzamer waren op een reactietijdtaak in vergelijking met de controle groep. Tien dagen na de operatie presteerden de patiënten onder het niveau van vóor de operatie. De oudere patiënten gingen relatief meer achteruit op een leertaak in vergelijking tot de jongere patiënten. Zes weken na de operatie presteerden de patiënten, als groep, weer op hetzelfde niveau als vóór de operatie of was de prestatie zelfs verbeterd. Individueel gezien echter vertoonde $40 \%$ van de patiënten een (lichte) cognitieve achteruitgang op de lange termijn onafhankelijk van leeftijd. Het eerder genoemde effect van leeftijd op de korte termijn kan een relevante zorg-consequentie van het onderzoek zijn.

Hoofdstuk 4 bespreekt verschillende manieren om de individuele achteruitgang te bepalen. 
Een neuropsychologische testbatterij kan gebruikt worden om veranderingen in thet cognitief functioneren te meten aa cer interventie. Wanneer slechts een klein percentage van de groep eem werandering in het cognitief functioneren laat zien en dit bij het merendeel van de groep niet verandert, is het mogelijk dat voor de groep als geheel geen verandering wordt gemeten. Het is dus belangrijk om naast veranderingen in het groepsgemiddelde, de individuele achteruitgang te bepalen, om zo een eventuele subgroep te detecteren die wel gevoelig is voor de interventie. De methodologische problemen die zich voordoen bij het bepalen van de individuele achteruitgang zijn in dit hoofdstuk ewereens beschreven.

Drie verschillende manieren om individuele cognitieve weranderingen te bepalen zijn onderzocht bij een groep yan 30 patienten die een open-hartoperatie ondergingen. Deze groep is vergeleken met 30 gezonde controlepersonen. De resultaten lieten zien dat een vergelijking met een controlegroep erg belangrijk is bij het bepalen van individuele achteruitgang. In de loop wan de lijd vertoonde de controlegroep namelijk ook cognitieve veranderingen die uiteraard niet te wijten waren aan de interventie. Als hiermee geen rekening wordt gehouden zouden cognitieve veranderingen in de patientengroep ten onrechte als veranderingen ten gevolge van de interventie gentenpreteerd kunnen worden. Uit de resultaten bleek dat sommige patiënten op de ene taak verbeterden en op de andere verslechterden en dat er binnen de patiëntengroep een grote variatie bestond in de cognitieve taken waarop verandering werd gemeten. In plaats van de prestatie op afzonderlijke taken te bestuderen, is het derhalve betrouwbaarder om een somscore van de taken te maken De resultaten van deze studie zijn nuttig voor toekomstig onderzoek naar individuele cognitieve veranderingen na een medische of psychologische interventie.

Hoofdstuk 5 besehrijft de resultaten van een onderzoek naar de invloed van een operatie onder algehele anesthesie op het cognitief functioneren. Dit werd onderzocht bij een groep patiènten ouder dan 60 jaar. In deze studie is met name gekeken naar de ernst en het karakter van de cognitieve achteruitgang en eventuele voorspellers, zoals de duur van de operatie en van het verblijf in het ziekenhuis. Het cognitief functioneren is zowel vór ( 1 dag) als na (1 week en 3 maanden) de operatie gemeten en vergeleken met een gezonde controlegroep. Eén week na de operatie vertoonden de patiënten, vergeleken met de controles, een cognitieve achteruitgang op eenvoudige snelheicligerelateerde taken. $\mathrm{Er}$ werd geen achteruitgang gevonden op de meer complexe snelheid-gerelateerde taken en de geheugen taken. Na 3 maanden presteerden de patiênten in alle taken weer op het niveau van voor de operatie. De individuele achteruitgang is ook onderzocht, mar in dit opzicht werd geen verschil tussen beide groepen gevonden. De duur wan de operatie en van het verblijf in het ziekenhuis hadden geen invloed op de cognitieve veranderingen. Na 6 maanden is bij alle patiënten een telefonisch semi-gestructureerd interview afgenomen, dat informeerde naar de subjectief ervaren veranderingen in het mentaal functioneren na ontslag uit het ziekenhuis. Van de 50 patienten gaven er 14 aan minder te functioneren dan voor de operatie. Van deze 14 gaven er 8 patiënten aan dat ze na 6 maanden nog steeds niet "de oude." waren. Deze studie laat duidelijk de discrepantie zien tussen cognitieve testprestatie en cognitieve klachten. "Toekomstig onderzoek zou meer aandacht moeten besteden aan deze discrepantie.

Hoofdstuk 6 beschrijft de resultaten van een cross-sectionele populatiestudie, de Maastricht Aging Study (MAAS). Deze studie onderzocht bij 1257 personen in de leeftijd van 25 tot 80 jaar de cognitieve effecten van het ondergaan hebben van een operatie onder algehele anesthesie in relatie tot leeftijd. Andere gehanteerde voorspellers van een versnelde cognitieve achteruitgang waren het aantal operaties en de duur van de operatie. Personen die in de afgelopen 15 jaar 
een operatie onder algehele anesthesie hadden ondergaan die langer duurde dan 3 wur, werden geselecteerd voor een zogenaamde "risicogroep". De cognitieve prestatie van deze groep is vergeleken met een controlegroep die nog nooit onder algehele anesthesie was geopereerd.

De effecten van het geopereerd zijn onder algehele anesthesie, het aantal operaties en de duur van de operatie konden zowel cognitief functioneren als cognitieve klachten niet woorspellen, zelfs niet bij de risicogroep. Leeftijd bleek eveneens niet van invloed te zijn. Wel gaf het hebben ondergaan van een operatie onder algehele anesthesie een indicatie voor de mate van subjectieve gezondheid. Deze bevinding is niet verrassend omdat deze personen ziek zijn geweest en een operatie hebben ondergaan. Wanneer deze personen gevraagd wordt naar hun gezondheid, zullen ze vaker aangeven minder gezond te zijn dan mensen die nog nooit geopereerd zijn. Deze resultaten geven geen bevestiging voor de hypothese dat een operatie onder algehele anesthesie een determinant zou zijn voor een versnelde cognitieve achteruitgang. Een definitieve conclusie over deze stelling kan uiteindelijk alleen na longitudinaal onderzoek verkregen worden. Een dergelijk onderzoek wordt momenteel uitgevoerd in MAAS.

Hoofdstuk 7 bespreekt de verschillende bevindingen en conclusies van dit proefschrift. Een. operatie onder algehele anesthesie kan de cognitieve prestatie op de korte termijn beinvloeden, maar lange termijn effecten worden zelden gevonden. Dit komt overeen met de bevindingen in de literatuur waarin zelden cognitieve stoornissen zijn beschreven, die langer persisteren dan enkele weken na de operatie. Deze bevindingen lijken niet veroorzaakt door methodologische factoren zoals de tests die gebruikt zijn, leereffecten, het ontbreken van een controlegroep of het meten van veranderingen in de gemiddelde groepsprestatie in plaats van individuele verandering. Het is duidelijk dat er patiènten zijn die lange tijd na de operatie cognitieve klachten hebben die niet gemeten (kunnen) worden met psychometrische tests. Andere factoren spelen waar"schijnlijk een belangrijker rol bij deze cognitieve klachten. Toekomstig onderzoek zou meer aandacht moeter besteden aan de discrepantie tussen (objectieve) cognitieve testprestatie en (subjectieve) cognitieve klachten op de lange termijn. Relevante onderwerpen hierbij zijn: het effect van voorlichting, het effect van psychosociale factoren zoals het sociale netwerk, coping-stijl en persoonlijkheid, bet effect van emotionele ondersteuning en financiële situatie op cognitieve klachten.

Samengevat kan gesteld worden dat de meeste patiënten goed herstellen na een operatie onder algehele anesthesie, alhoewel er een kleine groep patiènten is die lange tijd na de operatie cognitieve klachten houdt. Het identificeren van deze groep patiënten en mogelijke interventies om deze klachten te verminderen, zou de meeste aandacht moeten krijgen bij toekomstig onderzoek. 



\section{Dankwoord}

Hoewel er maar één auteur op de omslag van dit proefschrift staat vermeld is het niet én persoon geweest die het beschreven werk verricht heeft. Zonder de steun van veel mensen was dit boekje nooit tot stand gekomen. Voordat ik enkele personen bij naam noem wil ik eerst iedereen bedanken die hieraan heeft bijgedragen.

Als eerste wil ik mijn promotor en dagelijkse begeleider Jelle Jolles bedanken voor zijn niet stuk te krijgen enthousiasme en optimisme waarmee hij mij altijd weer wist te motiveren. Hij was altijd in staat mij de juiste weg te wijzen wanneer ik dreigde af te dwalen en op zijpaden belandde.

Al mijn collega's will ik bedanken voor hun luisterend oor en stimulerende woorden, zowel op het werk als daarbuiten. In het bijzonder Martin Klein met wie ik gedurende een groot deel wan deze periode een kamer deelde. Alweer bijna 5 jarr geleden zijn we beide als AIO begonnen en beide sluiten we nu deze periode af. Martin, het bestaan als AIO viel niet altijd mee, maar gelukkig wist jij altijd voor de nodige afleiding te zorgen. Ook Peter Houx will ik even apart vermelden. Peter, mede dankzij jou is het boekje een layout-technisch verantwoord geheel geworden. Nico Rozendaal bedank ik voor de statistische ondersteuning en voor al die keren dat hij rustig de tijd nam, wanneer ik weer eens in paniek aankwam rennen, om het met mij uit te zoeken.

Mijn vrienden op (geografische) afstand wil ik bedanken voor het tonen van hun belangstelling in de afgelopen jaren. Ik kan nu eindelijk de vraag "vlot het een beetje?" beantwoorden met "het is af!".

Verder wil ik de mensen bedanken, die geholpen hebben bij de praktische uitvoering van de onderzoeken en de dataverzameling: Annelien Duits, Hendrike van Weelderen en Patricia Hameleers. In het bijzonder wil ik Inge Crolla noemen zonder wie hoofdstuk 5 nooit tot stand zou zijn gekomen.

Ook wil ik alle patiënten bedanken die hun medewerking aan dit onderzoek hebben verleend. Alhoewel ze vaak een ingrijpende operatie in het vooruitzicht hadden, waren ze toch bereid mee te doen aan dit onderzoek. Zonder hun was dit proefischrift er nooit geweest.

Voor hun bijdragen aan het boekje in de laatste fase bedank ik: Bert Rodenrijs, Astrid Quist en Martin van Boxtel.

Mijn ouders bedank ik voor hun niet aflatende vertrouwen in mijn kunnen. Zij hebben mij altijd vrijgelaten in mijn keuzes. Mijn vader heeft het eindresultaat niet mogen zien. Hij is enkele weken voor de definitieve goedkeuring van het manuscript overleden.

En last but not least wil ik Jos bedanken woor zijn steun, advies en enorme geduld, met name bij de laatste loodjes van dit proefschrift die inderdaad het zwaarste wogen. Jos, wij hebben pas echt laten zien hoe $\mathrm{H}$ - en B-sectie optimaal kunnen integreren! 
तथ

- : $\quad:$

$\because$

$\therefore \quad$

$+\quad \cdots$

$\because \quad$

$\therefore \quad \therefore$

․

$\therefore:$ 


\section{Curriculum Vitae}

Jeanette Dijkstra werd op 15 April 1968 geboren te Joure. Na het VWO in 1986 studeerde zij psychologie aan de Rijksuniveriteit Groningen en de Katholveke Universiteit Nijmegen. De stageperiodes wervulde zij bij The Institute of Neurology te Londen en bij de afdeling neurologie van het Academisch Ziekenhuis Utrecht. Na het afstuderen in de neuro- en revaldatiepsychologie (1992) was zij werkzaam als assistent in opleiding aan de Universiteit Maastricht bij de Vakgroep Psychiatrie, sectie Neuropsychologie, Neuropsychiatrie en Psychobiologie, waar zij onderzoek verrichtte naar de invloed wan een operatie onder algehele anesthesie op cognitieve veroudering waarvan dit proefschrift de weerslag is. Vanaf 1996 is zij werkzaam als klinisch neuropsycholoog bij de Maastrichtse Geheugenpolikliniek in het Academisch Ziekenhuis Maastricht. 